\title{
Guía de Práctica Clínica sobre atención paliativa al adulto en situación de últimos días
}





\section{Guía de Práctica Clínica sobre atención paliativa al adulto en situación de últimos días}


Esta GPC es una ayuda a la toma de decisiones en la atención sanitaria. No es de obligado cumplimento ni sustituye el juicio clínico del personal sanitario.

Edición: 2021

Edita: Ministerio de Sanidad

Agencia Gallega para la Gestión del Conocimiento en Salud (ACIS)

Unidad de Asesoramiento Científico-técnico, Avalia-t

ISBN: 978-84-09-25534-4

NIPO: anticipo de edición

DL: en trámite

Maquetación: Tórculo Comunicación Gráfica, S. A. 
Este documento ha sido realizado por la Unidad de Asesoramiento Científico-técnico, Avalia-t, de la Agencia de Conocimiento en Salud (ACIS) en el marco de la financiación del Ministerio de Sanidad, para el desarrollo de las actividades del Plan anual de Trabajo de la Red Española de Agencias de Evaluación de Tecnologías Sanitarias y Prestaciones del SNS, aprobado en el Pleno del Consejo Interterritorial del SNS de 8 de noviembre de 2017 (conforme al Acuerdo del Consejo de Ministros de 1 de diciembre de 2017).

Esta guía debe citarse:

Grupo de trabajo de la Guía de Práctica Clínica sobre atención paliativa al adulto en situación de últimos días. Guía de Práctica Clínica sobre atención paliativa al adulto en situación de últimos días. Madrid: Ministerio de Sanidad; Santiago de Compostela: Agencia de Conocimiento en Salud (ACIS). Unidad de Asesoramiento Científico-técnico, Avalia-t; 2021. Guías de Práctica Clínica en el SNS. 



\section{Índice}

Índice de tablas y figuras $\quad 9$

Presentación 11

$\begin{array}{ll}\text { Autoría y colaboraciones } & 13\end{array}$

$\begin{array}{lr}\text { Preguntas para responder } & 19\end{array}$

Niveles de evidencia y grados de recomendaciones 21

Resumen de las recomendaciones de la GPC 23

1 Introducción $\quad 31$

2 Alcance y objetivos $\quad 35$

3 Reconocimiento de situación de últimos días 37

4 Comunicación e información 47

5 Toma de decisiones compartida y desarrollo del plan de cuidados 55

6 Hidratación $\quad 65$

$7 \quad$ Manejo de síntomas $\quad 73$

$\begin{array}{lll}7.1 & \text { Consideraciones generales } & 73\end{array}$

$\begin{array}{lll}7.2 & \text { Dolor } & 77\end{array}$

$\begin{array}{lll}7.3 & \text { Disnea } & 84\end{array}$

7.4 Náuseas y vómitos 90

7.5 Ansiedad y delirium 95

$\begin{array}{llr}7.6 & \text { Estertores } & 100\end{array}$

8 Sedación paliativa 107

9 Estrategias diagnósticas y terapéuticas 117

10 Metodología $r 119$

11 Difusión e implementación 123

12 Líneas de investigación futura 127

13 Plan de actualización 129

Anexos 131

Anexo 1. Material complementario al capítulo de comunicación 133

Anexo 2. Material complementario al capítulo de hidratación 135

Anexo 3. Material complementario al capítulo de manejo clínico de síntomas:

consideraciones generales (ESAS-r) 137

Anexo 4. Material complementario al capítulo de manejo clínico de síntomas: dolor 139 
Anexo 5. Material complementario al capítulo de manejo clínico de síntomas: disnea

Anexo 6. Material complementario al capítulo de manejo clínico de síntomas: náuseas y vómitos

Anexo 7. Material complementario al capítulo de manejo clínico de síntomas: ansiedad y delirium

Anexo 8. Material complementario al capítulo de manejo clínico de síntomas: estertores

Anexo 9. Uso de la vía subcutánea en cuidados paliativos

Anexo 10. Vademécum de fármacos utilizados en SUD

Anexo 11. Material complementario al capítulo de sedación paliativa

Anexo 12. Aspectos éticos, legales y deontológicos

Anexo 13. Abreviaturas

Anexo 14. Declaración de interés

Anexo 15. Información para familiares y allegados de personas en situación de últimos días

Bibliografía 


\section{Índice de tablas y figuras}

\section{Tablas}

Tabla 1. Temas y subtemas derivados de la evidencia del reconocimiento de situación de últimos días

Tabla 2. Tema y subtemas extraídos de los estudios incluidos sobre barreras y facilitadores de la comunicación

Tabla 3. Temas y subtemas extraídos de los estudios incluidos sobre toma de decisiones compartida y desarrollo del plan de cuidados

Tabla 4. Técnicas para una comunicación eficaz en situación de últimos días

Tabla 5. Manejo del pacto de silencio

Tabla 6. Cuidado de la boca seca en situación de últimos días

Tabla 7. Evaluación y valoración del dolor mediante escalas

Tabla 8. Cuidados y medidas no farmacológicas para controlar el dolor en la situación de últimos días

Tabla 9. Tabla de rotación de opioides (ROP-ICO): equivalencias entre diferentes dosis de opioides y ratios de conversión*

Tabla 10. Cuidados y medidas no farmacológicas para el abordaje de la disnea en la situación de últimos días

Tabla 11. Cuidados y medidas no farmacológicas en relación con las náuseas y vómitos 147

Tabla 12. Cuidados y medidas no farmacológicas en relación con la ansiedad $\quad 149$

Tabla 13. Cuidados y medidas no farmacológicas en relación con el delirium 149

Tabla 14. Cuidados y medidas no farmacológicas para el abordaje de los estertores en la situación de últimos días

Tabla 15. Fármacos más utilizados por vía subcutánea en cuidados paliativos 158

Tabla 16. Fármacos más frecuentes clasificados por síntomas 161

Tabla 17. Fármacos más frecuentes clasificados por principio activo 166

Tabla 18. Algoritmo de refractariedad 174

Tabla 19. Fármacos recomendados para sedación paliativa 175

$\begin{array}{ll}\text { Tabla 20. Escala de Ramsay } & 176\end{array}$

Tabla 21. Escala de Agitación en la Sedación de Richmond (RASS) 176

Tabla 22. Formulación de los principios y respuestas en los cuidados al final de la vida 183

Tabla 23. Recomendaciones desde el punto de vista de la bioética en los cuidados en el final de la vida

Tabla 24. Definición de algunos conceptos relacionados con diferentes escenarios al final de la vida

\section{Figuras}

Figura 1. Representación esquemática de los principales aspectos que aborda la guía 117

Figura 2. Zonas de punción recomendadas para la vía subcutánea 154

Figura 3. Algoritmo para el uso de fármacos en la sedación 177 



\section{Presentación}

Documentar la variabilidad de la práctica clínica, analizar sus causas y adoptar estrategias orientadas a eliminarla, han demostrado ser iniciativas que fomentan la toma de decisiones efectivas y seguras, centradas en los pacientes, por parte de los profesionales sanitarios. Entre dichas estrategias destaca la elaboración de Guías de Práctica Clínica, «conjunto de recomendaciones basadas en una revisión sistemática de la evidencia y en la evaluación de los riesgos y beneficios de las diferentes alternativas, con el objetivo de optimizar la atención sanitaria a los pacientes».

Entre las prioridades del Ministerio de Sanidad se encuentra consolidar la elaboración de Guías de Práctica Clínica, coordinada desde GuíaSalud, en el marco de la Red Española de Agencias de Evaluación de Tecnologías Sanitarias y Prestaciones del Sistema Nacional de Salud. Es en este contexto en el que se enmarca la presente Guía de Práctica Clínica sobre atención paliativa al adulto en situación de últimos días.

Los últimos días de vida son uno de los acontecimientos más difíciles de afrontar y con mayor impacto, en el que aparecen situaciones de una gran intensidad física, emocional y espiritual, tanto en el paciente como en su familia. Ante las múltiples y complejas necesidades de estos últimos días, el abordaje del sistema sanitario desde el enfoque de cuidados paliativos procura aliviar el sufrimiento de forma que permita conseguir una buena calidad de vida y una buena muerte, llegado el momento.

Los cuidados al final de la vida tienen grandes singularidades. Para la práctica totalidad de las personas morir es un proceso complejo, quizás ahora más que nunca, porque los límites de la vida se han vuelto imprecisos y susceptibles de ser alterados. Tampoco se duda de que en la actualidad las decisiones sanitarias sean, en este contexto, más complejas y difíciles. Pero es innegable que hoy en día la atención a los pacientes en el final de la vida es un derecho, que ha sido reconocido por organismos internacionales, además de una prestación sanitaria claramente descrita en la legislación española, tanto de ámbito nacional como autonómico.

Existe una demanda generalizada en la sociedad de que la atención al final de la vida se centre en las necesidades de las personas, que sea de calidad y que permita una muerte conforme a los valores de la persona. Estas necesidades deben tener respuesta, reconociendo la naturalidad y atendiendo a la dimensión biopsicosocial de este proceso.

Algunas de las peculiaridades que influyen en la atención en los últimos días son que la persona en situación de últimos días de vida tiene unas necesidades específicas y una especial vulnerabilidad, una sintomatología cambiante, con una aparición frecuente de complicaciones que provoca situaciones de urgencia en las que hay que tomar decisiones con rapidez y un mayor nivel de incerteza que requiere de una formación, sensibilidad y flexibilidad por parte de los profesionales que prestan la atención. Todo esto hace que para los profesionales sanitarios la atención a los pacientes también sea un reto. Por todo ello es importante promover actividades y herramientas basadas en la mejor evidencia científica disponible que tengan como objetivo final ayudar a mejorar la calidad de la asistencia al final de la vida. La elaboración, difusión y diseminación, y posterior implementación de 
una Guía de Práctica Clínica sobre atención paliativa en la situación de últimos días podrá mejorar la calidad asistencial, disminuir la variabilidad de la práctica clínica y favorecer los procesos de comunicación y toma de decisiones compartida entre los pacientes y sus familiares y los equipos multidisciplinares que participan en el cuidado de las personas en situación de últimos días de vida.

Esta Guía de Práctica Clínica es el resultado del trabajo de un amplio grupo de profesionales expertos implicados en los cuidados del fin de la vida. En el grupo de trabajo también han participado familiares y representantes de pacientes, y se ha tenido en cuenta la evidencia cualitativa sobre experiencias de pacientes y familias. Aunque la evidencia científica sobre la efectividad de las medidas destinadas a tratar los problemas que aparecen en el final de la vida puede ser escasa en algunas áreas clínicas, creemos que las recomendaciones elaboradas contribuirán a mejorar la atención y a constituir un apoyo a los profesionales sanitarios que atienden a pacientes terminales.

Desde la Dirección General de Salud Pública, agradecemos a todas estas personas el trabajo realizado y esperamos que pueda ayudar a profesionales, pacientes y familiares en la toma de decisiones, mejorando la asistencia en los últimos días de vida.

\section{PILAR APARICIO AZCÁRRAGA}

Directora General de Salud Pública, Calidad e Innovación 


\title{
Autoría y colaboraciones
}

\section{Grupo de trabajo de la GPC sobre atención paliativa al adulto en situación de últimos días}

\begin{abstract}
Alfonso Alonso Fachado. Médico especialista en Medicina Familiar y Comunitaria. Subdirección Xeral de Ordenación Asistencial. Dirección Xeral de Asistencia Sanitaria. Consellería de Sanidade de Galicia.

Luisa Andaluz Corujo. Trabajadora social. Complexo Hospitalario Universitario de A Coruña.

Rocío Basanta Matos. Psicóloga especialista en Psicología Clínica. Hospital Universitario Lucus Augusti.

Francisco Barón Duarte. Médico especialista en Oncología. Complexo Hospitalario Universitario de A Coruña.
\end{abstract}

Rosendo Bugarín González. Médico especialista en Medicina Familiar y Comunitaria. Centro de salud de Monforte de Lemos.

Catalina Caamaño Isorna. Farmacéutica de Atención Primaria. Centro de Salud de Burela.

Paula Cantero Muñoz. Técnica. Farmacéutica. Unidad de Asesoramiento Científico-técnico, Avalia-t. Agencia de Conocimiento en Salud (ACIS).

José Álvaro Fernández Rial. Médico especialista en Medicina Interna. Hospital Universitario Lucus Augusti.

Arantza García Martínez. Médica especialista en Medicina Familiar y Comunitaria. Servicio de Hospitalización a Domicilio (HADO) y Unidad de Cuidados Paliativos. Hospital Universitario Lucus Augusti.

Pablo López Pais. Médico especialista en Anestesia y Reanimación. Complexo Hospitalario Universitario de Santiago de Compostela.

Ángel López Triguero. Enfermero del Servicio de Hospitalización a Domicilio y Cuidados Paliativos. Hospital do Salnés. Vilagarcía de Arousa.

Sabela Maceda García. Psicóloga especialista en Psicología Clínica. Salud Mental. Complexo Hospitalario Universitario A Coruña.

María del Carmen Maceira Rozas. Técnica. Farmacéutica. Unidad de Asesoramiento Científico-técnico, Avalia-t. Agencia de Conocimiento en Salud (ACIS).

Marcelino Mosquera Pena. Médico especialista en Geriatría. Unidad de Cuidados Paliativos. Complejo Hospitalario Universitario de Ferrol.

Begoña Palacio Verdini. Familiar.

Yolanda Triñanes Pego. Técnica. Psicóloga. Unidad de Asesoramiento Científicotécnico, Avalia-t. Agencia de Conocimiento en Salud (ACIS). Santiago de Compostela.

Marta Vega Lorenzo. Familiar. 


\section{Coordinación}

Rosendo Bugarín González. Médico especialista en Medicina Familiar y Comunitaria. Centro de Salud de Monforte de Lemos. Coordinación clínica.

José Álvaro Fernández Rial. Médico especialista en Medicina Interna. Hospital Universitario Lucus Augusti. Coordinación clínica.

Yolanda Triñanes Pego. Técnica. Psicóloga. Unidad de Asesoramiento Científico-técnico, Avalia-t. Agencia de Conocimiento en Salud (ACIS). Coordinación metodológica.

\section{Colaboración}

Beatriz Casal Acción. Documentalista. Unidad de Asesoramiento Científico-técnico, Avalia-t. Agencia de Conocimiento en Salud (ACIS).

Teresa Mejuto Martí. Documentalista. Unidad de Asesoramiento Científico-técnico, Avalia-t. Agencia de Conocimiento en Salud (ACIS).

Noemí Raña Villar. Administrativa. Unidad de Asesoramiento Científico-técnico, Avalia-t. Agencia de Conocimiento en Salud (ACIS).

Cristina Rey Varela. Administrativa. Unidad de Asesoramiento Científico-técnico, Avalia-t. Agencia de Conocimiento en Salud (ACIS).

\section{Colaboración experta}

Eduardo Bruera. MD Anderson Cancer Center de Houston.

Ingrid Bullich Marín. Enfermera especialista en Enfermería Geriátrica. Coordinadora científica de la Estrategia en Cuidados Paliativos del Sistema Nacional de Salud. Grup Mutuam. Barcelona.

Itziar Etxeandia Ikobaltzeta. Doctora en Farmacia. Investigadora Independientefreelance en elaboración de GPC y revisiones sistemáticas, asociada a la American College of Physicians (ACP), entre otras instituciones.

Manuel Mejías Estévez. Médico especialista en Medicina Familiar y Comunitaria. Sociedad Española de Médicos de Atención Primaria (SEMERGEN) Andalucía.

Alberto Meléndez Gracia. Médico especialista en Medicina Familiar y Comunitaria. Vicepresidente de la Sociedad Española de Cuidados Paliativos (SECPAL).

Celia Muñoz Fernández. Economista de la Salud. Instituto Aragonés de Ciencias de la Salud.

Sonia Peláez Moya. Subdirección General de Promoción, Prevención y Calidad. Dirección General de Salud Pública. Ministerio de Sanidad.

Rafael Rotaeche del Campo. Médico especialista en Medicina Familiar y Comunitaria. Centro de Salud de Alza (San Sebastián). Coordinador metodológico de la GPC base.

Antonio Sacristán Rodea. Médico especialista en Oncología. Centro de Salud Jazmín. Dirección Asistencial Este. Atención Primaria. Madrid. 


\section{Revisión externa}

Enrique Álvarez Porta. Médico especialista en Medicina Familiar y Comunitaria. Unidad de Cuidados Paliativos, Hospital Joan March. Mallorca.

Francisco Eugenio Apolo Carvajal. Farmacéutico especialista en Farmacia Hospitalaria. Subdirección General de Farmacia y Productos Sanitarios. Servicio Madrileño de Salud (SERMAS). Farmacéutico de Atención a Centros Sociosanitarios. Madrid.

Jacinto Bátiz Cantera. Doctor en Medicina y Cirugía. Hospital San Juan de Dios de Santurtzi. Director del Instituto de Sensibilización, Formación, Investigación e Innovación para cuidar mejor. Bizkaia.

Rosario Baydal Cardona. Coordinadora de la Unidad de Hospitalización a Domicilio (HADO). Hospital de Denia. Alicante.

Marisa de la Rica Escuín. Enfermera. Instituto de Investigación Sanitaria de Aragón. Enfermera de Investigación. Zaragoza.

Ramón de las Peñas Bataller. Coordinador de la Sección de Cuidados Continuos de la Sociedad Española de Oncología Médica (SEOM).

Leyre Díez Porres. Médica especialista en Medicina Interna. Unidad de Cuidados Paliativos. Hospital Universitario La Paz. Madrid.

María Elviro Lloréns. Farmacéutica especialista en Farmacia Hospitalaria. Doctora en Farmacia. Coordinadora Nacional del Grupo de Trabajo de Dolor de la SEFH. Jefa del Servicio de Farmacia de la Fundación Vianorte Laguna, Cuidados Paliativos. Madrid.

Ángel Estella García. Médico especialista en Medicina Intensiva. Hospital Universitario de Jerez de la Frontera.

Carlos José Ferrer Albiach. Médico especialista en Oncología Radioterápica. Consorcio Hospitalario provincial de Castellón. Instituto Oncológico de Castellón.

Inés González Bolaños. Médica especialista en Medicina Familiar y Comunitaria. Unidad de Cuidados Paliativos, Complejo Hospitalario Universitario Insular Materno Infantil. Las Palmas

César González-Blanch Bosch. Facultativo Especialista de Área (FEA) en Psicología Clínica. Hospital Universitario Marqués de Valdecilla. Santander.

Natalia López-Casero Beltrán. Diplomada Universitaria de Enfermería. Unidad de Cuidados Paliativos Domiciliaria. Hospital Mancha Centro de Alcázar de San Juan. Ciudad Real.

Nieves Martín López. Psicóloga InfoCancer. Asociación Española Contra el Cáncer (AECC). Madrid.

Víctor Mayoral Rojals. Médico especialista en Anestesiología y Reanimación. Hospital Universitario de Bellvitge; Instituto Catalán de Oncología. Barcelona.

Manuel José Mejías Estévez. Médico especialista en Medicina Familiar y Comunitaria. Centro de Salud Ronda Histórica. Sevilla.

Juan Pérez Cajaraville. Médico especialista en Anestesiología y Reanimación. Grupo universitario HM Hospitales de Madrid. 
Pedro Pérez Segura. Miembro del Comité Ejecutivo de la Sección de Cuidados Continuos de la Sociedad Española de Oncología Médica (SEOM).

Susana Plaza Canteli. Medica especialista en Medicina Interna. Unidad de Cuidados Paliativos. Hospital Universitario Severo Ochoa. Madrid.

Amador Priede Díaz. Psicólogo especialista en Psicología Clínica Hospital de Laredo. Santander.

Paloma Romero Martín. Psicóloga InfoCancer. Asociación Española Contra el Cáncer (AECC). Madrid.

Olga Rubio Sanchiz. Médico especialista en Cuidados Intensivos. Althaia Xarxa Universitaria Hospitalaria de Manresa. Barcelona.

Ana María Tordable Ramírez. Enfermera de apoyo técnico Gerencia Asistencial de Atención Primaria del Servicio Madrileño de Salud. Vocal de Enfermería de la Sociedad Española de Cuidados Paliativos (SECPAL). Madrid.

\section{Agradecimientos}

A María José Faraldo Vallés, de la Unidad de Asesoramiento Científico-técnico, Avalia-t de la Agencia de Conocimiento en Salud (ACIS), por su labor de dirección y gestión.

A Patricia Gavín Benavent y María Bono Vega de GuíaSalud, y al Centro Cochrane Iberoamericano por el apoyo metodológico.

\section{Sociedades Colaboradoras}

Miembros de estas sociedades han participado en la autoría, colaboración experta y revisión externa de la GPC

Sociedad Española de Cuidados Paliativos (SECPAL)

Sociedad Española de Farmacéuticos de Atención Primaria (SEFAP)

Sociedad Española del Dolor (SED)

Sociedad Española de Hospitalización a Domicilio (SEHAD)

Sociedad Española de Medicina de Familia y Comunitaria (SEMFYC)

Sociedad Española de Medicina Intensiva, Crítica y Unidades Coronarias (SEMICYUC)

Sociedad Española de Medicina Interna (SEMI)

Sociedad Española de Oncología Médica (SEOM)

Sociedad Española de Médicos Generales y de Familia (SEMG)

Sociedad Española de Médicos de Atención Primaria (SEMERGEN)

Sociedad Española de Oncología Radioterápica (SEOR)

Sociedad Española de Farmacia Hospitalaria (SEFH)

Asociación de Enfermería Comunitaria (AEC)

Asociación Nacional de Psicólogos Clínicos y Residentes de Psicología (ANPIR)

Asociación Española de Enfermería en Cuidados Paliativos (AECPAL) Asociación Española Contra el Cáncer (AECC) (sección cuidados paliativos) 


\section{Exposición Pública}

Esta GPC ha sido sometida a un proceso de Exposición Pública. El listado completo de los grupos de interés que han participado en el proceso de exposición pública está disponible en la web de GuíaSalud: www.guiasalud.es

Declaración de interés: todos los miembros del Grupo de Trabajo, así como las personas que han participado en la colaboración experta y en la revisión externa, han realizado la declaración de interés que se presenta en el anexo 13. 



\section{Preguntas para responder}

\section{RECONOCIMIENTO DE SITUACIÓN DE ÚLTIMOS DÍAS ${ }^{1}$}

1. ¿Qué signos y síntomas se deben evaluar cuando sospechamos que un paciente adulto con enfermedad crónica avanzada puede estar en situación de últimos días?

\section{COMUNICACIÓN E INFORMACIÓN ${ }^{1}$}

2. ¿Cuáles son los factores asociados a una buena comunicación en los últimos días de vida entre el paciente, sus allegados y los profesionales sanitarios que lo atienden?

\section{TOMA DE DECISIONES COMPARTIDA Y DESARROLLO DEL PLAN DE CUIDADOS $^{1}$}

3. ¿Cuáles son los factores que pueden favorecer la toma de decisiones compartida sobre el plan de cuidados individualizado para los últimos días de vida?

\section{HIDRATACIÓN ${ }^{1}$}

4. ¿En pacientes en sus últimos días de vida, la hidratación artificial es efectiva para mejorar los síntomas y el confort general?

\section{MANEJO DE SÍNTOMAS: DOLOR, DISNEA, NÁUSEAS Y VÓMITOS,} ANSIEDAD, DELIRIUM Y ESTERTORES ${ }^{1}$

5. Para pacientes en los últimos días de vida, ¿qué fármacos son más efectivos para aliviar el dolor, la disnea, las náuseas y vómitos, la ansiedad, el delirium y los estertores?

\section{SEDACIÓN PALIATIVA ${ }^{2}$}

6. En pacientes en situación de últimos días, ¿es beneficiosa la sedación paliativa para aliviar el sufrimiento causado por síntomas refractarios?

1. Las preguntas clínicas de reconocimiento de situación de últimos días, comunicación e información, toma de decisiones compartida y desarrollo del plan de cuidados, hidratación y manejo de síntomas se han adaptado de la GPC del NICE Care of dying adults in the last days of life (NICE guideline [NG31]), mediante una actualización de la evidencia considerada en la Guía NICE y la adaptación del marco conceptual EtD para la elaboración de las recomendaciones.

2. Actualización de la evidencia identificada en una RS con elaboración de-novo del marco conceptual EtD de elaboración de recomendaciones. 



\section{Recomendaciones de buena práctica clínica (BPC)*}

\begin{tabular}{l|l} 
BPC & Práctica recomendada basada en la experiencia clínica y el consenso del equipo elaborador
\end{tabular}

*En ocasiones, el grupo elaborador se percata de que existe algún aspecto práctico sobre el que se quiere hacer énfasis y para el cual, probablemente, no existe evidencia científica que lo soporte. En general, estos casos se relacionan con algún aspecto del tratamiento considerado como buena práctica clínica y que nadie cuestionaría. Estos aspectos son valorados como puntos de buena práctica clínica.

\section{Adaptación de las recomendaciones con el método GRADE-ADOLOPMENT*}

\begin{tabular}{|l|l|}
\hline Adoptada & Adopción de la recomendación original \\
\hline Adaptada & Recomendación original modificada al contexto propio \\
\hline Nueva & Desarrollo de novo de la recomendación \\
\hline
\end{tabular}

*Las preguntas clínicas de reconocimiento de situación de últimos días, comunicación e información, toma de decisiones compartida y desarrollo del plan de cuidados, hidratación y manejo de síntomas se han adaptado de la GPC del NICE Care of dying adults in the last days of life (NICE guideline [NG31]). 


\section{Resumen de las recomendaciones de la GPC}

\section{Reconocimiento de situación de últimos días}

\begin{tabular}{|c|c|}
\hline BPC, nueva & $\begin{array}{l}\text { Cuando se esté atendiendo a personas que padecen enfermedades pro- } \\
\text { gresivas, en situación muy avanzada, se recomienda evaluar siempre el } \\
\text { pronóstico e identificar si se encuentra en una probable situación de } \\
\text { últimos días (diagnóstico situacional), y dejar registro en la historia } \\
\text { clínica. }\end{array}$ \\
\hline & $\begin{array}{l}\text { Se recomienda apoyar el juicio clínico y la valoración interdisciplinaria } \\
\text { (piezas clave en el diagnóstico de situación de últimos días) mediante los } \\
\text { siguientes aspectos: } \\
\text { - Valoración de las posibles causas reversibles del deterioro, princi- } \\
\text { palmente cuando no hay coherencia entre la evolución esperada y } \\
\text { la aparición de síntomas. } \\
\text { - Monitorización de cambios en las necesidades físicas, psicosociales y } \\
\text { espirituales de los pacientes. } \\
\text { - Evaluación de la situación funcional y velocidad de declive. En caso } \\
\text { de valorar el uso de escalas como apoyo a la evaluación, se sugiere } \\
\text { emplear la PPS (Palliative Performance Scale) o la ECOG (Eastern } \\
\text { Cooperative Oncology Group).Consideración de las opiniones del } \\
\text { resto del equipo interdisciplinar, y en caso de dudas contar con el } \\
\text { apoyo de profesionales expertos. }\end{array}$ \\
\hline $\begin{array}{l}\text { Débil a } \\
\text { favor, } \\
\text { adaptada }\end{array}$ & $\begin{array}{l}\text { Se sugiere evaluar los siguientes signos y síntomas: } \\
\text { - Cambios cardiovasculares: } \\
\text { - Hipotensión } \\
\text { - Oliguria } \\
\text { - Livideces } \\
\text { - Cambios respiratorios: } \\
\text { - Respiración ruidosa (estertores) } \\
\text { - Cambios en el patrón respiratorio: respiración de Cheyne-Stokes, } \\
\text { apneas } \\
\text { - Disnea } \\
\text { - Respiración con movimiento mandibular }\end{array}$ \\
\hline
\end{tabular}




\begin{tabular}{|c|c|}
\hline $\begin{array}{l}\text { Débil a } \\
\text { favor, } \\
\text { adaptada }\end{array}$ & $\begin{array}{l}\text { - Cambios del estado físico: } \\
\text { - Debilidad profunda y progresiva } \\
\text { - Indifida de la habilidad de cerrar los ojos hacia comida y bebida } \\
\text { - Dificultad para la deglución } \\
\text { - Incontinencia o retención urinaria } \\
\text { - Cambios cognitivos y neurológicos: } \\
\text { - Disminución del nivel de alerta (desde somnolencia al coma) } \\
\text { - Delirium hipoactivo o hiperactivo (con agitación) } \\
\text { - Cambios psicosociales y emocionales: } \\
\text { - Aislamiento } \\
\text { - Cambios en el estado de ánimo } \\
\text { - Cambios en la experiencia espiritual. }\end{array}$ \\
\hline $\begin{array}{l}\text { BPC, } \\
\text { adaptada }\end{array}$ & $\begin{array}{l}\text { Se recomienda investigar y descartar de forma proporcionada y teniendo } \\
\text { en cuenta los valores y preferencias de paciente/allegados, posibles } \\
\text { causas reversibles del deterioro: deshidratación, infección, toxicidad por } \\
\text { opioides, retirada de esteroides, insuficiencia renal aguda, alteraciones } \\
\text { metabólicas, y si es el caso, iniciar el tratamiento correspondiente. }\end{array}$ \\
\hline
\end{tabular}

\section{Comunicación e información}

\begin{tabular}{|l|l|}
\hline BPC, nueva & $\begin{array}{l}\text { Se recomienda fomentar un clima adecuado basado en la calidez, empatía, } \\
\text { asertividad y una actitud de escucha activa, prestando especial atención } \\
\text { a la comunicación no verbal. En la medida de lo posible, es importante } \\
\text { buscar un espacio físico que mantenga la privacidad, destinar el tiempo } \\
\text { necesario, y permitir hacer preguntas y aclarar dudas, dejando también } \\
\text { un espacio para la reflexión. }\end{array}$ \\
\hline $\begin{array}{l}\text { BPC, } \\
\text { adaptada }\end{array}$ & $\begin{array}{l}\text { Se recomienda identificar las necesidades de comunicación y expectati- } \\
\text { vas de las personas al final de la vida, teniendo en cuenta: } \\
- \text { Si el paciente desea o no que alguna persona determinada esté pre- } \\
\text { sente en el momento de tomar decisiones. } \\
- \text { El grado actual de conocimiento acerca de la situación final de vida. } \\
- \text { Cuánta información les gustaría tener acerca de su proceso. } \\
- \text { Sus preferencias y necesidades sociales, culturales, religiosas y espi- } \\
\text { rituales. } \\
- \text { Sus miedos y preocupaciones. }\end{array}$ \\
\end{tabular}




\begin{tabular}{|c|c|}
\hline BPC, nueva & $\begin{array}{l}\text { Se recomienda, a pesar de la incertidumbre pronóstica en muchos casos, } \\
\text { iniciar el proceso de toma de decisiones compartida lo antes posible } \\
\text { durante el proceso de enfermedad, o al principio de la relación clínica si } \\
\text { no ha sido realizado previamente por otros profesionales. }\end{array}$ \\
\hline $\begin{array}{l}\text { BPC, } \\
\text { adoptada }\end{array}$ & $\begin{array}{l}\text { Al principio del proceso de toma de decisiones compartida se reco- } \\
\text { mienda explorar el nivel de participación que la persona desea y puede } \\
\text { tener, y que las discusiones sobre el desarrollo e implementación del plan } \\
\text { de cuidados se realicen de forma honesta y transparente. }\end{array}$ \\
\hline $\begin{array}{l}\text { BPC, } \\
\text { adaptada }\end{array}$ & $\begin{array}{l}\text { Durante el proceso de toma de decisiones se recomienda explorar las } \\
\text { expectativas, deseos y preferencias del paciente respecto a la atención } \\
\text { y los cuidados que desea recibir, según sus valores. En caso de que el } \\
\text { paciente se encuentre en una situación que no le permita tomar decisio- } \\
\text { nes, revisar: } \\
\text { - La existencia de un documento de instrucciones previas o volunta- } \\
\text { des anticipadas. } \\
\text { - Las anotaciones en la historia clínica referidas a un proceso de pla- } \\
\text { nificación anticipada y compartida de la asistencia. } \\
\text { - Preferencias manifestadas a sus familiares y/o allegados acerca de } \\
\text { los cuidados que desearía recibir. } \\
\text { - Si existe un representante designado por el paciente. En caso de } \\
\text { no existir representante designado ni familiares y/o allegados, la } \\
\text { toma de decisiones corresponderá al equipo terapéutico, buscando } \\
\text { el mayor consenso y actuando siempre buscando el mejor beneficio } \\
\text { o interés para el paciente. }\end{array}$ \\
\hline $\begin{array}{l}\text { BPC, } \\
\text { adoptada }\end{array}$ & $\begin{array}{l}\text { Se recomienda registrar los temas tratados y el plan de cuidados en un } \\
\text { lugar adecuado para ello en la historia clínica, accesible para todos los } \\
\text { profesionales que intervienen en la atención, y compartir esta informa- } \\
\text { ción, además de con el resto del equipo de atención, con los allegados de } \\
\text { la persona enferma implicados en su cuidado y/o acompañamiento. }\end{array}$ \\
\hline
\end{tabular}




\begin{tabular}{|c|c|}
\hline $\begin{array}{l}\text { Débil en } \\
\text { contra, } \\
\text { adaptada }\end{array}$ & $\begin{array}{l}\text { Con carácter general no se recomienda la hidratación artificial en la } \\
\text { situación de últimos días. Excepcionalmente podría considerarse si: } \\
\text { - Existe mal control de síntomas que pueden estar relacionados con } \\
\text { la deshidratación (por ej. delirium) y han fracasado otras medidas } \\
\text { de control. } \\
\text { - La reducción de la ingesta oral produce malestar o inquietud emo- } \\
\text { cional en el paciente y su familia a pesar de un adecuado proceso de } \\
\text { comunicación con el equipo de atención. }\end{array}$ \\
\hline $\begin{array}{l}\text { BPC, } \\
\text { adaptada }\end{array}$ & $\begin{array}{l}\text { Si el paciente no está en condiciones de decidir, al considerar la hidra- } \\
\text { tación artificial en un paciente en situación de últimos días, es necesario } \\
\text { revisar en su historia clínica si el paciente ha expresado previamente en } \\
\text { un documento de instrucciones previas o en un proceso de planificación } \\
\text { anticipada y compartida de la asistencia, sus preferencias sobre la hidra- } \\
\text { tación artificial. }\end{array}$ \\
\hline $\begin{array}{l}\text { BPC, } \\
\text { adaptada }\end{array}$ & $\begin{array}{l}\text { Si se indica hidratación artificial: } \\
\text { - Se recomienda abordar las inquietudes de paciente y familia e infor- } \\
\text { mar sobre la evidencia de los beneficios y riesgos de la hidratación } \\
\text { artificial en situación de últimos días. } \\
\text { - Considerarla como una prueba limitada en el tiempo (acordada } \\
\text { previamente con paciente/familia). } \\
\text { - Se aconseja no usar cantidades de volumen mayores de } 1 \text { litro al día. } \\
\text { - Se recomienda no utilizar la vía enteral. La vía preferente será la } \\
\text { subcutánea en caso de atención domiciliaria o de no disponer vía } \\
\text { intravenosa ya canalizada. }\end{array}$ \\
\hline $\begin{array}{l}\text { BPC, } \\
\text { adaptada }\end{array}$ & 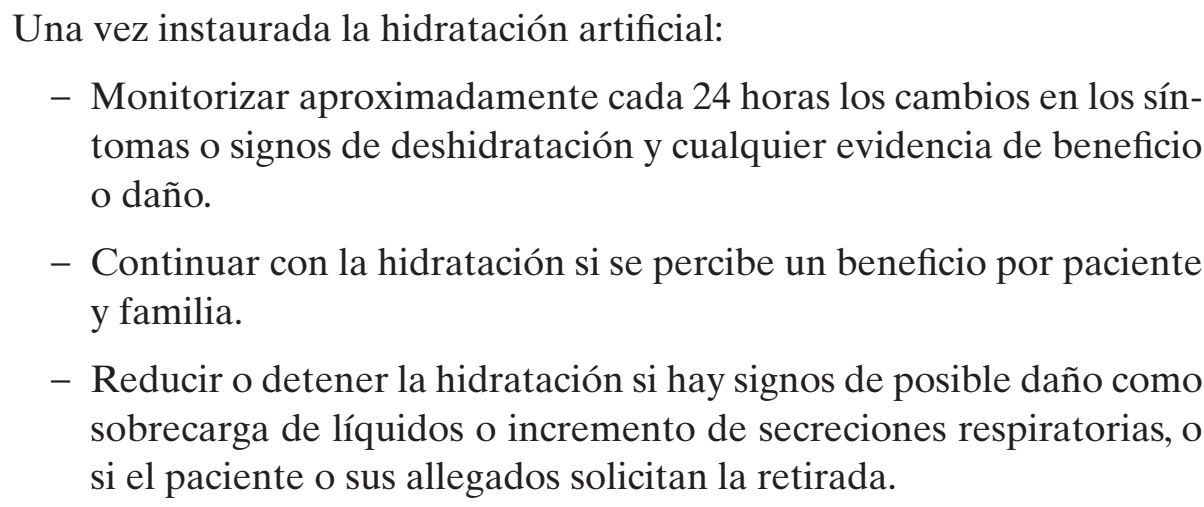 \\
\hline $\begin{array}{l}\text { BPC, } \\
\text { adoptada }\end{array}$ & $\begin{array}{l}\text { Para las personas que ya tienen instaurada la hidratación artificial (enteral } \\
\text { o parenteral) antes de los últimos días de vida: } \\
\text { - Revisar los riesgos y beneficios de continuar con la hidratación arti- } \\
\text { ficial en situación de últimos días con el paciente y sus allegados. } \\
\text { - Considerar si continuar, reducir o detener la hidratación artificial a } \\
\text { medida que la persona se acerca a la muerte. }\end{array}$ \\
\hline
\end{tabular}




\begin{tabular}{|l|l|}
\hline BPC, nueva & $\begin{array}{l}\text { Para guiar las decisiones sobre manejo de síntomas se recomienda reali- } \\
\text { zar una valoración sistemática de los síntomas principales, para disminuir } \\
\text { el riesgo de infraestimación de alguno de ellos, y cuantificar su intensidad } \\
\text { mediante escalas que permitan evaluar el resultado de las medidas aplicadas. }\end{array}$ \\
\hline $\begin{array}{l}\text { BPC } \\
\text { adaptada }\end{array}$ & $\begin{array}{l}\text { Se recomienda hacer una revisión rigurosa del tratamiento en la fase final } \\
\text { de la vida del paciente y adaptarlo a los objetivos terapéuticos centrados } \\
\text { en el bienestar y en el control de síntomas. }\end{array}$ \\
\hline $\begin{array}{l}\text { BPC } \\
\text { adaptada }\end{array}$ & $\begin{array}{l}\text { Se recomienda suspender todos aquellos tratamientos fútiles, que no aporten } \\
\text { beneficio a la situación actual del paciente, y discutir los riesgos y beneficios } \\
\text { de cualquier medicamento ofrecido, así como transmitir que la retirada de } \\
\text { un fármaco se debe a la futilidad en la situación actual del paciente. }\end{array}$ \\
\hline $\begin{array}{l}\text { BPC } \\
\text { adaptada }\end{array}$ & $\begin{array}{l}\text { Se recomienda dejar instrucciones claras y por escrito del tratamiento, } \\
\text { indicando pautas fijas y otras condicionadas a momentos de crisis. }\end{array}$ \\
\hline
\end{tabular}

Manejo de síntomas: dolor

\begin{tabular}{|l|l|}
\hline BPC, nueva & $\begin{array}{l}\text { Dentro de un enfoque global de los cuidados paliativos, se recomienda } \\
\text { promocionar la valoración y el manejo correcto del dolor para que los } \\
\text { pacientes lleguen a situación de últimos días con el dolor controlado, } \\
\text { manteniendo la medicación con los ajustes de dosis que sean precisos. } \\
\text { Se deben anticipar las posibles necesidades analgésicas del paciente y } \\
\text { dejar prescrita medicación para su adecuado control con la finalidad de } \\
\text { manejar la situación por los familiares, allegados y/o equipo sanitario en } \\
\text { el momento necesario. }\end{array}$ \\
\hline $\begin{array}{l}\text { BPC, } \\
\text { adaptada }\end{array}$ & $\begin{array}{l}\text { Se recomienda no prescribir analgésicos de forma rutinaria ya que, si } \\
\text { bien es un síntoma muy frecuente, no todas las personas en situación de } \\
\text { últimos días experimentan dolor. }\end{array}$ \\
\hline $\begin{array}{l}\text { BPC, } \\
\text { adaptada }\end{array}$ & $\begin{array}{l}\text { Se recomienda considerar un manejo no farmacológico del dolor en pacien- } \\
\text { tes en situación de últimos días asociado a las medidas farmacológicas. }\end{array}$ \\
\hline BPC, nueva & $\begin{array}{l}\text { El tratamiento farmacológico de elección cuando el dolor es moderado o } \\
\text { grave, una vez descartadas las causas reversibles, serían los opioides. En los } \\
\text { casos de dolor leve se sugiere utilizar fármacos de primer escalón excepto } \\
\text { que se prevea una mala respuesta o problemas en la vía de administración, } \\
\text { en cuyo caso se podría plantear un inicio con opioides a dosis bajas. }\end{array}$ \\
\hline BPC, nueva & $\begin{array}{l}\text { En caso de instauración de tratamiento opioide, el de elección en situa- } \\
\text { ción de últimos días es la morfina de acción rápida (oral o parenteral). }\end{array}$ \\
\hline BPC, nueva & $\begin{array}{l}\text { Se recomienda no retirar o disminuir abruptamente la medicación opioide } \\
\text { ya que, tanto esta disminución o retirada como el dolor mal controlado, } \\
\text { son factores reconocidos de desorientación y de delirium en pacientes } \\
\text { con enfermedad crónica avanzada. }\end{array}$ \\
$\begin{array}{l}\text { En pacientes con dolor neuropático, se recomienda mantener la medica- } \\
\text { ción basal en la medida de lo posible, si bien es frecuente que en situación } \\
\text { de últimos días se pierda la vía oral, por lo que se tendrá esto en conside- } \\
\text { ración de cara a la dosificación de opioide. }\end{array}$ \\
\hline BPC
\end{tabular}




\begin{tabular}{|l|l|}
\hline $\begin{array}{l}\text { BPC, } \\
\text { adaptada }\end{array}$ & $\begin{array}{l}\text { Se recomienda mantener o iniciar el tratamiento específico si se conoce el } \\
\text { problema que causa la disnea (por ejemplo, edema pulmonar o derrame } \\
\text { pleural) y el balance beneficio-riesgo individualizado es favorable. }\end{array}$ \\
\hline $\begin{array}{l}\text { BPC, } \\
\text { adaptada }\end{array}$ & $\begin{array}{l}\text { Se recomienda realizar inicialmente un manejo no farmacológico de la } \\
\text { disnea en una persona en los últimos días de vida, asociado a las medidas } \\
\text { farmacológicas en caso de ser necesario. }\end{array}$ \\
\hline BPC, nueva & $\begin{array}{l}\text { Se recomienda ofrecer una prueba terapéutica de oxigenoterapia inde- } \\
\text { pendiente de la hipoxemia en caso de que las medidas no farmacológicas } \\
\text { no produzcan un alivio de la disnea, y mantenerla si el paciente/familia } \\
\text { perciben un beneficio. }\end{array}$ \\
\hline $\begin{array}{l}\text { Débil a } \\
\text { favor, } \\
\text { adaptada }\end{array}$ & $\begin{array}{l}\text { Se recomienda añadir tratamiento sintomático si el control de la disnea } \\
\text { es inadecuado con las medidas previas: morfina, midazolam, o la combi- } \\
\text { nación de ambos. }\end{array}$ \\
\hline
\end{tabular}

\section{Manejo de síntomas: náuseas y vómitos}

\begin{tabular}{|c|c|}
\hline $\begin{array}{l}\text { BPC, } \\
\text { adaptada }\end{array}$ & $\begin{array}{l}\text { Se recomienda evaluar las causas de las náuseas y vómitos en situación } \\
\text { de últimos días de manera proporcionada. Entre las causas podrían } \\
\text { incluirse: } \\
\text { - Algunos fármacos. } \\
\text { - Quimioterapia y radioterapia. } \\
\text { - Causas psicológicas. } \\
\text { - Causas bioquímicas, por ejemplo, hipercalcemia. } \\
\text { - Presión intracraneal elevada. } \\
\text { - Trastornos de la motilidad gastrointestinal. } \\
\text { - Obstrucción intestinal. }\end{array}$ \\
\hline $\begin{array}{l}\text { BPC, } \\
\text { adoptada }\end{array}$ & $\begin{array}{l}\text { Se recomienda considerar medidas no farmacológicas para tratar las } \\
\text { náuseas y vómitos en personas en situación de los últimos días de vida. }\end{array}$ \\
\hline $\begin{array}{l}\text { Débil a } \\
\text { favor, } \\
\text { adaptada }\end{array}$ & $\begin{array}{l}\text { Para el tratamiento de las náuseas y vómitos en personas con obstrucción } \\
\text { intestinal se sugiere, además del resto de medidas farmacológicas y no } \\
\text { farmacológicas: } \\
\text { - Butilbromuro de hioscina o escopolamina como tratamiento antise- } \\
\text { cretor de primera línea. } \\
\text { - Octreótido si los síntomas no mejoran a las } 24 \text { horas del tratamiento } \\
\text { con butilbromuro de hioscina. }\end{array}$ \\
\hline BPC, nueva & $\begin{array}{l}\text { En el resto de situaciones clínicas se sugiere emplear la medicación antie- } \\
\text { mética estándar en la atención paliativa: neurolépticos, antihistamínicos, } \\
\text { procinéticos, antagonistas } 5 \text { HT3, corticoides y benzodiazepinas. }\end{array}$ \\
\hline
\end{tabular}




\begin{tabular}{|l|l|}
\hline BPC, nueva & $\begin{array}{l}\text { Se recomienda evaluar la presencia de ansiedad y delirium (con o sin } \\
\text { agitación) en todo paciente en situación de últimos días. }\end{array}$ \\
\hline $\begin{array}{l}\text { BPC, } \\
\text { adaptada }\end{array}$ & $\begin{array}{l}\text { Se recomienda explorar y manejar de manera proporcionada a la situa- } \\
\text { ción de últimos días y deseos del paciente y sus allegados, las posibles } \\
\text { causas de ansiedad o delirium, por ejemplo, dolor, retención urinaria o } \\
\text { impactación fecal. }\end{array}$ \\
\hline $\begin{array}{l}\text { BPC, } \\
\text { adaptada }\end{array}$ & $\begin{array}{l}\text { Se recomienda aplicar medidas no farmacológicas de prevención y } \\
\text { manejo de la ansiedad y el delirium. Se recomienda realizar soporte y } \\
\text { educación a la familia. }\end{array}$ \\
\hline $\begin{array}{l}\text { BPC, } \\
\text { adaptada }\end{array}$ & $\begin{array}{l}\text { Se recomienda considerar el uso de benzodiazepinas para controlar la } \\
\text { ansiedad. }\end{array}$ \\
\hline $\begin{array}{l}\text { BPC, } \\
\text { adaptada }\end{array}$ & $\begin{array}{l}\text { Se recomienda considerar el uso de un medicamento antipsicótico clásico } \\
\text { para controlar el delirium, y en caso de ausencia de respuesta su combi- } \\
\text { nación con benzodiacepinas. }\end{array}$ \\
\hline
\end{tabular}

\section{Manejo de síntomas: estertores}

\begin{tabular}{|l|l|}
\hline $\begin{array}{l}\text { BPC, } \\
\text { adaptada }\end{array}$ & $\begin{array}{l}\text { Se recomienda, cuando una persona entra en situación de últimos días, } \\
\text { evaluar la aparición de estertores para valorar el inicio de un manejo } \\
\text { precoz. }\end{array}$ \\
\hline $\begin{array}{l}\text { BPC, } \\
\text { adaptada }\end{array}$ & $\begin{array}{l}\text { Se recomienda informar sobre las causas de los estertores y resolver las } \\
\text { dudas que puedan surgir, incidiendo en que, aunque el ruido puede ser } \\
\text { angustiante, es poco probable que cause molestias a la persona enferma } \\
\text { por el bajo nivel de conciencia. }\end{array}$ \\
\hline $\begin{array}{l}\text { BPC, } \\
\text { adaptada }\end{array}$ & $\begin{array}{l}\text { Se recomienda iniciar medidas no farmacológicas para aliviar los ester- } \\
\text { tores, para reducir cualquier malestar en las personas al final de la vida y } \\
\text { en su entorno. }\end{array}$ \\
\hline $\begin{array}{l}\text { BPC, } \\
\text { adaptada }\end{array}$ & $\begin{array}{l}\text { Se recomienda considerar tratamiento farmacológico de los estertores } \\
\text { cuando la aplicación de las medidas no farmacológicas y un correcto } \\
\text { proceso comunicativo con el paciente y su familia son insuficientes. }\end{array}$ \\
\hline $\begin{array}{l}\text { Débil a } \\
\text { favor, } \\
\text { adaptada }\end{array}$ & $\begin{array}{l}\text { Se sugiere el uso de butilbromuro de escopolamina como primera opción, } \\
\text { aunque la atropina o bromhidrato de escopolamina pueden emplearse } \\
\text { como alternativas. }\end{array}$ \\
\hline
\end{tabular}

Sedación paliativa

\begin{tabular}{|l|l|}
\hline Débil a & Se sugiere aplicar sedación paliativa en pacientes en situación de últimos
\end{tabular} favor días con sufrimiento causado por uno o más síntomas refractarios. 



\section{Introducción}

Los avances científicos y tecnológicos desarrollados en las últimas décadas unidos a las mejoras sociales y de condiciones de vida, han cambiado la epidemiología de las enfermedades y también la epidemiología de la muerte, sobre todo en los países desarrollados. Dos consecuencias de los aspectos mencionados son el aumento de la esperanza de vida y el cambio en las causas y condiciones de muerte, de manera que en la actualidad se estima que 3 de cada 4 muertes podrían producirse por la progresión de uno o más problemas crónicos de salud (1) ${ }^{3}$. Además de la cronicidad están irrumpiendo en nuestro medio otros condicionantes que hacen aún más compleja la práctica clínica como son los movimientos migratorios, la crisis económica y la desigualdad en la distribución de la riqueza, los cambios en los modelos de familia, el aumento del coste sanitario y el reconocimiento de la finitud de los recursos, lo que conlleva a un escenario complejo, diverso, con poblaciones especialmente vulnerables y en riesgo de exclusión social.

Este nuevo escenario, con la aparición de la cronicidad y los factores sociodemográficos mencionados, obligan a replantear los objetivos de salud y con ellos, el ejercicio de las profesiones sanitarias y sociales.

El abordaje de la cronicidad implica conocer la trayectoria de las diferentes enfermedades para diseñar programas de salud y adecuar los planes de cuidados a cada caso individual (desde el paciente joven con cáncer con su trayectoria vital sin completar, a la persona mayor con enfermedad de órgano terminal), garantizando la continuidad asistencial (2). En este contexto, los cuidados y el enfoque paliativo de la práctica clínica se deben integrar desde el principio del diagnóstico de una enfermedad incurable y progresiva con pronóstico vital limitado, muchas veces impreciso, coexistiendo de modo sinérgico y complementario con aquellos tratamientos específicos de la enfermedad y acrecentándose a medida que las enfermedades van progresando, llegando a la etapa final o de enfermedad en situación terminal (3). Más allá del concepto de "paliativo oncológico y no oncológico" en este momento se prefiere un lenguaje no dicotómico, por lo que se ha propuesto hablar de "enfermedades crónicas avanzadas" incluyéndose en este concepto desde aquellos pacientes con enfermedades activas y avanzadas con pronóstico limitado, donde el objetivo fundamental es la mejora de la calidad de vida, hasta los cuidados de los pacientes con enfermedades de mal pronóstico, pero cuya muerte no parece cercana. Así se incluyen pacientes con diagnóstico reciente de cáncer avanzado, pacientes con enfermedad crónica avanzada de un órgano, demencia senil avanzada, enfermedades degenerativas del sistema nervioso central, ancianos frágiles y comas evolucionados de diferentes causas (4).

Surge así un nuevo paradigma, el de los cuidados paliativos precoces integrados en la cronicidad avanzada, que cambia notablemente el concepto de la medicina paliativa, anteriormente relegada a la etapa final de la vida (últimos 3-6 meses). Con ello, la atención paliativa deja de ser un ámbito exclusivo de los servicios específicos para convertirse en un modelo de atención transversal y multiprofesional, que requiere estrategias formativas y

3. En el momento de publicación de esta guía, con la aparición de la pandemia por SARS-COV-2 es probable que las principales causas de mortalidad cambien. 
de integración asistencial, que garantice la continuidad asistencial, y una adecuada planificación por parte de los responsables de los servicios de salud $(2,5)$.

En el año 1996 el prestigioso centro de bioética, Hastings Center, en Nueva York, convocó a un grupo de expertos mundiales para redefinir los fines de la medicina (6) en un contexto de progresivo aumento de las necesidades y posibilidades científicas y técnicas, pero también desde los planteamientos y principios de la bioética. Tres de los cuatro fines planteados tienen que ver con el alivio del dolor y sufrimiento al final de la vida:

- El alivio del dolor y el sufrimiento causado por las enfermedades.

- La atención a la curación de los enfermos y cuidados a los incurables.

- La evitación de la muerte prematura y la búsqueda de una muerte tranquila.

Se ha definido muerte tranquila o buena muerte como: "aquella libre de angustia y sufrimiento evitable, para los pacientes y sus familiares, de acuerdo a sus deseos y razonablemente coherentes con los estándares clínicos, culturales y éticos" (7-11). Facilitar un buen final de la vida define una sociedad avanzada y buena. Aunque el nuevo paradigma de la atención paliativa se extiende temporal y conceptualmente a estadios más precoces de la enfermedad, no podemos olvidar que la atención al moribundo es trascendental. Muchas veces es la última oportunidad de hacer bien las cosas o de mantener la adecuada atención de etapas previas del proceso asistencial.

Sin embargo, ya desde 1995, en que el paradigmático estudio SUPPORT (Study to Understand Prognoses and Preferences for Outcomes and Risks of Treatments) (12) puso de manifiesto el sufrimiento que rodea el final de la vida, son numerosos los trabajos que siguen evidenciando que el final de la vida está rodeado de dolor, agresividad terapéutica, inequidad y, en definitiva, gran sufrimiento (13-19). Además, cabe tener en cuenta que el proceso de final de vida y, especialmente, la situación de últimos días, conlleva, no solo el sufrimiento de la persona enferma, sino también el de sus allegados y de los profesionales implicados.

El complejo escenario descrito, justifica que el grupo elaborador de la guía (GEG) decidiera centrar esta guía en la atención a la SUD, excluyendo otros ámbitos como los cuidados paliativos precoces, los cuidados continuos integrados, o la atención al duelo, algunos de ellos contemplados en la guía previa (20), por considerar que cualquiera de ellos debería ser objeto de una guía o documentos específicos.

Existen múltiples denominaciones utilizadas en la literatura para definir el último periodo previo a la muerte: final de vida, agonía, fase terminal o paciente muriendo activamente. El GEG ha adoptado el término situación de últimos días (SUD) que se define como el periodo que precede a la muerte cuando esta se produce de forma gradual y en el que existe deterioro físico intenso, debilidad extrema, alta frecuencia de trastornos cognitivos y de la consciencia, dificultad de relación e ingesta y pronóstico de vida de días u horas.

Para alcanzar un buen final de la vida además de elaborar, actualizar e implementar guías de práctica clínica, algunos otros elementos se convierten en imprescindibles, entre los que destacan:

- Promover un cambio cultural en la sociedad que contemple la muerte como un fenómeno natural consustancial a la vida. 
- Diseñar estrategias de gestión del cambio orientadas a todos los agentes implicados (gestores, profesionales y ciudadanía), concienciando de la importancia de realizar una práctica clínica bajo la óptica de un abordaje paliativo.

- Desarrollar estrategias formativas transversales dirigidas a todos los ámbitos sanitarios implicados que favorezcan esta integración de cuidados.

- Dotar adecuadamente los dispositivos y unidades implicadas, siguiendo estándares ya definidos [por ejemplo, los del Ministerio de Sanidad (21)] y trabajar en el desarrollo de nuevos estándares.

- Proveer de una estructura residencial y sociosanitaria adecuada, acorde a los nuevos modelos familiares y sociodemográficos.

- Proveer de observatorios y comisiones institucionales que velen por la adecuada implementación y desarrollo de las guías.

La presente guía tiene como objetivo principal, servir para la orientación y la actuación de todos aquellos profesionales, tanto de unidades específicas como de cualquier otro servicio de atención primaria, hospitalaria o centros residenciales, que asisten a pacientes en SUD, y con el objetivo último de conseguir una buena calidad de vida hasta el final y una buena muerte. 



\section{Alcance y objetivos}

Esta Guía de Práctica Clínica (GPC) se enmarca en el Programa de GPC en el Sistema Nacional de Salud (SNS) y se ha realizado como parte de las actividades de la Red Española de Agencias de Evaluación de Tecnologías Sanitarias y Prestaciones del SNS (RedETS), financiadas por el Ministerio de Sanidad. Actualiza parcialmente la GPC previa sobre Cuidados Paliativos publicada en el año 2006 (20) (específicamente las áreas clínicas de atención en los últimos días y sedación paliativa).

El objetivo de la GPC es servir como instrumento para mejorar la atención sanitaria de las personas en situación de últimos días y de sus familias, en los distintos ámbitos y centros donde sean atendidos (atención hospitalaria, atención primaria, atención en domicilio, servicios de urgencias y centros sociosanitarios).

Nuestra población diana, por tanto, abarca pacientes adultos (mayores de 18 años) durante el periodo que precede a la muerte cuando esta se produce de forma gradual y en el que existe deterioro físico intenso, debilidad extrema, alta frecuencia de trastornos cognitivos y de la consciencia, dificultad de relación e ingesta y pronóstico de vida de días $\mathrm{u}$ horas, independientemente de que la persona estuviese o no en un programa de cuidados paliativos. El GEG ha optado por utilizar el término situación de últimos días, en vez de otros términos utilizados en la literatura y a nivel legislativo (agonía, fase terminal o paciente muriendo activamente), por considerar que los otros términos pueden ser ambiguos y llevar a equívocos, tal y como propone la GPC del National Institute for Health and Care Excellence (NICE) sobre el cuidado de adultos en los últimos días (22).

En cuanto al periodo temporal considerado, aunque la GPC del NICE se centra en los últimos 2-3 días, en esta guía el GEG ha extendido el marco temporal hasta los 7-10 días porque se considera un periodo temporal más cercano a la realidad asistencial.

En esta GPC se abordan las siguientes áreas clínicas de la atención al paciente adulto en situación de últimos días:

- Reconocimiento de la situación de últimos días.

- Comunicación e información.

- Toma de decisiones compartida y desarrollo del plan de cuidados.

- Hidratación.

- Manejo de síntomas: dolor, disnea, náuseas y vómitos, ansiedad, delirium y estertores.

- Sedación paliativa.

También se incluyen anexos con información relevante desde el punto de vista clínico (material complementario a los capítulos clínicos y aspectos ético-legales), y un documento de información para familiares y allegados, desarrollado paralelamente a la elaboración de la guía (también incluido en los anexos).

No se abordan la atención a pacientes menores de 18 años, los cuidados paliativos (CP) antes de los últimos días de la vida, la atención al duelo, la organización de los cuidados y modelos de atención, la composición de los equipos multidisciplinares o aspectos referidos al cuidado y autocuidado de los profesionales. 



\section{Reconocimiento de situación de últimos días}

\section{Pregunta}

- ¿Qué signos y síntomas se deben evaluar cuando sospechamos que un paciente adulto con enfermedad crónica avanzada puede estar en situación de últimos días?

\section{Contexto}

Identificar cuando un paciente con enfermedad avanzada e irreversible se encuentra en SUD (por consenso del grupo, los 7-10 últimos días de vida) o de muerte inminente (horas o días) es imprescindible para tomar decisiones adecuadas y efectivas que eviten actuaciones fútiles, la obstinación terapéutica y que puedan permitir a los pacientes y familiares una adecuada gestión del escaso tiempo de supervivencia (23-25). Es el primer paso para unos cuidados de calidad al final de la vida.

Sin embargo, algunos estudios han encontrado datos variables de identificación de la SUD (26-29), fundamentalmente debido a la complejidad y a la incertidumbre que la caracteriza. Todo ello podría generar inseguridad en el equipo multidisciplinar, lo que podría originar la no identificación del proceso y, por lo tanto, la no aplicación de un plan de atención al final de la vida, o la identificación errónea de una SUD cuando la muerte puede ser evitable. Esta incertidumbre podría ser mayor en los enfermos no oncológicos, por el tipo de evolución natural de estas enfermedades y por la presencia de síntomas propios de la enfermedad no siempre indicadores de muerte inminente, lo que podría generar inequidad en el proceso de morir entre enfermos oncológicos y no oncológicos $(23,24,30)$.

Aunque existen herramientas conocidas como la Palliative Performance Scale que pueden ayudar a la predicción del pronóstico al final de la vida (23), ninguna está universalmente aceptada, y por lo tanto son poco empleadas. En la práctica clínica, en un contexto de enfermedad incurable y muy avanzada, el proceso se fundamenta en la impresión subjetiva de los profesionales (basado en sus habilidades, años de experiencia y grado de conocimiento del paciente y del curso natural de su enfermedad) apoyado en signos, síntomas y, a veces, en biomarcadores.

Estas recomendaciones intentan ayudar a los profesionales a manejar la incertidumbre de identificar cuándo una persona está en una SUD y apoyar el juicio clínico del equipo médico en un proceso de transcendencia vital.

\section{Recomendaciones}

1. Cuando se esté atendiendo a personas que padecen enfermedades progresivas, en situación muy avanzada, se recomienda evaluar siempre el pronóstico e identificar si se encuentra en una probable situación de últimos días (diagnóstico situacional), y dejar registro en la historia clínica [BPC, nueva]. 
2. Se recomienda apoyar el juicio clínico (pieza clave en el diagnóstico de situación de últimos días) mediante los siguientes aspectos [BPC, adaptada]:

- Valoración de las posibles causas reversibles del deterioro, principalmente cuando no hay coherencia entre la evolución esperada y la aparición de síntomas.

- Monitorización de cambios en las necesidades físicas, psicosociales y espirituales de los pacientes.

- Evaluación de la situación funcional y velocidad de declive. En caso de valorar el uso de escalas como apoyo a la evaluación, se sugiere emplear la PPS (Palliative Performance Scale) o la ECOG (Eastern Cooperative Oncology Group).

- Consideración de las opiniones del resto del equipo interdisciplinar, y en caso de dudas contar con el apoyo de profesionales expertos.

3. Se sugiere evaluar los siguientes signos y síntomas [débil a favor, adaptada]:

- Cambios cardiovasculares:

- Hipotensión

- Oliguria

- Livideces

- Cambios respiratorios:

- Respiración ruidosa (estertores)

- Cambios en el patrón respiratorio: respiración de Cheyne-Stokes, apneas

- Disnea

- Respiración con movimiento mandibular

- Cambios del estado físico:

- Debilidad profunda y progresiva

- Pérdida de la habilidad de cerrar los ojos

- Indiferencia hacia comida y bebida

- Dificultad para la deglución

- Incontinencia o retención urinaria

- Cambios cognitivos y neurológicos:

- Disminución del nivel de alerta (desde somnolencia al coma)

- Delirium hipoactivo o hiperactivo (con agitación)

- Cambios psicosociales y emocionales:

- Aislamiento

- Cambios en el estado de ánimo

- Cambios en la experiencia espiritual. 
4. Se recomienda investigar y descartar de forma proporcionada y teniendo en cuenta los valores y preferencias de paciente/allegados, posibles causas reversibles del deterioro: deshidratación, infección, toxicidad por opioides, retirada de esteroides, insuficiencia renal aguda, alteraciones metabólicas, y si es el caso, iniciar el tratamiento correspondiente [BPC, adaptada].

\section{Consideraciones clínicas relevantes}

- Se discutirá en equipo interdisciplinar el pronóstico, teniendo en cuenta la información recogida por cualquier miembro del equipo y se revisará el plan a seguir teniendo en cuenta los deseos del paciente. En el caso de tener dudas sobre el diagnóstico de esta situación se pedirá apoyo o consejo de profesionales de referencia, con más experiencia en la atención al paciente en la fase final de vida.

- Una vez reconocida la situación de últimos días de vida, será necesario:

- Monitorizar diariamente las necesidades fisiológicas, psicosociales y espirituales de la persona.

- Priorizar el confort sobre la toma de constantes vitales.

- Revisar el historial y contexto clínico, teniendo en cuenta problemas secundarios.

- Conocer los valores, deseos y expectativas de la persona: investigar si se ha realizado una planificación anticipada y compartida de la asistencia o documento de instrucciones previas. En caso contrario, explorar.

- Actualizar el plan de cuidados con el equipo, paciente y allegados que evite procedimientos o tratamientos fútiles.

- Dejar registro de todo este proceso de toma de decisiones en la historia clínica.

\section{Justificación}

Se ha realizado una recomendación débil a favor sobre la evaluación de diferentes signos y síntomas en pacientes con enfermedades progresivas en situación avanzada y una serie de recomendaciones de buena práctica clínica que pretenden favorecer una evaluación sistematizada y un registro de las necesidades y preferencias de los pacientes y sus familiares. El grupo de trabajo ha considerado el balance beneficio-riesgo favorable, la importancia para los pacientes, y que la evaluación podría no suponer un coste añadido relevante con respecto a la práctica clínica habitual.

\section{Justificación detallada}

Balance beneficio-riesgo: la evaluación de los signos y síntomas revisados no requiere la realización de pruebas invasivas o complejas, por lo que no debería causar ningún daño al paciente. Debido a ello el grupo considera que el balance beneficio-riesgo es favorable a la evaluación de signos y síntomas, teniendo en cuenta que la estimación apropiada de la entrada en SUD podrá tener un impacto importante en la toma de decisiones sobre el plan de cuidados y los tratamientos, y podría favorecer la planificación de aspectos personales y familiares. 
Valoración de los desenlaces por parte de los pacientes: desde el punto de vista del grupo de trabajo, la mayoría de los pacientes, una vez informados de los pros y contras, estarían de acuerdo con la identificación de la SUD.

Recursos requeridos: la mayoría de síntomas y signos que se emplean en la práctica clínica habitual para predecir la SUD pueden hacerse en una evaluación clínica sin costes importantes.

\section{De la evidencia a la recomendación}

a) ¿Cuál es la magnitud de los efectos deseables esperados?

- Juicio: grande.

\section{- Evidencia procedente de la investigación:}

\section{Evidencia derivada de estudios cuantitativos}

La GPC del NICE (22) incluyó siete estudios de cohortes (31-37): dos prospectivos y cinco retrospectivos, con tamaños muestrales que variaron entre 93 y 71453 , y principalmente con pacientes oncológicos $(n=5)(22)$. En la actualización se localizó un nuevo artículo, derivado de un estudio incluido en la GPC del NICE (Hui et al., 2015) (38) que analiza el rendimiento diagnóstico de una batería de 52 signos físicos adicionales.

Existe evidencia de moderada calidad de dos estudios con pacientes con cáncer sobre la reducción en la puntuación del ECOG score (Eastern Cooperative Oncology Group performance scale) como predictor de la mortalidad a siete días $(\mathrm{n}=374$ y 459), con OR de 3.45 (IC 1.65, 7.20) y de 2.02 (IC 1.40,2.92). Un estudio de baja calidad $(\mathrm{n}=93)$ también mostró que la fatiga y la desaturación fueron predictores de la mortalidad a dos semanas en pacientes con cáncer de pulmón [HR $5.90(2.04,17.03)$ y HR $3.30(1.42,7.66)]$, respectivamente. También existe evidencia de baja calidad de un estudio $(\mathrm{n}=122)$ en pacientes oncológicos que acuden al servicio de urgencias por disnea, de una frecuencia cardíaca $\geq 110$ y respiración $>28 /$ min como predictores de mortalidad a dos semanas [RR $4.92(1.42,17.09) \mathrm{y}$ RR $12.72(3.08,52.49)]$, respectivamente (22).

La evidencia sobre rendimiento diagnóstico procede fundamentalmente de un estudio en pacientes con cáncer terminal derivados a una unidad de $\mathrm{CP}(\mathrm{n}=357)$ (Hui et al., 2014; Hui et al., 2015). Los resultados indican que existe evidencia de baja a moderada calidad de que varios signos y síntomas (presencia de estertores, apneas, respiración con movimiento mandibular, cianosis periférica, respiración de Cheyne-Stokes, ausencia de pulso radial y las escalas PPS-Palliative Performance Scale- y RASS-Richmond Agitation Sedation Scale) presentan una alta especificidad (81.3-99.2 \%), aunque las sensibilidades son altamente variables (11.3-64 \%) para la identificación de los últimos tres días de vida (22). En el análisis de los 52 signos y síntomas adicionales, se identificaron ocho nuevos signos y síntomas que presentaron una alta especificidad ( $>95 \%)$ : pupilas no reactivas, respuesta disminuida a estímulos verbales y visuales, incapacidad para cerrar los párpados, caída del pliegue nasolabial, hiperextensión del cuello, quejidos y gruñidos de cuerdas vocales y hemorragia gastrointestinal superior (38). 
También existe evidencia, aunque de baja calidad, sobre el rendimiento diagnóstico para identificar la mortalidad a dos días de diferentes pruebas de laboratorio de dos estudios retrospectivos ( $\mathrm{n}=42701$ y 71 453) (urea, creatinina, recuento de glóbulos blancos, bilirrubina, hemoglobina, hematocrito, bicarbonato total, $\mathrm{pH}$ y albúmina) con especificidades que oscilaron entre $64-84.7 \%$ y sensibilidades de 36.2-71.8 \%. El área bajo la curva de estos test osciló entre 0.53 - 0.80, lo que indica una precisión diagnóstica de muy pobre a moderada (22).

No se identificaron estudios en pacientes no oncológicos en los que el diagnóstico de muerte inminente es más impreciso por el tipo de evolución natural de la enfermedad y la presencia de síntomas propios de la enfermedad no siempre indicadores de muerte inminente $(23,24,30)$. Además, la edad media de los participantes se situó en torno a los 60 años, por lo que existe cierta incertidumbre sobre su extrapolación a pacientes mayores.

No se ha identificado evidencia sobre ninguna combinación de signos y síntomas en forma de regla de predicción clínica que prediga con exactitud la situación de últimos días.

Los estudios cualitativos revisados también señalan la importancia de los cambios físicos (respiratorios y vasculares, deterioro de la condición física, reducción de la ingesta oral y empeoramiento del dolor) y psicosociales y espirituales (aislamiento social, cambios en el estado de ánimo y espirituales) (39-48).

\section{Evidencia derivada de estudios cualitativos}

La GPC del NICE incluyó 8 estudios cualitativos ( 3 basados en grupos focales y 5 en entrevistas/encuestas) (39-46). La mayoría de estudios incluyeron profesionales sanitarios (enfermeras y médicos, o equipos multidisciplinares). Solo uno de ellos incluyó también la visión de los cuidadores (43). En el análisis temático de la evidencia identificaron 5 temas principales, con diferentes subtemas, relacionados con las experiencias de los profesionales con el pronóstico en los últimos días de vida (tabla 1).

Tabla 1. Temas y subtemas derivados de la evidencia del reconocimiento de situación de últimos días

\begin{tabular}{|c|c|}
\hline Tema principal & Subtemas \\
\hline Cambios físicos & $\begin{array}{l}\text { - Cambios cardiovasculares y respiratorios } \\
\text { - Deterioro físico y funcional } \\
\text { - Reducción de la ingesta oral } \\
\text { - Empeoramiento del dolor } \\
\text { - Cambios cutáneos }\end{array}$ \\
\hline $\begin{array}{l}\text { Cambios espirituales y } \\
\text { psicosociales }\end{array}$ & $\begin{array}{l}\text { - Aislamiento social } \\
\text { - Cambios en el estado de ánimo } \\
\text { - Cambios en la experiencia espiritual }\end{array}$ \\
\hline $\begin{array}{l}\text { Dificultad en el reconoci- } \\
\text { miento de los últimos días }\end{array}$ & $\begin{array}{l}\text { - Complejidad de diagnosticar la muerte } \\
\text { - Factores que pueden afectar a la precisión del pronóstico }\end{array}$ \\
\hline
\end{tabular}




\begin{tabular}{|l|l|}
\hline Trayectoria de muerte & $\begin{array}{l}\text { - Cambios en el patrón de síntomas en los últimos días } \\
- \text { Variabilidad en el periodo temporal hasta la muerte }\end{array}$ \\
\hline Manejo de la incertidumbre & $\begin{array}{l}\text { Cambios en el manejo clínico asociados a la identificación de la situación } \\
\text { de últimos días }\end{array}$ \\
\hline
\end{tabular}

Fuente: adaptado de NICE 2015 (22).

Tema 1) cambios físicos: la evidencia de 5 estudios de calidad moderada (2 estudios cualitativos, $\mathrm{n}=33 ; 2$ estudios tipo Delphi, $\mathrm{n}=324 ; \mathrm{y} 1$ estudio observacional, $\mathrm{n}=474$ ) indica que los síntomas más observados fueron los cambios cardiovasculares y respiratorios, deterioro físico y funcional, reducción de la ingesta, empeoramiento del dolor y cambios cutáneos (22).

Tema 2) cambios espirituales y psicosociales: en dos estudios cualitativos de calidad alta-moderada $(n=33)$, los profesionales identificaron el aislamiento social, y cambios en el estado de ánimo y espirituales como aspectos clave en la identificación de la SUD (22).

Tema 3) dificultad en el reconocimiento de los últimos días: tres estudios de calidad moderada señalaron la complejidad de diagnosticar la muerte ( 2 entrevistas y 1 encuesta, $\mathrm{n}=285$ ) y dos señalaron algunos factores que pueden afectar a la precisión del pronóstico (fundamentalmente, la especialidad médica o los años de la relación médico-paciente) (22).

Tema 4) trayectoria de muerte: un estudio de calidad moderada $(n=15)$ señaló que existe variabilidad en los cambios que se producen en los últimos días y se destacaron los síntomas respiratorios y cardiovasculares y el nivel de conciencia. Otro estudio de moderada calidad señaló la variabilidad en el periodo temporal que precede al fallecimiento (22).

Tema 5) manejo de la incertidumbre: se localizó evidencia de baja calidad, derivada de un estudio sobre la incertidumbre en los últimos días $(n=8)$, que indica que los profesionales perciben que el manejo clínico es diferente en función de si se identifica la SUD. Los profesionales destacan la importancia de clarificar con el paciente sus objetivos personales, mejorar la comunicación con las familias, y pasar más tiempo con el paciente (22).

En la actualización de la búsqueda bibliográfica, se localizaron dos nuevos estudios de moderada calidad $(47,48)$, que complementan la evidencia considerada en el tema "dificultad de reconocimiento de los últimos días". Fosse et al. (47) realizaron un estudio con profesionales de residencias de mayores $(n=679)$ sobre las barreras y estrategias para la provisión de cuidados en residencias de mayores en Noruega y Países Bajos, y entre ellas se señalan la ausencia de habilidades para el reconocimiento de síntomas y la necesidad de disponer de protocolos para la evaluación de síntomas en esta fase de la atención. Hui et al. (48) realizaron una encuesta a especialistas en oncología $(\mathrm{n}=182)$ explorando las diferencias entre hematólogos y oncólogos y encontraron que los primeros perciben que fallan en la estimación de la progresión al final de la vida en mayor medida. 
b) ¿Cuál es la magnitud de los efectos indeseables esperados?

- Juicio: pequeña.

- Evidencia procedente de la investigación: la evaluación de los signos y síntomas revisados no requiere la realización de pruebas invasivas o complejas, por lo que no deberían causar ningún daño al paciente.

c) ¿Cuál es la certeza global en la evidencia sobre los efectos?

- Juicio: baja.

- Evidencia procedente de la investigación: globalmente existe evidencia científica limitada sobre los signos y síntomas que pueden ser empleados en la predicción o identificación de los últimas días o horas de vida.

La calidad de la evidencia cuantitativa localizada es baja-moderada, y se basa en estudios de cohortes retrospectivos y prospectivos, principalmente en pacientes con cáncer.

La calidad de la evidencia cualitativa es moderada, aunque refleja principalmente la visión de los profesionales, dado que no se ha localizado ningún estudio que explore los signos y síntomas desde la perspectiva de los pacientes y solo uno incluye la visión de sus familias. Además, no se ha localizado ningún estudio en España, aunque teniendo en cuenta el objetivo principal de la revisión (identificación de síntomas y signos que pueden ayudar al reconocimiento de SUD) y los principales resultados obtenidos, el grupo de trabajo ha considerado que los resultados son aplicables a nuestro contexto sanitario.

d) ¿Existe incertidumbre o variabilidad importante sobre cómo los pacientes valoran los desenlaces principales?

- Juicio: la incertidumbre o la variabilidad probablemente no sean importantes.

- Evidencia procedente de la investigación: no se ha identificado ningún estudio que evalúe la valoración de los desenlaces de interés por parte de los pacientes o sus familias. Solo un estudio (Domeisen et al., 2013 (7)) incluyó la visión de cuidadores, pero su objetivo no fue investigar sus valores sino identificar los síntomas que pueden ser importantes en la predicción o identificación de los últimos días desde el punto de vista de los cuidadores.

- Información adicional: para la revisión se priorizaron como factores pronósticos o diagnósticos de SUD, aquellos signos y síntomas relacionados con las siguientes categorías: hemorragia aguda, insuficiencia renal aguda, respiratorios (incluidos los estertores y la respiración irregular), síntomas relacionados con el nivel de conciencia o cognitivos, síntomas emocionales, deterioro general (incluida la debilidad extrema), hidratación, nutrición, síntomas relacionados con el estado de la piel (incluidos los cambios en la coloración), aislamiento social, diuresis. Estas categorías fueron seleccionadas teniendo en cuenta un estudio cualitativo que intentó recoger la visión de expertos del ámbito internacional sobre los síntomas empleados en la identificación y predicción de las últimas horas y días (43). 
e) El balance entre los efectos deseables e indeseables esperados, ¿favorece a la intervención o a la comparación?

- Juicio: probablemente favorece a la intervención.

- Evidencia procedente de la investigación: descrito en la sección anterior.

- Información adicional: desde el punto de vista del grupo de trabajo conocer el pronóstico en los últimos días y realizar el diagnóstico situacional es importante para los pacientes y sus familias debido a que permite realizar los cambios oportunos en el plan de cuidados y planificar todas las cuestiones relacionadas con el final de la vida (por ejemplo, decisiones personales y familiares, o relacionadas con el lugar de fallecimiento). Además, según la experiencia en la práctica clínica del grupo podría no existir incertidumbre ni variabilidad importante al respecto, es decir, los pacientes una vez informados de los pros y contras, estarían de acuerdo con la identificación de la SUD.

f) ¿Cuál es la magnitud de los recursos requeridos (costes)?

- Juicio: costes y reducción de costes insignificante.

- Evidencia procedente de la investigación: no se ha localizado ningún estudio de evaluación económica.

- Información adicional: la mayoría de síntomas y signos que se emplean en la práctica clínica habitual para predecir la SUD pueden hacerse en una evaluación clínica sin costes importantes.

g) ¿Cuál es la certeza en torno a la evidencia sobre los recursos requeridos?

- Juicio: no hay estudios incluidos.

- Evidencia procedente de la investigación: no se ha localizado ningún estudio que describa de forma explícita el uso de recursos (costes) o estudios de evaluación económica.

h) La relación coste-efectividad, ¿favorece a la intervención o a la comparación?

- Juicio: no hay estudios incluidos.

- Evidencia procedente de la investigación: no se ha localizado ningún estudio de evaluación económica.

- Información adicional: desde el punto de vista del grupo de trabajo la detección de la SUD puede impedir el inicio de medidas diagnóstico-terapéuticas fútiles o favorecer la retirada de estas medidas, suponiendo un ahorro para el sistema.

i) ¿Cuál sería el impacto en la equidad en salud?

- Juicio: probablemente aumenta.

- Evidencia procedente de la investigación: no se ha realizado una revisión sistemática del tema. 
- Información adicional: en la actualidad sigue existiendo un problema de equidad relacionado con las diferencias en la atención a las personas con enfermedades no oncológicas con respecto a los pacientes con cáncer. También puede haber diferencias con respecto al lugar de residencia (áreas rurales con peor acceso a recursos asistenciales), distinta organización de recursos asistenciales según las instituciones o a nivel de las diferentes Comunidades Autónomas, y también diferencias entre profesionales en cuanto a la forma de entender el cuidado al final de la vida, entre otros.

Seguir estas recomendaciones podría favorecer la equidad en la identificación de la SUD, independientemente del tipo de enfermedad o situación, y evitar situaciones injustas en un momento tan crucial de la vida de las personas y sus seres queridos.

\section{j) ¿Es aceptable la opción para los agentes implicados?}

- Juicio: probablemente sí.

- Evidencia procedente de la investigación: no se ha realizado una revisión sistemática del tema.

- Información adicional: los signos y síntomas físicos evaluados forman parte de la evaluación clínica habitual por parte de los profesionales, y por lo tanto no se prevé una baja aceptabilidad por parte de los profesionales, y tampoco por parte de los pacientes y familiares. Sin embargo, cabe tener en cuenta que algunos profesionales pueden sentirse menos cómodos al evaluar síntomas psicosociales, emocionales y espirituales, y del mismo modo, algunos pacientes pueden encontrar dificultades a la hora de comunicar estas cuestiones. En el caso de los profesionales podría deberse a la falta de formación en estos aspectos, a la falta de psicólogos en los equipos interdisciplinares o a una visión biologicista (reduccionista) de la atención sanitaria y social. También puede haber profesionales que tengan dificultad para afrontar la muerte y el proceso de morir de sus pacientes con lo que todo el proceso de evaluación de las necesidades y por tanto el diagnóstico podría verse afectado. En el caso de los pacientes, también pueden existir diferencias culturales o sociales que puedan afectar y actuar como barreras.

k) ¿Es factible la implementación de la opción?

- Juicio: sí.

- Evidencia procedente de la investigación: no se ha realizado una revisión sistemática del tema.

- Información adicional: para que las recomendaciones puedan ser implementadas es necesario que los sistemas de provisión de cuidados garanticen una adecuada formación de los profesionales que van a atender a estas personas y a sus allegados. Esto implica, no sólo a profesionales del ámbito específico de los CP, sino a otras especialidades y ámbitos en los que más o menos frecuentemente se atiende a personas en el proceso de morir (atención primaria, medicina interna, geriatría, oncología o urgencias, entre otras).

Deben existir políticas públicas que fomenten la provisión de cuidados a la persona vulnerable, que garanticen la atención tanto a las situaciones poco comple- 
jas como a las más complejas, con profesionales específicamente preparados para el cuidado, el alivio de síntomas, la atención psicológica, social y espiritual. Además, las instituciones deben proporcionar un espacio organizativo (físico, temporal, funcional) para que se puedan llevar a cabo estas acciones con calidad, esto es, en el lugar adecuado, con el tiempo necesario y con la visión orientada en una atención exquisita a la persona que está muriendo y a su entorno familiar. En cuanto a los sistemas de información, deberían desarrollarse herramientas para facilitar la recogida de datos y análisis de las variables relacionadas con el reconocimiento de la SUD. 


\section{Comunicación e información}

\section{Pregunta}

- ¿Cuáles son los factores asociados a una buena comunicación en los últimos días de vida entre el paciente, sus allegados y los profesionales sanitarios que lo atienden?

\section{Contexto}

La comunicación juega un papel importante en toda la trayectoria de las enfermedades graves, favoreciendo la adaptación a la realidad y la toma de decisiones (49). Es una pieza importante del "puzzle" para un buen final de la vida, y suele ser, junto con la participación en la toma de decisiones, uno de los aspectos más valorados por los pacientes y sus familias. Sin embargo, la calidad de la comunicación en los últimos días no siempre es la deseable, y algunos estudios han identificado problemas importantes. Existe evidencia sobre barreras relativas a los profesionales sanitarios y las condiciones en las que tiene lugar la comunicación, aunque también existen barreras relacionadas con los propios pacientes y familiares, y con el sistema sanitario. Detectar estas dificultades es muy relevante, debido a que una mala comunicación en esta fase puede dar lugar a confusión y a un malestar evitable, así como disminuir la confianza en los profesionales sanitarios en un momento crucial en el que los pacientes deben prepararse para la muerte (22). Por todo ello, esta revisión sistemática pretende identificar las barreras, y también los facilitadores, para una comunicación efectiva en la SUD.

\section{Recomendaciones}

1. Se recomienda fomentar un clima adecuado basado en la calidez, empatía, asertividad y una actitud de escucha activa, prestando especial atención a la comunicación no verbal. En la medida de lo posible, es importante buscar un espacio físico que mantenga la privacidad, destinar el tiempo necesario, y permitir hacer preguntas y aclarar dudas, dejando también un espacio para la reflexión [BPC, nueva].

2. Se recomienda identificar las necesidades de comunicación y expectativas de las personas al final de la vida, teniendo en cuenta [BPC, adaptada]:

- Si el paciente desea o no que alguna persona determinada esté presente en el momento de tomar decisiones.

- El grado actual de conocimiento acerca de la situación final de vida.

- Cuánta información les gustaría tener acerca de su proceso.

- Sus preferencias y necesidades sociales, culturales, religiosas y espirituales.

- Sus miedos y preocupaciones. 


\section{Consideraciones clínicas relevantes}

- Aunque todos los miembros del equipo deben estar capacitados para comunicarse de forma eficiente con el paciente y su familia, puede valorarse la designación de un referente en el proceso de comunicación que favorezca una coherencia comunicativa y monitorice que las necesidades de información van siendo resueltas. La elección del miembro del equipo médico más apropiado para comunicar el pronóstico debe estar basada en su nivel de competencia y en la relación previa con la persona enferma.

- Cuando se comparte información en la situación de últimos días, es deseable partir del nivel de información que el paciente y/o la familia ya tiene e incluir información adecuada sobre:

- Su pronóstico, explicando también las incertidumbres y cómo se manejarán, evitando el falso optimismo y adecuando la información al nivel de compresión, valorando en todo momento su necesidad de información y su capacidad para tolerarla.

- Los signos y síntomas que pueden aparecer en esta fase, la aproximación terapéutica, y pautas que pueden ayudar.

- La forma de ponerse en contacto con su equipo asistencial, transmitiendo la disposición del equipo multidisciplinar y la continuidad de la atención.

- Es importante explorar con el paciente y la familia o allegados:

- Si existe un documento de voluntades anticipadas o instrucciones previas, o un proceso de planificación anticipada y compartida de la asistencia.

- Si la familia conoce las prioridades, preferencias y deseos del paciente.

- Si se ha entendido la información o si es necesaria información adicional para resolver cualquier cuestión relacionada con la situación de últimos días.

- Se dejará por escrito la información aportada al paciente y familia, especificando el grado o nivel de la información asumida por éstos si es posible.

\section{Justificación}

Estas recomendaciones pretenden favorecer una comunicación efectiva en los últimos días de vida que pueda mejorar la elaboración del plan de cuidados y la calidad de la atención. Las recomendaciones, aunque son de buena práctica clínica se han basado en estudios cualitativos sobre los factores que influyen en una buena comunicación al final de la vida.

\section{Justificación detallada}

Magnitud de los efectos deseables esperados: la evidencia señala diferentes factores relacionados con los pacientes, las familias, los profesionales sanitarios y los recursos disponibles que pueden actuar como barreras o facilitadores de la comunicación, y por lo tanto deben ser tenidos en cuenta para que la comunicación en los últimos días pueda ser efectiva. Los beneficios de una buena comunicación pueden tener un impacto importante en el paciente y en su familia, y por lo tanto es importante prestar atención al contenido, momento y estilo de la comunicación.

Certeza global en la evidencia: la calidad de la evidencia es globalmente baja, debido a las limitaciones metodológicas de los estudios, relacionadas con su propio diseño, que en muchos casos abordan la comunicación en CP y no específicamente la comunicación en los últimos días, y a que ninguno de los estudios se ha realizado en nuestro contexto. A 
pesar de ello, se ha considerado que los principales hallazgos podrían ser extrapolables a nuestro contexto sanitario y social, y son coherentes con la percepción sobre las barreras y facilitadores que el grupo de trabajo observa en la práctica clínica.

\section{De la evidencia a la recomendación}

a) ¿Cuál es la magnitud de los efectos deseables esperados?

- Juicio: grande.

- Evidencia procedente de la investigación: la GPC del NICE (22) incluyó cuatro estudios cualitativos (50-53) y dos estudios basados en encuestas retrospectivas (54, 55). En la actualización se identificaron cinco nuevos estudios basados en entrevistas semiestructuradas y cuestionarios realizados en EE. UU., Australia y Canadá (56-60).

La evidencia señala diferentes factores relacionados con los pacientes, las familias, los profesionales sanitarios y los recursos disponibles que pueden actuar como barreras o facilitadores de la comunicación, y por lo tanto deben ser tenidos en cuenta para que la comunicación en los últimos días pueda ser efectiva. Los beneficios de una buena comunicación pueden tener un impacto importante en el paciente y en su familia, y por lo tanto es importante prestar atención al contenido, momento y estilo de la comunicación.

En la siguiente tabla (tabla 2) se presentan los temas y subtemas extraídos de la evidencia considerada en la GPC del NICE (6). Para ver una descripción detallada de los estudios y sus resultados se puede consultar el material metodológico.

Tabla 2. Tema y subtemas extraídos de los estudios incluidos sobre barreras y facilitadores de la comunicación

\begin{tabular}{|l|l|}
\hline \multicolumn{1}{|c|}{ Tema principal } & \multicolumn{1}{c|}{ Subtemas } \\
\hline Factores relacionados con & - Dificultad para retener y procesar la información \\
los familiares o allegados & - Familia no consciente del diagnóstico \\
& - Evitación \\
& - Exclusión del paciente en las conversaciones sobre el pronóstico \\
\hline Factores relacionados con & - Tiempo \\
el paciente & - Diferencias culturales o valores \\
& - Nivel de conciencia \\
\hline Factores relacionados con & - Edad \\
\hline los profesionales sanitarios & - Incertidumbre en el pronóstico \\
& - Información compartida entre los profesionales sanitarios \\
& - Habilidades de comunicación \\
& - Incomodidad con la discusión \\
& - Relación con el paciente (poca relación con el paciente como barrera) \\
& - Papel de la ambigüedad (relacionado con los roles y responsabilidad de la \\
& - Entrenamiento y experiencia úlimos días) \\
& - Dificultades de programación de la comunicación (en relación con el tiem- \\
& po y los recursos disponibles) \\
\hline Factores relacionados con & - Privacidad \\
\hline los recursos & \\
\hline
\end{tabular}

Fuente: adaptado de NICE 2015 (22). 
En la actualización se identificaron 5 nuevos estudios basados en entrevistas semiestructuradas y cuestionarios realizados en EE. UU., Australia y Canadá. Tres de ellos abordaron la percepción de los familiares y dos la de profesionales sanitarios. Estos estudios aportaron evidencia para los temas factores relacionados con la familia y factores relacionados con los profesionales sanitarios:

- Factores relacionados con la familia: Generous et al. (2017) (n=107) (56) aportan evidencia adicional sobre la evitación de las conversaciones sobre el pronóstico, siendo los temas más evitados las cuestiones negativas de la propia relación, la muerte en sí, información personal y trámites tras la muerte. Odgers et al. (2018) $(\mathrm{n}=12)$ (57) además de poner de manifiesto la evitación sobre temas relacionados con el pronóstico, también destacan la complejidad para retener e interpretar la información por parte de los familiares. La evitación también se extrae como un tema relevante en el estudio de Park et al. (2015) (58) donde además se destaca la necesidad de más y mejor información sobre el pronóstico y los últimos días de vida.

- Factores relacionados con los profesionales: Nouvet et al. (2016) (n=30) (59) identificaron como barreras la evitación, la incertidumbre y una tendencia a intentar mejorar la situación clínica. Rodenbach (2016) (n=33) (60) aporta evidencia sobre cómo la percepción personal de la propia muerte y el proceso de morir afecta a la comunicación con el paciente.

- Información adicional: desde el punto de vista del grupo de trabajo la comunicación debe entenderse como un proceso en el que la forma en la que los profesionales y la familia se comunican con el paciente debe ir modificándose en función de sus necesidades. De cómo esto ocurra va a depender, en gran medida, la satisfacción con los cuidados y la atención recibida. Además, aunque no se ha identificado en los estudios, el grupo de trabajo considera que una buena comunicación al final de la vida podría facilitar el proceso de duelo en los familiares y allegados.

b) ¿Cuál es la magnitud de los efectos indeseables esperados?

- Juicio: pequeña.

- Evidencia procedente de la investigación: la revisión sistemática se ha orientado a barreras y facilitadores para una buena comunicación en la SUD.

- Información adicional: a pesar del malestar que la comunicación del pronóstico puede tener tanto en los pacientes como en la familia, una adecuada comunicación siempre se asocia al mejor cuidado de las personas en los últimos días de vida y a una mejor experiencia. Por lo tanto, se considera que una comunicación adecuada sobre el pronóstico y la planificación al final de la vida es beneficiosa a pesar del malestar que pueda estar asociado a la misma en el momento de la comunicación.

c) ¿Cuál es la certeza global en la evidencia sobre los efectos?

- Juicio: baja.

- Evidencia procedente de la investigación: la calidad de la evidencia es globalmente baja, debido a las limitaciones metodológicas de los estudios, relacionadas con el 
propio diseño de los mismos, que en muchos casos abordan la comunicación en CP y no específicamente la comunicación en los últimos días, y a que ninguno de los estudios se ha realizado en nuestro contexto. A pesar de ello, se ha considerado que los principales hallazgos podrían ser extrapolables a nuestro contexto sanitario y social, y son coherentes con la percepción sobre las barreras y facilitadores que el grupo de trabajo observa en la práctica clínica.

d) ¿Existe incertidumbre o variabilidad importante sobre cómo los pacientes valoran los desenlaces principales?

- Juicio: la incertidumbre o variabilidad no son importantes.

- Evidencia procedente de la investigación: se han considerado los factores (barreras y facilitadores) para la comunicación en los últimos días, teniendo en cuenta la experiencia y opiniones de los principales agentes implicados (pacientes, familiares y profesionales sanitarios).

- Información adicional: desde el punto de vista del GEG los factores socioculturales son de especial relevancia, ya que pueden influir en las necesidades y deseos de información, así como en el papel de la familia y entorno en el proceso de información y comunicación.

e) ¿El balance entre los efectos deseables e indeseables esperados, ¿favorece a

la intervención o a la comparación?

- Juicio: probablemente favorece a la intervención.

- Evidencia procedente de la investigación: la revisión sistemática se ha orientado a barreras y facilitadores para una buena comunicación en la SUD.

- Información adicional: el grupo de trabajo considera que la comunicación en los últimos días es un área relevante para los pacientes y sus familias, por lo que conocer las barreras y facilitadores es importante. A pesar de las dificultades que puedan existir o el malestar derivado inicialmente de la comunicación, el GEG considera que los efectos deseables de la comunicación llevada a cabo por profesionales capacitados para la comunicación en SUD superan a los efectos indeseables

f) ¿Cuál es la magnitud de los recursos requeridos (costes)?

- Juicio: costes y reducción de costes insignificantes.

- Evidencia procedente de la investigación: no se ha localizado ningún estudio que describa de forma explícita el uso de recursos (costes) o estudios de evaluación económica

- Información adicional: el GEG considera que el coste de la comunicación podría ser considerado bajo en relación con beneficios netos. Además, cabe destacar que la revisión aborda cuestiones relacionadas con el contenido y la forma de la comunicación, por lo que recomendaciones realizadas podrían no tener un impacto directo importante en el uso de recursos y costes. Sin embargo, el GEG considera que podrían considerarse factores relevantes para el uso de recursos y costes algunos factores como el 
tiempo necesario para la comunicación, la disponibilidad de espacios adecuados y de recursos de formación sobre comunicación para los profesionales.

g) ¿Cuál es la certeza en torno a la evidencia sobre los recursos requeridos?

- Juicio: no hay estudios incluidos.

- Evidencia procedente de la investigación: no se ha localizado ningún estudio que describa de forma explícita el uso de recursos (costes) o estudios de evaluación económica.

h) La relación coste-efectividad, ¿favorece a la intervención o a la comparación?

- Juicio: probablemente favorece a la intervención.

- Evidencia procedente de la investigación: no se ha localizado ningún estudio de evaluación económica.

- Información adicional: el GEG considera que el coste de la comunicación podría ser considerado bajo en relación con beneficios netos.

i) ¿Cuál sería el impacto en la equidad en salud?

- Juicio: aumenta.

- Evidencia procedente de la investigación: no se ha realizado una revisión sistemática del tema.

- Información adicional: para que se cumpla el principio de equidad los profesionales deberían tener la actitud y aptitud de establecer una relación terapéutica con el paciente y familia en la que la información adecuada y la comunicación fluida sean la regla. Las instituciones sanitarias deben poner sus esfuerzos en que los profesionales estén formados en habilidades de comunicación y acompañamiento.

j) ¿Es aceptable la opción para los agentes implicados?

- Juicio: sí.

- Evidencia procedente de la investigación: aunque se han identificado barreras en la literatura para la comunicación en la SUD, y puede existir cierto rechazo al intercambio de información, el GEG considera que es aceptable y necesaria para la mayoría de las personas.

k) ¿Es factible la implementación de la opción?

- Juicio: sí.

- Evidencia procedente de la investigación: no se ha realizado una revisión sistemática del tema.

- Información adicional: existen dificultades para establecer una comunicación efectiva y que facilite al paciente y familia el proceso por el que están pasando. No obstante, la experiencia de los profesionales que se dedican al cuidado de personas en el final de la vida demuestra que poner en práctica una buena comunicación con ellos es posible 
y que genera efectos muy positivos en esos momentos difíciles. Por todo ello, parece necesaria la formación en comunicación y establecer unas competencias mínimas que puedan aplicar y deben conocer todos los equipos que atienden a personas en SUD.

\section{I) Otras consideraciones}

El GEG estima que en la actualidad algunas personas llegan al final de su vida sin conocer su diagnóstico, pronóstico y otras cuestiones que le competen en primera persona. Las razones son variadas, incluido el derecho de la persona a no recibir información si no lo desea. Pero hay ocasiones en que es la familia o entorno, o los propios profesionales, los que ponen barreras para que la información llegue al destinatario, frecuentemente de una forma deliberada o por pactos implícitos de silencio. Es frecuente que los profesionales no informen porque el paciente no hace preguntas, o por una actitud paternalista, muy habitual con personas de edad avanzada. Hay que recordar que para que pueda haber rechazo a la información debe haber oferta de la misma. Desde la deontología y la ética la información es un deber del profesional, y no llevarlo a cabo tiene que estar adecuadamente justificado. Es más, los casos excepcionales en los que sea adecuado no informar a la persona de algo concreto no eximen de informar de otros aspectos del proceso.

El proceso de información debe iniciarse desde el mismo momento del diagnóstico de la enfermedad, utilizando todas las herramientas necesarias para la buena comunicación (ver tablas en anexo 1). Explorar qué sabe o qué desea saber la persona e informar de manera acorde a las necesidades de cada momento debe ser una tarea integrada en el día a día de los profesionales que atienden a los usuarios del sistema sanitario. 


\section{Toma de decisiones compartida y desarrollo del plan de cuidados}

\section{Pregunta}

- ¿Cuáles son los factores que pueden favorecer la toma de decisiones compartida sobre el plan de cuidados individualizado para los últimos días de vida?

\section{Contexto}

En la práctica clínica se ha ido produciendo una progresiva incorporación activa de los pacientes y los familiares en las decisiones sobre los tratamientos y los cuidados, como una expresión del aumento de la importancia dada a la autonomía del paciente, y el consiguiente cambio en la relación terapéutica.

El modelo de Decisiones Compartidas es un estilo de relación en el que el equipo sanitario y la persona enferma (y sus allegados si así lo desea) deliberan sobre la estrategia a seguir con respecto a la atención, cuidados, tratamientos, etc. Los profesionales aportan el conocimiento científico y sus habilidades de comunicación y el paciente aporta sus valores y preferencias. De esta manera se fomenta la participación del paciente y su autonomía, y se elabora de forma conjunta un plan de cuidados que, se revisará periódicamente.

En el contexto de SUD es posible planificar de forma anticipada determinadas decisiones (por ejemplo, decisiones relacionadas con la retirada de tratamientos o la sedación paliativa), aunque lo deseable es haber realizado con tiempo un proceso de Planificación anticipada y compartida de la atención.

Sin embargo, se han documentado dificultades para la implementación del modelo de toma de decisiones compartida en diferentes ámbitos asistenciales, también en la atención a la cronicidad avanzada, los CP y la atención en la fase final de la vida. Alguna evidencia señala la falta de formación de los profesionales, dificultades para las discusiones sobre los planes de atención en los últimos días de vida y dudas sobre su utilidad. Pero también se han descrito barreras por parte de los pacientes y los familiares o allegados. Todo ello podría generar problemas en la participación en la toma de decisiones, con consecuencias importantes en la planificación de los cuidados al final de la vida y con un importante impacto en la baja satisfacción con la atención por parte de los pacientes y sus familias $(61,62)$.

\section{Recomendaciones}

1. Se recomienda, a pesar de la incertidumbre pronóstica en muchos casos, iniciar el proceso de toma de decisiones compartida lo antes posible durante el proceso de enfermedad, o al principio de la relación clínica si no ha sido realizado previamente por otros profesionales [BPC, nueva].

2. Al principio del proceso de toma de decisiones compartida se recomienda explorar el nivel de participación que la persona desea y puede tener, y que las discusiones sobre 
el desarrollo e implementación del plan de cuidados se realicen de forma honesta y transparente [BPC, adoptada].

3. Durante el proceso de toma de decisiones se recomienda explorar las expectativas, deseos y preferencias del paciente respecto a la atención y los cuidados que desea recibir, según sus valores. En caso de que el paciente se encuentre en una situación que no le permita tomar decisiones, revisar [BPC, adaptada]:

- La existencia de un documento de instrucciones previas o voluntades anticipadas.

- Las anotaciones en la historia clínica referidas a un proceso de planificación anticipada y compartida de la asistencia.

- Las preferencias manifestadas a sus familiares y/o allegados acerca de los cuidados que desearía recibir.

- Si existe un representante designado por el paciente. En caso de no existir representante designado ni familiares y/o allegados, la toma de decisiones corresponderá al equipo terapéutico, buscando el mayor consenso y actuando siempre buscando el mejor beneficio o interés para el paciente.

4. Se recomienda registrar los temas tratados y el plan de cuidados en un lugar adecuado para ello en la historia clínica, accesible para todos los profesionales que intervienen en la atención, y compartir esta información, además de con el resto del equipo de atención, con los allegados de la persona enferma implicados en su cuidado y/o acompañamiento [BPC, adoptada].

\section{Consideraciones clínicas relevantes:}

- Es relevante definir las responsabilidades de los profesionales del equipo multidisciplinar en el diseño y aplicación del plan de cuidados.

- El equipo que lidera la toma de decisiones compartida podrá necesitar el apoyo de personal experimentado. Se buscará asesoramiento especializado si es necesario.

- Se deberá revisar periódicamente el plan de cuidados para actualizarlo según sea necesario, contando con el paciente mientras lo desee o pueda.

- Cuando el paciente, por diversos motivos no conoce su situación y su final cercano, los profesionales deben seguir acompañando desde el respeto al propio ritmo que presenta el paciente y estar disponible para mantener las conversaciones si el paciente las solicita, ya que a través del acompañamiento se puede generar el vínculo de confianza que facilite hablar de ello.

- Es necesario tener en cuenta que la capacidad de la persona moribunda para participar en la toma de decisiones sobre su atención, así como sus deseos y preferencias, pueden cambiar a medida que su situación cambia o empeora.

- En el caso de que no se pueda cumplir alguna de las preferencias o deseos de la persona en el proceso de morir se explicarán y justificarán las razones. 


\section{Justificación}

El GEG ha emitido una serie de recomendaciones que pretenden favorecer una adecuada toma de decisiones compartida y la elaboración del plan de cuidados. Las recomendaciones se han basado en la evidencia cualitativa considerada sobre barreras y facilitadores, y en la experiencia del grupo. El GEG considera relevante promover la toma de decisiones compartida y un proceso continuado de planificación durante todo el proceso de enfermedad ya que es frecuente que en los últimos días el paciente pierda la capacidad de tomar decisiones o la voluntad para tomarlas. En cualquier caso, la actitud de los profesionales debería ser la de fomentar la participación del paciente hasta el final mientras sea posible.

\section{Justificación detallada}

Magnitud de los efectos esperados: la evidencia señala barreras y facilitadores para una toma de decisiones efectiva que pueden clasificarse en factores relacionados con los profesionales, familiares o allegados, pacientes y recursos disponibles. Desde el punto de vista de todos ellos, es importante la toma de decisiones compartida para mejorar los cuidados al final de la vida, y por tanto es importante reconocer los factores que pueden influir en el proceso.

Un factor clave para la participación del paciente en la toma de decisiones es la planificación compartida de los cuidados. Este proceso permite al paciente ejercer su autonomía hasta el final manteniendo el control de su vida mientras puede. Permite a los profesionales conocer sus valores y preferencias, adecuar las intervenciones y facilitar el fallecimiento en el lugar preferido y de la forma deseada. Además, mejora el conocimiento del paciente sobre su proceso. Esto genera efectos positivos en su autoestima y tranquilidad, y por tanto en facilitar un final de vida en paz. Mejora la satisfacción por el trato recibido. También tiene efectos positivos sobre los familiares y representantes, mejorando su conocimiento sobre la enfermedad, ayuda al representante a conocer su función, disminuye la carga que supone tomar decisiones por otra persona, alivia el proceso de duelo y mejora la satisfacción. En cuanto a los profesionales, la toma de decisiones compartida puede mejorar la relación con el paciente y familia, ayuda a tomar decisiones clínicas y a tener una atención más humanizada y basada en la persona.

Certeza global en la evidencia: la calidad global de la evidencia de los estudios incluidos es baja, fundamentalmente debido a las limitaciones de los estudios y baja aplicabilidad de los hallazgos a nuestro contexto sanitario. La mayor parte de los estudios provienen de EE. UU., Canadá y Reino Unido. Todos los estudios incluyen la visión de familiares y cuidadores, y ninguno de ellos incluye a pacientes. Además, se han considerado estudios que abordan la toma de decisiones compartida fuera del contexto de últimos días, factor que también ha afectado a la disminución de la aplicabilidad de la evidencia. Otro factor a tener en cuenta es que la mayoría de los estudios abordan la toma de decisiones en el ámbito hospitalario, pero hay un déficit en la investigación que aborda la toma de decisiones en la atención domiciliaria. A pesar de todo ello, las barreras y facilitadores identificados en la literatura revisada han permitido al grupo de trabajo modular las recomendaciones. 


\section{De la evidencia a la recomendación}

a) ¿Cuál es la magnitud de los efectos esperados?

- Juicio: grande.

- Evidencia procedente de la investigación: se han considerado estudios cualitativos sobre barreras y facilitadores para una toma de decisiones efectiva desde la perspectiva de profesionales $(59,61,63-77)$, y familiares o allegados $(76,78-91)$.

La guía NICE incluyó 19 estudios cualitativos, ninguno realizado desde la visión de los pacientes, aunque diez de ellos incorporaron a familiares (realizados fundamentalmente en EE. UU. y en Reino Unido). El resto de los estudios abordaron la visión de los profesionales sanitarios. De los 12 nuevos estudios en la actualización de la búsqueda bibliográfica, cuatro abordan la visión de los familiares sobre la toma de decisiones compartida, siete la visión de profesionales sanitarios y 1 la visión de familiares y profesionales. La mayoría de ellos emplean entrevistas en profundidad y grupos focales, dos de ellos emplean cuestionarios y uno realiza un análisis de reuniones grabadas.

Desde el punto de vista de todos ellos, es importante la toma de decisiones compartida para mejorar los cuidados al final de la vida, y por tanto es importante reconocer los factores que pueden influir en el proceso.

En la siguiente tabla (tabla 3) se presentan los temas y subtemas extraídos de la evidencia. Para ver una descripción detallada de los estudios y sus resultados se puede consultar el material metodológico.

Tabla 3. Temas y subtemas extraídos de los estudios incluidos sobre toma de decisiones compartida y desarrollo del plan de cuidados

\begin{tabular}{|l|l|}
\hline Tema principal & \multicolumn{1}{|c|}{ Subtemas } \\
\hline Factores relacionados con los & - Habilidades de comunicación \\
profesionales sanitarios & - Relación y entendimiento \\
& - Provisión de información \\
& - Incertidumbre en el pronóstico \\
& - Papel de la enfermería \\
& - Disponibilidad de los clínicos \\
& - Tiempo para la toma de decisiones compartida \\
& - Responsabilidad de los diferentes profesionales en el proceso de toma \\
& - de decisiones compartida \\
\hline Factores relacionados con & - Impacto de las emociones y sentimientos de los profesionales \\
los familiares y allegados & - Apoyo de la familia y conflicto \\
implicados en la toma de & - Falta de conocimientos médicos \\
decisiones & - Negación del pronóstico \\
& - Responsabilidades \\
\hline & - Experiencia previa con la toma de decisiones compartida \\
& - Carga emocional \\
\hline
\end{tabular}




\begin{tabular}{|l|l|}
\hline Factores relacionados con los & - Negación del pronóstico \\
pacientes & - Voluntad de discutir \\
\hline Factores relacionados con la & - Disponibilidad de espacio privado \\
disponibilidad de recursos & - Disponibilidad de equipamientos, profesionales y servicios específicos \\
& - Herramientas disponibles \\
\hline
\end{tabular}

Fuente: adaptado de NICE 2015 (22).

La toma de decisiones compartida y la planificación de los cuidados permite al paciente ejercer su autonomía hasta el final manteniendo el control de su vida mientras puede. Permite a los profesionales conocer sus valores y preferencias, adecuar las intervenciones y facilitar el fallecimiento en el lugar preferido y de la forma deseada. Además, mejora el conocimiento del paciente sobre su proceso. Esto genera efectos positivos en su autoestima y tranquilidad, y por tanto en facilitar una muerte en paz. Mejora la satisfacción por el trato recibido. También tiene efectos positivos sobre los familiares y representantes, mejorando su conocimiento sobre la enfermedad, ayuda al representante a conocer su función, disminuye la carga que supone tomar decisiones por otra persona, alivia el proceso de duelo y mejora la satisfacción.

En cuanto a los profesionales, puede mejorar la relación con el paciente y familia, ayuda a tomar decisiones clínicas y a tener una atención más humanizada y centrada en la persona.

- Información adicional: desde el punto de vista del GEG un adecuado proceso de toma de decisiones compartida podría prevenir en los profesionales lo que se denomina "fatiga por compasión" (92), al generar sentimientos positivos durante la atención a personas vulnerables y en el proceso de morir, lo que disminuye el desgaste profesional.

b) ¿Cuál es la magnitud de los efectos indeseables esperados?

- Juicio: pequeña.

- Evidencia procedente de la investigación: no se ha identificado ningún daño asociado a la implicación en la toma de decisiones compartida, ni para los pacientes ni para los profesionales.

- Información adicional: cabe tener en cuenta que, podrían darse casos en los que el paciente no acepte su situación y el final cercano, pudiendo ser poco adecuado forzarlo a participar en la toma de decisiones y planificación, lo que le podría generar malestar y ansiedad.

c) ¿Cuál es la certeza global en la evidencia sobre los efectos?

- Juicio: baja.

- Evidencia procedente de la investigación: la calidad global de la evidencia de los estudios incluidos es baja, fundamentalmente debido a las limitaciones de los estudios y baja aplicabilidad de los hallazgos a nuestro contexto sanitario. La mayor parte de los estudios provienen de EE. UU., Canadá y Reino Unido. Todos los estudios incluyen 
la visión de familiares y cuidadores, y ninguno de ellos incluye a pacientes. Además, se han considerado estudios que abordan la toma de decisiones compartida fuera del contexto de últimos días, factor que también ha afectado a la disminución de la aplicabilidad de la evidencia. Otro factor a tener en cuenta es que la mayoría de los estudios abordan la toma de decisiones en el ámbito hospitalario, pero hay un déficit en la investigación que aborda la toma de decisiones en la atención domiciliaria. A pesar de todo ello, las barreras y facilitadores identificados en la literatura revisada han permitido al grupo de trabajo modular las recomendaciones.

\section{d) ¿Existe incertidumbre o variabilidad importante sobre cómo los pacientes} valoran los desenlaces principales?

- Juicio: la incertidumbre o la variabilidad probablemente no sean importantes.

- Evidencia procedente de la investigación: la revisión sistemática se ha centrado en las barreras y facilitadores para una toma de decisiones compartida efectiva.

- Información adicional: se han considerado los factores (barreras y facilitadores) que influyen en la toma de decisiones compartidas en los últimos días, teniendo en cuenta la experiencia y opiniones de los principales agentes implicados (pacientes, familiares y profesionales sanitarios). El grupo de trabajo considera que la mayor parte de los pacientes y familiares querrán participar en la toma decisiones, y por lo tanto la variabilidad probablemente no sea importante.

e) ¿Son mayores los efectos deseables que los efectos indeseables?

- Juicio: probablemente sí.

- Evidencia procedente de la investigación: teniendo en cuenta los beneficios del proceso de toma de decisiones compartida y que no se ha identificado ningún daño asociado, el GEG considera el balance riesgo beneficio favorable a la toma de decisiones compartida.

f) ¿Cuál es la magnitud de los recursos requeridos (costes)?

- Juicio: probablemente son pequeños.

- Evidencia procedente de la investigación: no se ha localizado ningún estudio que describa de forma explícita el uso de recursos (costes) o estudios de evaluación económica.

- Información adicional: la implementación de la toma de decisiones compartida requiere tiempo, espacios adecuados y disponibilidad de los profesionales, por lo que no precisa una gran inversión de recursos económicos.

g) ¿Cuál es la certeza en torno a la evidencia sobre los recursos requeridos?

- Juicio: no hay estudios incluidos.

- Evidencia procedente de la investigación: no se ha localizado ningún estudio que describa de forma explícita el uso de recursos (costes) o estudios de evaluación económica. 
h) La relación coste-efectividad, ¿favorece a la intervención o a la comparación?

- Juicio: probablemente favorece a la intervención.

- Evidencia procedente de la investigación: no se ha localizado ningún estudio que describa de forma explícita el uso de recursos (costes) o estudios de evaluación económica.

- Información adicional: desde la experiencia del GEG, la promoción de la toma de decisiones compartida mejora la calidad de la atención a un coste razonable, incluso evitando la realización de medidas terapéuticas no deseadas por la persona enferma.

i) ¿Cuál sería el impacto en la equidad en salud?

- Juicio: aumenta.

- Evidencia procedente de la investigación: no se ha realizado una revisión sistemática del tema.

- Información adicional: el GEG discute que el impacto en la equidad dependerá en gran medida de los profesionales sanitarios y su capacidad para ejercer el rol de promotor de la toma de decisiones compartida. Esta oportunidad llegará a todas las personas que se encuentren en la fase final de su vida en la medida en que los profesionales se impliquen en su realización y dispongan de tiempo, espacio y formación adecuados.

j) ¿Es aceptable la opción para los agentes implicados?

- Juicio: probablemente sí.

- Evidencia procedente de la investigación: no se ha realizado una revisión sistemática del tema.

- Información adicional: la toma de decisiones compartida y el desarrollo del plan de cuidados deben adaptarse a la capacidad del paciente y sus allegados para decidir y a su interés por participar. En una sociedad que cada vez defiende más la autonomía del paciente y la participación de la ciudadanía en las decisiones en salud, el hecho de que el paciente participe en lo que afecta a su salud y a su vida debería tener buena acogida a priori en la mayor parte de los casos.

En cuanto a la aceptabilidad por parte de los profesionales, en la evidencia se han localizado algunos factores que pueden favorecer o actuar como barreras, como las habilidades y la experiencia, los recursos disponibles, la relación médico-paciente, entre otros factores, que pueden afectar a la implementación de las recomendaciones.

k) ¿Es factible la implementación de la opción?

- Juicio: probablemente sí.

- Evidencia procedente de la investigación: no se ha realizado una revisión sistemática del tema.

- Información adicional: desde el punto de vista del GEG, además de los factores previamente mencionados, pueden existir dificultades debido a la falta de formación y 
experiencia de los profesionales y a la inercia diagnóstico-terapéutica tradicional, es decir, el modelo de relación paternalista y, posteriormente, meramente informativo. Se requiere la capacitación de los profesionales y también un cambio social que suponga la asunción por parte de las personas de sus responsabilidades para la toma de decisiones al final de la vida.

\section{I) Otras consideraciones}

El GEG discute sobre la relación entre los conceptos de toma de decisiones y planificación anticipada y compartida de la asistencia, y cómo estos procesos pueden favorecer la redacción de un documento de voluntades anticipadas o instrucciones previas. Este tipo de documentos aún no son suficientemente conocidos entre la población general de nuestro país, con la excepción de aquellas regiones donde existen programas específicos de difusión y fomento de su realización. Para ello, y como paso previo y fundamental, es necesario desarrollar procesos de planificación compartida de la atención (PCA) entre los pacientes y sus familias y los profesionales que lideran su asistencia sanitaria.

Este proceso de PCA es un paso más en el respeto por la autonomía de la persona que buscaba la llamada planificación anticipada de la atención (del inglés advance care planning, o planificación de los cuidados para el futuro) $(93,94)$, adquiriendo una perspectiva de relación terapéutica deliberativa para la realización de un plan de cuidados con una visión integral más allá del ámbito puramente sanitario. Es por ello que esta planificación, buena práctica desde el punto de vista clínico y ético, no se debe dejar sólo para los últimos días, que llegaría tarde en gran medida, sino que debería empezar con el momento mismo del diagnóstico de la enfermedad, siendo éste un proceso continuado y no un acto único.

El objetivo de la planificación anticipada y compartida es adecuar la atención sanitaria a los valores, deseos y preferencias de la persona al final de su vida. Para ello es necesario fomentar el inicio y desarrollo de conversaciones que traten sobre la enfermedad y su evolución, y los tratamientos y cuidados. Es necesario identificar qué aspectos del cuidado y tratamiento son aceptados y cuáles rechazados. También hay que tener en cuenta a la familia y al entorno de cuidado, que pueden opinar y ayudar a la persona enferma a tomar decisiones. Alguno de ellos, u otra persona que el enfermo designe, puede ser su representante en el caso de que, llegado el momento, pierda la capacidad de decidir. Todo ello debe ser registrado en la historia clínica y compartido con el resto de profesionales que intervengan en la atención. Además, el plan puede y debe ser revisado periódicamente para realizar los cambios que la persona enferma estime oportunos y adaptarlo a posibles incidencias o cambios de opinión (95).

Es necesario que los profesionales evalúen previamente la capacidad del paciente para la toma de decisiones. No se debe tratar a la persona como incapaz si no se ha valorado la capacidad o si toma una decisión que no gusta a los que tiene alrededor, y esto es particularmente importante en la atención de los mayores. Para la valoración de su capacidad de decisión deberá tenerse en cuenta si la persona puede entender la información, valorar la situación clínica, comprender las opciones y las consecuencias de cada opción y comunicar su elección de forma razonada. Si se confirma la incapacidad es fundamental respetar la máxima de buscar siempre el mejor interés, tomando decisiones que sean lo menos restrictivas posibles para los derechos del paciente (22). 
Este proceso debe realizarse en un clima adecuado, que hay que preparar previamente. Es necesario explorar qué información tiene el paciente en cada momento, qué significan para él las cosas de las que hablamos, y qué nivel de información desea para no excedernos en los datos. Hablar con franqueza y honestidad, recogiendo y acompañando las emociones del paciente y de sus allegados, y planificando en cada momento lo que sea oportuno, dejando la puerta abierta para nuevas conversaciones (96). Debe haber un responsable del proceso para que no quede sin hacer por falta de coordinación de los profesionales implicados. En este punto, el papel del personal de enfermería es fundamental y desarrollar su rol de gestión de casos y su posición cercana al paciente y su familia podría facilitar el inicio y desarrollo de las conversaciones (97).

Para llegar a esto es imprescindible que los profesionales se impliquen y se formen en habilidades de comunicación y herramientas para fomentar la toma de decisiones compartida. Además de aptitud el profesional debe tener ciertas actitudes facilitadoras, como son calidez, concreción, respeto, empatía, baja reactividad y asertividad. También actitud de trabajo en equipo ya que este proceso debería ser realizado en equipo interdisciplinar.

Desde el punto de vista del sistema sanitario también se debería fomentar la realización de la planificación anticipada y compartida de la asistencia, facilitando espacios y recursos adecuados para ello, así como desarrollar la historia clínica para que se pueda registrar esta planificación y pueda ser accesible para los profesionales responsables del paciente en cada momento. 


\section{Hidratación}

\section{Pregunta}

- ¿En pacientes en sus últimos días de vida, la hidratación artificial es efectiva para mejorar los síntomas y el confort general?

\section{Contexto}

La mayoría de pacientes en la fase final de una enfermedad avanzada experimentan una reducción de la ingesta oral. Puede desarrollarse como parte de una debilidad generalizada donde la capacidad de ingerir alimentos y líquidos es paralela al deterioro fisiológico general, o a otras circunstancias, como por ejemplo al efecto de algunos medicamentos, o a alteraciones metabólicas (98). Tiene un importante impacto emocional en los pacientes y sus familias (99).

Se denomina hidratación artificial (HA) o hidratación clínicamente asistida a la provisión de fluidos habitualmente de forma intravenosa, subcutánea (hipodermoclisis) o enteral (nasogástrica o gastrostomía), para prevenir y tratar la deshidratación. Su indicación en pacientes en últimos días ha generado un intenso debate en las últimas décadas.

Esto es así debido a la ausencia de evidencia científica sólida sobre los inconvenientes y beneficios tanto en el control de síntomas como en la supervivencia (100), y a las diferentes posiciones y puntos de vista en función de aspectos socioculturales y emocionales de clínicos, pacientes y familiares (101). Debido a ello existe variabilidad documentada en su práctica (98).

\section{Recomendaciones}

1. Con carácter general no se recomienda la hidratación artificial en la situación de últimos días. Excepcionalmente podría considerarse si [Débil en contra, adaptada]:

- Existe mal control de síntomas que pueden estar relacionados con la deshidratación (por ej. delirium) y han fracasado otras medidas de control.

- La reducción de la ingesta oral produce malestar o inquietud emocional en el paciente y su familia a pesar de un adecuado proceso de comunicación con el equipo de atención.

2. Si el paciente no está en condiciones de decidir, al considerar la hidratación artificial en un paciente en situación de últimos días, es necesario revisar en su historia clínica si el paciente ha expresado previamente en un documento de instrucciones previas o en un proceso de planificación anticipada y compartida de la asistencia, sus preferencias sobre la hidratación artificial [BPC, adaptada].

3. Si se indica hidratación artificial [BPC, adaptada]:

- Se recomienda abordar las inquietudes de paciente y familia e informar sobre la evidencia de los beneficios y riesgos de la hidratación artificial en situación de últimos días. 
- Considerarla como una prueba limitada en el tiempo (acordada previamente con paciente/familia).

- Se aconseja no usar cantidades de volumen mayores de 1 litro al día.

- Se recomienda no utilizar la vía enteral. La vía preferente será la subcutánea en caso de atención domiciliaria o de no disponer vía intravenosa ya canalizada.

4. Una vez instaurada la hidratación artificial [BPC, adaptada]:

- Monitorizar aproximadamente cada 24 horas los cambios en los síntomas o signos de deshidratación y cualquier evidencia de beneficio o daño.

- Continuar con la hidratación si se percibe un beneficio por paciente y familia.

- Reducir o detener la hidratación si hay signos de posible daño como sobrecarga de líquidos o incremento de secreciones respiratorias, o si el paciente o sus allegados solicitan la retirada.

5. Para las personas que ya tienen instaurada la hidratación artificial (enteral o parenteral) antes de los últimos días de vida [BPC, adoptada]:

- Revisar los riesgos y beneficios de continuar con la hidratación artificial en situación de últimos días con el paciente y sus allegados.

- Considerar si continuar, reducir o detener la hidratación artificial a medida que la persona se acerca a la muerte.

\section{Consideraciones clínicas relevantes}

- Al considerar el volumen diario en la hidratación artificial, es relevante tener en cuenta los volúmenes de líquidos administrados al diluir otras medicaciones administradas (por ejemplo, en infusores con medicación para el control de síntomas).

- Se apoyará al paciente para que beba si lo desea mientras pueda hacerlo. Es necesario comprobar previamente si hay dificultades, como problemas para tragar o riesgo de aspiración. Se discutirán los riesgos y beneficios de continuar bebiendo, con el paciente y su familia y/o allegados.

- Es relevante animar, aconsejar y apoyar a los cuidadores para realizar el cuidado de la boca y ofrecer bebidas de forma segura.

- Será necesario realizar periódicamente cuidados de la boca, tanto de limpieza como de la boca seca, vigilar causas tratables de disfagia y aplicar medidas que reduzcan el riesgo de aspiración (ver anexo 2).

\section{Justificación}

Estas recomendaciones se han formulado para intentar favorecer un adecuado manejo clínico de la hidratación en los últimos días de vida basado en la evidencia de los riesgos y beneficios y respetando los valores y deseos del paciente y su familia. 


\section{Justificación detallada}

Balance beneficio-riesgo: la evidencia científica no señala beneficios claros de la HA y podría estar asociada a la aparición de eventos adversos, por lo tanto, el GEG ha considerado que el balance beneficio-riesgo es globalmente desfavorable a la provisión de HA en los últimos días. Sin embargo, es necesario tener en cuenta que la evidencia disponible es insuficiente y puede haber un beneficio percibido por el paciente y su familia. Además, existen circunstancias en las que en la práctica clínica podría obtenerse beneficios con la HA, como en casos de delirium o cuando el paciente presente sed que no mejora con otras medidas. En todo caso la decisión tendrá que ser valorada individualmente sopesando con el paciente y su familia los beneficios frente a la posible aparición de complicaciones o malestar.

Valoración por parte de los pacientes de las variables de resultado: la evidencia señala que la pérdida de la capacidad de usar la vía oral en la SUD tiene un importante impacto psicológico y emocional. La HA tiene un importante valor simbólico, y en diferentes culturas se percibe como un símbolo de cuidado.

\section{De la evidencia a la recomendación}

a) ¿Cuál es la magnitud de los efectos deseables esperados?

- Juicio: pequeña.

- Evidencia procedente de la investigación: se ha considerado la evidencia incluida en la GPC del NICE (22), que a su vez se basó en una revisión Cochrane (100). En la actualización se añadió un estudio nuevo. La evidencia disponible no es suficiente para extraer conclusiones definitivas, aunque sugiere que no hay mejoras importantes en el bienestar o en el control de síntomas en los grupos que reciben HA frente a los que no.

- Hidratación artificial versus placebo: en los dos ensayos clínicos aleatorizados (ECA) ( $\mathrm{n}=129$ y 51) $(102,103)$ que compararon $1000 \mathrm{ml}$ día de suero fisiológico o glucosalino subcutáneos frente a $100 \mathrm{ml}$ subcutáneos (grupo placebo) en pacientes con cáncer que no presentaban deshidratación grave no se encontraron diferencias estadísticamente significativas en las variables calidad de vida, bienestar, tiempo de supervivencia o efecto en el control de síntomas (ansiedad, disnea, dolor, náuseas, sedación, somnolencia o delirium). La calidad de la evidencia fue moderada a muy baja (22).

- Hidratación artificial versus cuidados habituales: el ECA que comparó $1000 \mathrm{ml}$ al día de glucosa con $140 \mathrm{mEq}$ ClNa frente a hidratación oral (104) no encontró diferencias en la supervivencia. La hidratación no incrementó el riesgo de eventos adversos. La calidad de la evidencia fue de muy baja a moderada (22).

Un ensayo aleatorizado no controlado $(\mathrm{n}=26)(105)$ que comparó la HA con hialuronidasa frente a los cuidados habituales no encontraron beneficios clínicos informados por los pacientes en el bienestar o el control de síntomas (ansiedad, disnea, dolor, náuseas, sedación o somnolencia). La calidad de la evidencia fue de baja a muy baja (22). 
Otro ensayo aleatorizado no controlado (n=226) (106) encontró que la HA no aportó beneficios clínicos en la prevención del delirium, estado de hidratación o resultados en pruebas de laboratorio, frente a la hidratación oral. No se encontró un aumento del riesgo de edema, ascitis o derrame pleural. La calidad de la evidencia fue muy baja (22).

El nuevo estudio localizado (Davies 2018) (n=200) (107) no encontró diferencias estadísticamente significativas entre los grupos en la escala Richmond Agitation Sedation Scale modificada (delirium) ni en la probabilidad de presentar estertores, disnea, náuseas y vómitos, o dolor. El 38.5 \% abandonaron la intervención debido a la aparición de eventos adversos, aunque ninguno de ellos se calificó como grave o moderado. Los más frecuentes fueron: edema localizado, edema generalizado y secreciones respiratorias. La calidad de la evidencia fue baja-muy baja.

b) ¿Cuál es la magnitud de los efectos indeseables esperados?

- Juicio: variable.

- Evidencia procedente de la investigación: algunos estudios analizados informaron de reacciones locales adversas (edema localizado en el sitio de punción o dolor) (104, 107). Un estudio informó de síntomas relacionados con la sobrecarga de líquidos (derrame pleural, edema periférico y ascitis) significativamente más altos en el grupo que recibió HA (106).

- Información adicional: desde el punto de vista del GEG también es importante considerar que la sobrehidratación iatrogénica puede provocar malestar y síntomas como dolor o disnea por retención de líquidos. Sin embargo, los eventos adversos o complicaciones son poco frecuentes con cantidades que no superen el litro al día.

c) ¿Cuál es la certeza global en la evidencia sobre los efectos?

- Juicio: baja/muy baja.

- Evidencia procedente de la investigación: la calidad global de la evidencia es baja. Aunque para algunas de las variables consideradas la evidencia es moderada y proviene de ECA, los pocos estudios disponibles y la variabilidad en los diseños y variables consideradas dificulta la obtención de conclusiones definitivas y afecta a la certeza global en la evidencia. Además, cabe considerar que la mayoría de los estudios se han realizado en pacientes oncológicos con deshidratación leve o moderada (algunos de los estudios excluyen pacientes con deshidratación grave).

d) ¿Existe incertidumbre o variabilidad importante sobre cómo los pacientes valoran los desenlaces principales?

- Juicio: la incertidumbre o la variabilidad probablemente no sean importantes.

- Evidencia procedente de la investigación: no se ha realizado una revisión sistemática, pero se han considerado dos revisiones sistemáticas que señalan que la pérdida de la capacidad de hidratación oral en la SUD tiene un importante impacto emocional y la HA tiene un importante valor simbólico, y en diferentes culturas se percibe como un símbolo de cuidado $(99,108)$. 
- Información adicional: se han considerado como variables críticas la calidad de vida (bienestar, confort), la mejora en el control de síntomas y los eventos adversos relacionados con los procedimientos o con el balance de líquidos positivo; y como importantes: síntomas relacionados con la deshidratación (fatiga, delirium, sedación, mioclono o sed), estado de hidratación, y evaluación subjetiva de cuidadores en la calidad de los cuidados recibidos.

Desde el punto de vista del GEG la variabilidad en como los pacientes valoran los desenlaces probablemente no sea importante, teniendo en cuenta la evidencia y su experiencia en la práctica clínica.

e) El balance entre los efectos deseables e indeseables esperados, ¿favorece a la intervención o a la comparación?

- Juicio: variable.

- Evidencia procedente de la investigación: teniendo en cuenta que la evidencia clínica no señala beneficios claros y que podrían aparecer eventos adversos, el balance podría ser considerado globalmente desfavorable a la provisión de HA en los últimos días. Sin embargo, es necesario tener en cuenta que la evidencia disponible es insuficiente y puede haber un beneficio percibido por el paciente y su familia.

- Información adicional: el GEG señala que existen circunstancias en las que en la práctica clínica podría obtenerse beneficios con la HA, como en casos de delirium o cuando el paciente presente sed que no mejora con otras medidas. En todo caso la decisión tendrá que ser valorada individualmente sopesando con el paciente y su familia los beneficios frente a la posible aparición de complicaciones o malestar en el paciente.

f) ¿Cuál es la magnitud de los recursos requeridos (costes)?

- Juicio: costes y reducción de costes insignificante.

- Evidencia procedente de la investigación: no se ha localizado ningún estudio que describa de forma explícita el uso de recursos (costes) o estudios de evaluación económica.

- Información adicional: el GEG ha revisado los costes calculados para Reino Unido en la GPC del NICE. Aunque no ha considerado relevante calcular los costes para el SNS, se considera que el uso de recursos y costes para la hidratación artificial son mínimos. El uso de medios humanos en la SUD es similar esté con o sin hidratación artificial.

g) ¿Cuál es la certeza en torno a la evidencia de los recursos requeridos?

- Juicio: no hay estudios incluidos.

- Evidencia procedente de la investigación: no se ha localizado ningún estudio que describa de forma explícita el uso de recursos (costes) o estudios de evaluación económica. 
h) La relación coste-efectividad, ¿favorece a la intervención o a la comparación?

- Juicio: probablemente favorece a la intervención.

- Evidencia procedente de la investigación: no se ha localizado ningún estudio de evaluación económica.

- Información adicional: se podría considerar que la relación coste efectividad favorece a la intervención, al ser los costes tan pequeños.

i) ¿Cuál sería el impacto en la equidad en salud?

- Juicio: aumenta.

- Evidencia procedente de la investigación: no se ha llevado a cabo una búsqueda bibliográfica específica.

- Información adicional: el GEG ha considerado que las recomendaciones podrían aumentar la equidad en salud, mejorando la toma de decisiones sobre hidratación y su adecuación terapéutica. Desde su punto de vista la equidad podría depender de factores como la formación en CP del equipo asistencial, que identifique la SUD y aplique las recomendaciones basadas en la evidencia científica.

\section{j) ¿Es aceptable la opción para los agentes implicados?}

- Juicio: variable.

- Evidencia procedente de la investigación: no se ha realizado una revisión sistemática, pero algunas revisiones sistemáticas previas (por ejemplo, $(99,108)$ ), señalan que existen diferentes perspectivas, actitudes y factores emocionales que pueden influir en la percepción de la necesidad de la hidratación clínicamente asistida por parte de los pacientes y sus allegados. La evidencia también muestra que entre los profesionales también existen diferentes opiniones con respecto a la hidratación clínicamente asistida y su papel en los cuidados al final de la vida (99).

Por todo ello, el desarrollo del plan de cuidados y el manejo clínico de la hidratación ha de ser individualizado y considerar aspectos sociales y culturales, que puedan estar afectando al mismo.

- Información adicional: se debe informar al paciente y/o la familia de que la HA es una actuación médica que a menudo no está indicada cuando el paciente se está muriendo y no mejorará su estado (salvo en algunos casos puntuales). Además, la sobrehidratación iatrogénica puede provocar malestar y síntomas como el dolor o disnea por la retención de líquidos. El proceso comunicativo debería comenzar antes del inicio de la SUD, reflejando en la planificación de cuidados los valores y deseos del paciente sobre la HA.

Además, es importante atender a las inquietudes de los pacientes y la familia con respecto a la hidratación. En algunos casos la nutrición y la hidratación tienen un valor simbólico-cultural que se extiende más allá de los límites de la atención médica, por lo que es importante considerar su punto de vista siempre que no entre en conflicto con lo que pueda estar indicado o con los deseos expresados previamente por el paciente. 
Sin embargo, también es importante considerar que cuando el paciente fallece en el domicilio, la administración de la hidratación artificial (generalmente por vía subcutánea) puede suponer una sobrecarga más en el aprendizaje para sus cuidadores, lo que deberá ser tenido en cuenta al valorar su prescripción.

\section{k) ¿Es factible la implementación de la opción?}

- Juicio: sí.

- Evidencia procedente de la investigación: no se ha llevado a cabo una búsqueda bibliográfica específica.

- Información adicional: desde el punto de vista del GEG, las recomendaciones realizadas podrían ser implementadas en cualquier ámbito y situación en la que se encuentre un paciente en SUD. No se han identificado en el análisis realizado, factores que pudiesen actuar como barreras, más allá de los factores previamente mencionados relacionados con la aceptabilidad.

\section{l) Otras consideraciones}

La HA en la SUD ha generado un intenso debate desde la perspectiva ética, con argumentos en contra y a favor sobre su uso. Las principales discusiones se han centrado en su efecto en la supervivencia, en la conservación de las funciones superiores y en su significado simbólico-religioso (101). Estas cuestiones afectan a importantes principios morales en el final de la vida: respeto por la vida, la muerte, la dignidad, la autonomía y la obligación de proporcionar unos cuidados médicos proporcionados.

El GEG considera que ninguno de los argumentos cuenta con evidencia científica definitiva, por lo que existe consenso en que la decisión de usar HA en SUD debe individualizarse, discutirse en el equipo multidisciplinar y basarse en la promoción del confort del paciente, más que en conseguir una hidratación óptima. En muchos pacientes podría lograrse un confort aceptable con los cuidados de boca seca ya que, en SUD, es frecuente tener la boca seca pero no sed.

El abordaje de la cuestión debe tener la PCA como elemento fundamental. Este proceso, iniciado con tiempo suficiente permite conocer los valores y preferencias de la persona con respecto a la HA. Los profesionales podrán explicar los pros y contras de la misma, los objetivos de la atención y contextualizar el papel de la hidratación en los últimos días. 


\section{Manejo de síntomas}

\section{Pregunta}

- Para pacientes en los últimos días de vida, ¿qué fármacos son más efectivos para aliviar el dolor, la disnea, las náuseas y vómitos, la ansiedad, el delirium y los estertores?

\section{Contexto}

La situación de últimos días al igual que el resto de las fases evolutivas por las que atraviesa un paciente con enfermedad avanzada, progresiva e incurable, requiere el enfoque multidisciplinar propio de los CP orientado a aliviar el sufrimiento y mejorar la calidad de vida de los pacientes y sus familias.

El sufrimiento puede tener su origen en cualquiera de las dimensiones de la persona por lo que es necesario realizar una impecable valoración multidimensional que incluya las dimensiones física, psicológica, social y espiritual, con un abordaje holístico de la persona enferma. En cada una de estas dimensiones se hallan implicados diversos profesionales que deberán trabajar de manera coordinada, evaluando y compartiendo información y elaborando un plan de cuidados que deberá reevaluarse para ajustar continuamente los objetivos de cuidados (109).

En esta pregunta clínica se analiza la evidencia y se aportan recomendaciones sobre el manejo de los síntomas más frecuentemente observados en la práctica clínica en SUD. La secuencia de presentación en la pregunta no se corresponde necesariamente con su relevancia para los pacientes o para la práctica clínica. Se abordan inicialmente el dolor y la disnea porque son los más frecuentes, y a continuación se desarrollan el manejo de las náuseas y vómitos, la ansiedad, el delirium y los estertores.

Las medidas no farmacológicas son imprescindibles y necesarias, algunas veces más eficaces que el tratamiento farmacológico por lo que, aunque no son el objeto de estudio de esta pregunta, se han recomendado en cada síntoma y se detallan en los anexos (anexo 3-anexo 7). En el anexo 8 se presenta información sobre la administración de fármacos por vía subcutánea y en el anexo 9 un Vademécum de los fármacos más empleados en SUD.

Antes del análisis de cada uno de los síntomas más frecuentes se presentan un grupo de recomendaciones de buena práctica clínica sobre consideraciones generales.

\subsection{Consideraciones generales}

\section{Recomendaciones}

1. Para guiar las decisiones sobre manejo de síntomas se recomienda realizar una valoración sistemática de los síntomas principales, para disminuir el riesgo de infraestimación de alguno de ellos, y cuantificar su intensidad mediante escalas que permitan evaluar el resultado de las medidas aplicadas [BPC, nueva]. 
2. Se recomienda hacer una revisión rigurosa del tratamiento en la fase final de la vida del paciente y adaptarlo a los objetivos terapéuticos centrados en el bienestar y en el control de síntomas [BPC adaptada].

3. Se recomienda suspender todos aquellos tratamientos fútiles, que no aporten beneficio a la situación actual del paciente, y discutir los riesgos y beneficios de cualquier medicamento ofrecido, así como transmitir que la retirada de un fármaco se debe a la futilidad en la situación actual del paciente [BPC adaptada].

4. Se recomienda dejar instrucciones claras y por escrito del tratamiento, indicando pautas fijas y otras condicionadas a momentos de crisis [BPC adaptada].

\section{Consideraciones clínicas relevantes}

- En la valoración sistemática de síntomas generales para guiar las decisiones sobre manejo clínico pueden emplearse escalas como la Edmonton Symptom Assessment System (ESAS) (110) (ver anexo 3). Existen además otras escalas para síntomas específicos que se exponen en el apartado correspondiente a cada síntoma.

- Al considerar los medicamentos para el control de síntomas es preciso tener en cuenta:

- La causa probable del síntoma.

- Definir el objetivo del tratamiento. Este aspecto debe acordarse entre médico, paciente y cuando sea necesario con los cuidadores.

- Estimar el balance riesgo-beneficio de cada medicamento.

- Posibles interacciones con otros medicamentos que esté tomando para el control de síntomas.

- Simplificar las pautas de tratamiento.

- Monitorizar la respuesta.

- Para ayudar a la toma de decisiones sobre deprescripción, puede valorarse el empleo de criterios explícitos como STOPP- Frail (STOPP-Pal) (111).

- La administración de medicamentos será vía oral siempre y cuando sea posible. En caso de no poder mantener la vía oral la alternativa sería la parenteral según el medio y disponibilidad. Se recomienda adecuar la medicación a la vía parenteral (iv o sc, esta última de elección en domicilio) y explicar su manejo a familiares y cuidadores.

- Se implementará y se monitorizará un plan al menos diario de control de síntomas para reevaluar y ajustar el tratamiento.

- Para la prevención de la posibilidad de complicaciones agudas: se explicará cómo actuar si se dan estas circunstancias facilitando la medicación necesaria con pautas claras de actuación por escrito.

- El clínico responsable, tanto en el ámbito de la atención primaria como de la atención hospitalaria, solicitará asesoramiento especializado en CP si existen criterios de complejidad que dificulten el manejo (para valorar los criterios de complejidad puede emplearse la escala IDC-Pal (112). 


\section{Justificación}

El GEG ha emitido recomendaciones de buena práctica clínica centradas en principios generales de prescripción en CP. Se han elaborado también una serie de consideraciones clínicas relevantes y relacionadas con la implementación de las recomendaciones.

\section{Justificación detallada}

Las recomendaciones emitidas se basan en los principios de prescripción en el ámbito de la atención paliativa.

\section{De la evidencia a la recomendación}

a) ¿Cuál es la magnitud de los efectos deseables esperados?

- Juicio: grande.

- Evidencia procedente de la investigación: no aplicable.

- Información adicional: las recomendaciones responden a principios generales de buena práctica de actuación y prescripción (adecuación y deprescripción) y el GEG considera que los efectos deseables son sustanciales.

b) ¿Cuál es la magnitud de los efectos indeseables esperados?

- Juicio: pequeña.

- Evidencia procedente de la investigación: no aplicable.

- Información adicional: el grupo no ha identificado efectos indeseables derivados de las recomendaciones emitidas.

c) ¿Cuál es la certeza global en la evidencia sobre los efectos?

- Juicio: muy baja.

- Evidencia procedente de la investigación: no se ha identificado evidencia científica específica para estas recomendaciones, que han sido elaboradas siguiendo la experiencia del GEG y adaptando las recomendaciones realizadas en la GPC del NICE (19).

d) ¿Existe incertidumbre o variabilidad importante sobre cómo los pacientes valoran los desenlaces principales?

- Juicio: la incertidumbre o la variabilidad probablemente no sean importantes.

- Evidencia procedente de la investigación: no se ha realizado revisión sistemática del tema.

e) El balance entre los efectos deseables e indeseables esperados, ¿favorece a la intervención o a la comparación?

- Juicio: probablemente favorece a la intervención. 
- Evidencia procedente de la investigación: no se ha identificado evidencia científica específica para estas recomendaciones.

- Información adicional: las recomendaciones responden a principios generales de buena práctica clínica y no se han identificado efectos indeseables asociados.

f) ¿Cuál es la magnitud de los recursos requeridos (costes)?

- Juicio: no aplica.

- Evidencia procedente de la investigación: no se ha localizado ningún estudio que describa de forma explícita el uso de recursos (costes) o estudios de evaluación económica.

- Información adicional: el GEG concluyó que la implementación de estas recomendaciones no generaría costes adicionales, ya que estos puntos ya deberían constituir una práctica actual.

g) ¿Cuál es la certeza en torno a la evidencia de los recursos requeridos?

- Juicio: no hay estudios incluidos.

- Evidencia procedente de la investigación: no se ha localizado ningún estudio que describa de forma explícita el uso de recursos (costes) o estudios de evaluación económica.

h) La relación coste-efectividad, ¿favorece a la intervención o a la comparación?

- Juicio: no aplica.

- Evidencia procedente de la investigación: no se ha localizado ningún estudio de evaluación económica.

- Información adicional: se trata de práctica habitual que, en comparación con sus beneficios netos en salud, podría tener unos costes adicionales nulos, como se indica en el juicio previo del GEG sobre la magnitud de recursos.

i) ¿Cuál sería el impacto en la equidad en salud?

- Juicio: aumenta.

- Evidencia procedente de la investigación: no aplicable.

- Información adicional: desde el punto de vista del GEG, la implementación de las recomendaciones podría aumentar la equidad en salud.

j) ¿Es aceptable la opción para los agentes implicados?

- Juicio: probablemente sí.

- Evidencia procedente de la investigación: no se ha realizado revisión sistemática sobre el tema. 
- Información adicional: según la experiencia del GEG las recomendaciones podrían ser aceptables para los profesionales. En el caso de los pacientes y familiares, deberán de ir asociadas a un adecuado proceso comunicativo.

Algunos pacientes consideran la prescripción como una expresión de la relación médico-paciente. Consecuentemente, la retirada de fármacos puede ser malinterpretada por los pacientes y sus familias como un abandono del cuidado. Para evitar malentendidos, es necesaria una comunicación adecuada entre los profesionales, el paciente y los familiares cercanos.

\section{k) ¿Es factible la implementación de la opción?}

- Juicio: sí.

- Evidencia procedente de la investigación: no se ha realizado una revisión sistemática sobre el tema.

- Información adicional: el GEG no ha identificado ningún factor relevante relacionado con la factibilidad de las recomendaciones.

\section{l) Otras consideraciones}

El GEG estima que la polimedicación en los pacientes mayores con enfermedad avanzada constituye un grave problema sanitario, tanto por los efectos adversos asociados como por los costes sanitarios. La mayoría de pacientes que alcanza la etapa final de su vida tiene prescritos gran cantidad de medicamentos para enfermedades crónicas. Aunque no existe un consenso claro sobre qué fármacos son inadecuados en este periodo, algunos no se consideran apropiados, principalmente porque el tiempo necesario para producir beneficio es superior a la expectativa de vida del paciente y por los efectos adversos. Debe valorarse con el paciente y su familia/allegados la retirada de fármacos y transmitir que si se retira un fármaco es porque la situación del paciente lo requiere o por futilidad en la situación actual y en ningún caso por abandono.

Existen diferentes publicaciones que recomiendan la suspensión de determinados medicamentos cuando la esperanza de vida es limitada y el objetivo terapéutico no es la prevención ni la curación, sino el control de los síntomas. Recientemente se han publicado una lista de criterios explícitos (STOPP-Frail) que pueden ayudar al médico prescriptor a la toma de decisiones en la deprescripción de determinados fármacos en pacientes de edad avanzada y con enfermedad en fase terminal (111).

\subsection{Dolor}

\section{Contexto}

La prevalencia del dolor está entre el 30-75 \% en los últimos días de vida (113). Además, es muy frecuente que la presencia de dolor pueda complicarse asociándose a delirium y es uno de los síntomas más temidos por pacientes y familiares (113). Un escenario concreto son los pacientes oncológicos en SUD, donde la prevalencia de dolor intenso podría ser mayor. 
Si bien gran parte de los pacientes tiene un buen control del dolor en SUD sin necesidad de altas dosis de opioides, todavía existe un número significativo de pacientes que sienten dolor no controlado en los últimos días (114), por lo tanto, es importante enfatizar la importancia de tratar correctamente el dolor y realizar recomendaciones que promuevan su adecuado control en la SUD.

\section{Recomendaciones}

1. Dentro de un enfoque global de los cuidados paliativos, se recomienda promocionar la valoración y el manejo correcto del dolor para que los pacientes lleguen a situación de últimos días con el dolor controlado, manteniendo la medicación con los ajustes de dosis que sean precisos. Se deben anticipar las posibles necesidades analgésicas del paciente y dejar prescrita medicación para su adecuado control con la finalidad de manejar la situación por los familiares, allegados y/o equipo sanitario en el momento necesario [BPC, nueva].

2. Se recomienda no prescribir analgésicos de forma rutinaria ya que, si bien es un síntoma muy frecuente, no todas las personas en situación de últimos días experimentan dolor [BPC, adaptada].

3. Se recomienda considerar un manejo no farmacológico del dolor en pacientes en situación de últimos días asociado a las medidas farmacológicas [BPC, adaptada].

4. El tratamiento farmacológico de elección cuando el dolor es moderado o grave, una vez descartadas las causas reversibles, serían los opioides. En los casos de dolor leve se sugiere utilizar fármacos de primer escalón excepto que se prevea una mala respuesta o problemas en la vía de administración, en cuyo caso se podría plantear un inicio con opioides a dosis bajas [BPC, nueva].

5. En caso de instauración de tratamiento opioide, el de elección en SUD es la morfina de acción rápida (oral o parenteral) [BPC, nueva].

6. Se recomienda no retirar o disminuir abruptamente la medicación opioide ya que, tanto esta disminución o retirada como el dolor mal controlado, son factores reconocidos de desorientación y de delirium en pacientes con enfermedad crónica avanzada [BPC, nueva].

7. En pacientes con dolor neuropático, se recomienda mantener la medicación basal en la medida de lo posible, si bien es frecuente que en SUD se pierda la vía oral, por lo que se tendrá esto en consideración de cara a la dosificación de opioide [BPC, nueva].

\section{Consideraciones clínicas relevantes}

- De cara a obtener un óptimo control del dolor, es fundamental medir adecuadamente el mismo para ajustar dosis y medidas al resultado. Existen una serie de escalas validadas para medir el dolor (ver anexo 4).

- En pacientes en situación de últimos días se evaluará el dolor en intervalos regulares con escalas subjetivas numéricas (Escala analógica visual, EVA), siempre que sea posible, y se ajustará el tratamiento en función de resultados. Si no es posible aplicarlas se puede valorar el uso de escalas conductuales. También puede aportar información relevante consultar a un cuidador o familiar para obtener información 
sobre el dolor potencial y otras fuentes de inquietud cuando el deterioro cognitivo impida la evaluación.

- Las medidas no farmacológicas se presentan en el anexo 4.

- En situaciones en las que el dolor aparece de forma aguda o aumenta sobre una situación basal bien controlada, se deberá identificar y tratar causas reversibles (como la retención urinaria o la angustia, entre otras).

- El inicio, vía y ajuste de la medicación analgésica en situación de últimos días seguirá los mismos principios que en el resto de los escenarios clínicos, adaptándose a la intensidad del dolor y a los cambios en el balance riesgo-beneficio.

- Existen aspectos prácticos en el uso de opioides en la SUD que deberán tenerse en cuenta (titulación, dosificación y rotación) (ver anexo 4).

- Dado que es frecuente que pacientes, familia e incluso profesionales de la salud tengan la creencia de que el uso de opioides puede acelerar el fallecimiento del paciente, se deberá:

- Transmitir que no se ha probado una relación entre el uso de altas dosis y el tiempo de supervivencia en situación de últimos días.

- Explicar al paciente y familia los efectos esperables por la medicación y que la sedación excesiva o no deseada puede ser uno de ellos.

- Considerar los valores y preferencias del paciente y la familia.

\section{Justificación}

Dada la ausencia de evidencia científica sobre la efectividad de los diferentes fármacos para el control de dolor en los últimos días de vida, el GEG ha formulado las recomendaciones basándose en los principios generales del control del dolor y el manejo en etapas previas de la atención paliativa, y en su experiencia clínica. Estas recomendaciones pretenden favorecer la evaluación y control adecuados del dolor en los últimos días de vida, teniendo en cuenta el importante impacto del dolor.

\section{Justificación detallada}

Magnitud de los efectos deseables esperados: solo se ha localizado un ECA que comparó la diamorfina con la morfina en pacientes oncológicos incluido en la GPC del NICE (22), que no es aplicable a nuestro contexto dado que la diamorfina no se comercializa ni se usa con esta indicación en España. Por lo tanto, aunque el GEG ha considerado sus resultados, no ha tenido impacto en la formulación de las recomendaciones. Aunque no existe evidencia científica específica en los últimos días de vida, el tratamiento adecuado del dolor puede favorecer la llegada al final de la vida con un nivel de confort y bienestar adecuados. Por lo tanto, el GEG considera que los efectos deseables son sustanciales.

Balance entre efectos deseables e indeseables: a pesar de la ausencia de evidencia científica en esta etapa de la atención, el GEG considera el balance beneficio-riesgo favorable al uso de fármacos del primer escalón de la OMS en casos de dolor leve y de opioides para el control del dolor moderado/grave en la SUD de vida. Las recomendaciones estándar de uso racional de opioides en el dolor crónico (115), teniendo en cuenta a la escalada 
de dosis, pero también en la desescalada o incluso discontinuación, son aplicables en SUD, y pueden ayudar a optimizar el balance beneficio-riesgo. Además, en SUD, algunos efectos adversos como la somnolencia (y/o sedación) pueden ser mejor tolerados. En cada caso, deben valorarse los beneficios y riesgos esperados de forma individualizada, y tener en cuenta las preferencias de los pacientes y sus familias.

\section{De la evidencia a la recomendación}

a) ¿Cuál es la magnitud de los efectos deseables esperados?

- Juicio: grande.

- Evidencia procedente de la investigación: solo se ha localizado un ECA (116) que comparó la diamorfina con la morfina en pacientes oncológicos incluido en la GPC del NICE (22), que no es aplicable a nuestro contexto dado que la diamorfina no se comercializa ni se usa con esta indicación en España. Por lo tanto, aunque el GEG ha considerado sus resultados, no ha tenido impacto en la formulación de las recomendaciones.

- Información adicional: aunque no existe evidencia científica específica en los últimos días de vida, el tratamiento adecuado del dolor puede favorecer la llegada al final de la vida con un nivel de confort y bienestar adecuados. Por lo tanto, a pesar de no existir evidencia científica disponible, la experiencia y conocimiento disponible permiten esperar un razonable beneficio para el paciente.

b) ¿Cuál es la magnitud de los efectos indeseables esperados?

- Juicio: pequeña.

- Evidencia procedente de la investigación: no se ha identificado ningún estudio en SUD.

- Información adicional: los efectos adversos más frecuentes de los analgésicos más habitualmente empleados son: náuseas y/o vómitos, estreñimiento, somnolencia/ sedación, confusión, rigidez generalizada acompañada de mioclonías, dificultad o depresión respiratoria y delirium.

c) ¿Cuál es la certeza global en la evidencia sobre los efectos?

- Juicio: no hay estudios incluidos.

- Evidencia procedente de la investigación: no se ha identificado ningún estudio relevante en población en SUD.

d) ¿Existe incertidumbre o variabilidad importante sobre cómo los pacientes valoran los desenlaces principales?

- Juicio: la incertidumbre o variabilidad probablemente no sean importantes.

- Evidencia procedente de la investigación: no se ha identificado ningún estudio. 
- Información adicional: se han considerado el control del dolor, y la calidad de vida o bienestar como variables críticas para la toma de decisiones, y los efectos adversos, sedación y supervivencia como variables importantes.

Desde el punto de vista del GEG el dolor es uno de los síntomas más temidos en el final de la vida, y no se prevé variabilidad en como los pacientes valoran los desenlaces. Uno de los aspectos a tener en cuenta es que el uso de opioides puede causar somnolencia o sedación, y este puede ser uno de los temas que se prevé que pueda causar alguna variabilidad en las preferencias de los pacientes y sus familias.

e) El balance entre los efectos deseables e indeseables esperados, ¿favorece a la intervención o a la comparación?

- Juicio: probablemente favorece a la intervención.

- Evidencia procedente de la investigación: no se ha identificado ningún estudio en SUD.

- Información adicional: a pesar de la ausencia de evidencia científica en esta etapa de la atención, el GEG considera el balance beneficio-riesgo favorable al uso de fármacos del primer escalón de la OMS en casos de dolor leve y de opioides para el control del dolor moderado/grave en la SUD de vida. Las recomendaciones estándar de uso racional de opioides en el dolor crónico (115), teniendo en cuenta a la escalada de dosis, pero también en la desescalada o incluso discontinuación, son aplicables en SUD, y pueden ayudar a optimizar el balance beneficio-riesgo. Además, en SUD, algunos efectos adversos como la somnolencia (y/o sedación) pueden ser mejor tolerados. En cada caso, deben valorarse los beneficios y riesgos esperados de forma individualizada, y tener en cuenta las preferencias de los pacientes y sus familias.

f) ¿Cuál es la magnitud de los recursos requeridos (costes)?

- Juicio: costes y reducción de costes insignificante.

- Evidencia procedente de la investigación: no se ha localizado ningún estudio que describa de forma explícita el uso de recursos (costes) o estudios de evaluación económica.

- Información adicional: el GEG considera que el coste del tratamiento no es elevado, y que la duración del tratamiento es corta.

g) ¿Cuál es la certeza en torno a la evidencia de los recursos requeridos?

- Juicio: no hay estudios incluidos.

- Evidencia procedente de la investigación: no se ha localizado ningún estudio que describa de forma explícita el uso de recursos (costes) o estudios de evaluación económica.

h) El coste-efectividad de la intervención, ¿favorece a la intervención o a la comparación?

- Juicio: probablemente favorece a la intervención. 
- Evidencia procedente de la investigación: no se ha identificado ningún estudio de evaluación económica.

- Información adicional: el GEG considera que el incremento del coste está justificado en relación al beneficio (control del dolor).

i) ¿Cuál sería el impacto en la equidad en salud?

- Juicio: probablemente aumenta.

- Evidencia procedente de la investigación: no se ha realizado una revisión sistemática sobre el tema.

- Información adicional: desde el punto de vista del GEG es importante promover el manejo correcto del dolor dentro del enfoque global de la atención paliativa, para garantizar que todos los pacientes puedan llegar a la SUD con el dolor controlado.

$\mathrm{Al}$ igual que en el resto de áreas clínicas de esta guía, puede haber diferencias en el control del dolor en enfermedades oncológicas frente a las no oncológicas. Además, puede haber poblaciones especialmente vulnerables debido a la dificultad de expresar el dolor (por ejemplo, personas con deterioro cognitivo, demencia, discapacidad, problemas para la comunicación, o edad avanzada). Por todo ello la implementación de las recomendaciones de esta guía pueden mejorar la equidad en el acceso al tratamiento del dolor en situación de últimos días y en sus resultados. Para conseguir esto es importante la utilización de las escalas más adecuadas para cada paciente, así como el ajuste de dosis de manera individual.

j) ¿Es aceptable la opción para los agentes implicados?

- Juicio: probablemente sí.

- Evidencia procedente de la investigación: no se ha realizado una revisión sistemática sobre el tema.

- Información adicional: desde el punto de vista del GEG los tratamientos para el adecuado control del dolor serán generalmente aceptables por los pacientes y familiares. Sin embargo, el GEG discute que los mitos y miedos que rodean al uso de opioides en profesionales, pacientes y familia pueden ser una de las principales barreras para un manejo adecuado del dolor. Otra barrera para su aceptabilidad podría ser la presencia de efectos adversos o la dificultad de su valoración en algunas situaciones (por ejemplo, en pacientes con demencia o delirium). El correcto uso de opioides (escalada proporcional a la intensidad del dolor, uso de antieméticos, entre otros) puede mejorar la tolerabilidad a los opioides y, por tanto, su aceptabilidad. Además, es importante tener en cuenta las preferencias de los pacientes y sus allegados, y las posibles preocupaciones o dudas que puedan surgir con respecto al efecto de los fármacos empleados para el control del dolor en los últimos días (por ejemplo, sedación o aceleramiento de la muerte).

Si bien se debe siempre perseguir un correcto control del dolor, también debemos explicar al paciente y a los cuidadores que uno de los efectos de la medicación opioide es el aumento del grado de sedación. El paciente puede libremente considerar que un 
nivel mejor de control de dolor puede no ser deseable en esta situación si ello trae implícita una mayor sedación. Inversamente, algunos pacientes pueden aceptar un cierto nivel de sedación para obtener el adecuado control del dolor. Por otra parte, un aumento de los opioides por encima del nivel necesario o su empleo sistemático en ausencia de dolor como complemento para la sedación no son una estrategia correcta.

\section{k) ¿Es factible la implementación de la opción?}

- Juicio: sí.

- Evidencia procedente de la investigación: no se ha realizado una revisión sistemática sobre el tema.

- Información adicional: las principales cuestiones relacionadas con la factibilidad pueden ser las descritas previamente en relación a la aceptabilidad: formación de los profesionales y visión de los pacientes y sus familias. Paralelamente, se debe informar adecuadamente sobre el manejo del dolor (especialmente de opioides) y sobre los efectos secundarios esperables y las pautas de adecuación a pacientes y familiares. Otra cuestión importante que el grupo ha intentado enfatizar en las recomendaciones es que, en presencia de dolor, se debe valorar el establecimiento de pautas de rescate previas y formar al paciente y a los cuidadores y/o familiares para que puedan administrarlas sin necesidad de una presencia continua del personal sanitario, cuando ello es posible.

\section{l) Otras consideraciones}

El GEG está de acuerdo en la relevancia de los CP precoces y de la atención paliativa como un continuum que desemboca en una SUD, entendiendo que el correcto control del dolor debe comenzar en etapas previas a la SUD. Al igual que en el manejo de otros síntomas, la prescripción anticipada (prescripción de fármacos en previsión de la aparición síntomas, con el objetivo de favorecer un alivio rápido si el paciente desarrolla dichos síntomas), junto con formación específica a la familia/cuidadores para su manejo, son herramientas fundamentales para el control del dolor. Es decir, la etapa final de vida no debería ser sino una etapa más del continuum de los cuidados de las enfermedades avanzadas y progresivas. Por ello la buena práctica clínica en etapas anteriores suele repercutir en una mejor gestión de la SUD.

El GEG ha discutido sobre la relevancia de la formación en manejo del dolor para los profesionales sanitarios implicados en la atención en SUD, y aunque no ha generado una recomendación específica, ha concluido que las carencias actuales en formación reglada podrían suponer una barrera independiente para el correcto manejo del dolor en SUD. Además, se discute sobre la barrera que suponen las creencias de sanitarios, cuidadores y pacientes sobre las consecuencias de emplear dosis altas de opioides, tanto en un supuesto acortamiento del tiempo de supervivencia (no demostrado) $(117,118)$, como en un aumento de la sedación. Por ello se han considerado estas barreras en el análisis de la aceptabilidad y factibilidad.

El GEG considera que la valoración del dolor es fundamental para su control efectivo. Aunque no se ha llevado a cabo una revisión sistemática específica sobre el tema, se 
han realizado recomendaciones de buena práctica clínica, siguiendo las recomendaciones generales para la evaluación del dolor. Se considera que la escala visual analógica (EVA), o alguna de las otras escalas unidimensionales de valoración del dolor, siguen siendo de elección. En aquellas situaciones en las que estas escalas no son aplicables no existe un consenso claro sobre cual/es serían de elección, pero las más empleadas en CP son la escala de expresión facial, escala de Campbell o la PAINAD (Pain Assessment in Advanced Dementia) (escalas conductuales) (ver anexo 4). También consideramos que la familia/ cuidadores pueden ser una fuente de información sobre dolor y otras fuentes de inquietud, cuando el deterioro del paciente impide una obtención directa de información o como complemento a esta.

Se expone la sensación basada en la experiencia clínica de los miembros del GEG de una tendencia importante a la indicación de opioides incluso en ausencia de dolor, especialmente en pacientes oncológicos, y por ese motivo se recomienda no prescribir analgésicos de forma sistemática, si no de forma individualizada en función de las necesidades actuales y/o anticipadas.

Se discute que en un dolor de inicio reciente o en una descompensación del dolor basal, aunque se trate de una SUD, debe explorarse la posibilidad de una causa reversible tratable (como la retención urinaria, angustia o la impactación fecal).

El GEG discute la indicación concreta de uno u otro grupo de fármacos. Finalmente, decide establecer los opioides como fármaco de elección en la SUD para el dolor moderado/ grave, siempre sujeto al cumplimiento de las normas estándar de ajuste de tratamiento en función de la intensidad del dolor, balance riesgo-beneficio, efectos secundarios, y descarte previo de causas reversibles y posibilidad de manejo no farmacológico, por:

- la posibilidad de aumento progresivo de dosis según aumento de necesidades sin techo terapéutico,

- la disponibilidad de vías de administración alternativas a la oral, que es reducida en la mayoría de pacientes en SUD,

- la rapidez en lograr un correcto control del dolor.

Si bien no hay una evidencia concreta en situación de últimos días, el grupo considera que la medicación específica para el dolor neuropático debe mantenerse en la medida de lo posible si ya estaba pautada y era efectiva, salvo presencia de efectos adversos no tolerados o pérdida de la vía oral. El inicio de medicación específica para el dolor neuropático en situación de últimos días no parece razonable debido al largo tiempo de inicio de acción que presentan todos estos fármacos.

\subsection{Disnea}

\section{Contexto}

La disnea es la sensación subjetiva de falta de respiración o "hambre de aire", no siempre relacionada con la presencia de hipoxemia ni con los cambios en el ritmo respiratorio habituales en la SUD. Es uno de los síntomas más angustiosos y su frecuencia aumenta al acercarse al final de la vida $(119,120)$. 
La etiología de la disnea en la SUD es multifactorial: enfermedad neoplásica avanzada, EPOC, insuficiencia cardíaca, infección respiratoria, acidosis metabólica y anemia. La disnea ocurre cuando se precisa mayor esfuerzo respiratorio para superar obstrucción o una restricción producida por la enfermedad, cuando se precisan más músculos respiratorios para mantener una adecuada respiración (enfermedades neuromusculares, caquexia) o cuando hay un incremento de las necesidades ventilatorias (acidosis metabólica) (113).

\section{Recomendaciones}

1. Se recomienda mantener o iniciar el tratamiento específico si se conoce el problema que causa la disnea (por ejemplo, edema pulmonar o derrame pleural) y el balance beneficio-riesgo individualizado es favorable [BPC, adaptada].

2. Se recomienda realizar inicialmente un manejo no farmacológico de la disnea en una persona en los últimos días de vida, asociado a las medidas farmacológicas en caso de ser necesario [BPC, adaptada].

3. Se recomienda ofrecer una prueba terapéutica de oxigenoterapia independiente de la hipoxemia en caso de que las medidas no farmacológicas no produzcan un alivio de la disnea, y mantenerla si el paciente/familia perciben un beneficio [BPC, nueva].

4. Se recomienda añadir tratamiento sintomático si el control de la disnea es inadecuado con las medidas previas: morfina, midazolam, o la combinación de ambos [Débil a favor, adaptada].

\section{Consideraciones clínicas relevantes}

- Para la evaluación de la disnea pueden emplearse escalas que permitan monitorizar el efecto de las medidas aplicadas como la escala EVA, la NYHA (121) o la de Borg (122) y, en los pacientes que no pueden comunicarse, la escala Respiratory Distress Observation Scale (RDOS) (123).

- Algunas medidas objetivas como la frecuencia respiratoria, la saturación de oxígeno o el uso de la musculatura accesoria tienen una pobre correlación con la sensación subjetiva de disnea por lo que no deben usarse para iniciar o modificar tratamientos.

- Las medidas no farmacológicas se presentan en el anexo 5.

- En situaciones de crisis de disnea o disnea irruptiva, que son una emergencia paliativa en las que su control debe ser rápido, los opioides o benzodiazepinas (generalmente combinados) se utilizarán en formulaciones de acción rápida. Los medicamentos más habitualmente utilizados, sus dosis y principales características se resumen en el anexo 10 .

\section{Justificación}

Se han emitido tres recomendaciones de buena práctica clínica orientadas a la indicación de tratamiento farmacológico y al inicio de medidas no farmacológicas. La recomendación sobre el uso de fármacos (opioides, benzodiacepina (BDZ) y su combinación) es débil a favor teniendo en cuenta la calidad de la evidencia y el balance beneficio-riesgo. 


\section{Justificación detallada}

Certeza global en la evidencia sobre los efectos: la calidad global de la evidencia considerada es de moderada a muy baja, y procede de tres estudios (dos ECA y un estudio comparativo no aleatorizado) con limitaciones metodológicas. Los resultados no han podido meta-analizarse teniendo en cuenta la variabilidad en los diseños y variables de resultado. Las variables calidad de vida y supervivencia no se consideraron en ninguno de los estudios, mientras que la sedación solo se consideró en uno de los estudios.

Balance beneficio-riesgo: teniendo en cuenta que la disnea en los últimos días es un síntoma que genera un importante malestar en los pacientes y su relación e interacción con otros síntomas (como por ejemplo la ansiedad) es importante establecer medidas terapéuticas apropiadas y que permitan su control y con ello aliviar el sufrimiento, teniendo en cuenta intervenciones farmacológicas y no farmacológicas. Los opioides, BDZ y su combinación podrían ser opciones terapéuticas beneficiosas, pero siempre será necesario tener en cuenta los efectos adversos asociados.

\section{De la evidencia a la recomendación}

a) ¿Cuál es la magnitud de los efectos deseables esperados?

- Juicio: variable.

- Evidencia procedente de la investigación: existe evidencia de dos ECA y un estudio comparativo no aleatorizado considerados en la GPC del NICE (22). No se ha localizado ningún estudio posterior que cumpla con los criterios de inclusión.

En la actualización de la búsqueda no se identificó ningún estudio primario adicional ni evaluación económica. Se identificaron dos revisiones Cochrane sobre opioides para la disnea refractaria en pacientes con enfermedad avanzada y terminal (124) y sobre benzodiacepinas para el tratamiento de la disnea en enfermedades oncológicas y no oncológicas (125), pero solo se incluyó un único estudio con pacientes en situación terminal (Navigante et al., 2006) (126) (ya incluido en la GPC del NICE).

\section{Morfina versus midazolam versus combinación de morfina y midazolam}

Existe evidencia de moderada-baja calidad derivada del ECA realizado por Navigante et al. (126) ( $\mathrm{n}=101$, pacientes con cáncer hospitalizados y pronóstico de menos de una semana) que sugiere que la combinación de morfina y midazolam fue más beneficiosa clínicamente que ambos fármacos de forma individual para conseguir un alivio de la disnea a las 24 y 48 horas de su inicio. Sin embargo, en este mismo estudio no se encontraron diferencias entre la combinación de morfina y midazolam frente a la morfina sola en la intensidad de la disnea a las 24 o 48 horas.

Oxígeno versus aire

Existe evidencia de muy baja calidad de un ECA cruzado en pacientes con cáncer terminal (Booth et al., 1996 (127), $\mathrm{n}=38$, media de supervivencia 19 días) que sugiere que no hay diferencias entre oxígeno y aire proporcionados por cánula nasal en la intensidad de la disnea (medida a los 15 minutos de la administración). No se reportaron efectos adversos en ninguno de los grupos. 


\section{Oxígeno versus morfina o hidromorfona versus aire}

Existe evidencia de muy baja calidad de un estudio prospectivo no aleatorizado [Clemens et al., 2009 (128)]; en personas con enfermedad incurable $(\mathrm{n}=46)$ a las que se les proporcionaron las intervenciones secuencialmente, que sugiere que los opioides son más beneficiosos en comparación con el oxígeno o el aire en la reducción de la disnea. También existe evidencia de muy baja calidad del mismo estudio, que sugiere que no hay diferencias entre el oxígeno y aire en la reducción de la disnea.

b) ¿Cuál es la magnitud de los efectos indeseables esperados?

- Juicio: pequeña.

- Evidencia procedente de la investigación: los estudios incluidos no reportaron efectos adversos.

- Información adicional: los efectos indeseables son los derivados de los efectos secundarios de opioides y BDZ, principalmente la disminución del nivel de alerta y la posibilidad de depresión del centro respiratorio. Esto se reduce con la utilización de opioide y BDZ en dosis bajas y siempre proporcionales al grado de disnea y sufrimiento.

c) ¿Cuál es la certeza global en la evidencia sobre los efectos?

- Juicio: baja.

- Evidencia procedente de la investigación: la calidad global de la evidencia considerada es de moderada a muy baja, y procede de tres estudios [dos ECA $(126,127)$ y un estudio comparativo no aleatorizado (128)] con limitaciones metodológicas. Los resultados no han podido meta-analizarse teniendo en cuenta la variabilidad en los diseños y variables de resultado. Las variables calidad de vida y supervivencia no se consideraron en ninguno de los estudios, mientras que la sedación solo se consideró en uno de los estudios.

d) ¿Existe incertidumbre o variabilidad importante sobre cómo los pacientes valoran los desenlaces principales?

- Juicio: la incertidumbre o variabilidad probablemente no sean importantes.

- Evidencia procedente de la investigación: no se ha realizado una revisión sistemática sobre el tema.

- Información adicional: se consideraron variables de resultado claves el control de síntomas y la calidad de vida. También se consideraron importantes los eventos adversos, sedación y el tiempo de supervivencia.

Desde el punto de vista del GEG la incertidumbre o variabilidad probablemente no sean importantes, teniendo en cuenta que es un síntoma limitante que causa elevado sufrimiento y de difícil control, siendo la segunda causa de sedación paliativa en algunas series (113). 
e) El balance entre los efectos deseables e indeseables esperados, ¿favorece a la intervención o a la comparación?

- Juicio: probablemente favorece a la intervención.

- Evidencia procedente de la investigación: teniendo en cuenta que la disnea en los últimos días es un síntoma que genera un importante malestar en los pacientes y su relación e interacción con otros síntomas (como por ejemplo la ansiedad) es importante establecer medidas terapéuticas apropiadas y que permitan su control y con ello aliviar el sufrimiento, teniendo en cuenta intervenciones farmacológicas y no farmacológicas. Los opioides, BDZ y su combinación podrían ser opciones terapéuticas beneficiosas, pero siempre será necesario tener en cuenta los efectos adversos asociados.

f) ¿Cuál es la magnitud de los recursos requeridos (costes)?

- Juicio: costes y reducción de costes insignificante.

- Evidencia procedente de la investigación: no se ha localizado ningún estudio que describa de forma explícita el uso de recursos (costes) o estudios de evaluación económica.

- Información adicional: los fármacos y medidas recomendadas no tienen un coste elevado ni una duración prolongada.

g) ¿Cuál es la certeza en torno a la evidencia sobre los recursos requeridos?

- Juicio: no hay estudios incluidos.

- Evidencia procedente de la investigación: no se ha localizado ningún estudio que describa de forma explícita el uso de recursos (costes) o estudios de evaluación económica.

- Información adicional: el coste de los fármacos y medidas recomendadas es razonable teniendo en cuenta que el mal control de la disnea puede originar la utilización de tratamientos específicos o la realización de pruebas diagnósticas o incluso el ingreso hospitalario.

h) La relación coste-efectividad, ¿favorece a la intervención o a la comparación?

- Juicio: probablemente favorece a la intervención.

- Evidencia procedente de la investigación: no se ha localizado ningún estudio de evaluación económica.

- Información adicional: se podría considerar que la relación coste efectividad favorece a la intervención, al no tener un coste o duración elevada.

i) ¿Cuál sería el impacto en la equidad en salud?

- Juicio: probablemente aumenta.

- Evidencia procedente de la investigación: no se ha realizado una revisión sistemática sobre el tema. 
- Información adicional: la equidad dependerá de que los profesionales que atienden al paciente en SUD apliquen estas medidas que se pueden aplicar en cualquier ámbito asistencial. La implementación de las recomendaciones podría aumentar la equidad.

\section{j) ¿Es aceptable la opción para los agentes implicados?}

- Juicio: probablemente sí.

- Evidencia procedente de la investigación: no se ha realizado una revisión sistemática sobre el tema.

- Información adicional: la disnea y la taquipnea asociada originan un gran malestar y sufrimiento a los pacientes y familiares y su presencia se identifica con mal final de la vida. Debido a ello, el GEG considera que la aceptabilidad de los tratamientos por parte de pacientes y familias será buena salvo que se produzca la aparición de efectos secundarios, sobre todo disminución del nivel de alerta o sedación no deseada. A este respecto la utilización de dosis proporcionadas es clave.

k) ¿Es factible la implementación de la opción?

- Juicio: sí.

- Evidencia procedente de la investigación: no se ha realizado una revisión sistemática sobre el tema.

- Información adicional: no se han identificado factores que puedan afectar de forma sustancial a la factibilidad de las recomendaciones.

\section{I) Otras consideraciones}

El GEG discute que a pesar de la ausencia de evidencia científica está de acuerdo en que el tratamiento de la disnea en la SUD es similar al de etapas anteriores de la atención paliativa y debe basarse en:

- Medidas no farmacológicas (que hay que aplicar siempre y desde el inicio) (ver anexo 4).

- Tratamiento específico de la etiología, que implicará en ocasiones la realización de pruebas. Su aplicación dependerá de una valoración cuidadosa e individualizada de beneficios/inconvenientes en esta fase de SUD, así como de la aceptación por parte del paciente/familia.

- Administración de oxígeno solo si produce una mejoría de la disnea, independientemente de datos objetivos como la hipoxemia o la taquipnea.

- Tratamiento paliativo sintomático (que es el que se desarrolla en esta pregunta clínica) que incluye oxígeno, opioides y benzodiacepinas. Su aplicación será progresiva en función de la intensidad de la disnea y grado de control.

- Sedación paliativa. De aplicación en disnea refractaria a las medidas anteriores.

En cuanto al tratamiento etiológico (por ejemplo, antibióticos, corticoesteroides, broncodilatadores) el GEG está de acuerdo en que, aunque su beneficio (eficacia) se puede extrapolar de estudios realizados en pacientes con mayor supervivencia, el beneficio 
real para el paciente en SUD puede ser menor que en fases previas de su enfermedad, así como pueden cambiar los deseos/valores del paciente y su familia. El GEG considera que algunas intervenciones invasivas como la toracocentesis no son apropiadas en el escenario de SUD, y en el caso del uso de ventilación no invasiva con presión positiva u oxígeno a alto flujo, su balance beneficio-riesgo podría ser desfavorable en la mayoría de los pacientes.

\subsection{Náuseas y vómitos}

\section{Contexto}

Las náuseas y los vómitos son síntomas frecuentes al final de la vida. Podrían afectar a un 40-70 \% de pacientes oncológicos (129) y también son muy frecuentes en enfermedades no oncológicas $(130,131)$. Pueden causar un importante malestar físico y psicológico en los pacientes y en sus familias, debido que además del disconfort que producen, suelen ir acompañados de otros síntomas autonómicos como taquicardia o diarrea.

La etiología de las náuseas y vómitos en los últimos días de vida es multifactorial, especialmente en pacientes oncológicos.

\section{Recomendaciones}

1. Se recomienda evaluar las causas de las náuseas y vómitos en situación de últimos días de manera proporcionada. Entre las causas podrían incluirse [BPC, adaptada]:

- Algunos fármacos.

- Quimioterapia y radioterapia.

- Causas psicológicas.

- Causas bioquímicas, por ejemplo, hipercalcemia.

- Presión intracraneal elevada.

- Trastornos de la motilidad gastrointestinal.

- Obstrucción intestinal.

2. Se recomienda considerar medidas no farmacológicas para tratar las náuseas y vómitos en personas en situación de los últimos días de vida [BPC, adoptada].

3. Para el tratamiento de las náuseas y vómitos en personas con obstrucción intestinal se sugiere, además del resto de medidas farmacológicas y no farmacológicas [Débil a favor, adaptada]:

- Butilbromuro de hioscina o escopolamina como tratamiento antisecretor de primera línea.

- Octreótido si los síntomas no mejoran a las 24 horas del tratamiento con butilbromuro de hioscina.

4. En el resto de situaciones clínicas se sugiere emplear la medicación antiemética estándar en la atención paliativa: neurolépticos, antihistamínicos, procinéticos, antagonistas 5 HT3, corticoides y benzodiacepinas [BPC, nueva]. 


\section{Consideraciones clínicas relevantes}

- Las medidas no farmacológicas se presentan en el anexo 6.

- Los medicamentos más habitualmente utilizados, sus dosis y principales características se resumen en el anexo 10.

- En la elección de fármacos para el tratamiento de las náuseas y vómitos se deberá tener en cuenta:

- Las causas probables y su reversibilidad.

- El perfil de seguridad.

- Otros síntomas que pueden coexistir.

- El balance de los efectos cuando se manejan otros síntomas.

- Compatibilidad e interacciones farmacológicas.

\section{Justificación}

Se han emitido dos recomendaciones de buena práctica clínica orientadas a la evaluación de las causas de náuseas y vómitos y al inicio de medidas no farmacológicas. En casos de obstrucción intestinal se ha emitido una recomendación débil a favor teniendo en cuenta la calidad de la evidencia; para el resto de escenarios clínicos se ha realizado una recomendación de buena práctica clínica debido a la ausencia de estudios en la situación de últimos días.

\section{Justificación detallada}

Calidad de la evidencia (certeza): no se han encontrado ECAs para los antieméticos estándar en SUD. Globalmente la calidad de la evidencia es muy baja para todas las variables evaluadas, y centrada en la efectividad de la hioscina butilbromuro y el octeótrido en personas con obstrucción intestinal. Ningún estudio incluyó resultados sobre el efecto de los tratamientos en calidad de vida y la sedación se valoró en dos estudios, pero con medidas subrogadas (somnolencia y fatiga). Las muestras de los estudios eran pacientes con cáncer y obstrucción intestinal no candidatos a cirugía, en uno de ellos los pacientes no se encontraban en los últimos días de vida (aunque se incluyó porque se recogieron los resultados hasta el último día de vida). El tamaño muestral de dos de los estudios incluidos era muy pequeño $(n=15$ y $n=17)$, y en el que incluyó una muestra mayor $(n=68)$ hubo una alta tasa de abandonos. Además, los datos no han podido agregarse debido a las diferencias en las dosis y pautas de tratamiento.

Balance entre los efectos deseables e indeseables esperados: la evidencia sobre la eficacia de los dos fármacos evaluados no es concluyente. Dos de los ECA incluidos encontraron un beneficio clínico del octreótido en comparación con la hioscina butilbromuro en el control de las náuseas y la frecuencia de los vómitos, aunque uno de ellos solo mostró beneficios cuando se empleó en el ámbito domiciliario y no en el hospitalario. El tercer ECA no encontró diferencias entre los dos fármacos en el control de las náuseas. En cuanto a la seguridad, en dos de los estudios no se encontraron diferencias en los síntomas boca seca y mareo. 
Desde el punto de vista del GEG la medicación antiemética en los últimos días presenta un balance beneficio-riesgo favorable (y en el caso específico de obstrucción intestinal tanto la hioscina butilbromuro como el octreótido).

\section{De la evidencia a la recomendación}

a) ¿Cuál es la magnitud de los efectos deseables esperados?

- Juicio: grande.

- Evidencia procedente de la investigación: la GPC del NICE incluyó 3 ECA (132-135) que compararon hioscina butilbromuro frente a octreótido (ambos por vía subcutánea) en pacientes oncológicos con obstrucción intestinal. En la actualización de la búsqueda no se identificó ningún estudio primario adicional ni evaluación económica.

Se identificaron 5 revisiones Cochrane sobre diferentes fármacos (levopremomazina, droperidol, corticoides, haloperidol y olanzapina) para el tratamiento de las náuseas/vómitos en atención paliativa (136-140) pero ninguna de ellas abordó específicamente los últimos días de vida, ni incluyeron estudios que cumpliesen los criterios de inclusión/excusión de esta revisión.

De los estudios incluidos en la GPC del NICE, uno de ellos $(\mathrm{n}=15)$ mostró mayor beneficio clínico del octreótrido tanto en el ámbito hospitalario como en el domiciliario $(134,135)$. Sin embargo, otro estudio $(n=17)$ encontró beneficios en el manejo de las náuseas para el octreótido en el ámbito domiciliario, pero no en el hospital (133). El tercer estudio ( $n=68)$, realizado únicamente en el ámbito domiciliario, no encontró diferencias clínicas entre ambos fármacos en el efecto en las náuseas y los vómitos (132).

- Información adicional: desde el punto de vista del GEG y su experiencia en la práctica clínica, la medicación antiemética estándar en CP es efectiva en SUD.

b) ¿Cuál es la magnitud de los efectos indeseables esperados?

- Juicio: pequeña.

- Evidencia procedente de la investigación: dos de los estudios incluidos analizaron las diferencias entre el butilbromuro de hioscina y el octeótrido, y no encontraron diferencias entre ambos en los efectos adversos boca seca y sedación/mareo (133-135).

- Información adicional: desde el punto de vista del GEG los fármacos más frecuentemente empleados en la práctica clínica son generalmente bien tolerados.

c) ¿Cuál es la certeza global en la evidencia sobre los efectos?

- Juicio: muy baja.

- Evidencia procedente de la investigación: no se han encontrado ECAs para los antieméticos estándar en SUD. Globalmente la calidad de la evidencia es muy baja para todas las variables evaluadas, y centrada en la efectividad de la hioscina butilbromuro y el octeótrido en personas con obstrucción intestinal. Ningún estudio incluyó resultados sobre el efecto de los tratamientos en calidad de vida y la sedación se valoró en 
dos estudios, pero con medidas subrogadas (somnolencia y fatiga). Las muestras de los estudios son pacientes con cáncer y obstrucción intestinal no candidatos a cirugía, en uno de ellos los pacientes no se encontraban en los últimos días de vida (aunque se incluyó porque se recogieron los resultados hasta el último día de vida).

El tamaño muestral de dos de los estudios es muy pequeño ( $\mathrm{n}=15 \mathrm{y} n=17)$, y en el que incluyó una muestra mayor $(\mathrm{n}=68)$ hubo una alta tasa de abandonos. Además, los datos no han podido agregarse debido a las diferencias en las dosis y pautas de tratamiento.

d) ¿Existe incertidumbre o variabilidad importante sobre cómo los pacientes valoran los desenlaces principales?

- Juicio: la incertidumbre o variabilidad probablemente no sean importantes.

- Evidencia procedente de la investigación: no se ha realizado una revisión sistemática sobre el tema.

- Información adicional: se consideraron variables de resultado claves el control de las náuseas, número de episodios de vómitos y calidad de vida. También se consideraron como variables importantes los eventos adversos, la sedación y el tiempo de supervivencia.

El GEG considera que la variabilidad sobre como los pacientes valoran los resultados probablemente no sea importante.

e) El balance entre los efectos deseables e indeseables esperados, ¿favorece a la intervención o a la comparación?

- Juicio: probablemente favorece a la intervención.

- Evidencia procedente de la investigación: la evidencia sobre la eficacia de los dos fármacos evaluados no es concluyente. Dos de los ECA incluidos encontraron un beneficio clínico del octreótido en comparación con la hioscina butilbromuro en el control de las náuseas y la frecuencia de los vómitos, aunque uno de ellos solo mostró beneficios cuando se empleó en el ámbito domiciliario y no en el hospitalario. El tercer ECA no encontró diferencias entre los dos fármacos en el control de las náuseas. En cuanto a la seguridad, en dos de los estudios no se encontraron diferencias en los síntomas boca seca y mareo.

- Información adicional: desde el punto de vista del GEG la medicación antiemética en los últimos días presenta un balance riesgo-beneficio favorable (y en el caso específico de obstrucción intestinal tanto la hioscina butilbromuro como el octreótido).

f) ¿Cuál es la magnitud de los recursos requeridos (costes)?

- Juicio: variable.

- Evidencia procedente de la investigación: no se ha localizado ningún estudio que describa de forma explícita el uso de recursos (costes) o estudios de evaluación económica. 
- Información adicional: el octreótido es más caro que la hioscina de butilbromuro y, por lo tanto, debido a que la evidencia sugiere que podrían ser igual de efectivos y seguros, se ha recomendado la opción menos costosa como primera línea de tratamiento.

g) ¿Cuál es la certeza en torno a la evidencia sobre los recursos requeridos?

- Juicio: no hay estudios incluidos.

- Evidencia procedente de la investigación: no se ha localizado ningún estudio que describa de forma explícita el uso de recursos (costes) o estudios de evaluación económica.

- Información adicional: se han tenido en cuenta los costes unitarios de los diferentes fármacos.

h) La relación coste-efectividad, ¿favorece a la intervención o a la comparación?

- Juicio: probablemente favorece a la intervención.

- Evidencia procedente de la investigación: no se ha localizado ningún estudio de evaluación económica.

- Información adicional: en los casos de obstrucción intestinal se ha recomendado la opción menos costosa como primera línea, al presentar un balance beneficio-riesgo similar.

i) ¿Cuál sería el impacto en la equidad en salud?

- Juicio: probablemente aumenta.

- Evidencia procedente de la investigación: no se ha realizado una revisión sistemática sobre el tema.

- Información adicional: no se ha identificado ningún aspecto específico que pueda afectar a la equidad. Dependerá que los profesionales que atienden al paciente en SUD apliquen los tratamientos que permitan controlar las náuseas y vómitos, que se pueden emplear en cualquier ámbito asistencial.

\section{j) ¿Es aceptable la opción para los agentes implicados?}

- Juicio: probablemente sí.

- Evidencia procedente de la investigación: no se ha realizado una revisión sistemática sobre el tema.

- Información adicional: teniendo en cuenta el malestar que producen los síntomas evaluados, el GEG considera que el uso de medidas no farmacológicas y de fármacos puede ser aceptable para la mayoría de pacientes y familiares.

Aunque desde el punto de vista del GEG los fármacos habitualmente empleados para el control de las náuseas y los vómitos son bien tolerados, es importante tener en cuenta que algunos de ellos pueden producir sedación (por ejemplo, agentes antipsicóticos). 
k) ¿Es factible la implementación de la opción?

- Juicio: sí.

- Evidencia procedente de la investigación: no se ha realizado una revisión sistemática sobre el tema.

- Información adicional: no se han identificado factores que puedan afectar de forma sustancial a la factibilidad de las recomendaciones.

\section{I) Otras consideraciones}

Aunque el tratamiento de las náuseas y vómitos relacionados con la quimioterapia y radioterapia está apoyado en evidencia derivada de ensayos controlados aleatorizados, no existe evidencia de buena calidad para otras indicaciones de náuseas y vómitos, especialmente en la situación de últimos días. Por ello, una de las aproximaciones más extendidas en otras guías es la recomendación de diferentes tratamientos según la causa de las náuseas y/o vómitos, por ejemplo $(20,141,142)$.

Por ello, el GEG enfatiza la importancia de una adecuada valoración de los mecanismos etiológicos y los factores implicados para poder iniciar un tratamiento individualizado, considerando los riesgos y beneficios de la medicación. A la hora de la selección de un fármaco determinado es importante considerar que puede ser efectivo para más de un síntoma que esté experimentando el paciente.

Se resalta la importancia de la prevención de la aparición de náuseas y vómitos vigilando, sobre todo en los casos en los que las causas puedan ser potencialmente evitables o tratables, los efectos secundarios de los tratamientos, la presencia de ileo adinámico, estreñimiento u obstrucción intestinal. Al igual que en el resto de síntomas en el final de la vida, será importante considerar medidas no farmacológicas.

En aquellos casos en los que los pacientes llegan a los últimos días con algún tratamiento antiemético, puede producirse un empeoramiento debido a la progresión de la enfermedad. En estos casos puede ser necesario valorar un aumento de dosis o el cambio a otras alternativas terapéuticas o cambio en la vía de administración.

\subsection{Ansiedad y delirium}

\section{Contexto}

La ansiedad se define como una respuesta anticipatoria de un peligro o amenaza futura, acompañada de un sentimiento de disforia desagradable, síntomas somáticos de tensión o conductas evitativas.

El delirium es un estado confusional agudo y fluctuante que resulta de una disfunción cerebral difusa. Clínicamente se caracteriza por la alteración simultánea de la atención y del nivel de consciencia, con cambios en la cognición y la percepción. Cuando se produce en SUD se denomina delirium terminal.

Tanto la ansiedad como el delirium pueden desembocar en un estado de agitación, siendo a veces difícil discernir en SUD si la causa de la agitación es un trastorno psicoemo- 
cional o un delirium terminal. Todos ellos son síntomas frecuentes en los últimos días de vida y producen un importante sufrimiento en el paciente y sus familias (143).

Algunas estimaciones indican que el delirium podría estar presente en el $90 \%$ de los pacientes en los últimos días de vida (144). El delirium puede ser hiperactivo (con agitación), hipoactivo o mixto. El delirium hiperactivo es una complicación que dificulta enormemente el cuidado del paciente en el domicilio y frecuentemente es refractario, siendo una de las principales causas de sedación. El delirium está asociado a una menor supervivencia, a un peor control de otros síntomas, dificulta la comunicación y el proceso de toma de decisiones. Además, causa intenso estrés a los cuidadores y profesionales sanitarios.

\section{Recomendaciones}

1. Se recomienda evaluar la presencia de ansiedad y delirium (con o sin agitación) en todo paciente en situación de últimos días [BPC, nueva].

2. Se recomienda explorar y manejar de manera proporcionada a la situación de últimos días y deseos del paciente y sus allegados, las posibles causas de ansiedad o delirium, por ejemplo, dolor, retención urinaria o impactación fecal [BPC, adaptada].

3. Se recomienda aplicar medidas no farmacológicas de prevención y manejo de la ansiedad y el delirium. Se recomienda realizar soporte y educación a la familia [BPC, adaptada]

4. Se recomienda considerar el uso de benzodiazepinas para controlar la ansiedad [BPC, adaptada].

5. Se recomienda considerar el uso de un medicamento antipsicótico clásico para controlar el delirium, y en caso de ausencia de respuesta su combinación con benzodiacepinas [BPC, adaptada].

\section{Consideraciones clínicas relevantes}

- Para la evaluación de la ansiedad puede emplearse la escala Hospital Anxiety and Depression Scale (HADS) (145) o la escala ESAS (110).

- Para evaluar el delirium existen instrumentos útiles en la práctica habitual como la pregunta de cribado Single Question in Delirium (SQiD) (146), el Confusion Assessment Method (CAM) (147) o el test 4AT de detección rápida (148). Otros instrumentos como el Memorial Delirium Assessment Scale (MDAS) (149) o el Delirium Rating Scale-Revised-98 (DRS-R-98) (150) son más extensos y complejos para la práctica clínica habitual.

- Las medidas no farmacológicas se presentan en el anexo 7.

- Los medicamentos más habitualmente utilizados, sus dosis y principales características se resumen en el anexo 10.

- Se mantendrá u optimizará el tratamiento psicofarmacológico previo, en pacientes que ya estaban en tratamiento y estaba siendo efectivo.

- En SUD la causa del delirium suele ser multifactorial, sin un factor claramente tratable. Algunas de las causas más frecuentes son descompensaciones agudas que pueden provocar delirium, por lo tanto, se deberá tener en cuenta: 
- El mal control del dolor en paciente con un dolor previo estable.

- La necesidad de escalada rápida de la dosis de opioide por dolor no controlado.

- La ansiedad, depresión e insomnio o cambios de conducta intensos sin antecedentes previos.

- El predominio nocturno de las quejas de dolor y ansiedad.

- La retención urinaria y/o rectal.

- Además de las medidas no farmacológicas para la prevención y/o el control de la ansiedad y el delirium, también son importantes las medidas para prevenir accidentes o que la persona se autolesione.

\section{Justificación}

Se han emitido cinco recomendaciones de buena práctica clínica orientadas a mejorar la evaluación y la aplicación de medidas no farmacológicas. Dado que no se han localizado estudios que evalúen la efectividad y seguridad de los fármacos para el tratamiento de la ansiedad y el delirium en situación de últimos días, se recomiendan los fármacos más empleados en la práctica clínica y con más experiencia en su uso en esta fase.

\section{Justificación detallada}

No aplicable.

\section{De la evidencia a la recomendación}

a) ¿Cuál es la magnitud de los efectos deseables esperados?

- Juicio: grande.

- Evidencia procedente de la investigación: no se han identificado estudios.

- Información adicional: el GEG está de acuerdo en la importancia del manejo de estos síntomas y realizar recomendaciones, a pesar de la ausencia de evidencia científica. Por lo tanto, se han recomendado los fármacos más empleados en la práctica clínica y con más experiencia en su uso.

b) ¿Cuál es la magnitud de los efectos indeseables esperados?

- Juicio: variable.

- Evidencia procedente de la investigación: no se han identificado estudios.

- Información adicional: los fármacos recomendados pueden causar sedación no deseada. Los antipsicóticos pueden provocar síntomas extrapiramidales, particularmente relevantes en subgrupos de pacientes (como pacientes con Parkinson). Los riesgos en cada caso deberán ser comunicados al paciente y su familia y ser tenidos en cuenta en la toma de decisiones.

c) ¿Cuál es la certeza global en la evidencia sobre los efectos?

- Juicio: no hay estudios incluidos. 
- Evidencia procedente de la investigación: no se ha localizado ningún estudio que cumpliese los criterios de inclusión sobre el manejo de la ansiedad y el delirium en la situación de últimos días.

En la GPC del NICE (22) tampoco localizaron ningún estudio para el manejo de estos síntomas, al igual que otras revisiones recientes (151-153).

d) ¿Existe incertidumbre o variabilidad importante sobre cómo los pacientes valoran los desenlaces principales?

- Juicio: la incertidumbre o la variabilidad probablemente no sean importantes.

- Evidencia procedente de la investigación: no se ha realizado una revisión sistemática del tema.

- Información adicional: se consideraron variables de resultado claves el control de los síntomas, número de episodios y calidad de vida. También se consideraron como variables importantes los eventos adversos, la sedación y el tiempo de supervivencia.

Desde el punto de vista del GEG la variabilidad en como los pacientes valoran los resultados probablemente no sea importante, teniendo en cuenta la naturaleza de los síntomas.

e) El balance entre los efectos deseables e indeseables, ¿favorece a la intervención o a la comparación?

- Juicio: probablemente favorece a la intervención.

- Evidencia procedente de la investigación: el GEG está de acuerdo en que es importante el manejo de estos síntomas debido a su importante impacto y en que el balance beneficio-riesgo de los fármacos más empleados es favorable. Además, el adecuado manejo de la ansiedad y el delirium puede prevenir estados de agitación.

f) ¿Cuál es la magnitud de los recursos requeridos (costes)?

- Juicio: costes y reducción de costes insignificante.

- Evidencia procedente de la investigación: no se ha localizado ningún estudio que describa de forma explícita el uso de recursos (costes) o estudios de evaluación económica.

- Información adicional: se han considerado los costes unitarios de los principales fármacos recomendados, y no hay diferencias sustanciales en los costes de los fármacos más frecuentemente empleados.

g) ¿Cuál es la certeza en torno a la evidencia sobre los recursos requeridos?

- Juicio: no hay estudios incluidos.

- Evidencia procedente de la investigación: no se ha localizado ningún estudio que describa de forma explícita el uso de recursos (costes) o estudios de evaluación económica. 
h) La relación coste-efectividad, ¿favorece a la intervención o a la comparación?

- Juicio: probablemente favorece a la intervención.

- Evidencia procedente de la investigación: no se ha localizado ningún estudio de evaluación económica.

- Información adicional: los recursos necesarios son insignificantes, por lo que tendrían una relación de coste-efectividad favorecedora a la intervención.

i) ¿Cuál sería el impacto en la equidad en salud?

- Juicio: aumenta.

- Evidencia procedente de la investigación: no se ha realizado revisión sistemática del tema.

- Información adicional: no se ha identificado ningún aspecto específico que puedan afectar a la equidad. Dependerá que los profesionales que atienden al paciente en SUD apliquen los tratamientos que permitan controlar la ansiedad, el delirium y la agitación, que se pueden emplear en cualquier ámbito asistencial. La implementación de las recomendaciones podría aumentar la equidad.

j) ¿Es aceptable la opción para los agentes implicados?

- Juicio: probablemente sí.

- Evidencia procedente de la investigación: no se ha realizado revisión sistemática del tema.

- Información adicional: teniendo en cuenta el malestar que producen los síntomas evaluados, el grupo considera que el uso de medidas no farmacológicas y de fármacos puede ser aceptable para la mayoría de pacientes y familiares.

k) ¿Es factible la implementación de la opción?

- Juicio: sí.

- Evidencia procedente de la investigación: no se ha realizado revisión sistemática del tema.

- Información adicional: no se han identificado factores que puedan afectar de forma sustancial a la factibilidad de las recomendaciones.

\section{I) Otras consideraciones}

EL GEG discute sobre la relevancia de las medidas no farmacológicas en la prevención y control de la ansiedad, el delirium y la agitación. También en que deben ser tenidos en cuenta aquellos factores que pueden desencadenar estos síntomas y en las medidas para la prevención de accidentes o autolesiones no intencionadas. 


\subsection{Estertores}

\section{Contexto}

La aparición de ruidos respiratorios producidos por la acumulación de secreciones respiratorias en el tracto respiratorio de pacientes en SUD o estertores respiratorios premortem, es frecuente. Se estima que pueden estar presentes en al menos un tercio de los pacientes (154).

Aunque no hay evidencia de que produzca malestar en los pacientes, dado que habitualmente aparecen en situaciones de bajo nivel de conciencia, suelen causar un importante malestar y preocupación en los familiares y profesionales. Debido a ello cualquier medida farmacológica o no farmacológica debe ir acompañada siempre de un adecuado proceso de comunicación y toma de decisiones. El objetivo de esta revisión es evaluar la evidencia sobre la efectividad y seguridad de las diferentes opciones farmacológicas para el control de los estertores.

\section{Recomendaciones}

1. Se recomienda, cuando una persona entra en situación de últimos días, evaluar la aparición de estertores para valorar el inicio de un manejo precoz [BPC, adaptada].

2. Se recomienda informar sobre las causas de los estertores y resolver las dudas que puedan surgir, incidiendo en que, aunque el ruido puede ser angustiante, es poco probable que cause molestias a la persona enferma por el bajo nivel de conciencia [BPC, adaptada].

3. Se recomienda iniciar medidas no farmacológicas para aliviar los estertores, para reducir cualquier malestar en las personas al final de la vida y en su entorno [BPC, adaptada].

4. Se recomienda considerar tratamiento farmacológico de los estertores cuando la aplicación de las medidas no farmacológicas y un correcto proceso comunicativo con el paciente y su familia son insuficientes [BPC, adaptada].

5. Se sugiere el uso de butilbromuro de escopolamina como primera opción, aunque la atropina o bromhidrato de escopolamina pueden emplearse como alternativas [Débil a favor, adaptada].

\section{Consideraciones clínicas relevantes}

- Las medidas no farmacológicas se presentan en el anexo 8.

- Los medicamentos más habitualmente utilizados, sus dosis y principales características se resumen en el anexo 10.

- En caso de iniciar tratamiento farmacológico para los estertores se deberá monitorizar la efectividad y efectos secundarios (principalmente con la atropina en personas mayores). 


\section{Justificación}

Se ha emitido una recomendación débil a favor sobre el empleo de fármacos para los estertores en la SUD, teniendo en cuenta la calidad de la evidencia, muy baja según GRADE, y el balance riesgo-beneficio de los tratamientos. Esta recomendación se acompaña de una serie de recomendaciones de práctica clínica enfocadas a la identificación y manejo temprano de los estertores, a la mejora del proceso comunicativo y a la puesta en marcha de medidas no farmacológicas.

\section{Justificación detallada}

Certeza global en la evidencia: se consideró evidencia de calidad moderada a muy baja de cinco ECA $(n=524)(155-159)$ y tres estudios de cohortes $(n=374)(160-163)$ en personas en los últimos días de vida con cáncer avanzado $(\mathrm{n}=822)$ y enfermedades no oncológicas $(\mathrm{n}=76)$. A pesar de que dos de los ECA fueron mejores teniendo en cuenta su diseño y tamaño muestral, el resto de ECA fueron pequeños o ensayos piloto y los estudios observacionales fueron retrospectivos. La variable de resultado crítica, mejoría de los estertores, fue considerada en los 8 estudios $(\mathrm{n}=898)$. Ninguno de los estudios consideró la variable calidad de vida. Los resultados no pudieron metanalizarse debido a la variabilidad en las variables de resultado, en el diseño y tiempos de seguimiento. Las escalas empleadas para la valoración de los estertores en los estudios en algunos casos se describieron de forma pobre y son subjetivas.

Balance entre los efectos deseables e indeseables esperados: el GEG, tras revisar la evidencia científica disponible ha concluido que los fármacos revisados son igual de eficaces para el manejo de los estertores, y no pudo priorizar un fármaco sobre el otro (se ha recomendado como primera opción el butilbromuro de escopolamina por ser uno de los más empleados). Desde el punto de vista del GEG en general los fármacos evaluados son bien tolerados, y algunos efectos secundarios, como la reducción del nivel de alerta pueden ser beneficiosos en la SUD. Aunque la efectividad de los fármacos es modesta, no existen otros tratamientos (salvo las medidas no farmacológicas).

\section{De la evidencia a la recomendación}

a) ¿Cuál es la magnitud de los efectos deseables esperados?

- Juicio: moderada.

- Evidencia procedente de la investigación: se consideró evidencia de calidad moderada a muy baja de cinco ECA $(\mathrm{n}=524)(155-159)$ y tres estudios de cohortes (160163) $(n=374)$ en personas en los últimos días de vida con cáncer avanzado $(n=822)$ y enfermedades no oncológicas $(n=76)$. La variable de resultado crítica mejoría de los estertores fue considerada en los ocho trabajos $(n=898)$. Cuatro estudios no encontraron diferencias en la mejoría de ruidos respiratorios entre medicamentos $(155,158,160,161)$, un estudio encontró resultados favorables al placebo (159), un estudio encontró resultados favorables a la atropina (158) y dos estudios encontraron resultados favorables al glicopirronio $(157,163)$. Un ECA $(n=130)$ encontró que, en personas con cáncer, la atropina era menos sedante que el butilbromuro de hioscina o el bromhidrato de hioscina (158). Ningún estudio informó sobre calidad de vida. 
La evidencia no permite establecer la superioridad del bromuro de atropina, bromuro de glicopirronio, escopolamina bromhidrato y butilbromuro de escopolamina para el tratamiento de los estertores en los últimos días, y la magnitud de los efectos es globalmente modesta. El octreótrido solo fue evaluado en un pequeño ensayo $(n=21)$ que lo comparó con escopolamina bromhidrato y obtuvo peores resultados en el control de los estertores (155).

b) ¿Cuál es la magnitud de los efectos indeseables esperados?

- Juicio: pequeña.

- Evidencia procedente de la investigación: la escopolamina bromhidrato ha sido asociada a un peor perfil de seguridad teniendo en cuenta el nivel de conciencia (podría producir una mayor disminución de consciencia), y también se ha asociado a la aparición de agitación, y por lo tanto deberá tenerse en cuenta a la hora de su prescripción.

- Información adicional: aunque no han sido informados en los estudios, existen otros efectos adversos comunes a los anticolinérgicos que deberán ser tenidos en cuenta como la sequedad bucal o la retención urinaria. Además, la atropina podría afectar a la contractilidad cardiaca y provocar arritmias.

El GEG considera que los fármacos recomendados son generalmente bien tolerados.

c) ¿Cuál es la certeza global en la evidencia sobre los efectos?

- Juicio: muy baja.

- Evidencia procedente de la investigación: se consideró evidencia de calidad moderada a muy baja de cinco ECA $(\mathrm{n}=524)(155-159)$ y tres estudios de cohortes (160163) $(n=374)$ en personas en los últimos días de vida con cáncer avanzado $(n=822)$ y enfermedades no oncológicas $(n=76)$. A pesar de que dos de los ECA fueron mejores teniendo en cuenta su diseño y tamaño muestral, el resto de los ECA fueron pequeños o ensayos piloto y los estudios observacionales fueron retrospectivos. La variable de resultado crítica mejoría de los estertores fue considerada en los ocho trabajos $(\mathrm{n}=898)$. Ninguno de los estudios consideró la variable calidad de vida. Los resultados no pudieron metanalizarse debido a la variabilidad en las variables de resultado, en el diseño y tiempos de seguimiento.

Las escalas empleadas para la valoración de los estertores en los estudios en algunos casos se describieron de forma pobre y son subjetivas (habitualmente cumplimentadas por enfermería).

d) ¿Existe incertidumbre o variabilidad importante sobre cómo los pacientes valoran los desenlaces principales?

- Juicio: la incertidumbre o la variabilidad probablemente no sean importantes.

- Evidencia procedente de la investigación: no se ha realizado revisión sistemática del tema.

- Información adicional: se han considerado las siguientes variables críticas para la toma de decisiones: control de síntomas, calidad de vida/bienestar/confort y reducción 
del ruido respiratorio. Como variables importantes para la toma de decisiones se han considerado: eventos adversos, supervivencia, sedación.

El GEG considera que no existirían diferencias sustanciales en cómo los pacientes valoran los desenlaces principales.

e) El balance entre los efectos deseables e indeseables esperados, ¿favorece a la intervención o a la comparación?

- Juicio: probablemente favorece a la intervención.

- Evidencia procedente de la investigación: el GEG, tras revisar la evidencia científica disponible ha concluido que los fármacos revisados son igual de eficaces para el manejo de los estertores, y no pudo priorizar un fármaco sobre el otro.

Desde el punto de vista del GEG en general los fármacos evaluados son bien tolerados, y, algunos efectos secundarios, como la reducción del nivel de alerta pueden ser beneficiosos en la SUD. Aunque la efectividad de los fármacos es modesta, no existen otros tratamientos (salvo las medidas no farmacológicas).

- Información adicional: dada la incertidumbre en los efectos del tratamiento farmacológico, el balance beneficio-riesgo deberá valorarse de forma individualizada, considerando principalmente el impacto de los estertores en el paciente y sus familiares, el estado global de paciente y los tratamientos que esté recibiendo. Sin embargo, en general el balance beneficio-riesgo es favorable en la mayoría de los casos.

f) ¿Cuál es la magnitud de los recursos requeridos (costes)?

- Juicio: costes y reducción de costes insignificante.

- Evidencia procedente de la investigación: no se ha localizado ningún estudio que describa de forma explícita el uso de recursos (costes) o estudios de evaluación económica.

- Información adicional: los costes unitarios de los fármacos recomendados son similares, y por tanto el grupo de trabajo no considera relevante hacer una mención especial al respecto.

g) ¿Cuál es la certeza en torno a la evidencia sobre los recursos requeridos?

- Juicio: no hay estudios incluidos.

- Evidencia procedente de la investigación: no se ha localizado ningún estudio que describa de forma explícita el uso de recursos (costes) o estudios de evaluación económica.

h) La relación coste-efectividad, ¿favorece a la intervención o a la comparación?

- Juicio: no aplica.

- Evidencia procedente de la investigación: no se ha localizado ningún estudio de evaluación económica. 
- Información adicional: siendo tan insignificante la magnitud de recursos se asume que la estrategia de intervención es coste-efectiva.

i) ¿Cuál sería el impacto en equidad en salud?

- Juicio: aumenta.

- Evidencia procedente de la investigación: no se ha realizado revisión sistemática del tema.

- Información adicional: no se ha identificado ningún aspecto específico que pueda afectar a la equidad. Dependerá de que los profesionales que atienden al paciente en SUD apliquen los tratamientos que permitan controlar los estertores, que se pueden emplear en cualquier ámbito asistencial.

j) ¿Es aceptable la opción para los agentes implicados?

- Juicio: probablemente sí.

- Evidencia procedente de la investigación: no se ha realizado revisión sistemática del tema.

- Información adicional: los estertores suelen aparecer cuando el nivel de conciencia del paciente disminuye y no existe evidencia que los asocie a malestar en los pacientes. Sin embargo, sí que suele ser un síntoma asociado a un importante malestar en los familiares (164), y por ello podrían aceptar las intervenciones propuestas por los profesionales para el tratamiento de las secreciones respiratorias. Desde el punto de vista del GEG, la mayoría de los pacientes también aceptarían el tratamiento para el control de los estertores.

Alguna de las opciones farmacológicas puede empeorar el nivel de conciencia, la agitación, o producir sequedad de boca, y por ello estos efectos adversos deberán tenerse en cuenta en la estimación del balance beneficio-riesgo individualizado y en la toma de decisiones compartida con el paciente y sus familias. También será importante la evaluación de estos síntomas una vez instaurado el tratamiento.

k) ¿Es factible la implementación de la opción?

- Juicio: sí.

- Evidencia procedente de la investigación: no se ha realizado revisión sistemática del tema.

- Información adicional: no se ha identificado ningún aspecto específico que puedan afectar a la implementación de las recomendaciones.

\section{l) Otras consideraciones}

El GEG considera relevante enfatizar la importancia de la comunicación y toma de decisiones compartida sobre el manejo de los estertores, que deberá comenzar lo antes posible en el proceso de SUD. También considera relevante enfatizar la importancia del manejo no farmacológico y de su inicio precoz. 
Los cuidados no farmacológicos son importantes como intervención única o como adyuvantes al tratamiento farmacológico. Aunque no se ha realizado una revisión sistemática sobre su efectividad como parte de esta guía, las intervenciones no farmacológicas más recomendadas son la colocación en posición lateral y la retirada de secreciones manualmente o con aspiración poco profunda (esta última medida deberá ponerse en marcha con cautela debido a que puede provocar malestar). Aunque se han publicado dos estudios observacionales que no encontraron mejoras en la reducción de los estertores relacionadas con la hidratación (164), desde el punto de vista del GEG, el adecuado manejo de líquidos y alimentación, puede ser una estrategia que ayude a prevenir y reducir las secreciones.

En cuanto a los fármacos, en España el fármaco más usado en la práctica clínica es el butilbromuro de escopolamina y por lo tanto existe más experiencia en su uso. La atropina y la escopolamina bromhidrato son menos usados, pero pueden ser una opción para el manejo de los estertores teniendo en cuenta la evidencia científica disponible. La GPC del NICE también recomienda el bromuro de glicopirronio, pero en España en la actualidad solo se comercializa de forma inhalada, y por lo tanto no se recomienda.

Todos los fármacos recomendados suponen un uso off-label, puesto que ninguno de ellos tiene recogida esta indicación en su ficha técnica.

Un enfoque que está siendo investigado recientemente es la instauración de tratamiento farmacológico de forma profiláctica, antes de la aparición de las secreciones. En la búsqueda se ha identificado un ECA y un protocolo de ECA que investigan esta aproximación $(165,166)$. Aunque este estudio no se ha incluido en la revisión realizada al no cumplir criterios de inclusión (todos los estudios analizados incluyen pacientes con secreciones respiratorias), este enfoque todavía no cuenta con la evidencia suficiente en la actualidad que la respalde. 



\section{Sedación paliativa}

\section{Pregunta}

- En pacientes en situación de últimos días, ¿cuáles son los beneficios de la sedación paliativa en el alivio del sufrimiento y el control de síntomas refractarios?

\section{Contexto}

En los últimos días de vida los pacientes experimentan numerosos síntomas (143,167-170), tal y como se ha descrito en la presente guía. Puede llegar un momento en que estos síntomas no se controlen adecuadamente a pesar de recibir CP óptimos (171).

La sedación paliativa es "el uso de medicación sedante para aliviar el sufrimiento intolerable causado por un síntoma refractario, mediante la disminución del nivel de consciencia" $(171,172)$. Se ha definido síntoma refractario como "aquel que no puede ser adecuadamente controlado con medidas terapéuticas que no comprometan el nivel de consciencia". Los síntomas más frecuentemente descritos en la literatura como refractarios son la disnea, el delirium, las convulsiones, el dolor y el sufrimiento existencial (143, 172, 173).

Se puede conseguir la sedación mediante fármacos primariamente sedantes y no utilizados para intentar controlar el síntoma subyacente (sedación primaria) o mediante fármacos utilizados para intentar aliviar el síntoma y que van a tener la sedación como efecto secundario (sedación secundaria). Puesto que la intencionalidad de la sedación paliativa es la disminución de la consciencia, cuando se hable de sedación paliativa será siempre primaria.

El nivel de disminución de la consciencia puede variar de superficial, intermedio a profundo; y puede ser intermitente o continuo desde el inicio. El nivel de sedación dependerá del grado de control del síntoma refractario, resultando en una sedación superficial o profunda según la respuesta, y también según las preferencias de los pacientes y familiares.

Se pretende que este apartado sirva para mejorar la práctica clínica de la sedación paliativa en SUD (también denominada sedación en la agonía o sedación terminal), mediante una adecuada identificación de los síntomas refractarios, un correcto manejo de los fármacos a las dosis adecuadas y teniendo siempre en cuenta los valores y preferencias de los pacientes y sus familias.

\section{Recomendaciones}

1. Se sugiere aplicar sedación paliativa en pacientes en situación de últimos días con sufrimiento causado por uno o más síntomas refractarios [Débil a favor].

\section{Consideraciones clínicas relevantes}

Para favorecer la implementación de la recomendación, se aportan una serie de consideraciones clínicas relevantes, algoritmo para la evaluación de la refractariedad, las dosis y 
observaciones de los fármacos recomendados, el algoritmo para el uso de fármacos, las escalas para la valoración del control del síntoma refractario y el grado de sedación, y los cuidados de confort en la sedación.

- El fármaco de elección para la sedación paliativa, tanto en el ámbito domiciliario como hospitalario es el midazolam (ver dosis de inducción y mantenimiento en anexo 11). La alternativa más habitual es la levomepromazina, de primera elección en caso de delirium. En caso de fracaso de los anteriores, otras alternativas son el fenobarbital o el propofol (ámbito hospitalario) (ver algoritmo en anexo 11).

- Es recomendable consensuar con otro profesional la situación de refractariedad, para no confundirlo con un síntoma de difícil manejo e indicar correctamente una sedación paliativa. Identificada la situación de refractariedad, debe registrarse en la historia clínica (ver algoritmo de refractariedad en anexo 11).

- Antes de iniciar la sedación paliativa se debe obtener el consentimiento del paciente; puesto que en SUD puede ser perjudicial o maleficente se recomienda abordar el tema con anterioridad o de manera anticipada. Se debe comprobar si tiene documento de instrucciones previas o anotaciones en la historia clínica en las que se reflejen sus deseos en este sentido. En caso de incapacidad o en caso de que se considere maleficente obtener el consentimiento explícito y no tenga documento de instrucciones previas ni anotaciones en la historia clínica, será la familia/allegados/cuidador principal quienes otorguen el consentimiento verbal, según lo estipulado para el consentimiento por representación. Se actuará siempre según el criterio de mayor beneficio para el paciente. El proceso de consentimiento y toma de decisiones compartida debe registrarse en la historia clínica.

- Los fármacos sedantes empleados (principalmente benzodiacepinas) deben ser titulados para alcanzar el nivel de sedación requerido (que puede ser superficial, intermedio o profundo).

- Las dosis y combinaciones de fármacos deberán ser proporcionadas al control del síntoma refractario. En situaciones de emergencia (hemorragia masiva, obstrucción respiratoria abrupta) existe consenso para recomendar desde el inicio sedación paliativa profunda continua.

- Se monitorizará el control del síntoma refractario y el nivel de sedación obtenido con el fin de garantizar el buen control y la proporcionalidad. Se recomienda utilizar escalas estandarizadas (por ejemplo, la escala de Ramsay o la RASS) (ver escalas en anexo 11).

- En un paciente en sedación paliativa se realizará adecuación terapéutica:

- Retirando la nutrición artificial si la estaba recibiendo.

- La hidratación se mantendrá o no dependiendo del balance beneficio-riesgo individualizado (ver apartado de hidratación).

- Respecto a los fármacos únicamente se mantendrán (o añadirán) aquellos necesarios para el control de síntomas. 
- Es importante mantener todas aquellas medidas orientadas al bienestar y confort, asegurándose en todo momento, que se realiza todo lo posible por aliviar su sufrimiento. Salvo en situaciones excepcionales, no se recomienda el control de constantes vitales (ver información sobre cuidados en anexos).

- Se mantendrá una actitud de disponibilidad y acompañamiento con la familia y allegados, explicando que el objetivo de la sedación paliativa no es acortar la vida sino aliviar el sufrimiento causado por un síntoma que no se ha podido controlar de otro modo; se aportará toda la información que la familia y allegados puedan precisar sobre el proceso de sedación y adecuación terapéutica (ver documento de información a pacientes y familiares).

- Se dejará registro por escrito en la historia clínica del paciente de:

- Determinación de la situación de refractariedad.

- Proceso de obtención del consentimiento y toma de decisiones.

- Nivel de sedación indicado, fármacos y dosis.

- Monitorización del nivel de control del síntoma refractario y el nivel de sedación alcanzado.

- Debería garantizarse que las recomendaciones de sedación paliativa pudiesen ser implementadas independientemente del nivel asistencial o el tipo de patología de base (por ejemplo, diferencias que puede haber en función del lugar de residencia o de si la enfermedad es oncológica o no oncológica).

\section{Justificación}

El GEG ha formulado una recomendación débil a favor de aplicar sedación paliativa en esta población (pacientes en SUD con sufrimiento causado por uno o más síntomas refractarios) debido a que la calidad de la evidencia sobre los efectos es globalmente muy baja y a que probablemente la incertidumbre o la variabilidad sobre como los pacientes y familiares valoran los desenlaces son importantes.

Se han elaborado también una serie de consideraciones clínicas relevantes y relacionadas con la implementación de la recomendación realizada. Estas están orientadas a favorecer el proceso de sedación paliativa, incluyendo: la necesidad de consenso en el equipo multidisciplinar sobre la indicación de sedación, la obtención del consentimiento informado, el tipo de sedación, la monitorización, medidas de adecuación terapéutica y de confort, la actitud de los profesionales, así como el registro del proceso en la historia clínica.

\section{Justificación detallada}

Calidad de la evidencia: la calidad de la evidencia sobre los beneficios de la sedación paliativa es globalmente muy baja, debido a que solo se han identificado estudios observacionales (series de casos consecutivas) con grupo de comparación. La calidad de la evidencia de los estudios cualitativos sobre las experiencias y preferencias de los pacientes y familiares es moderada-baja. El principal problema de la evidencia cualitativa revisada son algunas limitaciones metodológicas de los estudios y las dudas relacionadas con la aplicabilidad, 
porque solo uno de los estudios incluye a pacientes y familiares de España. Las revisiones sistemáticas sobre indicaciones y recomendaciones son de calidad moderada, aunque pocas de las guías incluidas cumplen los estándares de calidad actuales.

Incertidumbre o variabilidad importante sobre cómo los pacientes valoran los desenlaces principales: la evidencia cualitativa revisada indica que tanto para los pacientes como para los familiares el bienestar y el alivio del sufrimiento es una de las prioridades en los últimos días. Sin embargo, pueden existir diferencias entre los pacientes y sus propios familiares al valor otorgado a estar consciente, y también diferencias entre pacientes.

Balance riesgo-beneficio: a pesar de la ausencia de evidencia científica de calidad, el GEG está de acuerdo en que los beneficios de la sedación paliativa en los pacientes en situación de últimos días (alivio del malestar provocado por síntomas refractarios que no son controlados con otros métodos) probablemente superan a los riesgos en la mayoría de los casos. Los fármacos sedantes empleados (principalmente BDZ) pueden ser titulados para alcanzar el nivel de sedación requerido y deseado (que puede ser superficial, intermedio o profundo), el nivel de sedación puede ser mantenido y los efectos son reversibles.

\section{De la evidencia a la recomendación}

a) ¿Cuál es la magnitud de los efectos deseables esperados?

- Juicio: grande.

- Evidencia procedente de la investigación: se ha identificado una revisión Cochrane (6) que cumple los criterios de inclusión predefinidos por el grupo de trabajo para la pregunta sobre los beneficios de los fármacos empleados para realizar una sedación paliativa en situación de últimos días, y por lo tanto se ha actualizado su búsqueda bibliográfica (año 2014 en adelante). Solo se ha localizado un estudio posterior que aporta evidencia para la variable supervivencia (Prado et al., 2018) (68). Esto es congruente con la revisión realizada por los autores de la revisión Cochrane en noviembre del 2018, en la que no identificaron ningún estudio relevante, y por lo tanto consideraron la revisión estable hasta el año 2024.

No se ha localizado ningún estudio cuantitativo que evalúe el efecto de la sedación paliativa en la calidad de vida o bienestar/confort. Los cuatro estudios observacionales que evaluaron el control de síntomas incluidos en una revisión Cochrane mostraron que fue similar entre pacientes sedados y no sedados, aunque en algunos estudios el delirium y la disnea siguieron presentes a pesar de la sedación (174). En cuanto a la supervivencia, 14 estudios (175-188) evidenciaron que no hubo diferencias significativas entre sedados y no sedados en el tiempo transcurrido desde la hospitalización hasta la muerte (174). El único estudio localizado en la actualización encontró que la supervivencia en el grupo de pacientes sedados fue más del doble que en pacientes no sedados (189). La satisfacción fue abordada en solo un estudio cuantitativo (178), que encontró que tanto los familiares como los pacientes estuvieron satisfechos con la sedación (174). Solo un estudio cuantitativo evaluó la seguridad (178), y no informó de ningún efecto adverso en el grupo que recibió la sedación (174). 
La evidencia cualitativa sobre las experiencias de pacientes y familiares señala que la mayoría de los familiares estaban satisfechos con la sedación y el proceso (190199).

- Información adicional: el GEG ha priorizado las siguientes variables de resultado para evaluar los beneficios de la sedación paliativa: calidad de vida o bienestar evaluada por parte de los pacientes y/o cuidadores, control de síntomas específicos, efectos adversos del tratamiento, supervivencia, y satisfacción del cuidador con la calidad de los cuidados recibidos.

b) ¿Cuál es la magnitud de los efectos indeseables esperados?

- Juicio: pequeña.

- Evidencia procedente de la investigación: solo un estudio incluido en la revisión Cochrane evaluó la seguridad de los fármacos empleados para la sedación paliativa, y no encontró efectos adversos mayores (178). La revisión Cochrane no encontró que la sedación paliativa tuviese ningún efecto en acortar la vida, ya que no hubo diferencias entre sedados y no sedados en la supervivencia (174).

- Información adicional: a pesar de no haberse encontrado en la evidencia científica revisada efectos en la supervivencia, algunos autores han descrito el riesgo de provocar la muerte en algunos pacientes (debido a depresión respiratoria, aspiración o compromiso hemodinámico). También se ha descrito como riesgo la agitación paradójica (172).

c) ¿Existe incertidumbre o variabilidad importante sobre cómo los pacientes valoran los desenlaces principales?

- Juicio: la incertidumbre o la variabilidad probablemente sean importantes.

- Evidencia procedente de la investigación: se han identificado 11 estudios que han explorado las experiencias y perspectivas de los pacientes y familiares con la sedación paliativa, aunque solo dos de ellos incluyeron la visión de pacientes (en los dos casos de pacientes oncológicos en la fase final). La evidencia cualitativa revisada indica que, tanto para los pacientes como para los familiares, el bienestar y el alivio del sufrimiento es una de las prioridades en los últimos días. Sin embargo, pueden existir diferencias entre los pacientes y sus propios familiares al valor otorgado a estar consciente, y diferencias entre pacientes, que pueden depender de las preferencias individuales y/o de factores culturales y sociales (190-199).

d) ¿Cuál es la certeza global en la evidencia sobre los efectos?

- Juicio: muy baja.

- Evidencia procedente de la investigación: la calidad de la evidencia sobre los beneficios de la sedación paliativa es globalmente muy baja, debido a que solo se han identificado estudios observacionales (series de casos consecutivas) con grupo de comparación. Solo tres de los estudios fueron prospectivos y únicamente uno de ellos intentó controlar el sesgo de selección a través del control de las características clínicas de base, y seis estudios informaron de diferencias entre sedados versus no 
sedados en las características de los pacientes. El resto de estudios no informaron de las características basales de los participantes en los estudios. Más del $95 \%$ de la muestra total en los estudios fueron pacientes oncológicos.

Ningún estudio evaluó la calidad de vida o bienestar de los pacientes, una de las variables clave. El control de síntomas fue medido de forma diferente entre los estudios (como prevalencia de cada síntoma en los últimos siete días, prevalencia de síntomas, puntuación media y adecuación del control de síntomas), por lo que no fue posible obtener una medida agregada. Además, la prevalencia de síntomas podría considerarse una variable indirecta debido a que no informa sobre el efecto de la sedación en síntomas concretos.

Tampoco se pudo obtener una medida agregada de supervivencia y, además, fue medida como el período desde la hospitalización o el inicio de los CP hasta la muerte, por lo que también puede considerarse una medida indirecta del efecto de la sedación en la supervivencia.

\section{Estudios cualitativos}

La calidad de la evidencia de los estudios cualitativos es moderada-baja. El principal problema de la evidencia revisada son algunas limitaciones metodológicas de los estudios y las dudas relacionadas con la aplicabilidad, porque solo uno de los estudios incluye a pacientes y familiares de España. Sin embargo, cabe destacar que globalmente los temas identificados son relevantes desde el punto de vista del grupo de trabajo.

- Información adicional: a pesar de la insuficiente evidencia derivada de estudios primarios, existe consenso en la mayor parte de las guías sobre las indicaciones, tipos de sedación y fármacos empleados. El fármaco más frecuentemente recomendado es el midazolam, aunque existen variaciones.

e) ¿Son mayores los efectos deseables que los efectos indeseables?

- Juicio: probablemente sí.

- Información adicional: a pesar de la baja calidad de los estudios disponibles, el GEG está de acuerdo en que los beneficios de la sedación paliativa en los pacientes en situación de últimos días (alivio del malestar provocado por síntomas refractarios que no son controlados con otros métodos) probablemente superan a los riesgos en la mayoría de los casos.

\section{f) ¿Cuál es la magnitud de los recursos requeridos (costes)?}

- Juicio: probablemente pequeña.

- Evidencia procedente de la investigación: no se ha identificado ningún estudio que describa de forma explícita el uso de recursos (costes) o estudios de evaluación económica.

- Información adicional: el GEG está de acuerdo en que las diferencias en los costes unitarios (ver tabla de costes unitarios en el material metodológico) entre los fármacos no son sustanciales, y por lo tanto se recomiendan los fármacos más empleados 
en la práctica clínica, teniendo en cuenta tanto los síntomas que predominan como el ámbito de la sedación (domicilio o en el hospital).

g) ¿Cuál es la certeza en torno a la evidencia de los recursos requeridos?

- Juicio: no hay estudios incluidos.

- Evidencia procedente de la investigación: no se ha identificado ningún estudio que describa de forma explícita el uso de recursos (costes) o estudios de evaluación económica.

h) ¿Es pequeño el incremento del coste en relación con los beneficios netos?

- Juicio: probablemente sí.

- Evidencia procedente de la investigación: no se ha identificado ningún estudio de coste-efectividad ni análisis de evaluación económica.

- Información adicional: el GEG está de acuerdo en que el coste de la intervención puede considerarse pequeño teniendo en cuenta los potenciales beneficios (alivio del sufrimiento por síntomas refractarios).

i) ¿Cuál sería el impacto en la equidad en salud?

- Juicio: aumenta.

- Evidencia procedente de la investigación: no se ha realizado una revisión sistemática del tema. Existe evidencia que sugiere que algunos factores sociodemográficos como la edad, el género o el nivel educativo podrían afectar a la equidad (200).

- Información adicional: desde el punto de vista del GEG, los pacientes que ante la misma situación clínica (síntoma refractario en los últimos días de vida) tengan distinto acceso a los recursos que garanticen una adecuada indicación y práctica de la sedación paliativa estarían en situación de inequidad.

La implementación de las recomendaciones podría mejorar la equidad.

j) ¿Es aceptable la opción para los agentes implicados?

- Juicio: probablemente sí.

- Evidencia procedente de la investigación: según la evidencia revisada, la sedación paliativa para el alivio de los síntomas refractarios es generalmente aceptable para los pacientes y los familiares en SUD. Cabe tener en cuenta que las situaciones en las que un familiar es sedado suelen ser difíciles para sus familiares y allegados y ser una causa de importante malestar. Es relevante considerar que algunos pacientes y familiares querrán una oportunidad para despedirse de sus seres queridos (190-199). Los estudios también señalan la importancia de una adecuada toma de decisiones compartida y de dar respuesta a las posibles preocupaciones que pueden surgir en los familiares en el proceso (190-199).

La evidencia cualitativa sobre la experiencia de los profesionales sugiere la existencia de algunas discrepancias entre expertos en la indicación de sedación paliativa 
en casos de sufrimiento existencial y demencias, y también diferencias en los tipos y niveles de sedación para casos concretos. También se encontró preocupación de los profesionales sobre la sedación paliativa establecida de modo definitivo al final del continuum de atención paliativa como equivalente a la eutanasia (201-203). Todo ello sugiere que para algunos profesionales todavía pueden existir preocupaciones conceptuales, clínicas o éticas, relacionadas con la sedación paliativa y por ello es importante mejorar la formación en cuidados paliativos y bioética, y disponer de GPC o protocolos específicos que ayuden a la toma de decisiones (201-203).

- Información adicional: la experiencia del GEG coincide en que la sedación paliativa es generalmente aceptable, aunque puede existir variabilidad en las preferencias sobre el nivel de sedación y tipo de sedación entre los pacientes y familiares.

\section{k) ¿Es factible la implementación de la opción?}

- Juicio: sí.

- Evidencia procedente de la investigación: a pesar de la insuficiente evidencia derivada de estudios primarios, existe consenso en la mayor parte de las guías sobre las indicaciones, tipos de sedación y fármacos empleados. El fármaco más frecuentemente recomendado es el midazolam, aunque existen variaciones $(204,205)$.

- Información adicional: el GEG considera que las recomendaciones sobre sedación paliativa son factibles en el SNS. Sin embargo, algunas de las cuestiones relacionadas con la aceptabilidad de los profesionales o algunos aspectos descritos relacionados con el mal uso de la sedación paliativa podrían ser causantes de la variabilidad en la sedación paliativa, y son relevantes desde el punto de vista del GEG. A este respecto se ha señalado que una decisión consensuada por todas las partes implicadas y su discusión en el equipo multidisciplinar podría redundar en la mejora de la práctica clínica de la sedación paliativa (206).

Además, desde el punto de vista del GEG es necesaria formación sobre CP y sedación paliativa para todos los profesionales que atienden personas en SUD.

\section{l) Otras consideraciones}

Uno de los aspectos más relevantes en el proceso de toma de decisiones para la indicación de sedación paliativa es la determinación de refractariedad. En la práctica clínica, se considera que un síntoma es refractario cuando no existen métodos para su control en un marco temporal aceptable para la persona en SUD y sin provocar efectos adversos intolerables $(172,207)$. El documento de sedación paliativa de la Organización Médica Colegial (OMC) y la Sociedad Española de Cuidados Paliativos (SECPAL) define síntoma refractario como aquel que no puede ser adecuadamente controlado con los tratamientos disponibles, aplicados por médicos expertos, en un plazo de tiempo razonable (en la fase agónica breve) (207).

Los síntomas refractarios más frecuentes son el delirium, la disnea, el dolor y las convulsiones. En ocasiones pueden aparecer procesos agudos como la hemorragia masiva o la asfixia (172). Un síntoma refractario que merece especial atención es el sufrimiento existencial o psicoexistencial. Se refiere a la "pérdida de sentido y propósito en la vida”. Se 
incluye en este concepto: un sentimiento profundo de sinsentido y desesperanza, ansiedad o miedo a la muerte, sentimiento de carga para los seres queridos, desesperanza por la pérdida de control o dependencia, consideración de pérdida de dignidad, sufrimiento por la falta de soporte social o por la soledad. Parece existir consenso en la literatura, en que en casos de sufrimiento existencial debería exigirse un mayor rigor en la determinación de la refractariedad, la implicación de un equipo interdisciplinar y a ser posible, con valoración por profesionales de la salud mental $(208,209)$. A este respecto, el marco de la EAPC (del inglés European Association for Palliative Care) también propone que, en estos casos, la sedación profunda debería considerarse después de ensayos repetidos de sedación de respiro o intermitente (172).

En cuanto a la obtención del consentimiento informado, en situaciones en las que el paciente tenga la capacidad de decidir, deberían discutirse los objetivos, beneficios y consecuencias de la sedación paliativa. Sin embargo, obtener el consentimiento explícito en la SUD, podría resultar maleficente por lo que es deseable que el consentimiento se obtenga previamente, en un proceso de planificación anticipada y compartida de las decisiones, y así quede registrado en la historia clínica. Por otro lado, uno de los principales síntomas refractarios es el delirium con lo que el consentimiento en esa situación no sería posible, tratándose en este caso de un consentimiento por representación. En este caso, la decisión corresponde al representante asignado legalmente o en un documento de instrucciones previas, o a las personas vinculadas por razones familiares o de hecho, siempre atendiendo al mayor beneficio para el paciente.

En cuanto al nivel y profundidad de la sedación es necesario considerar que el objetivo de la sedación es el alivio del síntoma y que el descenso del nivel de conciencia es la herramienta o medio para conseguir ese fin $(210,211)$. Por ello un enfermo al final de la vida con un síntoma refractario que consigue el alivio de este con sedación superficial es un enfermo aliviado y el objetivo de la sedación se ha conseguido. Por regla general se asume que el nivel de sedación debería ser el mínimo necesario para el alivio del sufrimiento (172). Sin embargo, ante eventos catastróficos como una hemorragia masiva o asfixia y en situaciones muy cercanas al final de la vida (agonía) la sedación debe ser profunda y continua desde el inicio. En situaciones de emergencia en la que la vida peligra rápidamente, como un sangrado masivo, no sería preciso el consentimiento por representación para instaurar una SP profunda, continua y rápida.

En ocasiones ocurre que el familiar o cuidador del paciente pide una sedación más profunda pese al adecuado control del síntoma. Esto puede deberse al desbordamiento emocional del familiar y debe ser manejado en un proceso continuo de comunicación y tratado en la aproximación informativa con los familiares. También sucede el caso contrario: el familiar solicita la retirada de una sedación ya instaurada o disminución de la misma para que el paciente recupere el nivel de consciencia. El GEG está de acuerdo en que la información continuada sobre el proceso de sedación y el acompañamiento a familiares disminuye considerablemente las dudas y el sufrimiento familiar al respecto.

Respecto a la temporalidad de la sedación en algunos escenarios clínicos (principalmente en fases anteriores a la SUD) puede ser intermitente, sobre todo cuando el síntoma refractario es de predominio nocturno de modo prioritario. En la práctica clínica no es 
infrecuente la sedación intermitente nocturna durante unos días como preludio de la sedación continua.

Para revisar el nivel de sedación, el GEG recomienda la escala de Richmond (Richmond Agitation-Sedation Scale, RASS) (212) (recomendada por la EAPC y validada en población española (213)) o la escala de Ramsay que, aunque no ha sido validada en población española, es de uso frecuente y fácil aplicabilidad (20).

El GEG considera relevante considerar que las circunstancias y estatus del paciente en últimos días y en situación de indicación de sedación paliativa dificulta la realización de estudios. Esto explica, la ausencia de estudios de calidad que hayan evaluado resultados como el confort/bienestar o calidad de vida, y la existencia de resultados discrepantes, además de la incertidumbre en los hallazgos. Por ello, es importante disponer de GPC y marcos conceptuales de referencia, así como tener en cuenta los principios de la ética clínica.

Recientemente, y con motivo de la pandemia por SARS-COV-2, el Ministerio de Sanidad ha publicado un documento con recomendaciones con el objetivo de ayudar a los profesionales de Atención Primaria en la toma de decisiones para la aplicación de Sedación Paliativa en domicilio en situación de últimos días (SUD) para pacientes con sospecha o confirmación de COVID-19 (214). Este documento también contempla alternativas farmacológicas en caso de desabastecimiento.

En cuanto a la eutanasia cabe considerar que, en nuestro país, ha sido aprobada recientemente a través de la Ley Orgánica 3/2021 de 24 de marzo, de regulación de eutanasia, lo que conllevará su puesta en práctica en los próximos meses. 


\section{Estrategias diagnósticas y terapéuticas}

Dada la complejidad de la situación de últimos días no se ha realizado un algoritmo diagnóstico-terapéutico detallado. En el material complementario al capítulo de sedación paliativa se incluye un algoritmo para el uso de fármacos en la sedación (anexo 11).

En la figura a continuación se presenta una representación esquemática de los principales aspectos que aborda la guía.

Figura 1. Representación esquemática de los principales aspectos que aborda la guía

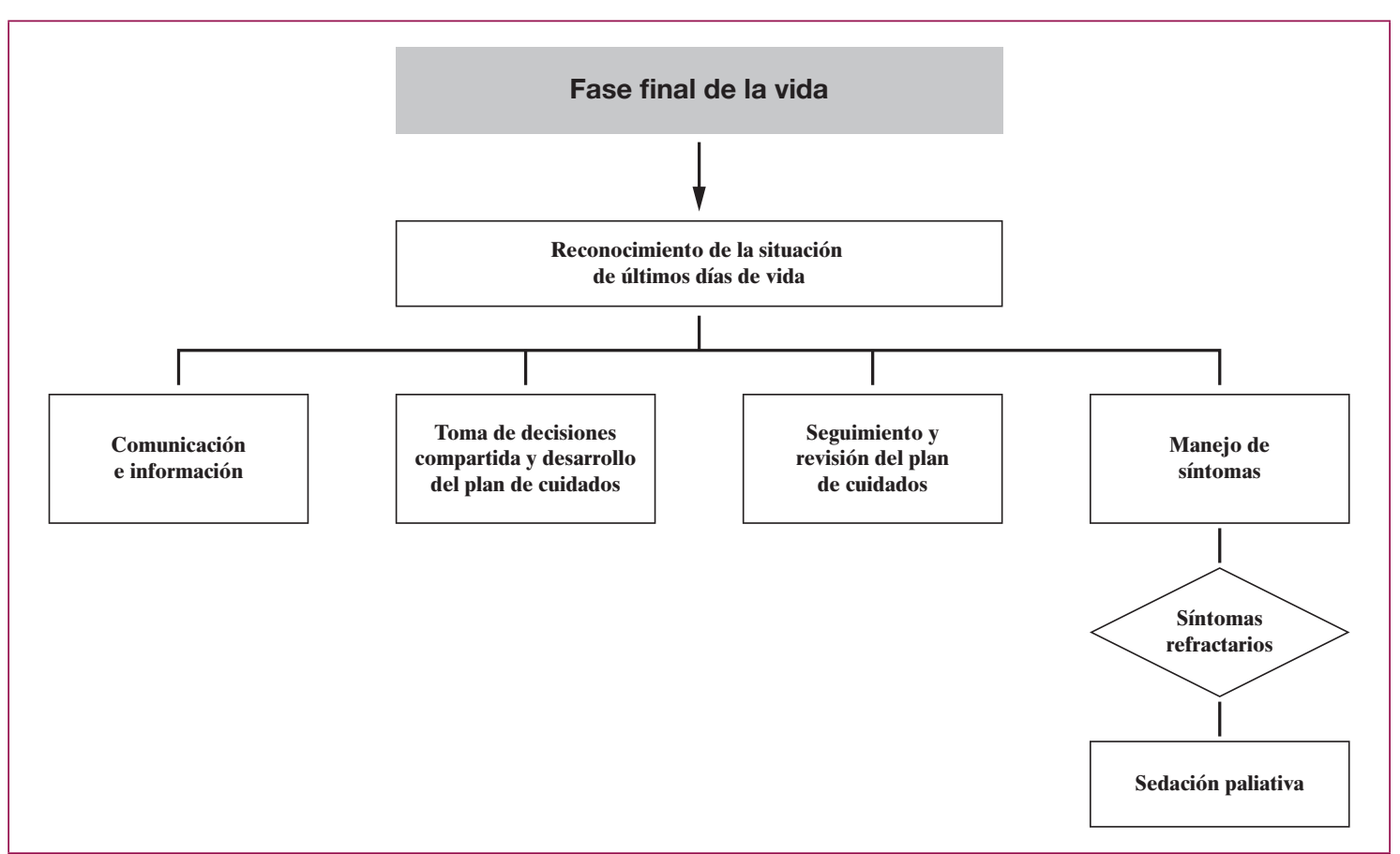





\section{Metodología}

La metodología empleada para elaborar la GPC, se recoge en el documento "Elaboración de Guías de Práctica Clínica en el Sistema Nacional de Salud. Actualización del Manual Metodológico" (215).

\section{Constitución del grupo de trabajo}

Se constituyó un grupo de trabajo multidisciplinar, formado por profesionales de perfil clínico y metodológico. Además, se contó con colaboradores expertos y con un amplio grupo de revisores externos propuestos por distintas asociaciones de pacientes, sociedades científicas y por el propio grupo de trabajo.

Los distintos participantes se relacionan en el apartado de autoría y colaboraciones:

- Coordinación: llevada a cabo por tres miembros del grupo de trabajo, dos de perfil clínico y uno metodológico.

- Grupo de trabajo: formado por 3 técnicos (metodólogos con experiencia en la elaboración y actualización de guías), 2 familiares y 11 profesionales sanitarios de diferentes especialidades y niveles asistenciales con experiencia en CP y asistencia a personas en la fase final de la vida.

- Colaboración experta: 9 profesionales con conocimiento y experiencia en elaboración de GPC y/o expertos en CP.

- Grupo de revisión externa: formado por 22 profesionales propuestos por las diferentes sociedades científicas y asociaciones de pacientes directamente relacionadas con los CP.

- Exposición Pública: el borrador de la GPC fue revisado por organizaciones del ámbito de la salud que no participaron en la revisión externa, registradas previamente e interesadas en hacer aportaciones al mismo. En el caso de esta GPC han participado 7 organizaciones cuyas aportaciones y comentarios están disponibles para su consulta en la web de GuíaSalud: http:// http://www.guiasalud.es.

- Documentación y difusión: participaron 2 documentalistas y 2 administrativas.

\section{Revisión de la GPC de base y decisión sobre la actualización}

Esta GPC es una actualización parcial de la GPC sobre paliativos del SNS (20). El proceso para la revisión de la GPC base y la decisión sobre la actualización fue:

1. Se realizó una búsqueda de la literatura sobre evidencia secundaria (revisiones sistemáticas y GPC) relacionada con los temas incluidos en la guía de paliativos a actualizar.

2. Se realizó un análisis del impacto de la evidencia en las recomendaciones.

3. Se priorizaron las preguntas clínicas susceptibles de ser actualizadas en base a lo anterior y los aspectos clínicos. 
4. Se consensuó actualizar la atención en los últimos días y sedación paliativa.

Para la atención en los últimos días se identificó una GPC elaborada por el NICE (22) que abordaba las áreas clínicas más relevantes y cumplía el criterio metodológico para valorar su adaptación (puntuación superior al $80 \%$ en el «dominio 3: rigor en la elaboración» del instrumento AGREE-II (216)), y por lo tanto se decidió proceder a su adaptación siguiendo el método GRADE-ADOLOPMENT (217).

Para la sedación paliativa también se identificó una revisión Cochrane (174) de alta calidad según la herramienta (AMSTAR-II (218)) por lo que también se procedió a su actualización.

\section{Preguntas clínicas y variables de resultado}

Se empleó un proceso de revisión y priorización formal (a través de discusiones presenciales) de las preguntas clínicas y variables de resultado tanto de la GPC del NICE como de la revisión Cochrane identificadas.

\section{Búsquedas bibliográficas y criterios de selección}

Se actualizaron las búsquedas bibliográficas empleando las mismas estrategias de búsqueda que la guía del NICE (22) y la revisión Cochrane (174) seleccionada para la pregunta clínica de sedación paliativa. Las búsquedas se realizaron en las bases de datos Medline, Embase, Cochrane y PsycInfo y se activaron alertas que estuvieron activas hasta la edición de la GPC (junio 2021).

Se emplearon los mismos criterios de selección y se siguió una metodología de revisión sistemática estándar que incluyó un análisis duplicado e independiente para la selección de títulos y resúmenes, la selección del texto completo y la extracción de datos. En caso de desacuerdo entre los revisores se implicó a un tercer revisor.

\section{Evaluación de la calidad de la evidencia}

La evaluación de la calidad de la evidencia se desarrolló según el método "Grading of Recommendations Assessment, Development and Evaluation" (GRADE) (219) y GRADECERQual (220) para los estudios cualitativos.

Para la evaluación del riesgo de sesgo de los estudios se siguieron los criterios empleados en la GPC del NICE (fundamentalmente herramienta RoB para estudios de intervención, QUADAS para estudios de pruebas diagnósticas y herramienta CASPe para estudios cualitativos). Todas estas herramientas, así como los criterios para la evaluación de la calidad según GRADE y GRADE-CERQual, se describen en el manual metodológico (215).

\section{Preparación de perfiles de evidencia y marcos de la Evidencia a la Recomendación}

Para cada pregunta clínica se prepararon los perfiles de evidencia GRADE y los marcos de la evidencia a la recomendación. 
- Perfiles de evidencia: proporcionan para cada una de las variables o resultados de interés un resumen de la evidencia y la calificación de la certeza de la evidencia (disponibles en el documento de material metodológico).

- Marcos de la evidencia a la recomendación: tienen como objetivo facilitar el proceso de toma de decisiones del GEG para pasar de la evidencia a la recomendación al resumir de manera estructurada y transparente la evidencia de los siguientes factores: magnitud de los efectos deseables y no deseables esperados, certeza global de la evidencia, variabilidad en cómo los pacientes valoran los desenlaces principales, balance entre los efectos deseables e indeseables esperados, magnitud de los recursos requeridos (costes), certeza en torno a los recursos requeridos, coste-efectividad de la intervención, impacto en la equidad en salud, aceptabilidad para los agentes implicados y factibilidad de la implementación. En el caso de las preguntas adaptadas de la GPC del NICE (22) se adaptaron sus marcos al contexto de la presente guía (SNS). En el caso de la pregunta sobre sedación paliativa se desarrollaron recomendaciones basadas en marcos EtD de novo, originalmente elaborados para esta guía.

\section{Elaboración de las recomendaciones}

Para cada pregunta clínica, el GEG revisó los perfiles de evidencia y proporcionó información de interés antes de las reuniones presenciales. Durante las reuniones se emplearon los marcos Evidence to Recommendations (EtR) de GRADE para ayudar al grupo de trabajo a emitir las recomendaciones finales.

Con el proceso de GRADE-ADOLOPMENT se llegó a tres posibles resultados:

- Adopción de la recomendación, es decir, el uso de la recomendación original;

- Adaptación de la recomendación, es decir, la modificación de la recomendación original;

- Desarrollo de novo de la recomendación, es decir, la creación de una nueva recomendación.

Cada recomendación fue etiquetada según su origen como adoptada, adaptada o nueva, y según el método GRADE como fuertes o débiles (a favor/en contra). El GEG también ha emitido recomendaciones de Buena Práctica Clínica (BPC) y consideraciones clínicas relevantes para la implementación de las recomendaciones.

\section{Revisión externa}

En la revisión de la guía participaron profesionales expertos a propuesta de las diferentes sociedades científicas y asociaciones de pacientes involucradas en el tema objeto de la guía, así como otros considerados relevantes desde el punto de vista clínico por el propio grupo de actualización de la GPC.

\section{Exposición pública}

En la exposición pública participaron organizaciones del ámbito de la salud que no participaron en la revisión externa, registradas previamente e interesadas en hacer aportaciones al mismo. 


\section{Declaración de intereses}

Todos los miembros del grupo de trabajo de la GPC, así como los miembros del grupo de revisión externa firmaron una declaración de intereses. La gestión de los potenciales conflictos de interés se realizó de acuerdo al procedimiento planteado para las guías del Programa de GPC en el SNS.

\section{Actualización}

Está previsto actualizar la guía siguiendo un procedimiento de actualización continuada que consiste en la realización de búsquedas bibliográficas y evaluación de la nueva evidencia cada $6-12$ meses.

Las actualizaciones se realizarán sobre la versión electrónica de la guía, disponible en la URL: http://www.guiasalud.es. 


\section{Difusión e implementación}

\section{Estrategias de difusión e implementación}

Esta GPC consta de una versión completa, un documento de información para pacientes y familiares y un documento con material metodológico. Todos los documentos relacionados con la guía están disponibles a través de las páginas web de la Unidad de Asesoramiento Científico-técnico (Avalia-t) (http://acis.sergas.es) y de GuíaSalud (http://portal.guiasalud. es).

Las estrategias planteadas para la difusión y diseminación de esta GPC son las siguientes:

- Presentación oficial de la guía y sus versiones por parte de las autoridades sanitarias a profesionales de servicios centrales, atención primaria y hospitalaria del Sistema Nacional de Salud.

- Presentación oficial de la guía y sus versiones por parte de las autoridades sanitarias a profesionales del ámbito residencial.

- Presentación de la guía en actividades científicas (jornadas, congresos y reuniones).

- Envío individualizado por correo electrónico a los profesionales sanitarios implicados y distribución a los pacientes y familiares en colaboración con las asociaciones de pacientes y escuelas para ciudadanos.

- Difusión en formato electrónico en las páginas web de los servicios de salud y de las sociedades científicas y asociaciones de pacientes implicadas en la atención paliativa.

- Inclusión de la guía a bases de datos recopiladoras de GPC, a nivel nacional (GuíaSalud) e internacional.

- Planificación e implementación de actividades de formación en línea y/o presenciales sobre la atención paliativa al adulto en situación de últimos días.

- Realización de talleres con pacientes, familiares y ciudadanos interesados, en colaboración con las escuelas de salud para la ciudadanía.

- Realización de publicaciones derivadas de la guía en revistas científicas.

\section{Propuesta de Indicadores}

Tras la elaboración de una GPC, es importante conocer si se alcanzan los objetivos esperados con la implementación de sus recomendaciones. Para ello se han diseñado una serie de indicadores de proceso que podrían ser empleados para monitorizar la calidad asistencial en la atención en los últimos días de vida.

A continuación, se relacionan y describen los indicadores propuestos por el grupo de trabajo, desarrollados por consenso del grupo y siguiendo las directrices del manual metodológico para la elaboración de GPC en el SNS (215). No son indicadores únicos y cerrados, sino que representan una propuesta orientativa que pueda servir de herramienta 
en caso de que los profesionales decidan emplearlos. En caso de su uso para la mejora de la calidad asistencial, deberían ser adaptados en función de la evaluación y medición específica que se quiera llevar a cabo o analizar, así como del contexto en el que se quieran implementar.

\begin{tabular}{|l|l|}
\hline Denominación del indicador & 1. Reconocimiento de situación de últimos días. \\
\hline Justificación & $\begin{array}{l}\text { Reconocer la situación de últimos días es un proceso que puede ser com- } \\
\text { plejo, pero es de gran importancia porque permite readaptar el plan de } \\
\text { cuidados individualizado y buscar la aplicación de medidas que puedan } \\
\text { mejorar el bienestar y confort de los pacientes y sus familias. }\end{array}$ \\
\hline Fórmula & $\begin{array}{l}\text { Proporción de muertes de adultos con registro documentado de que se } \\
\text { reconoció que la persona se encontraba en los últimos días de vida. } \\
\text { Numerador: total de adultos en los que se registró en la historia clínica } \\
\text { electrónica que la persona estaba en los últimos días de vida. } \\
\text { Denominador: total de muertes de adultos. }\end{array}$ \\
\hline Estándar orientativo & Cuanto más cercano a 100, mejor será el resultado del indicador. \\
\hline Población & Adultos. \\
\hline $\begin{array}{l}\text { Área geográfica y periodo de } \\
\text { tiempo de referencia }\end{array}$ & $\begin{array}{l}\text { Se indicará el área geográfica de referencia y se incluirán aquellos pacien- } \\
\text { tes atendidos en el periodo de referencia, generalmente anual. }\end{array}$ \\
\hline Tipo de indicador & Proceso. \\
\hline Fuente & Historia clínica electrónica/sistemas de registro. \\
\hline
\end{tabular}

\begin{tabular}{|c|c|}
\hline Denominación del indicador & $\begin{array}{l}\text { 2. Evaluación de evolución de signos y síntomas una vez que se } \\
\text { identifica la situación de últimos días. }\end{array}$ \\
\hline Justificación & $\begin{array}{l}\text { Una vez que se identifica la situación de últimos días es relevante la eva- } \\
\text { luación de la evolución de signos y síntomas para detectar cambios adi- } \\
\text { cionales. }\end{array}$ \\
\hline Fórmula & $\begin{array}{l}\text { Proporción de adultos en situación de últimos días de vida con registro } \\
\text { documentado de evaluación de signos y síntomas al menos diariamente. } \\
\text { Numerador: total de adultos en situación de últimos días en los que se } \\
\text { registró la evaluación de signos y síntomas al menos una vez al día. } \\
\text { Denominador: total de adultos reconocidos en situación de últimos días } \\
\text { de vida. }\end{array}$ \\
\hline Estándar orientativo & Cuanto más cercano a 100, mejor será el resultado del indicador. \\
\hline Población & Adultos. \\
\hline $\begin{array}{l}\text { Área geográfica y periodo de } \\
\text { tiempo de referencia }\end{array}$ & $\begin{array}{l}\text { Se indicará el área geográfica de referencia y se incluirán aquellos pacien- } \\
\text { tes atendidos en el periodo de referencia, generalmente anual. }\end{array}$ \\
\hline Tipo de indicador & Proceso. \\
\hline Fuente & Historia clínica electrónica/sistemas de registro. \\
\hline
\end{tabular}




\begin{tabular}{|l|l|}
\hline Denominación del indicador & $\begin{array}{l}\text { 3. Toma de decisiones compartida y revisión o elaboración del plan de } \\
\text { cuidados individualizado en pacientes en situación de últimos días. }\end{array}$ \\
\hline Justificación & $\begin{array}{l}\text { La atención en los últimos días debe responder a las necesidades y prefe- } \\
\text { rencias personales del paciente y/o sus familias. Aunque las conversacio- } \\
\text { nes sobre el plan de cuidados deberían haber comenzado en etapas an- } \\
\text { teriores de la atención, en la situación de últimos días debería revisarse el } \\
\text { plan de cuidados individualizado y en caso de no existir debería realizarse. }\end{array}$ \\
\hline Fórmula & $\begin{array}{l}\text { Proporción de adultos en situación de últimos días de vida que cuentan } \\
\text { con un plan de atención individualizado. } \\
\text { Numerador: total de adultos en situación de últimos días con un plan de } \\
\text { atención individualizado. } \\
\text { Denominador: total de adultos en situación de últimos días de vida. }\end{array}$ \\
\hline Estándar orientativo & Cuanto más cercano a 100, mejor será el resultado del indicador. \\
\hline Población & Adultos. \\
\hline $\begin{array}{l}\text { Área geográfica y periodo de } \\
\text { tiempo de referencia }\end{array}$ & $\begin{array}{l}\text { Se indicará el área geográfica de referencia y se incluirán aquellos pacien- } \\
\text { tes atendidos en el periodo de referencia, generalmente anual. }\end{array}$ \\
\hline Tipo de indicador & Proceso. \\
\hline Fuente & Historia clínica electrónica/sistemas de registro. \\
\hline
\end{tabular}

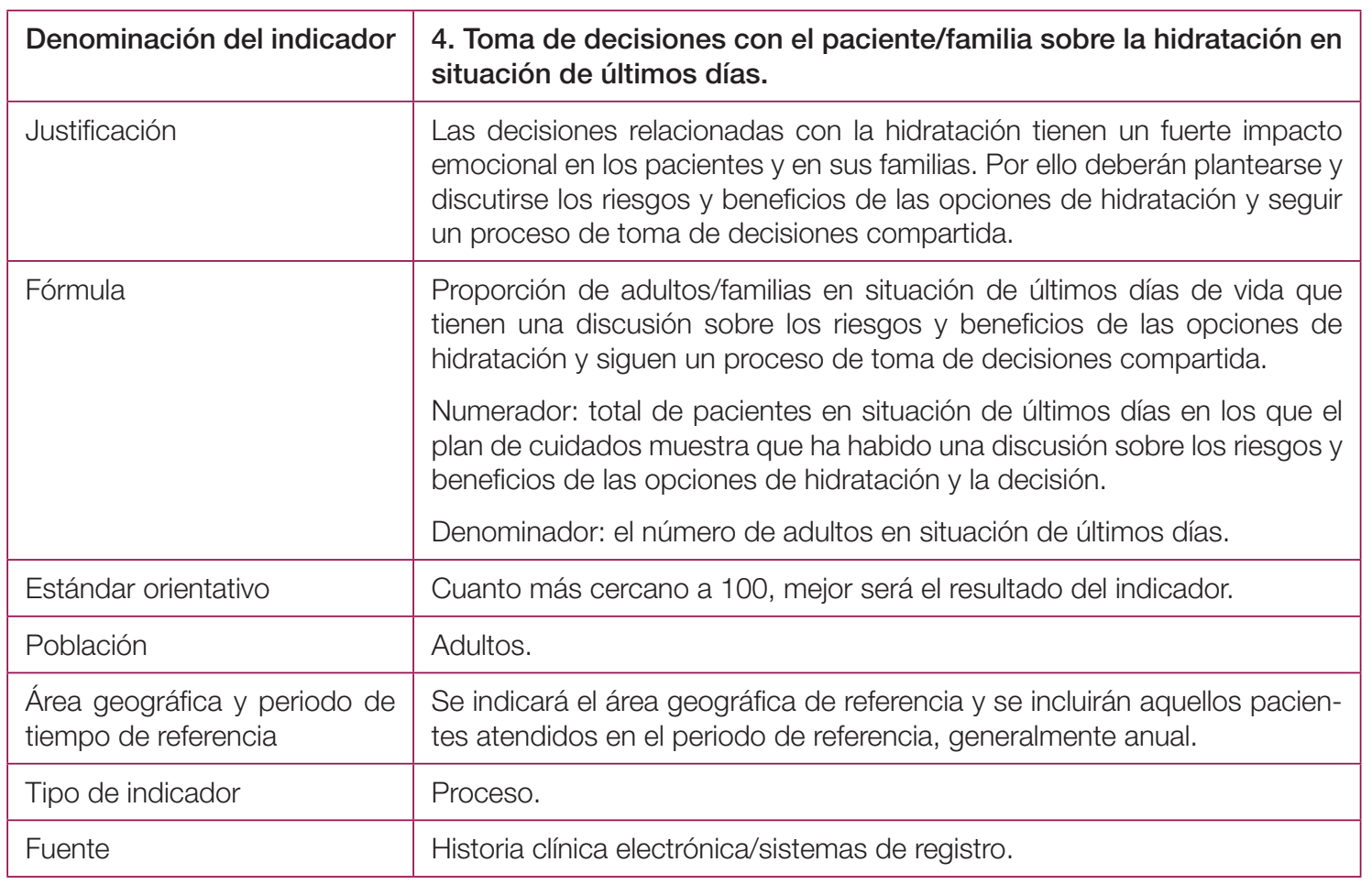




\begin{tabular}{|l|l|}
\hline Denominación del indicador & $\begin{array}{l}\text { 5. Toma de decisiones compartida sobre la aplicación de sedación } \\
\text { paliativa en síntomas refractarios en situación de últimos días. }\end{array}$ \\
\hline Justificación & $\begin{array}{l}\text { En la fase final de la vida es relevante la discusión entre los profesionales, } \\
\text { el paciente y su familia sobre el balance beneficio-riesgo de la sedación } \\
\text { paliativa ante la aparición de síntomas refractarios y su registro en la his- } \\
\text { toria clínica. }\end{array}$ \\
\hline Fórmula & $\begin{array}{l}\text { Proporción de adultos en situación de últimos días en los que se discute } \\
\text { el balance beneficio-riesgo con el paciente/familia sobre sedación paliativa } \\
\text { para aliviar el sufrimiento causado por síntomas refractarios. } \\
\text { Numerador: total de adultos/familia en situación de últimos días en los que } \\
\text { se discute el balance beneficio-riesgo de la sedación paliativa para el alivio } \\
\text { de síntomas refractarios y se sigue un proceso de toma de decisiones } \\
\text { compartida. } \\
\text { Denominador: total de adultos en situación de últimos días de vida a los } \\
\text { que se les aplica algún tipo de sedación paliativa. }\end{array}$ \\
\hline Estándar orientativo & Cuanto más cercano a 100, mejor será el resultado del indicador. \\
\hline Población & Adultos. \\
\hline $\begin{array}{l}\text { Área geográfica y periodo de } \\
\text { tiempo de referencia }\end{array}$ & $\begin{array}{l}\text { Se indicará el área geográfica de referencia y se incluirán aquellos pacien- } \\
\text { tes atendidos en el periodo de referencia, generalmente anual. }\end{array}$ \\
\hline Tipo de indicador & Proceso. \\
\hline Fuente & Historia clínica electrónica/sistemas de registro. \\
\hline
\end{tabular}




\section{Líneas de investigación futura}

En el proceso de elaboración de la GPC se han identificado las siguientes líneas de investigación futura, que el grupo elaborador de la guía ha considerado que pueden ser relevantes para profesionales y pacientes.

\section{Reconocimiento de situación de últimos días}

- Poner en marcha estudios con un enfoque de métodos mixtos (evidencia cuantitativa y cualitativa) para explorar cómo las diferentes intervenciones pueden reducir el impacto de la incertidumbre en el reconocimiento de la SUD en la atención clínica, la toma de decisiones compartida y la comunicación, específicamente en la participación de la persona enferma y las personas importantes para ella en discusiones sobre cuidados al final de la vida.

- Realizar estudios sobre herramientas y modelos de pronóstico para el reconocimiento de la SUD.

\section{Comunicación e información}

- Poner en marcha estudios cuantitativos y cualitativos en España sobre las barreras y facilitadores para una adecuada comunicación e intercambio de información entre los profesionales, pacientes y familia en la situación de últimos días.

- Poner en marcha estudios cuantitativos y cualitativos en España sobre las barreras y facilitadores para una adecuada toma de decisiones compartida en situación de últimos días.

- Realizar estudios que evalúen el impacto de talleres, cursos y otras actividades formativas en la práctica asistencial de los profesionales implicados en la SUD.

\section{Manejo de síntomas}

- Realizar ensayos clínicos aleatorizados para investigar cuáles son las mejores opciones farmacológicas y las dosis para controlar el delirium en SUD, teniendo en cuenta la efectividad y los efectos adversos (por ejemplo, sedación no deseada).

- Realizar ensayos clínicos aleatorizados para investigar si los fármacos para el control de los estertores en combinación con las medidas no farmacológicas (cuidados de enfermería) son más eficaces en comparación con las medidas no farmacológicas solo.

- Realizar estudios sobre control de síntomas en el ámbito domiciliario, menos frecuentes que en ámbito hospitalario.

- Realizar estudios sobre intervenciones no farmacológicas que permitan evaluar el efecto directo en los síntomas y también en variables como la calidad de vida o el bienestar psicológico.

- Promover estudios para el manejo de síntomas emocionales en allegados. 


\section{Sedación paliativa}

- Realizar estudios que midan específicamente la eficacia (calidad de vida y control de síntomas refractarios) en personas con sedación paliativa, y cuantifiquen los efectos adversos.

\section{Nuevas tecnologías y teleasistencia}

- Realizar estudios que permitan investigar la incorporación a la SUD del apoyo y soporte con nuevas tecnologías y teleasistencia. 


\section{Plan de actualización}

Está previsto actualizar la guía siguiendo un procedimiento de actualización continuada planteado para las guías del Programa de GPC en el SNS, que consiste en la realización de búsquedas bibliográficas y evaluación de la nueva evidencia cada 6-12 meses.

- Integrantes del Grupo de Actualización de la GPC: formarán parte del grupo de actualización continuada una documentalista, los coordinares clínicos y la coordinadora metodológica y tres integrantes más del grupo de trabajo.

- El GEG ha considerado que deben monitorizarse en el proceso de actualización continuada las siguientes preguntas clínicas:

- Para personas en los últimos días de vida, ¿qué fármacos son más efectivos para aliviar el dolor, la disnea, las náuseas y vómitos, la ansiedad y el delirium, y los estertores?

- En pacientes en situación de últimos días con sufrimiento por síntomas refractarios, ¿cuáles son los beneficios de la sedación paliativa en el alivio del sufrimiento y el control de síntomas refractarios?

- Listado de preguntas clínicas que no fueron priorizadas para ser monitorizadas:

- ¿Qué signos y síntomas se deben evaluar cuándo sospechamos que un paciente adulto con enfermedad crónica avanzada puede estar en situación de últimos días?

- ¿Cuáles son los factores asociados a una buena comunicación en los últimos días de vida entre el paciente, sus allegados y los profesionales sanitarios?

- ¿Cuáles son los factores que pueden favorecer la toma de decisiones compartida sobre el plan de cuidados individualizado para los últimos días de vida?

- ¿En pacientes en sus últimos días de vida, la hidratación artificial es efectiva para mejorar los síntomas y el confort general?

- Fuentes de información que se consultarán: se activarán alertas en Medline.

- Cronograma de ejecución de las búsquedas y evaluación del impacto de la nueva evidencia: se realizará el primer ciclo de actualización transcurridos doce meses desde la fecha de cierre de las búsquedas de la GPC y los siguientes ciclos de actualización con una periodicidad de seis meses, tal y como se contempla en la metodología de actualización continuada de las GPC del programa.

Las actualizaciones se realizarán sobre la versión electrónica de la guía, disponible en la URL: http://www.guiasalud.es 

Anexos 



\section{Anexo 1. Material complementario al capítulo de comunicación}

Tabla 4. Técnicas para una comunicación eficaz en situación de últimos días

\begin{tabular}{|c|c|}
\hline Técnica & Ejemplo \\
\hline $\begin{array}{l}\text { Cuidar el paralenguaje y el lenguaje cor- } \\
\text { poral }\end{array}$ & $\begin{array}{l}\text { Hablar de forma tranquila, mantener el contacto ocular y una } \\
\text { postura abierta y cercana. }\end{array}$ \\
\hline $\begin{array}{l}\text { Evitar frases hechas y respuestas evasi- } \\
\text { vas que de forma instintiva surgen para } \\
\text { aliviar la ansiedad de la persona que sufre } \\
\text { y la propia. }\end{array}$ & Evitar respuestas como "no te preocupes, todo va a salir bien...". \\
\hline $\begin{array}{l}\text { Favorecer que la persona exprese lo que } \\
\text { piensa y siente a través de una escucha } \\
\text { activa, preguntas abiertas, con gestos o } \\
\text { palabras que le estimulen a seguir ha- } \\
\text { blando o mediante el uso del silencio sig- } \\
\text { nificativo. }\end{array}$ & $\begin{array}{l}\text { - “¿Qué le preocupa?" } \\
\text { - “¿Cómo le ha hecho sentir esto que le he dicho?" } \\
\text { _ "Siga contándome" } \\
\text { _ "Veo que está llegando el final”. } \\
\text { "¿Te parece que queda poco tiempo?" } \\
\text { - "Me muero" } \\
\text { (silencio, el profesional mantiene la mirada, toca su mano) } \\
\text { - "Tengo miedo al dolor" } \\
\text { "¿Te preocupa sufrir en los últimos días?" }\end{array}$ \\
\hline $\begin{array}{l}\text { Legitimar y validar las preguntas que nos } \\
\text { hace; normalizar disminuye la ansiedad } \\
\text { de ambos interlocutores. }\end{array}$ & - "Es normal que te preguntes esto" \\
\hline $\begin{array}{l}\text { Explorar los porqués de la persona para } \\
\text { tratar este tema, los motivos pueden ser } \\
\text { diferentes y no debemos presuponerlos. }\end{array}$ & $\begin{array}{l}\text { - "Voy a responderte, pero antes dime qué te ha hecho pensar } \\
\text { en esto" }\end{array}$ \\
\hline $\begin{array}{l}\text { Acompasar el ritmo y tono de voz al de la } \\
\text { persona, centrándonos en lo que le preo- } \\
\text { cupa y no en lo que nosotros pensamos } \\
\text { que es importante. Pedir clarificaciones } \\
\text { es muy importante, evita dar por supues- } \\
\text { to lo que la otra persona quiere decir. }\end{array}$ & $\begin{array}{l}\text { - "Quiero dormir y acabar ya". } \\
\text { "¿Qué quieres decir con dormir y acabar?" } \\
\text { - "Sé que estoy mal, pero tengo esperanza" } \\
\text { "Háblame de esa esperanza" }\end{array}$ \\
\hline $\begin{array}{l}\text { Abordar la conversación desde una acti- } \\
\text { tud de empatía compasiva, que consiste } \\
\text { en ponerse en el lugar del otro, hacérselo } \\
\text { ver y poner en marcha acciones de ayu- } \\
\text { da. }\end{array}$ & $\begin{array}{l}\text { - "Mi padre se está muriendo y no están haciendo nada". } \\
\text { - "Entiendo tu enfado y tu angustia. Tiene que ser muy duro } \\
\text { para ti. Vamos a acompañarle y a cuidarle para que esté lo } \\
\text { mejor posible hasta el final". }\end{array}$ \\
\hline $\begin{array}{l}\text { Para la comunicación de malas noticias, } \\
\text { tanto presencialmente como de forma te- } \\
\text { lefónica o a través de otros medios tele- } \\
\text { máticos, se pueden emplear las } 6 \text { etapas } \\
\text { de Buckman (96). }\end{array}$ & $\begin{array}{l}\text { 1) Preparar el entorno; } \\
\text { 2) Explorar qué es lo que sabe la persona; } \\
\text { 3) Explorar qué es lo que quiere saber; } \\
\text { 4) Dar la información a partir de lo que sabe o pregunta; } \\
\text { 5) Acoger la reacción emocional de la persona que recibe la } \\
\text { información facilitando que exprese lo que siente; y } \\
\text { 6) Explicar qué es lo que vamos a hacer a partir de ese momen- } \\
\text { to y ofrecer disponibilidad. }\end{array}$ \\
\hline
\end{tabular}

Fuente: elaboración propia. 
Tabla 5. Manejo del pacto de silencio

\begin{tabular}{|c|c|}
\hline Técnica & Ejemplo \\
\hline \multirow{3}{*}{\multicolumn{2}{|c|}{$\begin{array}{l}\text { Como consecuencia del pacto de silencio, pueden surgir en el paciente sentimientos de soledad, incomu- } \\
\text { nicación, aislamiento, falta de comprensión, falta de confianza en los sanitarios, sintomatología ansiosa o } \\
\text { depresiva, miedo e ira, disminución del umbral de percepción del dolor y otros síntomas y además se impide } \\
\text { la ventilación emocional y la posibilidad de cerrar asuntos pendientes. Cuando esto ocurre, podemos sentir } \\
\text { el impulso de utilizar el argumento de que la persona enferma tiene derecho por ley. Esto puede ser nece- } \\
\text { sario en algún caso, pero podemos utilizar otras estrategias que sean más efectivas y que eviten el conflicto } \\
\text { con los familiares. } \\
\text { El primer OBJETIVO no sería informar al paciente, sino crear un puente de comunicación entre la persona } \\
\text { con enfermedad avanzada y sus seres queridos. Para ello podemos seguir varias pautas, que se describen } \\
\text { a continuación. } \\
\qquad \text { "Mi padre no sabe nada de lo que tiene. No queremos que lo sepa para que no sufra más" }\end{array}$}} \\
\hline & \\
\hline & \\
\hline $\begin{array}{l}\text { Poner sobre la mesa cual es el problema que se pre- } \\
\text { senta. }\end{array}$ & $\begin{array}{l}\text { - "Quiere decir que han acordado que él no sepa } \\
\text { nada de lo que le pasa". }\end{array}$ \\
\hline $\begin{array}{l}\text { Explorar, empatizar y validad sus emociones, mie- } \\
\text { dos y preocupaciones con respecto a la comunica- } \\
\text { ción al enfermo. Identificar el mayor temor y hacerlo } \\
\text { explícito, facilitando la expresión emocional y tran- } \\
\text { quilizando. }\end{array}$ & $\begin{array}{l}\text { - "Entiendo que ustedes quieren mucho a su padre } \\
\text { y es normal que quieran evitarle más sufrimiento". }\end{array}$ \\
\hline Hacer ver las implicaciones que tiene para la familia. & $\begin{array}{l}\text { - "Tiene que ser muy duro tener que disimular ante } \\
\text { él. ¿Qué supone para ustedes tener que ocultar- } \\
\text { se y no poder expresarse?". }\end{array}$ \\
\hline $\begin{array}{l}\text { Favorecer la reflexión sobre lo que puede pensar o } \\
\text { sentir la persona enferma y poner en contexto. }\end{array}$ & $\begin{array}{l}\text { - “ ¿Crees que no se da cuenta?”. } \\
\text { _ "Él se ve cada vez más deteriorado”. } \\
\text { - “ ¿Cómo cree que se sentirá en el momento que } \\
\text { perciba lo avanzado de su enfermedad y se sien- } \\
\text { ta engañado por todos?”. }\end{array}$ \\
\hline $\begin{array}{l}\text { Ofrecer la posibilidad de explorar lo que piensa la } \\
\text { persona enferma. } \\
\text { Establecer el nivel de información a partir del conoci- } \\
\text { miento y de las necesidades del paciente. } \\
\text { Ofrecerse como mediador si la conspiración del si- } \\
\text { lencio genera problemas. }\end{array}$ & $\begin{array}{l}\text { _- "Quizá no sea necesario decirle la palabra cáncer, } \\
\text { pero podríamos ver qué es lo que sabe y lo que } \\
\text { quiere saber. Si ustedes quieren puedo hablar } \\
\text { con él o podemos estar los tres y hablamos de } \\
\text { cómo se sienten". } \\
\text { _ "¿Qué le parece si escuchamos juntos al paciente } \\
\text { y vemos qué necesita o le puede ayudar mejor?" }\end{array}$ \\
\hline
\end{tabular}

Fuente: elaboración propia. 


\section{Anexo 2. Material complementario al capítulo de hidratación}

\section{Tabla 6. Cuidado de la boca seca en situación de últimos días}

- Limpieza de la boca evitando generar disconfort: mantener los labios y la mucosa oral limpios, suaves y sin lesiones en la medida de lo posible.

- Retirar prótesis dentales si no son necesarias.

- Humedecer con una gasa o spray la boca y aplicar protector labial en los labios con una gasa o spray la boca e hidratar los labios con cacao (no utilizar vaselina dado que es hidrófoba).

- Limpiar la lengua con suavidad (usando una torunda de gasa o un cepillo suave) evitando molestar, para retirar restos de secreciones secas. Si hay costras se pueden utilizar soluciones de agua y bicarbonato.

- En caso de que la persona mantenga la capacidad de tragar valorar ofrecer pequeñas cantidades de líquido fresco en sorbos pequeños (valorar usar espesantes).

- También puede valorarse el uso de estimuladores de la salivación como hielo para chupar, helados, zumos o frutas ligeramente ácidas (piña, fresa, etc.). Pueden ofrecerse líquidos aromatizados con limón, zumos de fruta con hielo, manzanilla con limón.

Fuente: elaboración propia. 



\section{Anexo 3. Material complementario al capítulo de manejo clínico de síntomas: consideraciones generales (ESAS-r)}

\section{Cuestionario de evaluación de síntomas de Edmonton, versión española revisada ESAS-r (es) (110)}

Por favor, marque el número que describa mejor como se siente AHORA:

\begin{tabular}{|c|c|c|c|c|c|c|c|c|c|c|c|c|}
\hline Nada de dolor & 0 & 1 & 2 & 3 & 4 & 5 & 6 & 7 & 8 & 9 & 10 & $\begin{array}{l}\text { El peor dolor que se } \\
\text { pueda imaginar }\end{array}$ \\
\hline $\begin{array}{l}\text { Nada agotado } \\
\text { (cansancio, debilidad) }\end{array}$ & 0 & 1 & 2 & 3 & 4 & 5 & 6 & 7 & 8 & 9 & 10 & $\begin{array}{l}\text { Lo más agotado que se } \\
\text { pueda imaginar }\end{array}$ \\
\hline $\begin{array}{l}\text { Nada somnoliento } \\
\text { (adormilado) }\end{array}$ & 0 & 1 & 2 & 3 & 4 & 5 & 6 & 7 & 8 & 9 & 10 & $\begin{array}{l}\text { Lo más somnoliento } \\
\text { que se pueda imaginar }\end{array}$ \\
\hline Sin náuseas & 0 & 1 & 2 & 3 & 4 & 5 & 6 & 7 & 8 & 9 & 10 & $\begin{array}{l}\text { Las peores náuseas que } \\
\text { se pueda imaginar }\end{array}$ \\
\hline $\begin{array}{l}\text { Ninguna pérdida de } \\
\text { apetito }\end{array}$ & 0 & 1 & 2 & 3 & 4 & 5 & 6 & 7 & 8 & 9 & 10 & $\begin{array}{l}\text { El peor apetito que se } \\
\text { pueda imaginar }\end{array}$ \\
\hline $\begin{array}{l}\text { Ninguna dificultad } \\
\text { para respirar }\end{array}$ & 0 & 1 & 2 & 3 & 4 & 5 & 6 & 7 & 8 & 9 & 10 & $\begin{array}{l}\text { La mayor dificultad } \\
\text { para respirar que se } \\
\text { pueda imaginar }\end{array}$ \\
\hline Nada desanimado & 0 & 1 & 2 & 3 & 4 & 5 & 6 & 7 & 8 & 9 & 10 & $\begin{array}{l}\text { Lo más desanimado que } \\
\text { se pueda imaginar }\end{array}$ \\
\hline $\begin{array}{l}\text { Nada nervioso } \\
\text { (intranquilidad, } \\
\text { ansiedad) }\end{array}$ & 0 & 1 & 2 & 3 & 4 & 5 & 6 & 7 & 8 & 9 & 10 & $\begin{array}{l}\text { Lo más nervioso que se } \\
\text { pueda imaginar }\end{array}$ \\
\hline Duermo perfectamente & 0 & 1 & 2 & 3 & 4 & 5 & 6 & 7 & 8 & 9 & 10 & $\begin{array}{l}\text { La mayor dificultad } \\
\text { para dormir que se } \\
\text { pueda imaginar }\end{array}$ \\
\hline $\begin{array}{l}\text { Sentirse perfectamente } \\
\text { (sensación de } \\
\text { bienestar) }\end{array}$ & 0 & 1 & 2 & 3 & 4 & 5 & 6 & 7 & 8 & 9 & 10 & $\begin{array}{l}\text { Sentirse lo peor que se } \\
\text { pueda imaginar }\end{array}$ \\
\hline $\begin{array}{l}\text { Nada } \\
\text { Otro problema (por ej; } \\
\text { sequedad de boca) }\end{array}$ & 0 & 1 & 2 & 3 & 4 & 5 & 6 & 7 & 8 & 9 & 10 & Lo peor posible \\
\hline
\end{tabular}





\section{Anexo 4. Material complementario al capítulo de manejo clínico de síntomas: dolor}

Tabla 7. Evaluación y valoración del dolor mediante escalas

\begin{tabular}{|c|c|}
\hline \multicolumn{2}{|c|}{ Métodos de Evaluación Verbal } \\
\hline $\begin{array}{l}\text { Permiten una evaluación por } \\
\text { parte del propio paciente } \\
\text { verbalmente o por escrito. }\end{array}$ & $\begin{array}{l}\text { a. Unidimensionales. Valoran una única dimensión (cantidad de dolor). Son } \\
\text { la EVA (escala visual analógica), EVN (escala de valoración numérica), } \\
\text { donde es el propio paciente el que "puntúa" su dolor. Son las más em- } \\
\text { pleadas en la práctica clínica. } \\
\text { b. Multidimensionales. Valoran más de una dimensión, siendo la cuantifica- } \\
\text { ción del dolor una de ellas en la mayoría de los casos. } \\
\text { - McGill Pain Questionnaire (MPQ) (221) } \\
\text { - Cuestionario Breve del Dolor (BPI) (222) } \\
\text { - Test de Lattinen }(223,224) \\
\text { - Escalas de valoración del dolor neuropático como DN4 }(225,226) \text { y } \\
\text { - LANSS (227) }\end{array}$ \\
\hline \multicolumn{2}{|l|}{ Métodos conductuales } \\
\hline $\begin{array}{l}\text { Es un evaluador externo, y } \\
\text { no el propio paciente quien } \\
\text { evalúa el dolor del paciente. }\end{array}$ & $\begin{array}{l}\text { a. Escala facial (escala de expresión facial, FPS) (228) } \\
\text { b. Escala de Campbell (229) } \\
\text { c. PAINAD (230) }\end{array}$ \\
\hline
\end{tabular}

Fuente: elaboración propia.

Tabla 8. Cuidados y medidas no farmacológicas para controlar el dolor en la situación de últimos días

- Tener en cuenta las dimensiones psicosocial, espiritual y cultural que puedan acompañar al dolor y dificultar su alivio.

- Educar al entorno de cuidado para la prevención de situaciones que provoquen dolor (por ejemplo, movilizaciones).

- Utilizar actitudes y herramientas de acompañamiento y apoyo emocional (empatía compasiva, escucha activa, presencia, acogimiento). Incluir a la familia y entorno de cuidado, reforzando positivamente su rol de cuidado.

- Procurar un ambiente tranquilo y confortable (temperatura de la habitación, iluminación, ruidos, visitas).

- Valorar el uso de medidas que puedan aliviar el dolor como aplicación de calor/frío, masajes, técnicas de relajación y meditación, distracción, musicoterapia, etc. Valorar de forma personalizada el uso de estas medidas antes, después y, si es posible, durante la experiencia dolorosa.

- Fomentar o facilitar el descanso.

- Valorar la efectividad de las medidas analgésicas tomadas.

- Vigilar la aparición de efectos secundarios no deseados y tomar las medidas oportunas. Informar a paciente y familia sobre las causas y las medidas a tomar.

- Valorar la factibilidad de usar la vía oral y compartir con el equipo la necesidad de cambiar la vía de administración si es el caso.

Fuente: elaboración propia a partir de varias fuentes $(20,231-234)$. 


\section{ASPECTOS PRÁCTICOS EN EL USO DE OPIOIDES: VÍAS DE ADMINISTRACIÓN; TITULACIÓN Y MEDICACIÓN DE RESCATE; CAMBIO y ROTACIÓN}

\section{Vías de administración}

El GEG, por las peculiaridades que presentan las vías de administración en los pacientes en cuidados paliativos, especialmente en la SUD, y por su importante impacto en el manejo del dolor, cree necesario establecer unas recomendaciones específicas:

a) Frecuentemente en SUD la vía oral no está disponible (incapacidad para tragar, disfagia, deterioro del nivel de conciencia, etc.), por lo que la alternativa será la parenteral (subcutánea o intravenosa) según el medio y disponibilidad.

b) La necesidad de esta vía debería anticiparse cuando se vea próxima la pérdida de la vía oral o para mejorar la eficacia analgésica (mayor rapidez).

c) La vía de elección en el domicilio es la vía subcutánea.

d) Se utilizará la vía iv si:

- Vía iv disponible antes de entrar en SUD.

- Anasarca.

- Riesgo de hemorragia.

- Discrasia sanguínea con o sin riesgo de hemorragia con capacidad para producir hematomas subcutáneos.

- Rechazo del paciente o de la familia al uso de la vía sc.

- Necesidad de fármacos de uso exclusivo iv.

e) Debe tenerse presente la importancia de evitar procedimientos agresivos y a veces, la canalización dificultosa de una vía venosa puede serlo.

f) Se puede plantear el empleo del reservorio en pacientes portadores del mismo, pero se debe valorar cuidadosamente en el medio domiciliario por la frecuente necesidad de establecer una infusión continua.

g) La vía transdérmica puede no ser confiable por la disminución de la perfusión en la SUD, aunque si el síntoma está controlado podrá mantenerse esta opción utilizando la vía sc o iv para el resto de fármacos.

h) Deben tenerse en cuenta las preferencias del paciente y/o familia en cuanto a la vía de administración.

i) Para el cambio de vía oral a vía parenteral se tendrán en cuenta las siguientes consideraciones:

- La dosis equianalgésica por vía sc es la mitad de la dosis oral y un tercio por vía iv aunque algunos autores consideran ambas vías parenterales similares (vo: $\mathrm{sc}=1 / 1 / 2$; vo: iv=1/1/3) (235). 
- Se iniciará la infusión continua de morfina parenteral (iv o sc) entre las 6-8 horas de la última toma de morfina oral de liberación retardada. Puede optarse por la administración en bolus cada 4 h. en lugar de infusión continua, si se prevé escasa supervivencia o si no hay disponibilidad de infusores.

\section{Titulación y medicación de rescate:}

Si el paciente no tenía un opioide previo, el fármaco de elección en SUD es la morfina. La dosis de inicio de morfina de acción rápida es:

- Si mantiene la vía oral, de 5-10 mg/4 h de morfina oral de liberación rápida (235).

- Si no disponemos de la vía oral: $3-5 \mathrm{mg} / 4 \mathrm{~h}$ iv o sc. O perfusión continua con $15-30 \mathrm{mg} / 24$ h vía subcutánea ó 10-20 mg/24 h vía iv (235).

Siempre se dejará medicación de rescate que será entre un 10 y un 16 \% (1/6) de la dosis total diaria.

\section{Cambio y rotación de opioides}

Se mantendrá, en principio el opioide previo, si bien en SUD puede ser necesario realizar un cambio de opioide cuando se presente la pérdida de la vía oral. Para ello se tendrá en cuenta las dosis equianalgésicas según lo referido en tabla 9.

En algunas ocasiones, si bien poco frecuente en SUD, puede ser necesario realizar el procedimiento conocido como rotación de opioides que consiste en un cambio de un opioide potente por otro con el objetivo de mejorar la analgesia o disminuir los efectos secundarios.

Puede ser útil realizar una rotación opioide en los siguientes casos (235):

- Somnolencia excesiva o enlentecimiento psicomotor sin fallo cognitivo.

- Neurotoxicidad inducida por opioides (delirium, mioclonías, hiperalgesia).

- Náuseas, vómitos, íleo paralítico.

- Fallo primario opioide.

Para realizar una rotación opioide se recomienda seguir los siguientes pasos (236):

1. Calcular la dosis total de opioide utilizada en las últimas 24 horas. Para ello sumaremos la dosis de opioide basal y la dosis de los rescates utilizados.

2. Calcular la dosis equivalente de morfina oral (DEMO). Para ello emplearemos una tabla de equivalencia o factor de conversión (235). La tabla de equivalencia se aplicará con precaución debido a que hay gran variedad en el metabolismo y farmacodinámica de los medicamentos, por lo que muchos pacientes con características similares pueden tener respuestas muy diferentes a los mismos.

3. Elección del nuevo opioide y calcular la dosis equivalente del opioide al que vamos a rotar, en general, morfina parenteral (fentanilo o metadona en casos de dolor difícil a nivel hospitalario).

4. Reducción de dosis entre un 25 y 50 \% de la dosis del nuevo opioide: 
- Reducción del 50 \% si:

- Dosis altas de opioide basal.

- No caucasiano.

- Anciano/fragilidad.

- Insuficiencia hepática o renal severas.

- Reducción del 25 \% si:

- No se cumplen las condiciones anteriores.

- Se cambia la vía de administración, pero no el opioide.

- Dolor severo sin efectos adversos.

5. Establecer la dosis total diaria del nuevo opioide y dividir por el número de dosis diarias. En el caso más habitual de la SUD, que será la rotación a morfina iv o subcutánea, se podrá utilizar:

- En bolus, cada 4 horas.

- En perfusión continua, iv o subcutánea en infusores (ISCC).

6. Dejar siempre medicación de rescate:

- Dosis de rescate: $10-15 \%$ de la dosis total diaria (1/6).

- Tiempo para repetir los rescates:

- 1 ó 2 horas para la vía oral, excepto los fentanilos ultrarrápidos (sublinguales o nasales), que se podrán repetir entre 15 y 30 minutos (según formulación)

- 30 minutos para la vía subcutánea o intravenosa.

7. Ajustar en $48-72 \mathrm{~h}$.

\section{Algunas consideraciones especiales}

- Respecto al fentanilo: si la rotación es a fentanilo, no se aplicará reducción de dosis. Debe tenerse en cuenta que la disminución de la perfusión periférica en la SUD puede disminuir la efectividad del fentanilo TTS, si bien, si el paciente está bien controlado, puede mantenerse añadiendo las dosis necesarias vía subcutánea.

- En cuanto a la metadona, la rotación debería realizarse por personal experto, dada la dificultad en su uso por su farmacocinética impredecible con posibilidad de acumulación, determinación ratio equianalgésica muy variable y gran cantidad de interacciones farmacológica.

- Insuficiencia renal: especial precaución con el uso de morfina, oxicodona e hidromorfona por su eliminación vía renal. En estos casos puede considerarse ajuste de dosis. Fentanilo y metadona se consideran seguros en insuficiencia renal.

- Insuficiencia hepática: precaución también con la morfina, oxicodona y metadona siendo el fentanilo el más seguro en este caso. 
Tabla 9. Tabla de rotación de opioides (ROP-ICO): equivalencias entre diferentes dosis de opioides y ratios de conversión*

\begin{tabular}{|c|c|c|c|c|c|c|c|c|c|c|c|c|}
\hline Opioide & Posología/vía & \multicolumn{10}{|c|}{ Dosis } & \multirow{4}{*}{$\begin{array}{l}\text { Ratio de } \\
\text { conversión morfina } \\
\text { vo: opioide }\end{array}$} \\
\hline \multirow[t]{7}{*}{ Morfina (mg) } & $\mathrm{c} / 4 \mathrm{~h}$ vo & 5 & 10 & 15 & 20 & 30 & 45 & 60 & 90 & 120 & 160 & \\
\hline & c/24 h vo & 30 & 60 & 90 & 120 & 180 & 270 & 360 & 540 & 740 & 960 & \\
\hline & DE vo & 5 & 10 & 15 & 20 & 30 & 45 & 60 & 90 & 120 & 160 & \\
\hline & $\mathrm{c} / 24 \mathrm{~h} \mathrm{sc}$ & 15 & 30 & 45 & 60 & 90 & 135 & 180 & 270 & 370 & 480 & \multirow{2}{*}{$2: 1(\div 2)$} \\
\hline & DE sc & 3 & 5 & 8 & 10 & 15 & 23 & 30 & 45 & 62 & 80 & \\
\hline & $\mathrm{c} / 24 \mathrm{~h}$ iv & 10 & 20 & 30 & 40 & 60 & 90 & 120 & 180 & 247 & 320 & \multirow{2}{*}{$3: 1(\div 3)$} \\
\hline & DE iv & 2 & 3 & 5 & 7 & 10 & 15 & 20 & 30 & 41 & 53 & \\
\hline \multirow{2}{*}{$\begin{array}{l}\text { Oxicodona } \\
(\mathrm{mg})\end{array}$} & $\mathrm{c} / 24 \mathrm{~h}$ vo & 20 & 40 & 60 & 80 & 120 & 180 & 240 & 360 & 490 & 640 & \multirow{2}{*}{$1,5: 1(\div 1,5)$} \\
\hline & DE vo & 3 & 6 & 10 & 13 & 20 & 30 & 40 & 60 & 80 & 100 & \\
\hline \multirow{2}{*}{$\begin{array}{l}\text { Hidromorfona } \\
\star \star(\mathrm{mg})\end{array}$} & $\mathrm{c} / 24 \mathrm{~h}$ vo & 6 & 12 & 18 & 24 & 36 & 54 & 72 & 108 & 148 & 192 & \multirow{2}{*}{$5: 1(\div 5)$} \\
\hline & DE morfina vo & 5 & 10 & 15 & 20 & 30 & 45 & 60 & 90 & 120 & 160 & \\
\hline \multirow{2}{*}{$\begin{array}{l}\text { Tapentadol } \\
{ }^{\star \star} \neq(\mathrm{mg})\end{array}$} & c/24 h vo & 100 & 200 & 300 & 400 & 600 & 900 & 1.200 & 1.800 & 2.400 & 3.150 & \multirow{2}{*}{$1: 3,3(\times 3,3)$} \\
\hline & DE morfina vo & 5 & 10 & 15 & 20 & 30 & 45 & 60 & 90 & 120 & 160 & \\
\hline \multirow{4}{*}{$\begin{array}{l}\text { Metadona } \\
(\mathrm{mg})\end{array}$} & $\mathrm{c} / 8 \mathrm{~h}$ vo & 3 & 5 & 7 & 5 & 7 & 12 & 10 & 15 & 20 & 26 & \multirow{2}{*}{$\begin{array}{l}<90 \mathrm{mg} \rightarrow 4: 1 \\
90-300 \mathrm{mg} \rightarrow 8: 1 \\
>300 \mathrm{mg} \rightarrow 12: 1\end{array}$} \\
\hline & DE vo & 1,5 & 3 & 4 & 3 & 4 & 6 & 5 & 8 & 10 & 13 & \\
\hline & c/24 h iciv/icsc & 7 & 12 & 17 & 12 & 17 & 28 & 24 & 36 & 48 & 60 & \multirow{2}{*}{$\begin{array}{l}\text { Metadona oral: } \\
\text { metadona sc/iv } \\
1: 0,8 \rightarrow \times 0,8\end{array}$} \\
\hline & DE iv/sc & 1 & 2 & 3 & 2 & 3 & 5 & 4 & 6 & 8 & 10 & \\
\hline \multirow[t]{2}{*}{$\begin{array}{l}\text { Fentanilo } \\
(\mu \mathrm{g} / \mathrm{h})^{\star \star \star}\end{array}$} & $\begin{array}{l}\text { Dosis/h c/72 h } \\
\text { TTS }\end{array}$ & 12,5 & 25 & 37.5 & 50 & 75 & 112,5 & 150 & 225 & 308 & 400 & \multirow{3}{*}{$\begin{array}{l}1 \text { mg morfina: } \\
10 \mu g \text { fentanilo }(x 10) \\
(x \text { 10/24 h si parche) }\end{array}$} \\
\hline & $\begin{array}{r}\text { Dosis del } \\
\text { parche }\end{array}$ & $\begin{array}{r}1 \mathrm{de} \\
12\end{array}$ & $\begin{array}{r}1 \mathrm{de} \\
25\end{array}$ & $\begin{array}{r}1 \text { de } \\
25+1 \\
\text { de } 12\end{array}$ & $\begin{array}{r}1 \mathrm{de} \\
50\end{array}$ & $\begin{array}{r}1 \text { de } \\
75\end{array}$ & $\begin{array}{r}1 \text { de } \\
100+1 \\
\text { de } 12\end{array} \mid$ & $\begin{array}{r}2 \mathrm{de} \\
75\end{array}$ & $\begin{array}{r}3 \text { de } \\
75\end{array}$ & $\begin{array}{r}3 \mathrm{de} \\
100\end{array}$ & $\begin{array}{r}4 \text { de } \\
100\end{array}$ & \\
\hline $\begin{array}{l}\text { Fentanilo } \\
(\mu g)^{\star \star \star}\end{array}$ & $\mathrm{c} / 24 \mathrm{~h}$ iv o sc & 300 & 600 & 900 & 1.200 & 1.800 & 2.700 & 3.600 & 5.400 & 7.400 & 9.600 & \\
\hline \multirow{2}{*}{$\begin{array}{l}\text { Buprenorfina } \\
(\mu \mathrm{g} / \mathrm{h})\end{array}$} & c/72 h TTS & 17,5 & 35 & 52 & 70 & 105 & 157 & \multirow{2}{*}{\multicolumn{4}{|c|}{$\begin{array}{l}\text { No administrar dosis superio- } \\
\text { res de buprenorfina }\end{array}$}} & \multirow{2}{*}{$\begin{array}{l}1 \mathrm{mg} \text { morfina: } \\
14 \mu \mathrm{g} \text { buprenorfina } \\
(\times 14 / 24 \mathrm{~h} \rightarrow \\
\mathrm{FC}=0,583)\end{array}$} \\
\hline & $\begin{array}{r}\text { Dosis del } \\
\text { parche }\end{array}$ & $\begin{array}{r}1 / 2 \text { de } \\
35\end{array}$ & $\begin{array}{r}1 \mathrm{de} \\
35\end{array}$ & $\begin{array}{l}1 \mathrm{de} \\
52,5\end{array}$ & $\begin{array}{r}1 \mathrm{de} \\
70\end{array}$ & $\left|\begin{array}{r}1 \text { de } \\
70+1 \\
\text { de } 35\end{array}\right|$ & 2 de 70 & & & & & \\
\hline \multicolumn{13}{|c|}{$\begin{array}{l}\text { *Las ratios de conversión expuestas en esta tabla corresponden al paso de morfina oral a otras vías de administración u otros opioides. Para realizar la conversión } \\
\text { inversa se deberían aplicar los factores multiplicadores inversos, excepto en el caso de pasar de hidromorfona oral a morfina oral (ratio 3,7:1) y para pasar de } \\
\text { metadona oral a morfina no existe una conversión específica, pero se propone la ratio metadona oral: morfina oral 1:5. } \\
* * \text { En estos momentos, no existen formulaciones de acción rápida que puedan ser utilizadas como medicación de rescate. } \\
* * * \text { Puede rescatar con la dosis extra de los correspondientes opioides potentes o con la dosis efectiva de fentanilo transmucoso. En el caso de administrar fenta- } \\
\text { nilo parenteral: rescate inicial con } 50 \mu \mathrm{g} \text { iv y ajustar posteriormente según respuesta analgésica y duración. } \\
\text { f En el caso de tapentadol, la conversión a morfina se realiza a partir de las equivalencias entre tapentadol y oxicodona. Las dosis máximas recomendadas en } \\
\text { la ficha técnica son } 500 \mathrm{mg} / 24 \mathrm{~h} \text {. A partir de estas dosis se debe evaluar de forma muy precisa la indicación y vigilar la posible aparición de efectos secundarios. } \\
\text { DE: dosis extra; vo: oral; sc: subcutánea; iv: intravenosa; iciv: infusión continua intravenosa; icsc: infusión continua subcutánea;TTS: parche transdérmico; Fc: factor } \\
\text { de conversión. }\end{array}$} \\
\hline
\end{tabular}

Fuente: tomado de Alvaro Pardo et al. (2019) (235). 



\section{Anexo 5. Material complementario al capítulo de manejo clínico de síntomas: disnea}

Tabla 10. Cuidados y medidas no farmacológicas para el abordaje de la disnea en la situación de últimos días

- Posición cómoda.

- Conservación de energía (ayudas para la deambulación).

- Introducir distractores.

- Presencia de una compañía tranquilizadora.

- Facilitar un ambiente abierto, tranquilo.

- Reforzar el entrenamiento muscular.

- Limitar el número de personas en la habitación.

- Evitar el estrés emocional.

- Favorecer corrientes de aire hacia la cara, mediante ventiladores, abanico.

- Comunicación con el paciente: tranquilizadora, enseñar estrategias para disnea basal y para crisis, informar del significado, elaborar plan de cuidados que incluya la sedación.

- Comunicación con la familia: enseñarles a actuar en situaciones de crisis.

Fuente: elaboración propia. 



\section{Anexo 6. Material complementario al capítulo de manejo clínico de síntomas: náuseas y vómitos}

\section{Tabla 11. Cuidados y medidas no farmacológicas en relación con las náuseas y vómitos}

- Valoración continua y proactiva de la sensación de náuseas (intensidad, factores desencadenantes). Valorar la utilización de una escala para valorar el nivel de náuseas (ESAS-r para pacientes oncológicos).

- Si hay vómitos valorar características, sobre todo si hay cambios relevantes (aparición de vómito hemático, fecaloideo, etc.).

- Educar al entorno de cuidado para prevención de situaciones que provoquen náuseas y/o vómitos (ingesta, olores intensos, movilizaciones, etc.).

- Cuidar la higiene bucal, sobre todo si hay vómitos. Evitar medidas que provoquen más náuseas.

- Si la persona puede y desea ingerir algo que sean pequeñas cantidades, mejor líquidos fríos, sin colores u olores que desagraden, lo que podría generar más náuseas (evitar abrir las bandejas o recipientes delante de la persona enferma, dejar enfriar, etc.).

- Reducir o eliminar factores personales que puedan aumentar o desencadenar las náuseas (ansiedad, miedo, fatiga, incertidumbre).

- Utilizar actitudes y herramientas de acompañamiento y apoyo emocional (empatía compasiva, escucha activa, presencia, acogimiento, etc.). Incluir a la familia y entorno de cuidado, reforzando positivamente su rol de cuidado.

- Valorar el uso de medidas no farmacológicas que puedan aliviar la sensación de náuseas como técnicas de relajación, imaginación simple dirigida, distracción etc.

- Fomentar o facilitar el descanso. Procurar un ambiente tranquilo y confortable (temperatura de la habitación, iluminación, ruidos, visitas).

- En algunos casos la sonda nasogástrica puede ser adecuada. Si está indicada, realizar los cuidados propios de la misma.

- Valorar la efectividad de las medidas tomadas. Avisar el médico en caso de síntoma refractario.

Fuente: elaboración propia. 



\section{Anexo 7. Material complementario al capítulo de manejo clínico de síntomas: ansiedad y delirium}

\section{Tabla 12. Cuidados y medidas no farmacológicas en relación con la ansiedad}

- Observar signos verbales y no verbales de ansiedad.

- Procurar un ambiente tranquilo y confortable (temperatura de la habitación, iluminación, ruidos, visitas).

- Permanecer con la persona para dar seguridad y reducir el miedo. Animar a la familia a permanecer con su ser querido transmitiendo calma y tranquilidad (coger de la mano, hablar con suavidad, etc.).

- Utilizar actitudes y herramientas de acompañamiento y apoyo emocional (empatía compasiva, escucha activa, presencia, acogimiento, etc.). Animar a la expresión de sentimientos y emociones.

- Explicar los procedimientos que se van a realizar, incluidas las posibles sensaciones que se han de experimentar durante el procedimiento.

- Resolver las dudas de la persona enferma en cada caso.

- Valorar el uso de masajes relajantes, técnicas de relajación.

Fuente: elaboración propia.

\section{Tabla 13. Cuidados y medidas no farmacológicas en relación con el delirium}

- Observar la aparición de signos que puedan indicar delirium hipoactivo o con agitación. Descartar causas desencadenantes y reversibles (retención urinaria, fecalomas, dolor mal controlado, etc.).

- Procurar un ambiente tranquilo y confortable (temperatura de la habitación, iluminación, ruidos, visitas).

- Hablar a la persona con delirium con suavidad, explicando lo que se va a hacer.

- Evitar confrontación.

- Evitar medidas de restricción física.

- Animar a la familia a permanecer con su ser querido transmitiendo calma y tranquilidad (coger de la mano, hablar con suavidad, etc.).

- Atender a la familia utilizando actitudes y herramientas de acompañamiento y apoyo emocional (empatía compasiva, escucha activa, presencia, acogimiento, etc.). Animar a la expresión de sentimientos y emociones.

Fuente: elaboración propia a partir de varias fuentes $(20,235)$. 



\section{Anexo 8. Material complementario al capítulo de manejo clínico de síntomas: estertores}

Tabla 14. Cuidados y medidas no farmacológicas para el abordaje de los estertores en la situación de últimos días

- Informar sobre las causas y dudas que puedan tener, incidiendo en que, aunque el ruido puede ser angustiante, es poco probable que cause molestias a la persona enferma por el bajo nivel de conciencia.

- Valorar la discontinuación de líquidos IV no esenciales.

- Valorar la posición decúbito lateral o semiprono para facilitar el drenaje postural, posición lateralizada de la cabeza, colocando una toalla o empapador debajo de la boca para recoger las secreciones eliminadas.

- Valorar la necesidad de aspiración de secreciones en cavidad oral (más profunda puede provocar irritación y más secreciones). Evitar incomodar a la persona enferma.

- Cuidar la higiene bucal, procurando que la cavidad oral esté lo más limpia posible de secreciones, evitando provocar disconfort.

- Utilizar actitudes y herramientas de acompañamiento y apoyo emocional a los familiares y allegados, escuchar sus preocupaciones y miedos.

- Reforzar positivamente su rol de cuidado y animarles a participar activamente.

Fuente: elaboración propia a partir de varias fuentes $(20,231,237)$. 



\section{Anexo 9. Uso de la vía subcutánea en cuidados paliativos}

El contenido de este anexo se ha adaptado de la guía sobre uso de la vía subcutánea en CP del Observatorio Regional de Cuidados Paliativos de Extremadura (238).

\section{Aspectos generales de la vía subcutánea}

La vía subcutánea es una técnica de fácil aplicación en el domicilio. Facilita el uso de medicamentos para el control de síntomas, a la vez que mejora la calidad de vida del paciente, objetivo primordial en los pacientes en SUD. Precisamente esta ventaja, la del tratamiento en domicilio, es fundamental para los pacientes en SUD, al permitirles permanecer en su domicilio si ese es su deseo.

\section{Indicaciones de uso de la vía subcutánea}

La utilización de la vía subcutánea está indicada en aquellas circunstancias en las que el paciente no puede utilizar la vía oral o cuando los síntomas no están suficientemente controlados por esta vía. También cuando la vía intravenosa no es posible o no es deseable. Puede utilizarse tanto para la administración de fármacos como para la administración de líquidos (hipodermoclisis).

\section{Contraindicaciones (relativas en SUD):}

- Mala adaptación del paciente, claudicación familiar o situación social no adecuada al tratamiento domiciliario.

- Anasarca. Edema severo.

- Alteraciones de la coagulación o trombocitopenia.

- Hipoperfusión periférica, incluyendo situaciones de shock.

- Alteraciones locales:

- Radiodermitis o zonas donde se esté administrando RDT.

- Zonas infiltradas por el tumor o con pérdida de continuidad.

- Zonas sometidas a cirugía radical como el caso de las mastectomías, al menos mientras persiste la induración del tejido.

- Infecciones de repetición en el punto de inserción.

\section{Inconvenientes y complicaciones más habituales:}

- Desconexión en la zona de punción.

- Salida accidental de la vía (segunda en frecuencia de aparición).

- Reacciones locales: enrojecimiento, induración (suele ser una de las más frecuentes), crepitación y necrosis (rara), absceso, calor, dolor, hematoma y reflujo.

- Reacción adversa al material o a la medicación. 
Cualquiera de ellas puede ser motivo de cambio en el lugar de punción.

\section{Técnica para la utilización de la vía subcutánea}

- Material necesario:

- Guantes.

- Jeringas.

- Gasas.

- Solución antiséptica, preferiblemente clorhexidina.

- Catéteres plásticos de teflón o poliuretano 23-25 G.

- Tiras adhesivas para fijar las alas de la palomilla.

- Apósitos transparentes como los usados para vías ev. para fijar toda la palomilla.

- Suero fisiológico o agua para inyección, es el diluyente de elección (siempre que no esté contraindicado).

- Bomba de infusión si se precisa.

- Zona de punción:

Las zonas de punción más habituales son (figura abajo):

- Zona infraclavicular, evitando el tejido mamario. De elección para comodidad del paciente y la familia, por su facilidad de acceso tanto para uso como para vigilancia de la misma.

- Zona deltoidea (no utilizable para hipodermoclisis).

- Cuadrantes superiores de abdomen, evitando la zona periumbilical e insertando la aguja lateralmente para evitar sensación de pinchazo al paciente cuando se siente o se acueste.

- Cara anterior de los muslos (son de preferencia para la hipodermoclisis, sin embargo, para la infusión de pequeños volúmenes son preferibles las zonas 1 y 2 por ser de mejor acceso y control para enfermos y familiares).

- Zona escapular, sobre todo en pacientes confusos. También se puede utilizar para grandes volúmenes.

Figura 2. Zonas de punción recomendadas para la vía subcutánea

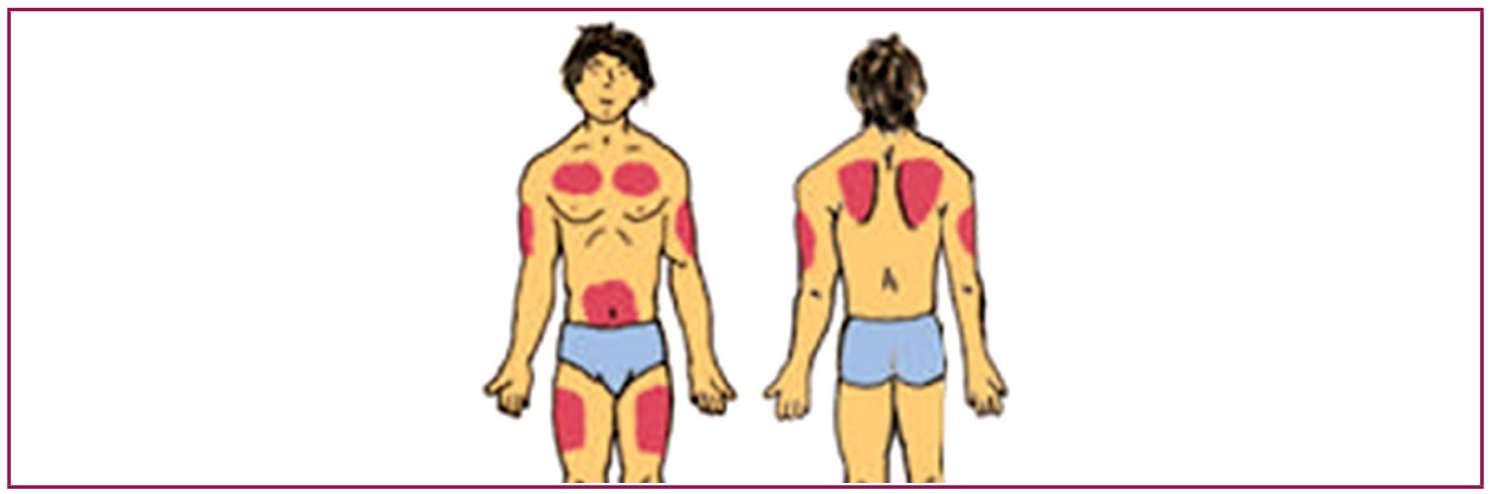

Fuente: tomada de Uso y recomendaciones de la Vía Subcutánea en Cuidados Paliativos (238). 
Para la elección de la zona, se aconseja tener presente las posturas habituales y movilidad individuales de cada paciente, evitando zonas de pliegue, articulaciones, prominencias óseas y zonas distales. Se recomienda un buen grosor de la capa grasa del tejido.

Los cambios en el lugar de punción se recomiendan que se hagan siguiendo un orden, en el sentido de las agujas del reloj.

La duración del lugar de punción, además de la zona seleccionada, depende básicamente del tipo de palomilla (las de Teflón duran una media de 11,9 $\pm 1,7$ días frente a las metálicas 5,3 \pm 0,5 días), del tipo de fármaco administrado (más o menos irritante), volumen y frecuencia de aplicación.

- Técnica de punción

Se recomienda seguir los siguientes pasos:

1. Explicar el procedimiento al paciente.

2. Lavarse las manos y preparar el equipo a utilizar.

3. Ponerse guantes desechables.

4. Elegir la zona de punción y desinfectar con antiséptico. Esperar a que esté seca.

5. Tomar un pellizco generoso entre el dedo índice y pulgar.

6. Insertar la aguja en la base del pellizco. En el caso de las palomillas no metálicas no se recomienda la punción con ángulo de $45^{\circ}$, debido a que es una posición forzada del catéter y tiende a acodarse (con las metálicas se hacía esto para evitar la presión de las alas del catéter sobre la piel).

7. El bisel se debe introducir hacia arriba (aunque algunos autores recomiendan que se inserte hacia abajo cuando se usen palomillas metálicas para hipodermoclisis y en enfermos caquécticos).

8. Si refluyera sangre, cambiar la aguja y el lugar de inserción.

9. Colocar un apósito, siendo aconsejable hacer un bucle con el sistema bajo el apósito, para evitar desplazamientos o salidas accidentales.

10. Lavar con $0,5 \mathrm{ml}$ de suero tras la medicación, en el caso de las metálicas y 0,2 en las de Vialon ya que se podría perder parte de la dosis de medicación en el trayecto del sistema.

11. Registrar correctamente en la Historia Clínica toda la información relativa al procedimiento empleado (zona escogida, fecha de punción, complicaciones). 


\section{Formas y dispositivos de administración:}

Podemos considerar dos formas de administrar medicamentos por vía subcutánea:

1. Bolo:

a. Se recomienda usar el mínimo volumen posible, con un volumen máximo de $2 \mathrm{ml}$ (límite de tolerancia de la piel).

b. Lavar la vía con suero tras la administración de cualquier fármaco (ver apartado anterior).

c. Tener en cuenta la tolerancia local del fármaco.

d. Tener en cuenta la farmacocinética. Habitualmente el efecto va aumentando progresivamente desde el momento de la punción hasta un nivel máximo, y posteriormente remite lentamente.

e. Los bolos se pueden administrar de forma puntual o periódica.

2. Infusión continua:

Puede ser por gravedad o mediante infusores.

a. La velocidad máxima de goteo es de $80 \mathrm{ml} /$ hora, aunque se recomienda un ritmo de 40-60 ml/hora en los casos de hidratación.

b. En cuanto al volumen de infusión de fármacos en general se recomienda no superar os $3 \mathrm{ml} / \mathrm{h}$ (mediante infusores). Algunos autores amplían este margen a los $5-7 \mathrm{cc} / \mathrm{h}$.

c. El volumen máximo aconsejable de perfusión (para hidratación subcutánea) es de 1000 a $1500 \mathrm{ml} / 24 \mathrm{~h}$ por cada vía.

\section{Infusores elastoméricos}

Existen en el mercado varios tipos de infusores: elastoméricos (con mecanismo de balón), mecánicos (con mecanismo de resorte o de jeringa) y electrónicos (con mecanismo de tipo peristáltico). Hablaremos en este apartado de los más utilizados, los infusores elastoméricos.

- Son dispositivos desechables, ligeros y cómodos para el paciente.

- Permiten mezclar medicamentos.

- Los hay de alto (entre 240 y $275 \mathrm{ml}$ ) y bajo volumen (de 48 a $100 \mathrm{ml}$ ).

- En general, constan de los siguientes elementos:

- Carcasa, que protege al reservorio y lleva impresa una escala, para el control del vaciado.

- Reductor de flujo o válvula: capilar de cristal de diámetro determinado al final del tubo de conexión. Debe estar en contacto con la piel ya que la temperatura de la misma influirá en la velocidad de infusión (por ese motivo hay que tener en cuenta la posible presencia de fiebre).

- Tubo de conexión, que une el reservorio con el conector tipo luer- lock. 
- Reservorio: es el globo donde se introduce la medicación.

- En el caso de usar fármacos fotosensibles (morfina, haloperidol y en general todas aquellas ampollas que vienen con cristal oscuro) es preciso protegerlos de la luz.

- Los hay para tratamientos de horas, días o de tiempo variable (con la posibilidad de cambiar de flujo a lo largo de la infusión).

- En algunos modelos es posible administrar bolos adicionales de una cantidad predeterminada.

- Para calcular el volumen total del infusor se seguirá la siguiente fórmula:

- vt $(\mathrm{ml})=$ Flujo $(\mathrm{ml} / \mathrm{h}) \times 24 \mathrm{~h} \times \mathrm{n}^{\circ}$ días de duración del infusor (teniendo siempre en cuenta las instrucciones del fabricante respecto a volumen residual, el diluyente empleado, y los factores que pudieran afectar a la velocidad de infusión).

- Por norma general el volumen de líquido calculado se conseguirá añadiendo suero fisiológico a la suma de la medicación pautada para el conjunto de los días de duración del infusor hasta llegar al volumen máximo indicado por el fabricante.

\section{Cuidados de la vía subcutánea}

1. Utilizar suero fisiológico al $0.9 \%$ como diluyente de elección (siempre que no esté contraindicado).

2. Asegurarse que la aguja no esté muy superficial.

3. Preferencia de uso por las palomillas de Teflón o Vialón en lugar de agujas.

4. En caso de dolor en la zona de punción, descartar infección. Descartada infección, disminuir el volumen y la velocidad de inyección.

5. Revisar regularmente el lugar de punción y considerar la regularidad de los cambios si presentan reacciones locales persistentes.

6. Cambiar frecuentemente la vía de administración de los fármacos más irritantes.

7. Proteger de la luz aquellos fármacos que se dejen cargados en jeringas y sean fotosensibles.

8. Respecto a los infusores:

a. Inspeccionar al menos una vez al día que el infusor se esté descargando correctamente y que la vía está en buen estado.

b. Comenzar con la infusión 2 horas antes de que termine de hacer efecto la medicación pautada previamente, siempre y cuando los síntomas estuvieran bien controlados. Si, por el contrario, no existiera control sintomático debe comenzarse de inmediato la infusión, añadiendo una dosis extra previa a la conexión del infusor (equivalente a $1 / 6$ de la dosis total diaria).

c. No modificar la medicación una vez puesto el infusor y hasta que se termine, ya que en ese caso se induciría a errores en la concentración de la mezcla y de la velocidad de infusión. 
d. Evitar que, al cargar la medicación desde ampollas de cristal, pequeñas partículas de éstas no se filtran en la mezcla. Podríamos evitar este problema utilizando filtros en las agujas o recipientes de plástico para la medicación.

e. Utilizar el mínimo número de fármacos en la mezcla; a mayor número, mayor riesgo de precipitación y pérdida de eficacia.

f. Inspeccionar la mezcla antes de colocar el infusor, buscando signos de precipitación o cristalización.

g. Protegeremos la mezcla de la luz (existen muchos fármacos fotosensibles) y el calor.

\section{Medicación administrada por vía subcutánea}

Pueden administrarse varios fármacos simultáneamente, aunque su compatibilidad en un mismo dispositivo no está bien establecida en muchas ocasiones.

Tabla 15. Fármacos más utilizados por vía subcutánea en cuidados paliativos

\begin{tabular}{|c|c|c|}
\hline Fármaco & Indicaciones & Presentaciones \\
\hline Morfina & Dolor, disnea & $\begin{array}{l}\text { Amp } 1 \mathrm{ml} 1 \%=10 \mathrm{mg} \\
\text { Amp } 1 \mathrm{ml} 2 \%=20 \mathrm{mg} \\
\text { Vial } 20 \mathrm{ml} 2 \%=400 \mathrm{mg}\end{array}$ \\
\hline Butilescopolamina & $\begin{array}{l}\text { Estertores premortem, sialorrea, } \\
\text { secreciones respiratorias, } \\
\text { obstrucción intestinal }\end{array}$ & Amp $1 \mathrm{ml}=20 \mathrm{mg}$ \\
\hline Midazolam & Convulsiones, sedación paliativa & $\begin{array}{l}\text { Amp } 3 \mathrm{ml}=15 \mathrm{mg} \\
\text { Amp } 5 \mathrm{ml}=5 \mathrm{mg} \\
\text { Amp } 50 \mathrm{mg}=10 \mathrm{ml}\end{array}$ \\
\hline Metoclopramida & Náuseas y vómitos & Amp $2 \mathrm{ml}=10 \mathrm{mg} \mathrm{Amp} 20 \mathrm{ml}=100 \mathrm{mg}$ \\
\hline Haloperidol & $\begin{array}{l}\text { Náuseas y vómitos por opioides, } \\
\text { vómitos en la obstrucción } \\
\text { intestinal, delirium }\end{array}$ & Amp $1 \mathrm{ml}=5 \mathrm{mg}$ \\
\hline Levomepromazina & Delirium & Amp $1 \mathrm{ml}=25 \mathrm{mg}$ \\
\hline Dexametasona & $\begin{array}{l}\text { Obstrucción intestinal, } \\
\text { convulsiones, hipertensión } \\
\text { endocraneal }\end{array}$ & Amp $1 \mathrm{ml}=4 \mathrm{mg} \mathrm{Amp} 5 \mathrm{ml}=40 \mathrm{mg}$ \\
\hline $\begin{array}{l}\text { Diclofenaco*/ } \\
\text { dexketoprofeno** }\end{array}$ & Dolor, fiebre & $\begin{array}{l}\text { *Amp } 3 \text { ml=75 mg } \\
\text { (en infusor o perfusión iv) } \\
{ }^{\star \star} \text { Amp } 50 \text { mg=2 ml }\end{array}$ \\
\hline Ondansetrón & Náuseas y vómitos & $\begin{array}{l}\text { Amp } 2 \mathrm{ml}=4 \mathrm{mg} \\
\text { Amp } 4 \mathrm{mg}=8 \mathrm{mg}\end{array}$ \\
\hline
\end{tabular}

Fuente: modificado de GPC de Cuidados Paliativos (20)

Otros fármacos que pueden ser utilizados en la SUD y de los que hay evidencia de utilización por vía SC son: fentanilo, metadona, oxicodona, clonazepam, ketamina, furosemida, octreótido y fenobarbital. 


\section{Compatibilidad de mezclas}

Como medida general se recomienda no mezclar más de cinco fármacos.

Algunas mezclas que han demostrado estabilidad en la literatura son (235):

- Morfina + midazolam

- Morfina + levomepromazina

- Morfina + metoclopramida

- Morfina + haloperidol

- Morfina + haloperidol + midazolam

- Morfina + levomepromazina + midazolam

- Morfina + haloperidol + butilescopolamina

- Morfina + dexametasona + ranitidina

- Oxicodona + butilescopolamina + octreótido

- Oxicodona + levomepromazina+ ketamina

- Fentanilo + butilescopolamina + octreótido

- Morfina + haloperidol + midazolam + butilescopolamina

Mezclas de 2 fármacos incompatibles:

- Midazolam + dexametasona

- Haloperidol + dexametasona

Cualquier combinación de ésta mezcla con otros fármacos adicionales, seguirá siendo incompatible.

En general:

- Dexametasona puede cristalizar por lo que no deben ser mezclados con otros fármacos.

- Levomepromazina: por vía subcutánea es muy irritante por lo que también se recomienda utilizar en palomilla separada. En la práctica clínica es una de los fármacos más habitualmente mezclados en la SUD sin problemas.

- Diclofenaco y dexketoprofeno: muy irritantes por lo que es preferible la administración continua. No mezclar.

- Es aconsejable desechar cualquier mezcla que produzca precipitados o turbidez de la solución. 


\section{Uso de la vía subcutánea para hidratación: hipodermoclisis (238,}

\section{9)}

En algunos estudios se habla indistintamente de administración por vía subcutánea o hipodermoclisis para considerar cualquier tipo de administración subcutánea, sin embargo, algunos autores utilizan el término hipodermoclisis para referirse únicamente a la hidratación por vía subcutánea como alternativa a la fluidoterapia intravenosa. La hipodermoclisis también se conoce con el nombre de clisis o hidratación subcutánea.

Las principales formas de administración de fluidos por vía subcutánea son:

1. Infusión continua en $24 \mathrm{~h}$ a una velocidad de $40-60 \mathrm{ml} / \mathrm{h}$, lo cual limita la movilidad del paciente; no se deben administrar más de 31 en $24 \mathrm{~h}$.

2. Infusión intermitente durante $12 \mathrm{~h}$ a $80 \mathrm{ml} / \mathrm{h}$, mejor tolerada tanto para el paciente como para los cuidadores.

3. Bolos de $500 \mathrm{ml}$ en aproximadamente una hora, 2 ó 3 veces al día. Normalmente bien tolerados y muy útiles para los pacientes más activos.

Se recomienda:

1. Utilizar suero fisiológico o glucosalino (al $33 \%$ de salino), ya que la dextrosa produce dolor por atraer líquidos adyacentes al lugar de inyección.

2. Utilizar vías diferentes a la de la hipodermoclisis para la administración de fármacos.

3. Si aparece edema en el lugar de punción conviene realizar un suave masaje para que el líquido acumulado se vaya absorbiendo. 


\section{Anexo 10. Vademécum de fármacos utilizados en SUD}

Se presenta el vademécum de fármacos más frecuentemente empleados en la situación de últimos días (por síntomas y principio activo). Se ha realizado adaptando la información incluida en la GPC de Cuidados Paliativos (2008) (20) y las fichas técnicas (consultadas en el Centro de información online de medicamentos de la AEMPS-CIMA).

\section{Vademécum por síntomas}

Tabla 16. Fármacos más frecuentes clasificados por síntomas

\begin{tabular}{|c|c|c|c|}
\hline Síntoma & Fármaco & Dosis recomendada & $\begin{array}{c}\text { Observaciones } \\
\text { (Algunas no relevantes en SUD) }\end{array}$ \\
\hline \multirow[t]{4}{*}{$\begin{array}{l}\text { DOLOR } \\
\text { *Ver anexo } \\
\text { sobre } \\
\text { opioides } \\
\text { (Anexo 4) }\end{array}$} & PARACETAMOL & $\begin{array}{l}\text { VO: } 500-1000 \text { mg/4-6 h (máx } 4 \text { g/día) } \\
\text { Rectal: } 650 \text { mg/4-6 h } \\
\text { IV: } 1000 \text { mg/6 h } \\
\text { Dosis máxima: } 4 \text { g/día }\end{array}$ & $\begin{aligned} \text { - } & \text { Otros usos: antitérmicos. } \\
\text { - } & \text { Reducir dosis en insuficiencia hepática } \\
& (\mathrm{IH}) . \\
\text { - } & \text { Conservar los supositorios en nevera. }\end{aligned}$ \\
\hline & DICLOFENACO & $\begin{array}{l}\text { VO: } 50 \mathrm{mg} / 8 \mathrm{~h} \\
\text { VO retard: } 75-150 \mathrm{mg} / 24 \mathrm{~h} \\
\text { Rectal: } 100 \mathrm{mg} / 24 \mathrm{~h} \\
\text { IV: } 75 \mathrm{mg} / 24 \mathrm{~h} \\
\text { (excepcionalmente } 150 \mathrm{mg} / 24 \mathrm{~h} \text { ) } \\
\text { Dosis máxima: } 150 \mathrm{mg} / \mathrm{día}\end{array}$ & $\begin{array}{l}\text { - Los AINE son la primera opción en do- } \\
\text { lor óseo. } \\
\text { - Se puede utilizar en infusión continua } \\
\text { vía SC (no en bolos), pero no mezclar } \\
\text { con otros fármacos*. } \\
\text { - En IH avanzada reducir dosis. } \\
\text { - En insuficiencia renal (IR) empeora la } \\
\text { función renal. } \\
\text { - En insuficiencia cardíaca (IC), empeora } \\
\text { los síntomas congestivos. }\end{array}$ \\
\hline & $\begin{array}{l}\text { DEXKETO- } \\
\text { PROFENO }\end{array}$ & 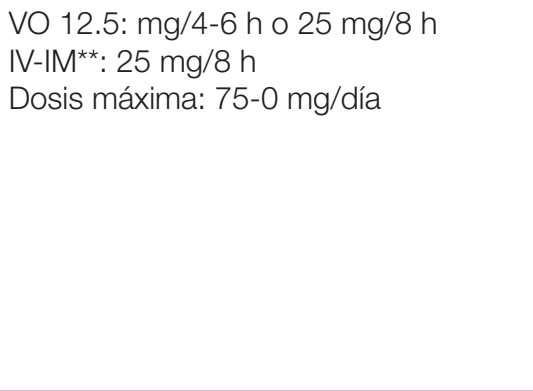 & $\begin{array}{l}\text { - } \text { Reducir dosis en IR e IH. } \\
\text { - } \text { Evitar usar en IH severa y CICr <50ml/ } \\
\text { min. } \\
\text { - } \text { Los AINE son la primera opción en do- } \\
\text { lor óseo. } \\
\text { - Se puede utilizar vía SC, pero no mez- } \\
\text { clar con otros fármacos*. } \\
\text { - Otros usos: antitérmico. } \\
\text { - Proteger de la luz. La disolución es es- } \\
\text { table } 24 \text { h a temperatura ambiente. }\end{array}$ \\
\hline & TRAMADOL & $\begin{array}{l}\text { VO: } 50-100 \text { mg/4-6h } \\
\text { VO retard: } 50-200 \text { mg/12h } \\
\text { SC, IV o IM**: } 50-100 \text { mg/6-8 h } \\
\text { Dosis máxima: } 400 \text { mg/día }\end{array}$ & $\begin{array}{l}\text { - Puede ser necesario asociar laxante. } \\
\text { - Reducir dosis en ancianos e IR. }\end{array}$ \\
\hline
\end{tabular}




\begin{tabular}{|c|c|c|c|}
\hline & MORFINA & $\begin{array}{l}\text { Dosis inicial en pacientes no tratados } \\
\text { con opioides: } \\
\text { VO: } 10-30 \mathrm{mg} / \mathrm{d} \text { repartidos en } 4 \text { dosis; si } \\
\text { es de acción rápida o en } 2 \text { dosis en las de } \\
\text { liberación prolongada. } \\
\text { Vía SC: mitad de la dosis de la VO } \\
\text { Vía IV: un tercio de la dosis de la VO } \\
\text { Aumentos de dosis: } 25-50 \% \text { de la dosis } \\
\text { Puede darse el doble de la dosis al acostar- } \\
\text { se para evitar una toma } \\
\text { Dosis de rescate: } 1 / 6 \text { de la dosis total diaria }\end{array}$ & $\begin{array}{l}\text { - No tiene techo terapéutico salvo por la } \\
\text { aparición de efectos adversos. } \\
\text { - Asociar laxante y si se inicia su uso un } \\
\text { antiemético. } \\
\text { - Se puede administrar por vía SC. } \\
\text { - Proteger de la luz. } \\
\text { - Rescate: con morfina de acción rápi- } \\
\text { da (solución o comprimidos o, morfina } \\
\text { parenteral). } \\
\text { - La solución oral es adecuado si proble- } \\
\text { mas de deglución pero aún se mantie- } \\
\text { ne la vía oral. }\end{array}$ \\
\hline & $\begin{array}{l}\text { FENTANILO } \\
\text { TRANSDERMICO }\end{array}$ & $\begin{array}{l}\text { Dosis inicial en pacientes no tratados con } \\
\text { opioides: parche de } 12 \text { o } 25 \mathrm{mcg} / \mathrm{h} \text { cada } \\
72 \mathrm{~h} \text {, incrementar la dosis en } 12-25 \mathrm{mcg} / \mathrm{h} \\
\text { cada } 72 \text { h hasta dosis eficaz }\end{array}$ & $\begin{array}{l}\text { - No es el opioide más recomendable } \\
\text { para comenzar en SUD. } \\
\text { - El aumento de temperatura aumenta } \\
\text { su absorción y la mala perfusión peri- } \\
\text { férica la disminuye. } \\
\text { - Rescate: con morfina oral de acción rá- } \\
\text { pida, morfina parenteral o fentanilo oral } \\
\text { transmucosa. }\end{array}$ \\
\hline & $\begin{array}{l}\text { FENTANILO ORAL } \\
\text { TRANSMUCOSA }\end{array}$ & $\begin{array}{l}0,2-1,6 \text { mg a demanda } \\
\text { La dosis no puede predecirse a partir de la } \\
\text { dosis de mantenimiento }\end{array}$ & $\begin{array}{l}\text { - Dolor irruptivo y como rescate. } \\
\text { - Acción rápida y corta. } \\
\text { - Conservarlo en el embalaje original } \\
\text { para protegerlo de la humedad. }\end{array}$ \\
\hline & METADONA & $\begin{array}{l}\text { VO, SC, dosis inicial: } 5-1 \mathrm{mg} / 6-8 \mathrm{~h} \text { ajustado } \\
\text { según respuesta } \\
\text { Si se utiliza de forma prolongada no admi- } \\
\text { nistrar con frecuencia inferior a } 12 \mathrm{~h}\end{array}$ & $\begin{array}{l}\text { - Vida media larga con riesgo de acumu- } \\
\text { lación. } \\
\text { - La IR e IH no interfieren en su elimina- } \\
\text { ción. } \\
\text { - Gran variabilidad interindividual en la } \\
\text { dosis. } \\
\text { - Manejo por personal experto. } \\
\text { - Útil en rotación de opioide. }\end{array}$ \\
\hline DISNEA & MORFINA & $\begin{array}{l}\text { Dosis inicial en pacientes no tratados } \\
\text { con opioides: VO, SC o IV: } 2,5-5 \mathrm{mg} / 4-6 \mathrm{~h} \\
\text { Si está en tratamiento con morfina: aumen- } \\
\text { tar la dosis un } 25-50 \%\end{array}$ & $\begin{array}{l}\text { - No recomendado su uso por vía inha- } \\
\text { lada. } \\
\text { - En monoterapia o asociada a BDZ. } \\
\text { - En disnea por IC o enfermedad pul- } \\
\text { monar NO maligna, la dosis necesaria } \\
\text { suele ser menor. } \\
\text { - } \text { Aunque es el opioide más estudiado en } \\
\text { el tratamiento de la disnea, se pueden } \\
\text { utilizar otros, principalmente fentanilo } \\
\text { en caso de IH o IR. } \\
\text { - En las crisis de disnea (emergencia pa- } \\
\text { liativa) se recomienda preparados de } \\
\text { acción rápida. } \\
\text { - Indicación fuera de ficha técnica (FT) } \\
\text { salvo en IC. } \\
\text { - Proteger las ampollas de la luz. }\end{array}$ \\
\hline & LORAZEPAM & $\begin{array}{l}\text { VO o SL: 0,5-1 mg a demanda o pautado } \\
\text { cada 8-12 h } \\
\text { Dosis máxima: } 10 \mathrm{mg} / \mathrm{d}\end{array}$ & $\begin{array}{l}\text { - Disnea asociada a ansiedad. } \\
\text { - Para un alivio rápido (SL). } \\
\text { - En monoterapia o asociado a opioides. }\end{array}$ \\
\hline & MIDAZOLAM & $\begin{array}{l}2.5-5 \mathrm{mg} \mathrm{SC} \mathrm{SC}^{*} \text { IV puntual en las crisis o } \\
\text { pautado cada } 4-6 \text { h o en perfusión }\end{array}$ & $\begin{array}{l}\text { - En crisis de disnea. } \\
\text { - Acción rápida y duración corta. } \\
\text { - En monoterapia o asociado a opioides. } \\
\text { - La solución diluida es estable durante } \\
\quad 24 \text { h a temperatura entre } 2-8^{\circ} \mathrm{C} \text {. }\end{array}$ \\
\hline & DIAZEPAM & $\begin{array}{l}\text { VO: } 5 \text { mg a demanda o pautado } 5-20 \text { mg/ } \\
\text { día en 1-2 tomas oral, rectal, } \text { IM }^{\star *} \text { o IV }\end{array}$ & $\begin{array}{l}\text { - Disnea asociada a ansiedad. } \\
\text { - Acción más larga. } \\
\text { - En monoterapia o asociado a opioides. }\end{array}$ \\
\hline
\end{tabular}




\begin{tabular}{|c|c|c|c|}
\hline \multirow[t]{3}{*}{ DELIRIUM } & $\begin{array}{l}\text { LEVOMEPRO- } \\
\text { MAZINA }\end{array}$ & $\begin{array}{l}\text { Rango de dosis habitual VO, SC, } \text { IM }^{\star *} \text { : } \\
12,5-50 \mathrm{mg} / 4-12 \mathrm{~h} \\
\text { Dosis habitual bolos SC: } 12,5 \mathrm{mg} \text { (cada } 30 \\
\text { minutos, máximo } 3 \text { veces) } \\
\text { Dosis habitual en infusión SC: } 50-200 \text { mg/ } \\
\text { día }\end{array}$ & $\begin{array}{l}\text { - Más sedante que haloperidol. } \\
\text { - Se puede utilizar por vía SC*. }\end{array}$ \\
\hline & HALOPERIDOL & $\begin{array}{l}\text { Rango de dosis habitual VO, SC*, IM**, IV*: } \\
\text { 0,5-5 mg/24-8 } \mathrm{h} \\
\text { Dosis habitual VO: } 1-3 \mathrm{mg} / 24-8 \mathrm{~h} \\
\text { Dosis habitual bolos SC: } 2,5 \mathrm{mg} \text { (cada } \\
30 \text { minutos, máximo } 3 \text { veces) } \\
\text { Dosis habitual infusión SC: } 5-15 \mathrm{mg} / \mathrm{día} \\
\text { Dosis máxima: } 20 \mathrm{mg} / \mathrm{d}\end{array}$ & $\begin{array}{l}\text { - Mayor riesgo de síntomas extrapirami- } \\
\text { dales si se asocia a otros neurolépticos } \\
\text { como metoclopramida. } \\
\text { - Poco sedante. }\end{array}$ \\
\hline & MIDAZOLAM & $\begin{array}{l}\text { Bolos SC*, IV: } 2,5-5 \text { mg y repetir hasta que } \\
\text { ceda. Mantenimiento en perfusión IV, SC*: } \\
\text { 20-100 mg/día Dosis máxima: } 200 \text { mg/día }\end{array}$ & $\begin{array}{l}\text { - Asociado a haloperidol y levomepro- } \\
\text { mazina en delirium con agitación inten- } \\
\text { sa. } \\
\text { - Ampollas de Uso Hospitalario. }\end{array}$ \\
\hline \multirow[t]{7}{*}{ ANSIEDAD } & LORAZEPAM & $\begin{array}{l}\text { VO } 1-2 \mathrm{mg} / 8-12 \mathrm{~h} \text { o } 2 \mathrm{mg} \text { a demanda } \\
\text { Dosis máxima: } 10 \mathrm{mg} / \mathrm{d}\end{array}$ & - Acción rápida y duración intermedia. \\
\hline & ALPRAZOLAM & VO: 0,25-0,5 mg/8 h o a demanda & - Acción rápida y duración intermedia. \\
\hline & MIDAZOLAM & $\begin{array}{l}\text { VO: } 7,5 \mathrm{mg} \text { a demanda o cada } 8 \text { h IV o SC*: } \\
2.5 \text { mg a demanda o cada } 6-8 \mathrm{~h}\end{array}$ & $\begin{array}{l}\text { - Acción rápida y duración corta } \\
\text { - Ampollas de Uso Hospitalario. }\end{array}$ \\
\hline & DIAZEPAM & $\begin{array}{l}\text { VO, rectal o IV: } 5-20 \text { mg/día en varias tomas } \\
\text { o } 5 \text { mg a demanda }\end{array}$ & $\begin{array}{l}\text { - Acción más larga. } \\
\text { - Disponible por vía rectal. }\end{array}$ \\
\hline & $\begin{array}{l}\text { CLORAZEPATO } \\
\text { DIPOTASICO }\end{array}$ & VO: 5-10 mg/12 h o a demanda & $\begin{array}{l}\text { - Inicio de acción rápido, duración pro- } \\
\text { longada. }\end{array}$ \\
\hline & CLONAZEPAM & $\begin{array}{l}\text { VO, IV o SC*: 4-8 mg/día en } 3 \text { o } 4 \text { tomas o } \\
\text { 0,5-1 mg a demanda }\end{array}$ & - Se puede utilizar por vía SC*. \\
\hline & CLOMETIAZOL & VO: 192 mg/8 h o a demanda & - No produce depresión respiratoria. \\
\hline
\end{tabular}




\begin{tabular}{|c|c|c|c|}
\hline \multirow[t]{5}{*}{$\begin{array}{l}\text { NÁUSEAS Y } \\
\text { VÓMITOS }\end{array}$} & DEXAMETASONA & VO, SC*, IV: 4 mg/6-8 h & $\begin{array}{l}\text { - Se puede administrar vía SC* evitando } \\
\text { mezclar con otros fármacos. } \\
\text { - Náuseas y vómitos por quimioterapia } \\
\text { (riesgo moderado-alto de emesis) y } \\
\text { asociados a hipertensión endocraneal. }\end{array}$ \\
\hline & $\begin{array}{l}\text { METOCLO- } \\
\text { PRAMIDA }\end{array}$ & $\begin{array}{l}\text { Dosis habitual VO, SC } \mathrm{SC}^{\star}, \mathrm{IM}^{\star *} \text {, IV: } \\
15-60 \mathrm{mg} / \mathrm{dí}^{\mathrm{a}} \text { en } 2-4 \text { tomas } \\
\text { Infusión SC}: 30-100 \mathrm{mg} / \mathrm{día} \\
\text { Dosis máxima: } 30 \mathrm{mg} / \mathrm{d}\end{array}$ & $\begin{array}{l}\text { - Contraindicado en obstrucción intesti- } \\
\text { nal. } \\
\text { - Riesgo de arritmia si se asocia a on- } \\
\text { dansetrón. } \\
\text { - Precaución en pacientes con síndro- } \\
\text { mes extrapiramidales o en tratamiento } \\
\text { con otros neurolépticos. } \\
\text { - Reducir dosis en IR. } \\
\text { - Proteger de la luz. } \\
\text { - Administrar } 30 \text { minutos antes de las } \\
\text { comidas. }\end{array}$ \\
\hline & DOMPERIDONA & $\begin{array}{l}\text { VO: } 10 \mathrm{mg} / 8 \mathrm{~h} \\
\text { Vía rectal: } 60 \mathrm{mg} / 8 \mathrm{~h}\end{array}$ & $\begin{array}{l}\text { - Administrar } 15-20 \text { minutos antes de las } \\
\text { comidas. } \\
\text { - Los efectos extrapiramidales son raros. }\end{array}$ \\
\hline & ONDANSETRÓN & $\begin{array}{l}\text { VO, SC*, IV: } 12-24 \text { mg/día } \\
\text { Vía y dosis variable según riesgo de emesis. } \\
\text { No usar dosis únicas IV mayores de } 16 \text { mg }\end{array}$ & $\begin{array}{l}\text { - Aumenta su eficacia si se asocia dexa- } \\
\text { metasona. } \\
\text { - Reducir dosis en IH. } \\
\text { - Potencial arritmogénico. } \\
\text { - Otros usos*: prurito por uremia y opioi- } \\
\text { des. }\end{array}$ \\
\hline & HALOPERIDOL & VO, SC ${ }^{\star}$, V:1,5-5 mg/día & $\begin{array}{l}\text { - Náuseas y vómitos asociados a opioi- } \\
\text { des, insuficiencia renal o hipercalcemia. } \\
\text { - Precaución en pacientes con síndro- } \\
\text { mes extrapiramidales o en tratamiento } \\
\text { con otros neurolépticos. }\end{array}$ \\
\hline \multirow[t]{2}{*}{$\begin{array}{l}\text { NÁUSEAS } \\
\text { Y VÓMITOS } \\
\text { (OBSTRUC- } \\
\text { CIÓN IN- } \\
\text { TESTINAL) }\end{array}$} & OCTREÓTIDO* & $\begin{array}{l}\text { SC: } 300-800 \text { mg/día } \\
\text { Infusión SC o IV: } 300-600 \mu g / d i ́ a \\
\text { Dosis máxima: } 1.500 \mu g / d i ́ a\end{array}$ & $\begin{array}{l}\text { - En nauseas/vómitos por obstrucción } \\
\text { intestinal. } \\
\text { - Indicación no recogida en ficha técni- } \\
\text { ca). }\end{array}$ \\
\hline & $\begin{array}{l}\text { BUTILESCO- } \\
\text { POLAMINA }\end{array}$ & $\begin{array}{l}\text { IV, SC: } 60-80 \text { mg/día en 3-4 dosis Infusión } \\
\text { SC: } 60-80 \text { mg/día } \\
\text { Dosis máxima } 100 \text { mg/día. }\end{array}$ & $\begin{array}{l}\text { - En nauseas/vómitos por obstrucción } \\
\text { intestinal. } \\
\text { - Llamado también butilbromuro de es- } \\
\text { copolamina. } \\
\text { - No confundir con bromhidrato de es- } \\
\text { copolamina. } \\
\text { - La presentación asociada a metamizol } \\
\text { no se puede usar por vía SC. }\end{array}$ \\
\hline
\end{tabular}




\begin{tabular}{|c|c|c|c|}
\hline \multirow[t]{4}{*}{ SEDACIÓN } & MIDAZOLAM & $\begin{array}{l}\text { Sedación vía SC*: } \\
\text { Inducción: } 2,5-5 \mathrm{mg} \\
\text { Perfusión: } 15-30 \mathrm{mg} \text { en } 24 \mathrm{~h} \\
\text { Rescate: bolos } 2,5-5 \mathrm{mg} \\
\text { Doble dosis si tomaba previamente benzo- } \\
\text { diacepinas (BDZ) } \\
\text { Sedación vía IV: } \\
\text { Inducción: } 1,5-3 \mathrm{mg} \text { cada } 5 \text { min hasta que } \\
\text { esté sedado (la dosis requerida será la do- } \\
\text { sis de inducción) } \\
\text { Perfusión: dosis de inducción x } 6 \\
\text { Rescate: dosis de inducción }\end{array}$ & $\begin{array}{l}\text { - Doblar la dosis de la sedación si el pa- } \\
\text { ciente ya tomaba BDZ. } \\
\text { - Dosis máxima: } 200 \text { mg/día. } \\
\text { - Ampollas de uso hospitalario. }\end{array}$ \\
\hline & $\begin{array}{l}\text { LEVOMEPRO- } \\
\text { MAZINA }\end{array}$ & $\begin{array}{l}\text { Sedación vía SC*: } \\
\text { Inducción: } 12,5-25 \mathrm{mg} \\
\text { Perfusión: } 75-100 \mathrm{mg} / \text { día } \\
\text { Rescate: } 12,5 \mathrm{mg} \\
\text { Sedación vía IV: } \\
\text { La mitad de la dosis empleada por vía SC }\end{array}$ & $\begin{array}{l}\text { - Sedación cuando el síntoma predomi- } \\
\text { nante es el delirium. } \\
\text { - Dosis máxima: } 300 \mathrm{mg} \text {. }\end{array}$ \\
\hline & PROPOFOL & $\begin{array}{l}\text { Sedación IV: } \\
\text { Inducción: } 1-1,5 \mathrm{mg} / \mathrm{kg} \\
\text { Perfusión: } 2 \mathrm{mg} / \mathrm{kg} / \mathrm{h} \\
\text { Rescate: bolos de } 50 \% \text { de la dosis de in- } \\
\text { ducción }\end{array}$ & $\begin{array}{l}\text { - Previamente suspender perfusión de } \\
\text { BZD o neurolépticos y reducir los opioi- } \\
\text { des a la mitad. } \\
\text { - Uso hospitalario. }\end{array}$ \\
\hline & FENOBARBITAL & $\begin{array}{l}\text { Sedación vía SC: } \\
\text { Inducción: } 100-200 \text { mg } \\
\text { Perfusión: } 600 \mathrm{mg} / \mathrm{día} \\
\text { Rescate: bolos } 100 \mathrm{mg} \\
\text { Sedación vía IV: } \\
\text { Inducción: } 2 \mathrm{mg} / \mathrm{kg} \text { lento } \\
\text { Perfusión: } 1 \mathrm{mg} / \mathrm{kg} / \mathrm{h} \text { y modificar según res- } \\
\text { puesta }\end{array}$ & $\begin{array}{l}\text { - Previamente suspender perfusión de } \\
\text { BZD o neurolépticos y reducir los opio- } \\
\text { des a la mitad. } \\
\text { - Indicado si falla midazolam y levome- } \\
\text { promazina. } \\
\text { - Se puede administrar vía SC. }\end{array}$ \\
\hline $\begin{array}{l}\text { ESTERTO- } \\
\text { RES PRE- } \\
\text { MORTEM }\end{array}$ & $\begin{array}{l}\text { BUTILESCO- } \\
\text { POLAMINA }\end{array}$ & $\begin{array}{l}\text { IV, SC*: } 20 \text { mg/4-6 h o perfusión de } \\
\text { 20-100 mg/día }\end{array}$ & $\begin{array}{l}\text { - Llamado también butilbromuro de es- } \\
\text { copolamina. } \\
\text { - No confundir con bromhidrato de es- } \\
\text { copolamina. } \\
\text { - La presentación asociada a metamizol } \\
\text { no se puede usar por vía SC. }\end{array}$ \\
\hline \multicolumn{4}{|c|}{$\begin{array}{l}\text { VO: vía oral. SC: subcutánea. IV: intravenosa. IM: intramuscular. SL: sublingual. IH: insuficiencia hepática. IC: insuficiencia cardíaca. IR: insuficiencia } \\
\text { renal. BDZ: benzodiacepinas. SUD: situación de últimos días. FT: ficha técnica. } \\
\text { * Indicaciones o uso de vía SC no recogido en la ficha técnica. } \\
\text { ***a vía IM no es recomendable en SUD. }\end{array}$} \\
\hline
\end{tabular}




\section{Vademécum por principio activo}

Tabla 17. Fármacos más frecuentes clasificados por principio activo

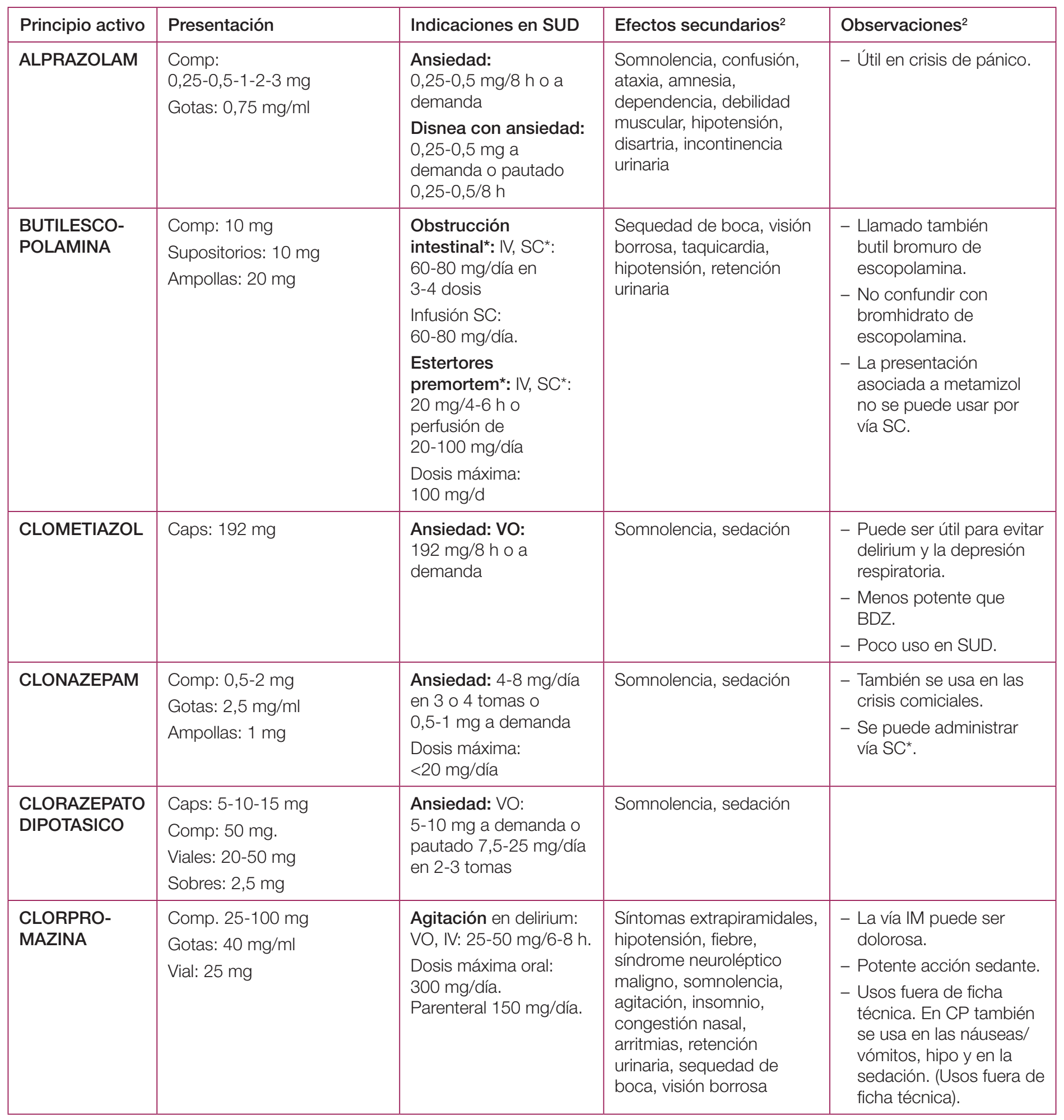




\begin{tabular}{|c|c|c|c|c|}
\hline $\begin{array}{l}\text { DEXAME- } \\
\text { TASONA }\end{array}$ & $\begin{array}{l}\text { Comp: } 1 \mathrm{mg} \text { y } 4 \mathrm{mg} \\
\text { Ampollas: } 4 \mathrm{mg}\end{array}$ & $\begin{array}{l}\text { Náuseas y vómitos: } \\
\text { VO, SC*, IV: } \\
4-16 \mathrm{mg} / \mathrm{dí}^{\prime}\end{array}$ & $\begin{array}{l}\text { Hiperglucemia, miopatía, } \\
\text { síndrome Cushing, } \\
\text { osteonecrosis, trastornos } \\
\text { psíquicos (hipomanía, } \\
\text { depresión, insomnio, } \\
\text { apatía, psicosis), } \\
\text { dispepsia, ulcus, retención } \\
\text { hidrosalina, HTA }\end{array}$ & $\begin{array}{l}\text { - Se puede administrar vía } \\
\text { SC*, pero sin mezclar } \\
\text { con otros fármacos en } \\
\text { infusión SC. } \\
\text { - En pauta corta (hasta } 3 \\
\text { semanas) habitualmente } \\
\text { no se precisa retirada } \\
\text { gradual. } \\
\text { - Otros usos en CP*: } \\
\text { anorexia/caquexia, } \\
\text { compresión medular } \\
\text { + hipertensión } \\
\text { endocraneal. }\end{array}$ \\
\hline DIAZEPAM & $\begin{array}{l}\text { Comp: 5-10 mg } \\
\text { Ampollas: } 10 \mathrm{mg} \\
\text { Supositorios: 5-10 mg } \\
\text { Microenema: 5-10 mg } \\
\text { Gotas: } 2 \mathrm{mg} / \mathrm{ml}\end{array}$ & $\begin{array}{l}\text { Ansiedad: } \\
\text { 5-10 mg cada 6-8 h } \\
\text { Dosis máxima: } \\
40 \text { mg/día }\end{array}$ & Somnolencia, sedación & $\begin{array}{l}\text { - Uso también en crisis } \\
\text { epilépticas. }\end{array}$ \\
\hline DICLOFENACO & $\begin{array}{l}\text { Comp.: } 50 \text { mg } \\
\text { Comp. retard: } \\
75-100 \text { mg } \\
\text { Supositorios: } \\
100 \text { mg } \\
\text { Ampollas: } \\
75 \text { mg } \\
\text { Dosis máxima: } \\
150 \text { mg/día }\end{array}$ & $\begin{array}{l}\text { Oral: } 50 \text { mg/8 h } \\
\text { Oral retard: } \\
75-150 \text { mg/24 h } \\
\text { Rectal: } 100 \text { mg/24 h } \\
\text { IM-IV: } 75 \text { mg/24 h }\end{array}$ & $\begin{array}{l}\text { Gastropatía, ulcus, } \\
\text { deterioro de función } \\
\text { renal, edemas, confusión, } \\
\text { precipitación de asma, } \\
\text { angioedema, rash }\end{array}$ & $\begin{array}{l}\text { - Ajustar dosis en IR, } \\
\text { ancianos e IC. } \\
\text { - Se puede utilizar en } \\
\text { infusión continua vía } \\
\text { SC* (no en bolos), pero } \\
\text { no mezclar con otros } \\
\text { fármacos* }\end{array}$ \\
\hline $\begin{array}{l}\text { ESCOPOLAMI- } \\
\text { NA BROMHI- } \\
\text { DRATO }\end{array}$ & $\begin{array}{l}\text { Ampollas: } \\
0.5 \mathrm{mg} / \mathrm{ml}\end{array}$ & $\begin{array}{l}\text { Estertores } \\
\text { respiratorios } \\
0.5-1 \mathrm{mg} / 4-6 \mathrm{~h} \mathrm{SC,} \mathrm{IM} \\
\text { O IV }\end{array}$ & & $\begin{array}{l}\text { - Indicación fuera de FT. } \\
\text { - Uso en preanestesia } \\
\text { para reducir salivación } \\
\text { y secreciones } \\
\text { respiratorias. (0.3- } \\
0.6 \text { mg/IM). } \\
\text { - No confundir con } \\
\text { Butilescopolamina } \\
\text { (buscapina). }\end{array}$ \\
\hline $\begin{array}{l}\text { FENOBAR- } \\
\text { BITAL }\end{array}$ & $\begin{array}{l}\text { Comp.: } \\
\text { 50-100 mg } \\
\text { Gotas: } \\
126 \mathrm{mg} / \mathrm{ml} \\
\text { Ampollas: } \\
200 \mathrm{mg} / \mathrm{ml}\end{array}$ & $\begin{array}{l}\text { Sedación vía SC: } \\
\text { Inducción: } \\
\text { 100-200 mg, } \\
\text { Perfusión SC: } \\
600 \text { mg/día, } \\
\text { Rescate: bolos } 100 \text { mg } \\
\text { Sedación vía IV: } \\
\text { Inducción: } 2 \text { mg/kg } \\
\text { lento, } \\
\text { Perfusión: } 1 \text { mg/kg/h } \\
\text { y modificar según } \\
\text { respuesta }\end{array}$ & $\begin{array}{l}\text { Mareo, letargia, ataxia, } \\
\text { confusión, reacciones } \\
\text { cutáneas, excitación, } \\
\text { inquietud, anemia } \\
\text { megaloblástica }\end{array}$ & $\begin{array}{l}\text { - Se puede administrar } \\
\text { vía SC*. } \\
\text { - Contraindicado en } \\
\text { la porfiria aguda } \\
\text { intermitente. } \\
\text { - Reducir dosis en IR e IH. } \\
\text { - También se usa en CP } \\
\text { en las crisis epilépticas. }\end{array}$ \\
\hline
\end{tabular}




\begin{tabular}{|c|c|c|c|c|}
\hline FENTANILO & $\begin{array}{l}\text { Parches TTS: 12-25-50-75- } \\
100 \text { mg } \\
\text { Comp o película de } \\
\text { disolución oral: 0,2-0,4-0,6- } \\
\text { 0,8-1,2-1,6 mg } \\
\text { Pulverización nasal: 50, 100, } \\
200,400 \\
\text { Ampollas: } 1 \text { mg, } 2 \text { mg, } 5 \text { mg }\end{array}$ & $\begin{array}{l}\text { Dolor: dosis inicial } \\
\text { en pacientes no } \\
\text { tratados con opioides: } \\
25 \text { mcg/72 h en parche, } \\
\text { incrementar la dosis en } \\
25 \text { mcg/h hasta dosis } \\
\text { eficaz. Tratados con } \\
\text { morfina: según dosis de } \\
\text { morfina. Dolor irruptivo } \\
\text { o rescate: } 0,2-1,6 \text { mg } \\
\text { a demanda (la dosis } \\
\text { no puede predecirse } \\
\text { a partir de la dosis de } \\
\text { mantenimiento) }\end{array}$ & $\begin{array}{l}\text { Náuseas, vómitos, } \\
\text { estreñimiento, } \\
\text { somnolencia, sequedad } \\
\text { de boca, sudoración, } \\
\text { depresión respiratoria, } \\
\text { alucinaciones, disforia, } \\
\text { retención urinaria, } \\
\text { mioclonías, erupción local } \\
\text { por parche }\end{array}$ & $\begin{array}{l}\text { - El aumento de } \\
\text { temperatura aumenta } \\
\text { su absorción. } \\
\text { Ocasionalmente se } \\
\text { precisa cambio de } \\
\text { parche cada } 48 \mathrm{~h} . \\
\text { - Asociar laxante. } \\
\text { - Útil en rotación de } \\
\text { opioides. } \\
\text { - Opioide de elección en } \\
\text { IH e IR. }\end{array}$ \\
\hline HALOPERIDOL & $\begin{array}{l}\text { Comp: } 10 \text { mg } \\
\text { Solución oral: } 2 \text { mg/ml ( } 20 \\
\text { gotas, } 1 \text { ml) } \\
\text { Solución inyectable: } 5 \text { mg/ml } \\
\text { Dosis máxima: } \\
20 \text { mg/día }\end{array}$ & $\begin{array}{l}\text { Delirium: rango de } \\
\text { dosis habitual VO, SC, } \\
\text { IM, IV: 0,5-5 mg/2-12 h } \\
\text { Dosis habitual VO: } \\
\text { 1-3 mg/8 h } \\
\text { Dosis habitual bolos } \\
\text { SC: 2,5 mg (cada } \\
30 \text { minutos, máximo } 3 \\
\text { veces) } \\
\text { Dosis habitual infusión } \\
\text { SC: } 5-15 \text { mg/día } \\
\text { Náuseas y vómitos: } \\
\text { VO, SC, IV:1,5-5 mg/día }\end{array}$ & $\begin{array}{l}\text { Síntomas extrapiramidales } \\
\text { (distonías y acatisia), } \\
\text { hipotensión, fiebre, } \\
\text { síndrome neuroléptico } \\
\text { maligno, somnolencia, } \\
\text { agitación, insomnio, } \\
\text { congestión nasal, } \\
\text { arritmias, retención } \\
\text { urinaria, sequedad de } \\
\text { boca, visión borrosa }\end{array}$ & $\begin{array}{l}\text { - La solución inyectable } \\
\text { es para uso IM. Se } \\
\text { puede administrar vía } \\
\text { SC*. } \\
\text { - } \text { Otros usos en CP: hipo. } \\
\text { - } \\
\text { Reducir dosis en } \\
\text { ancianos e IH. }\end{array}$ \\
\hline $\begin{array}{l}\text { LEVOMEPRO- } \\
\text { MAZINA }\end{array}$ & $\begin{array}{l}\text { Comp: } 25,100 \mathrm{mg} \\
\text { Gotas: } 40 \mathrm{mg} / \mathrm{ml} \\
\text { Ampollas(IM): } 25 \mathrm{mg}\end{array}$ & $\begin{array}{l}\text { Disnea: VO, SC: 2,5-10 } \\
\text { mg } \\
\text { Delirium: rango de } \\
\text { dosis habitual VO, SC, } \\
\text { IM: } 12,5-50 \text { mg/4-12 h. } \\
\text { Dosis habitual bolos } \\
\text { SC: } 12,5 \text { mg (cada } \\
30 \text { minutos, máximo } 3 \\
\text { veces). Dosis habitual } \\
\text { en infusión SC: } \\
50-200 \text { mg/día. } \\
\text { Sedación vía SC: } \\
\text { Inducción: } 12,5-25 \text { mg, } \\
\text { Perfusión: } 100 \text { mg/día, } \\
\text { Rescate: } 12,5 \text { mg } \\
\text { Sedación vía IV: } \\
\text { la mitad de la dosis } \\
\text { empleada por vía SC }\end{array}$ & $\begin{array}{l}\text { Somnolencia, sedación, } \\
\text { sequedad de boca, } \\
\text { estreñimiento, retención } \\
\text { urinaria, síntomas } \\
\text { extrapiramidales, } \\
\text { hipotensión }\end{array}$ & $\begin{array}{l}\text { - Se puede utilizar por vía } \\
\text { SC * Más sedante que } \\
\text { haloperidol, alternativa } \\
\text { a haloperidol en } \\
\text { paciente con delirium } \\
\text { con agitación intensa. } \\
\text { - Reducir dosis en } \\
\text { ancianos, IH y en IR. }\end{array}$ \\
\hline LORAZEPAM & $\begin{array}{l}\text { Comp: 1, 2, } 5 \text { mg. } \\
\text { Dosis máxima: } 5 \mathrm{mg} / \mathrm{d}\end{array}$ & $\begin{array}{l}\text { Disnea con ansiedad: } \\
\text { VO: 0,5-1 mg/8-12 h o } \\
\text { a demanda } \\
\text { Ansiedad: VO: } \\
\text { 0,5-2 mg/8-12 h o a } \\
\text { demanda }\end{array}$ & $\begin{array}{l}\text { Somnolencia, confusión, } \\
\text { ataxia, amnesia, } \\
\text { dependencia, debilidad } \\
\text { muscular, hipotensión, } \\
\text { disartria, incontinencia } \\
\text { urinaria }\end{array}$ & $\begin{array}{l}\text { - Duración intermedia. } \\
\text { - Poca sedación diurna. } \\
\text { - Otros usos en CP: } \\
\text { Vómitos anticipatorios, } \\
\text { insomnio. }\end{array}$ \\
\hline
\end{tabular}




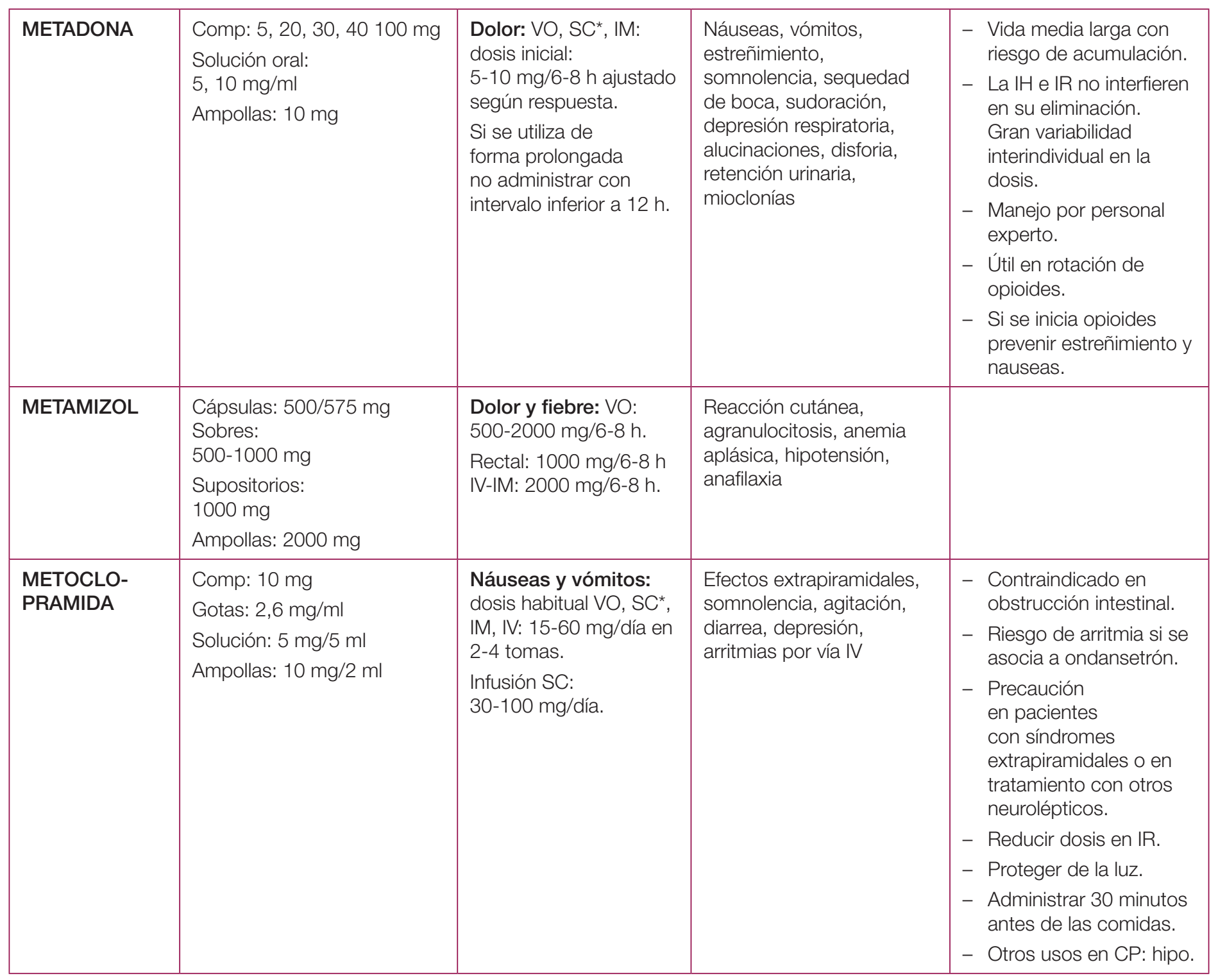




\begin{tabular}{|c|c|c|c|c|}
\hline MIDAZOLAM & $\begin{array}{l}\text { Comp: } 7,5 \mathrm{mg} \\
\text { Ampollas: } 1 \mathrm{mg} / \mathrm{ml} \text {, } \\
5 \mathrm{mg}(5 \mathrm{ml}-15 \mathrm{mg} / 3 \mathrm{ml} \text { - } \\
50 \mathrm{mg} / 10 \mathrm{ml} \\
\text { Solución oral: } 2.5 \mathrm{mg}, 5 \mathrm{mg} \text {, } \\
7.5 \mathrm{mg}, 10 \mathrm{mg}\end{array}$ & $\begin{array}{l}\text { Disnea con ansiedad: } \\
\text { VO: } 7,5 \text { mg a demanda } \\
\text { o pautado } 7,5 \text { mg/8 h. } \\
\text { Crisis disnea: } \\
2.5-5 \text { mg SC o IV. } \\
\text { Delirium con agitación } \\
\text { Intensa: bolos SC, } \\
\text { IV: 2,5-5 mg y repetir } \\
\text { hasta que ceda. } \\
\text { Mantenimiento en } \\
\text { perfusión IV, } \\
\text { SC: } 20-100 \text { mg/día. } \\
\text { Sedación vía SC: } \\
\text { Inducción: 2,5-5 mg. } \\
\text { Perfusión: } \\
\text { 15-30 mg/24 h. } \\
\text { Rescate: } \\
\text { bolos 2,5-5 mg. } \\
\text { Doble dosis si tomaba } \\
\text { previamente BDZ. } \\
\text { Sedación vía IV: } \\
\text { Inducción: 1,5-3 mg } \\
\text { cada } 5 \text { minutos hasta } \\
\text { que esté sedado (la } \\
\text { dosis requerida será la } \\
\text { dosis de inducción) } \\
\text { Perfusión: dosis de } \\
\text { inducción x } 6 \\
\text { Rescate: dosis de } \\
\text { inducción Dosis } \\
\text { máxima: } 200 \text { mg/día. }\end{array}$ & $\begin{array}{l}\text { Aumento de apetito, } \\
\text { ictericia, hipotensión, } \\
\text { alteración del } \\
\text { ritmo cardiaco, } \\
\text { anafilaxia, trombosis, } \\
\text { broncoespasmo, } \\
\text { depresión respiratoria, } \\
\text { somnolencia, confusión, } \\
\text { ataxia, amnesia, } \\
\text { alucinaciones, debilidad } \\
\text { muscular }\end{array}$ & $\begin{array}{l}\text { - Se puede administrar } \\
\text { vía SC. } \\
\text { - También se usa en } \\
\text { CP en el hipo, crisis } \\
\text { comiciales. }\end{array}$ \\
\hline MORFINA & $\begin{array}{l}\text { Ampollas: } 10 \text { mg/ml, } \\
20 \text { mg/ml, } 40 \text { mg/ml IV, SC, } \\
\text { epidural. } \\
\text { Comp: } 10 \text { mg, } 20 \text { mg } \\
\text { Solución: } 2 \text { mg/ml; } 20 \text { mg/ml } \\
\text { Comp liberación retardada } \\
\text { (continuos): } 5,10,15,30 \text {, } \\
\text { 60, } 100 \text { y } 200 .\end{array}$ & $\begin{array}{l}\text { Dosis inicial en } \\
\text { pacientes no tratados } \\
\text { con opioides: } \\
\text { Dolor: } 10-30 \text { mg/d vía } \\
\text { oral repartidos en } 4 \\
\text { dosis si es de acción } \\
\text { rápida o en } 2 \text { dosis } \\
\text { en las de liberación } \\
\text { prolongada. } \\
\text { Disnea: } \\
2,5-5 \text { mg/4-6 h, vía oral } \\
\text { de acción rápida } \\
\text { Si está en tratamiento } \\
\text { con morfina: } \\
\text { Aumentar la dosis un } \\
25-50 \% \\
\text { Dosis de rescate: } 1 / 6 \\
\text { de la dosis total diaria }\end{array}$ & $\begin{array}{l}\text { Náuseas, vómitos, } \\
\text { estreñimiento, } \\
\text { somnolencia, sequedad } \\
\text { de boca, sudoración, } \\
\text { depresión respiratoria, } \\
\text { alucinaciones, disforia, } \\
\text { retención urinaria, } \\
\text { mioclonías }\end{array}$ & $\begin{array}{l}\text { _ Vía SC: mitad de la } \\
\text { dosis de la VO } \\
\text { _ Vía IV: un tercio de la } \\
\text { dosis de la VO } \\
\text { - No tiene techo } \\
\text { terapéutico } \\
\text { - Proteger de la luz } \\
\text { - No se recomienda su } \\
\text { uso por vía inhalada } \\
\text { - La indicación en disnea } \\
\text { es fuera de FT salvo } \\
\text { en IC }\end{array}$ \\
\hline
\end{tabular}




\begin{tabular}{|c|c|c|c|c|}
\hline OCTREÓTIDO & Vial: 50, 100, $1000 \mu \mathrm{g}$ & 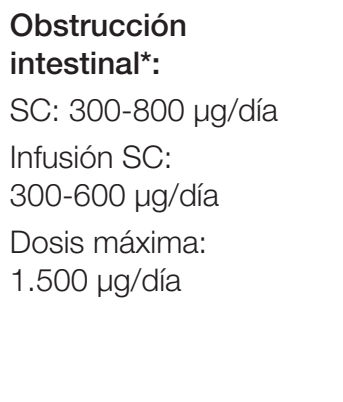 & Diarrea, dolor abdominal & $\begin{array}{l}\text { - Se puede administrar } \\
\text { por vía SC. } \\
\text { Medicamento de } \\
\text { diagnóstico hospitalario } \\
\text { (indicaciones no } \\
\text { recogidas en FT). } \\
\text { - En CP también se } \\
\text { puede usar en la } \\
\text { diarrea refractaria } \\
\text { (50-500 } \mu \mathrm{g} / \text { día). }\end{array}$ \\
\hline $\begin{array}{l}\text { ONDAN- } \\
\text { SETRON }\end{array}$ & $\begin{array}{l}\text { Comp: } 4-8 \text { mg } \\
\text { Ampollas: } 4-8 \text { mg }\end{array}$ & $\begin{array}{l}\text { Náuseas y vómitos: } \\
\text { VO, IM*, SC*, IV: } \\
12-24 \text { mg/día Vía y } \\
\text { dosis variable según } \\
\text { riesgo de emesis } \\
\text { Dosis máxima: } \\
32 \text { mg/día }\end{array}$ & $\begin{array}{l}\text { Estreñimiento, cefalea, } \\
\text { rubefacción, hipo, } \\
\text { alteraciones visuales, } \\
\text { mareo, movimientos } \\
\text { involuntarios, convulsiones }\end{array}$ & 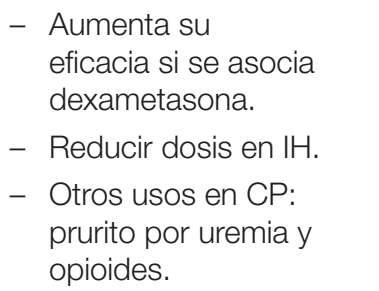 \\
\hline $\begin{array}{l}\text { PARACE- } \\
\text { TAMOL }\end{array}$ & $\begin{array}{l}\text { Comp: 500/650/1000 mg } \\
\text { Comp efervesc.: } 1000 \text { mg } \\
\text { Sobres: 650/1000 mg } \\
\text { Supositorios: } 650 \text { mg Vial IV: } \\
1000 \text { mg }\end{array}$ & $\begin{array}{l}\text { Dolor y fiebre: } \\
\text { VO: } 500-1000 \mathrm{mg} / \\
\text { 4-6 h } \\
\text { Rectal: } 650 \mathrm{mg} / 4-6 \mathrm{~h} \\
\text { IV: } 1000 \mathrm{mg} / 6 \mathrm{~h} \\
\text { Dosis máxima: } 4 \text { g/día }\end{array}$ & $\begin{array}{l}\text { Escasa toxicidad. Rash, } \\
\text { toxicidad hepática, fiebre }\end{array}$ & \\
\hline
\end{tabular}




\begin{tabular}{|c|c|c|c|c|}
\hline TRAMADOL & $\begin{array}{l}\text { Caps: } 50 \mathrm{mg} \\
\text { Gotas (hay presentaciones } \\
\text { con pulverizador): } 100 \mathrm{mg} / \mathrm{ml} \\
\text { Supositorios: } 100 \mathrm{mg} \\
\text { Vial: } 100 \mathrm{mg}\end{array}$ & $\begin{array}{l}\text { Dolor: } \\
\text { VO: 50-100 mg/6-8 h } \\
\text { VO retard: } \\
\text { 50-100-150-200 mg/ } \\
12 \mathrm{~h} \\
\text { Rectal: } 100 \text { mg/6-8 h } \\
\text { SC-IM: } \\
\text { 50-100 mg/6-8 h } \\
\text { Dosis máxima: } \\
400 \text { mg/día }\end{array}$ & $\begin{array}{l}\text { Mareo, confusión, } \\
\text { sudoración, hipotensión } \\
\text { postural, náuseas, } \\
\text { sequedad de boca }\end{array}$ & $\begin{array}{l}\text { - Puede ser necesario } \\
\text { asociar laxante. Reducir } \\
\text { dosis en ancianos e } \\
\text { insuficiencia renal. } \\
\text { - } \text { Menor somnolencia } \\
\text { y estreñimiento que } \\
\text { codeína, pero mayor } \\
\text { riesgo de interacciones } \\
\text { (ISRS, antidepresivos } \\
\text { tricíclicos, triptanes, } \\
\text { IMAO, anticoagulantes } \\
\text { orales, bupropion, } \\
\text { neurolépticos). } \\
\text { - Se puede administra } \\
\text { vía SC. } \\
\text { - Poco uso actual en CP. } \\
\text { Preferibles opioides } \\
\text { mayores a dosis bajas. }\end{array}$ \\
\hline
\end{tabular}




\section{Anexo 11. Material complementario al capítulo de sedación paliativa}

\section{Cuidados antes y durante la sedación paliativa}

\section{Antes de la sedación:}

- Se proporcionarán cuidados de confort y alivio de los síntomas físicos.

- Se intentará un adecuado acompañamiento facilitando las despedidas.

- En el medio hospitalario, se intentará proporcionar una habitación individual para preservar la intimidad durante el proceso de sedación y muerte.

- Se obtendrá el consentimiento expreso del paciente en la medida de lo posible; en los casos en que se considere maleficente se obtendrá el consentimiento verbal de la familia/allegados.

Una vez iniciada la sedación y durante la misma se llevará a cabo el plan de cuidados programado:

- Asegurarse de que el paciente y la familia han sido correctamente informados acerca de la sedación paliativa y consienten su realización.

- Si el paciente está en su domicilio se valorarán las condiciones de salubridad adecuadas, identificando los factores de riesgo social y de salud para cumplir dichas condiciones.

- Se instruirá a los cuidadores en cuidados en situación de últimos días y se capacitará a los cuidadores en el manejo de vía subcutánea, uso de rescates si precisa y en todas las medidas de confort.

- Administrar rescates pautados para aliviar los síntomas que pudieran aparecer durante la sedación.

- Cuidar la vía por la que se administra la medicación para evitar complicaciones en la zona de infusión (flebitis, irritación, acodamiento, salida accidental del catéter, etc).

- Evaluar el nivel de sedación (escala RASS, Ramsay) y monitorizar los síntomas.

- Mantener en todo momento un proceso de comunicación continuada con el paciente y la familia, cuidando aspectos verbales y no verbales.

- Proporcionar unas condiciones ambientales adecuadas: luz tenue, temperatura adecuada, evitar estímulos auditivos desagradables o poco significativos para el enfermo, y procurar que el número de personas en la habitación permita la comodidad y siga los deseos del paciente.

- Mantener medidas de confort (higiene, cuidados de la piel y de la boca) reduciéndolas a las imprescindibles para evitar incomodar. Limitar los cambios posturales a los imprescindibles para proporcionar comodidad y evitarlos en las últimas horas de vida.

- Si hay estertores eliminar las secreciones que pudieran llegar a la boca, procurando comodidad. Se recomienda el decúbito lateral para facilitar la expulsión de secreciones. Evitar la aspiración profunda. 
- Evitar la toma de constantes vitales si no es estrictamente necesario.

- Si hay fiebre aplicar medidas de confort con paños en la frente mojados con agua a temperatura ambiente (evitar agua helada).

- Si fuera necesaria la realización de curas limitar el procedimiento a lo imprescindible para procurar confort (control del exceso de exudado y olor). El desbridamiento cortante está contraindicado.

- Evitar la administración de enemas ya que esto puede provocar incomodidad.

- Vigilar la retención urinaria y valorar la necesidad de sondaje vesical si fuera necesario (sólo si la retención genera incomodad).

- Adaptar la alimentación al nivel de conciencia y deseos del paciente. La nutrición forzada no contribuye a mejorar la calidad de vida del paciente y puede provocar broncoaspiraciones. La nutrición parenteral está contraindicada.

- En cuanto a la hidratación adaptarla a los deseos del paciente y a su nivel de conciencia.

- Dar apoyo a la familia, facilitar que expresen sus preocupaciones y aclarar sus dudas. Informar sobre la evolución y los cuidados.

- Facilitar la presencia de personas significativas para el enfermo e invitarles a colaborar en los cuidados si lo desean.

- Facilitar asistencia espiritual según preferencias del paciente y familia.

- Facilitar información sobre el momento de la muerte, incluyendo trámites burocráticos si es necesario.

- Prestar especial atención al cuidador o cuidadora principal, reforzando su papel y promoviendo que otras personas se impliquen para que pueda descansar.

- Si hay menores en el entorno cercano facilitarles participar en el proceso y acompañar en la medida que quieran (ver guía de familiares).

- Empezar cuanto antes acciones destinadas a facilitar el duelo de la familia.

- Aportar información sobre trámites a los familiares. Puede ser necesaria la participación del trabajador social sanitario, sobre todo cuando sea necesaria la coordinación con servicios sociales y tercer sector, u otras coordinaciones no sanitarias. En el documento de información para familias se incluye alguna información sobre trámites.

Tabla 18. Algoritmo de refractariedad

1. ¿Existen más intervenciones capaces de proporcionar mayor alivio?

2. ¿La morbilidad prevista de la intervención es tolerable para el paciente?

3. ¿Las intervenciones propuestas proporcionan alivio dentro de un marco de tiempo razonable?

Si la respuesta a cualquiera de estas tres preguntas es "no" se trata de síntomas refractarios para los que puede ser necesario considerar la sedación paliativa. 
Tabla 19. Fármacos recomendados para sedación paliativa

\begin{tabular}{|c|c|c|c|}
\hline Fármaco* & Dosis recomendada** & Observaciones & Compatibilidad \\
\hline MIDAZOLAM & $\begin{array}{l}\text { Sedación vía SC: } \\
\text { Inducción: 2,5-5 mg } \\
\text { Perfusión: } 15-30 \text { mg en } 24 \text { h } \\
\text { Rescate: bolos 2,5-5 mg } \\
\text { Sedación vía IV: } \\
\text { Inducción: } 1,5-3 \text { mg cada } \\
5 \text { min hasta que esté se- } \\
\text { dado*** (la suma de dosis } \\
\text { requeridas será la dosis de } \\
\text { inducción) } \\
\text { Perfusión: dosis de induc- } \\
\text { ción x } 6 \\
\text { Rescate: dosis de inducción }\end{array}$ & $\begin{array}{l}\text { - Doblar la dosis si el paciente ya to- } \\
\text { maba benzodiazepinas. } \\
\text { - Dosis máxima: } 200 \mathrm{mg} / \text { día (dosis } \\
\text { mayores pueden provocar agita- } \\
\text { ción paradójica). } \\
\text { - Se puede administrar por vía SC } \\
\text { (uso de la vía no recogido en ficha } \\
\text { técnica). No es necesario diluir para } \\
\text { su administración SC. } \\
\text { - Presentación: ampollas } 15 \mathrm{mg} / 3 \mathrm{ml} \\
\text { (para vía subcutánea); ampollas de } \\
5 \mathrm{mg} / 5 \mathrm{ml} \text {, ampollas } 50 \mathrm{mg} / 10 \mathrm{ml} \text {. }\end{array}$ & $\begin{array}{l}\text { - Butilescopolamina } \\
\text { - Cloruro mórfico } \\
\text { - Fentanilo } \\
\text { - Haloperidol } \\
\text { - Ketamina } \\
\text { - Levomepromazina } \\
\text { - Metadona } \\
\text { - Metoclopramida } \\
\text { - Octreótido } \\
\text { - Ondansetrón } \\
\text { - Oxicodona } \\
\text { - Tramadol }\end{array}$ \\
\hline $\begin{array}{l}\text { LEVOME- } \\
\text { PROMAZINA }\end{array}$ & $\begin{array}{l}\text { En este caso las dosis son } \\
\text { similares para ambas vías } \\
\text { sc/iv. } \\
\text { Inducción: } 12,5-25 \mathrm{mg} \\
\text { Perfusión: } 75-100 \mathrm{mg} / \text { día } \\
\text { Rescate: } 12,5-25 \mathrm{mg}\end{array}$ & $\begin{array}{l}\text { - Sedación cuando el síntoma pre- } \\
\text { dominante es el delirium. } \\
\text { - Dosis máxima: } 300 \text { mg. } \\
\text { - Se puede administrar vía SC (uso } \\
\text { de la vía no recogido en ficha téc- } \\
\text { nica). } \\
\text { - Larga vida media, puede adminis- } \\
\text { trarse dosis única diaria en bolo } \\
\text { SC. } \\
\text { - Produce irritación en el punto de in- } \\
\text { fusión, por lo que se cambiará la vía } \\
\text { frecuentemente. } \\
\text { - Presentación: ampollas } 25 \text { mg/1 ml. }\end{array}$ & \\
\hline $\begin{array}{l}\text { FENOBAR- } \\
\text { BITAL }\end{array}$ & $\begin{array}{l}\text { Sedación vía SC: } \\
\text { Inducción: } 100-200 \text { mg } \\
\text { Perfusión: 600-800 mg/día } \\
\text { Rescate: bolos } 100 \text { mg } \\
\text { Sedación vía IV: } \\
\text { Inducción: } 2 \text { mg/kg lento } \\
\text { Perfusión: } 1 \text { mg/kg/h y } \\
\text { modificar según respuesta }\end{array}$ & $\begin{array}{l}\text { - Previamente suspender perfusión } \\
\text { de BZD o neurolépticos y reducir } \\
\text { los opioides a la mitad. } \\
\text { - Indicado si falla midazolam y levo- } \\
\text { mepromazina. } \\
\text { - Ventaja de uso en domicilio si fallan } \\
\text { los anteriores, por la posibilidad de } \\
\text { vía subcutánea. } \\
\text { - Presentación: ampollas de } \\
200 \text { mg/ml. }\end{array}$ & $\begin{array}{l}\text { - No mezclar con } \\
\text { otros fármacos. }\end{array}$ \\
\hline PROPOFOL & $\begin{array}{l}\text { Sedación IV: } \\
\text { Inducción: } 1-1,5 \mathrm{mg} / \mathrm{kg} \\
\text { Perfusión: } 2 \mathrm{mg} / \mathrm{kg} / \mathrm{h} \\
\text { Rescate: bolos de } 50 \% \text { de } \\
\text { la dosis de inducción }\end{array}$ & $\begin{array}{l}\text { - Previamente suspender perfusión } \\
\text { de BZD o neurolépticos y reducir } \\
\text { los opioides a la mitad. } \\
\text { - Uso hospitalario (uso exclusivo IV). } \\
\text { - Presentación: ampollas de } 20,50 \text { y } \\
100 \text { ml; conteniendo } 10 \text { mg/ml. } \\
\text { - Indicado si falla midazolam y levo- } \\
\text { mepromazina. }\end{array}$ & $\begin{array}{l}\text { - No mezclar con } \\
\text { otros fármacos. }\end{array}$ \\
\hline
\end{tabular}

(*) Indicación no recogida en ficha técnica para ninguno de los fármacos recomendados

(**) La dosis debe individualizarse teniendo en cuenta la respuesta clínica de cada paciente y las recomendaciones de la ficha técnica. (***) Diluir 1 ampolla de midazolam de $15 \mathrm{mg} / 3 \mathrm{ml}$ en $7 \mathrm{ml}$ de suero fisiológico. Administrar $1 \mathrm{ml}(1,5 \mathrm{mg})$ iv cada $5 \mathrm{minutos}$ hasta conseguir RAMSAY 2-3.

Fuente: modificado de GPC de Cuidados Paliativos (2008) (20). 
Tabla 20. Escala de Ramsay

\begin{tabular}{|l|l|}
\hline Nivel & Descripción \\
\hline Nivel I & Paciente agitado, angustiado \\
\hline Nivel II & Paciente tranquilo, orientado y colaborador \\
\hline Nivel III & Paciente con respuesta a estímulos verbales \\
\hline Nivel IV & Paciente con respuesta rápida a la presión glabelar o estímulo doloroso \\
\hline Nivel V & Paciente con respuesta perezosa a la presión glabelar o estímulo doloroso \\
\hline Nivel VI & Paciente sin respuesta \\
\hline
\end{tabular}

Fuente: tomado de GPC de Cuidados Paliativos (2008) (20).

Tabla 21. Escala de Agitación en la Sedación de Richmond (RASS)

\begin{tabular}{|c|c|c|c|}
\hline Puntuación & Término & \multicolumn{2}{|l|}{ Descripción } \\
\hline 4 & Combativo & \multicolumn{2}{|c|}{ Abiertamente combativo, violento, peligro directo para los profesionales } \\
\hline 3 & Muy agitado & \multicolumn{2}{|l|}{ Tira o se quita la sonda o catéter; agresivo } \\
\hline 2 & Agitado & \multicolumn{2}{|c|}{$\begin{array}{l}\text { Se mueve con frecuencia de manera no intencionada, intenta quitarse la mas- } \\
\text { carilla o gafas nasales de oxigenoterapia }\end{array}$} \\
\hline 1 & Inquieto & \multicolumn{2}{|l|}{ Ansioso pero no agresivo en los movimientos } \\
\hline 0 & $\begin{array}{l}\text { Despierto y } \\
\text { calmado }\end{array}$ & & \\
\hline-1 & Adormilado & $\begin{array}{l}\text { No contempla alerta, pero mantiene los ojos abiertos } \\
\text { (ojos abiertos/contacto visual) cuando le hablan (10 o } \\
\text { más segundos) }\end{array}$ & Estimulación verbal \\
\hline-2 & $\begin{array}{l}\text { Sedación } \\
\text { ligera }\end{array}$ & $\begin{array}{l}\text { Mantiene los ojos abiertos por poco tiempo cuando le } \\
\text { hablan (menos de } 10 \text { segundos) }\end{array}$ & \\
\hline-3 & $\begin{array}{l}\text { Sedación } \\
\text { moderada }\end{array}$ & $\begin{array}{l}\text { Se mueve o abre los ojos cuando le hablan pero no } \\
\text { mantiene contacto visual }\end{array}$ & \\
\hline-4 & $\begin{array}{l}\text { Sedación } \\
\text { profunda }\end{array}$ & $\begin{array}{l}\text { No responde a un estímulo verbal pero se mueve o } \\
\text { abre los ojos ante una estimulación física }\end{array}$ & Estimulación física \\
\hline-5 & Inconsciente & No responde a la voz ni a estímulos físicos & \\
\hline \multicolumn{4}{|c|}{ Procedimiento para la evaluación del RASS } \\
\hline \multicolumn{4}{|c|}{ 1. Observe al paciente } \\
\hline \multicolumn{3}{|c|}{ a) El paciente está alerta, inquieto o agitado } & Puntuación de $0 \mathrm{a}+4$ \\
\hline \multicolumn{4}{|c|}{ 2. Si no está alerta, diga su nombre y que abra los ojos y mire a quien le habla } \\
\hline \multicolumn{3}{|c|}{ a) El paciente despierta y mantiene los ojos abiertos y contacto visual } & Puntuación de -1 \\
\hline \multicolumn{3}{|c|}{ b) El paciente despierta con ojos abiertos y contacto visual pero no lo mantiene } & Puntuación de -2 \\
\hline \multicolumn{3}{|c|}{$\begin{array}{l}\text { c) El paciente realiza algún movimiento como respuesta a la voz pero no hay } \\
\text { contacto visual }\end{array}$} & Puntuación de -3 \\
\hline \multicolumn{4}{|c|}{$\begin{array}{l}\text { 3. Si no responde a estímulos verbales, estimule físicamente al paciente tocándole el hombro y/o frotando } \\
\text { el esternón }\end{array}$} \\
\hline \multicolumn{3}{|c|}{ a) El paciente realiza algún movimiento ante la estimulación física } & Puntuación de -4 \\
\hline \multicolumn{3}{|c|}{ b) El paciente no responde a ninguna estimulación } & Puntuación de -5 \\
\hline
\end{tabular}

Fuente: tomado de guía clínica de sedación paliativa del Programa Regional de Cuidados Paliativos de Extremadura (206). 
Figura 3. Algoritmo para el uso de fármacos en la sedación.

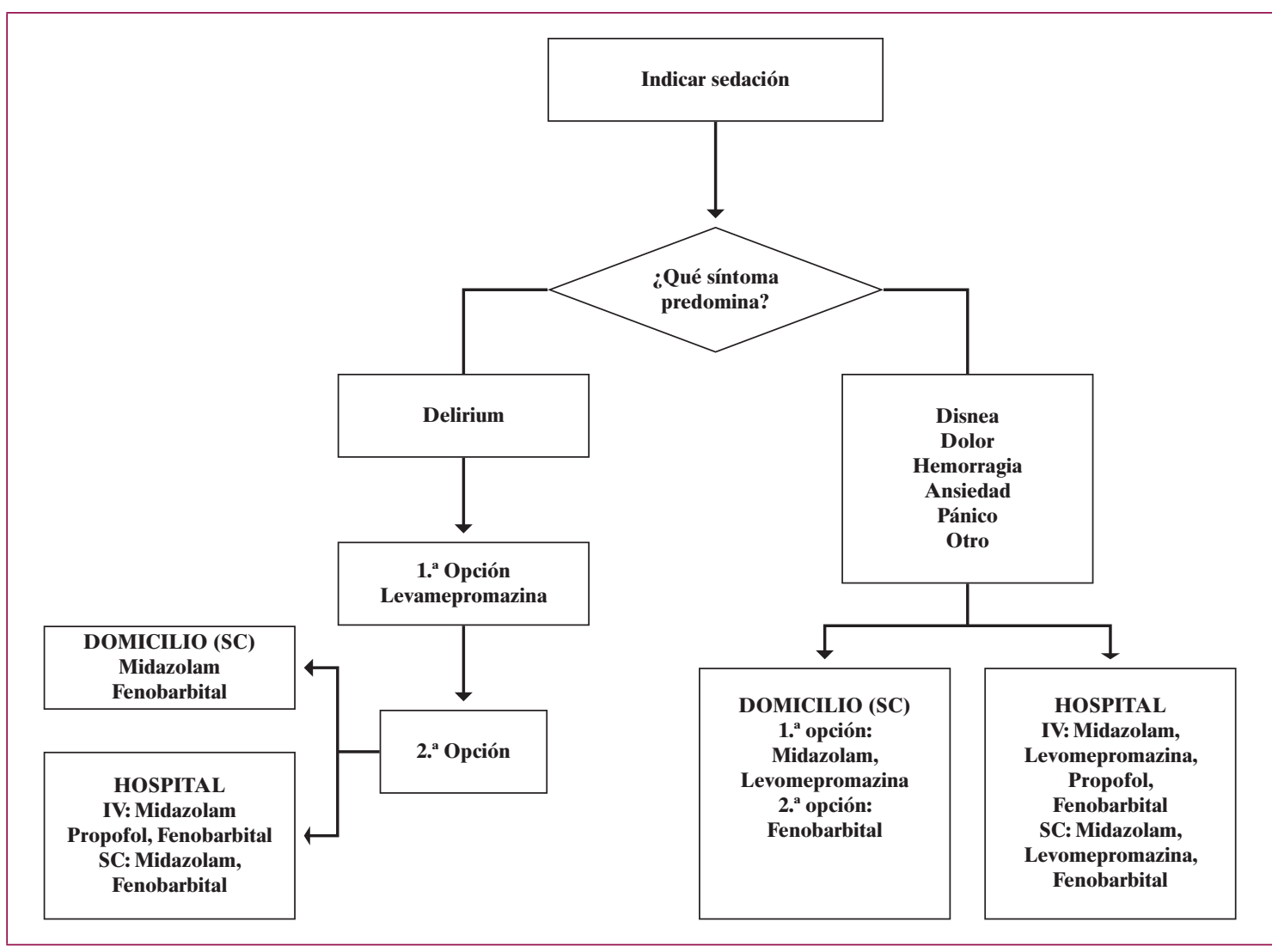

Fuente: tomado de GPC de Cuidados Paliativos (2008) (20). 



\section{Anexo 12. Aspectos éticos, legales y deontológicos}

\section{Aspectos éticos}

El final de la vida es probablemente uno de los temas más tratados por la bioética. No tiene nada de extrañar ya que buscar la calidad de la muerte, tener una buena muerte, ha sido invariablemente una preocupación de la sociedad y, paradójicamente, no siempre se produce de la forma más adecuada. De ahí que los sistemas sanitarios, y por tanto también las guías de práctica clínica, deban ofrecer respuestas a esta demanda ciudadana, que es un derecho del paciente y un deber de los profesionales.

Por otra parte, en ocasiones, los avances científicos han propiciado en nuestra sociedad la percepción errónea de que la muerte casi siempre puede y debe ser evitada o al menos retrasada. Este enfoque de la medicina es el responsable de que muchos profesionales se encuentren incómodos e inseguros ante el desenlace final de la enfermedad sin saber bien cómo actuar. Así, aparecen dificultades para reconocer el momento en que ha llegado esta etapa lo que genera dudas y miedo para no aplicar o retirar determinadas medidas terapéuticas. En este sentido, ya hace unos cuantos años que el Hastings Center advirtió contra la tentación de prolongar la vida indebidamente, haciendo énfasis, dentro de los fines de la medicina, en la paliación del dolor y el sufrimiento (241).

El desarrollo de la bioética y de los cuidados paliativos ha supuesto una mejora en la atención del enfermo cuando no tiene posibilidades de curación y consecuentemente en el objetivo de conseguir una buena muerte. La medicina paliativa considera que el proceso de morir es un hecho natural, de ahí que, aunque afirma y promueve la vida, no pretende alargarla de forma innecesaria, ni acortarla, sino fomentar su calidad.

Si bien existen diferencias en cómo quieren morirse las personas (en casa o en el hospital, sin deterioro psicofísico o con avanzada edad, de forma repentina o no...), también es cierto que ciertas condiciones pueden considerarse generalizables: todos queremos fallecer sin dolor, sin sufrimiento y rodeados de nuestros familiares y seres queridos (242).

Las cuestiones éticas relativas a la atención en los últimos días pueden, genéricamente, diferenciarse en dos partes: aquellas relacionadas con la calidad de la atención en el sentido de facilitar una gestión más autónoma del proceso del final de la vida y aquellas referidas a la equidad en el acceso a dicha atención (243).

Con respecto a la autonomía, las personas tienen derecho a una información veraz, completa, gradual y compasiva, lo que se ha llamado la verdad soportable (244), teniendo en cuenta la falta de certezas absolutas en medicina, que les permita la toma de decisiones. Esto se plasma en la necesidad de obtener el consentimiento informado para cualquier procedimiento diagnóstico y terapéutico. Es, por tanto, el paciente el que tiene derecho a ser informado, así como también tiene el derecho a no serlo, si así lo manifiesta y solo él es el que puede renunciar a dicho derecho.

Ocultar el diagnóstico al paciente puede llegar a generar el indeseable pacto del silencio (anteriormente denominado conspiración del silencio), que se puede definir como el acuerdo implícito o explícito, por parte de familiares, allegados o profesionales, de alterar la información que se le da al paciente con el fin de ocultarle el diagnóstico o pronóstico y 
la gravedad de la situación (244). El pacto del silencio dificulta la adaptación del paciente a su enfermedad y dificulta la toma de decisiones (245).

Para mejorar el proceso de toma de decisiones los sanitarios debemos permitir y facilitar que las personas expresen, definan y concreten, si así lo desean, con antelación suficiente y cuando todavía están en condiciones de hacerlo, cuáles son sus valores, preferencias y deseos, que quieren sean tenidos en cuenta, respecto a la atención sanitaria que recibirá como paciente para cuando no sea capaz de decidir. Es lo que se conoce como Proceso de planificación anticipada o compartida de la asistencia que deberá ser registrado adecuadamente en la historia clínica del paciente, ser revisado periódicamente y comunicado a todas las personas implicadas en la atención. Podrá plasmarse si se desea, en un Documento de Instrucciones Previas, testamento vital o voluntades anticipadas. Podrá depositarse en el Registro habilitado en cada CCAA con el fin de que sea incorporado a la historia clínica electrónica y al Registro Nacional (246).

El modelo de decisiones compartidas es un estilo de relación mediante el cual el profesional aplica conocimientos científicos y habilidades de comunicación teniendo en cuenta los valores y preferencias del paciente para ayudarle y apoyarle en su decisión, siendo un modelo de relación clínica deliberativo. Se distingue, por tanto, del modelo clásico "paternalista" en el que el paciente era un agente pasivo y del modelo informativo, en el que el paciente, tras ser informado, decide solo sin ayuda del profesional (247).

Algunos autores denominan conversaciones sensibles, de punto crítico o conversaciones difíciles a aquellas en las que el médico plantea una decisión compartida por la que se reorientan los objetivos, antes más centrados en la supervivencia y ahora en la calidad de vida. Con frecuencia, la falta de entrenamiento y actitud por parte de los profesionales hacen que estas conversaciones difíciles se retrasen a momentos de enfermedad muy avanzada (16).

Estos retrasos pueden traer consigo lo que se ha denominado la agresividad terapéutica. En los últimos años, algunos trabajos han diseñado indicadores relacionados con dicha agresividad que básicamente se agrupan en tres áreas (248): la sobreutilización de quimioterapia cerca de la muerte, el mal uso de tratamientos y dispositivos en relación con visitas a urgencias e ingresos en unidades de cuidados intensivos y la escasa o tardía utilización de los programas de cuidados paliativos.

En ocasiones, la pluralidad de creencias y valores de las personas conllevan, en el ejercicio de su autonomía, que se originen situaciones conflictivas desde el punto de vista ético como pueden ser solicitudes de actuaciones diagnósticas y terapéuticas desproporcionadas $\mathrm{o}$, todo lo contrario, el rechazo al tratamiento.

El rechazo al tratamiento es un derecho de la persona de ahí que sea prioritario garantizar que ningún paciente en situación de enfermedad avanzada sea tratado en contra de su voluntad ni abandonado en su cuidado.

Es básico conocer y distinguir correctamente los conceptos de obstinación terapéutica, limitación del esfuerzo terapéutico y actuaciones clínicas limitadas en el tiempo. El correcto uso de los términos facilitará la compresión de las acciones a los que éstos se refieren, hecho imprescindible para la práctica asistencial de los profesionales sanitarios. 
Otro concepto relacionado con el anterior es el de futilidad. Se considera acción fútil, según criterio médico, la que es ineficaz o perjudicial para obtener beneficio clínico, y no sólo fisiológico, o bien aquella cuyas cargas (sobre el ámbito afectivo, economía o sociedad), sean desproporcionadas para el beneficio esperable. En contraposición, un tratamiento proporcionado es aquel que mantiene un balance adecuado entre beneficios/costes sociales/costes económicos, en función de los objetivos perseguidos (249). La proporcionalidad trata de evaluar los efectos positivos del tratamiento y los negativos, como la falta de confort o el dolor. Es una obligación moral incorporar solo las medidas terapéuticas que guarden una relación de debido equilibrio entre los medios empleados y el resultado previsible. Si falta este equilibrio, se consideran desproporcionadas y no son éticamente aceptables.

En este contexto es donde se enmarcan conceptos como la obstinación terapéutica, la utilización de medios que no tienen más sentido que la prolongación de la vida biológica con escasas probabilidades de supervivencia sin dichos medios o bien de sobrevivir con una calidad de vida ínfima, o la limitación del esfuerzo terapéutico, que consiste en no instaurar o retirar medidas terapéuticas que no le aportarán un beneficio claro al percibirse una desproporción entre los fines y los medios terapéuticos (249). Si bien la limitación del esfuerzo terapéutico es, a priori, una decisión exclusiva del profesional, lo deseable sería plantear la toma de decisiones dentro de un proceso de decisiones compartidas. En este mismo sentido, también se puede hablar de la adecuación de las intervenciones clínicas y de las actuaciones clínicas limitadas en el tiempo.

La adecuación de las intervenciones clínicas implica ofertar sólo aquellos procedimientos diagnósticos o terapéuticos proporcionados al pronóstico y momento evolutivo de la enfermedad y llevar a cabo, únicamente, los consentidos por el paciente o su representante (250).

Las actuaciones clínicas limitadas en el tiempo consisten en un acuerdo entre el equipo sanitario y el paciente y la familia del paciente o cuidadores sobre el uso de ciertos tratamientos médicos durante un periodo definido (251). En caso de no conseguir los objetivos propuestos se suspenderá el tratamiento y se reorientarán los objetivos de la atención.

Dependiendo de la fase de la enfermedad en que se encuentre el paciente, la tipología de la medida terapéutica (252-254) se puede clasificar en obligatoria, es decir, eficaz en dicha situación (como por ejemplo los analgésicos para el control del dolor), opcional o de eficacia dudosa (como la antibioterapia o las transfusiones en pacientes con enfermedad avanzada) y no indicada si es ineficaz en esa situación (el soporte vital o la respiración mecánica serían dos buenos ejemplos).

Una realidad frecuente al final de la vida que causa un gran desasosiego a los profesionales, a los pacientes y a sus familiares son los problemas relacionados con la alimentación y la hidratación (255). Las indicaciones de soporte nutricional prolongado en estos pacientes, y especialmente en aquellos con deterioro neurológico irreversible, suscitan a menudo conflictos éticos. La malnutrición no es la causa sino la consecuencia de la enfermedad y es irreversible en los estadios finales. El objetivo principal no es corregirla sino tratar de controlar los síntomas y mejorar la calidad de vida de los pacientes. 
Tanto en la aplicación de nutrición como hidratación existe controversia entre quienes los consideran cuidados básicos - y por tanto siempre de obligado cumplimiento - y aquellos que consideran que se trata de un tratamiento más y que, por tanto, su aplicación depende de la situación clínica y de los deseos del paciente. Se define tratamiento médico como aquel cuya instauración requiere de los conocimientos y la participación de los profesionales sanitarios y además supone una invasión corporal, por lo que podemos considerar que tanto la hidratación como la nutrición artificial cumplen ambos requisitos y, por tanto, se pueden considerar tratamientos médicos (250).

En lo relativo a la equidad, es imprescindible dejar claro que los servicios de salud han de garantizar que toda persona, tanto en su domicilio como en un centro hospitalario, recibirá una atención sanitaria de calidad en relación a los cuidados al final de la vida. Es decir, se deben tomar medidas incisivas que eviten las desigualdades en la calidad de los cuidados paliativos. La diferencia en los cuidados sanitarios dispensados a las personas durante el proceso del final de la vida, solo es aceptable si ésta es fruto de la consideración y del respeto a la diversidad de sus valores y de sus diferentes necesidades. Es importante conseguir, no solo equidad de acceso, sino también la equidad de resultados.

Así, la ley de cuidados inversos explica que el acceso a la atención médica o social de calidad varía en proporción inversa a su necesidad en la población asistida $(256,257)$. Al final de la vida, la mayor necesidad de cuidados de los pacientes crónicos complejos puede generar una discriminación negativa si no existe una adecuada estructura y función de atención paliativa.

Esto pasa por una apropiada estrategia de dispositivos de cuidados paliativos de tal manera que se asegure que sean accesibles a toda la población y por la adecuada formación de los profesionales en este campo asistencial.

Uno de los peligros constatados es la fragmentación de los cuidados. Se debe promover el trabajo en equipo, de tal manera que todos sus miembros compartan las incertidumbres y decisiones, para así favorecer la coherencia de la continuidad asistencial a lo largo del tiempo (249).

El Comité de Bioética de España hace pocos años publicó una declaración en la que hace referencia a la formación de los profesionales en cuidados paliativos (243). Así, manifiesta que parecen necesarias tanto una formación básica del personal sanitario como una formación avanzada y específica de los profesionales que van a atender a los pacientes en situación paliativa. Igualmente, insiste en la necesidad de desarrollar procedimientos de toma de decisiones que integren los principios y valores de todas las partes en las especiales circunstancias de los pacientes al final de la vida. Por todo ello, dicho comité concluye exhortando a que considera necesario avanzar en la capacitación específica en cuidados paliativos, en orden a garantizar los derechos de los pacientes y familiares y allegados en este ámbito tan sensible de la medicina.

A modo de síntesis, se puede concluir, enmarcando todos estos conceptos dentro de los cuatro principios de la bioética (258) (tabla 22): 
Tabla 22. Formulación de los principios y respuestas en los cuidados al final de la vida

\begin{tabular}{|c|c|c|}
\hline Principio & Formulación & Respuesta \\
\hline Beneficencia & $\begin{array}{l}\text { ¿Qué es bueno para el paciente en situación } \\
\text { de últimos días? Lo que tenemos que buscar. }\end{array}$ & $\begin{array}{l}\text { Atención paliativa integral, con ade- } \\
\text { cuación diagnóstica y terapéutica } \\
\text { para conseguir el máximo alivio del } \\
\text { sufrimiento y una buena muerte. }\end{array}$ \\
\hline $\begin{array}{l}\text { No } \\
\text { maleficencia }\end{array}$ & $\begin{array}{l}\text { ¿Qué es malo para el paciente en situación de } \\
\text { últimos días? Lo que tenemos que evitar. }\end{array}$ & $\begin{array}{l}\text { Evitar la futilidad, la agresividad y la } \\
\text { obstinación terapéutica. }\end{array}$ \\
\hline Autonomía & $\begin{array}{l}\text { ¿Qué quiere el paciente en situación de últi- } \\
\text { mos días? Lo que tenemos que considerar y } \\
\text { atender. }\end{array}$ & $\begin{array}{l}\text { Respetar sus valores y tomar deci- } \\
\text { siones compartidas. }\end{array}$ \\
\hline Justicia & $\begin{array}{l}\text { ¿Qué es justo en la atención del paciente en } \\
\text { situación de últimos días? Pensando en el pa- } \\
\text { ciente y en la sociedad. }\end{array}$ & $\begin{array}{l}\text { La atención adecuada al final de la } \\
\text { vida como derecho del paciente y } \\
\text { como eficiencia del sistema. }\end{array}$ \\
\hline
\end{tabular}

Fuente: modificado de Amor-Pan et al, 2017 (258).

En la tabla 23 se incluyen las recomendaciones, desde el punto de vista de la bioética, de los cuidados al final de la vida.

En la tabla 24 se recoge la definición de algunos conceptos referidos a escenarios del final de la vida (249). 
Tabla 23. Recomendaciones desde el punto de vista de la bioética en los cuidados en el final de la vida

\begin{tabular}{|c|c|c|c|}
\hline \multirow{12}{*}{$\begin{array}{l}\text { Principio } \\
\text { de } \\
\text { dignidad } \\
\text { de las } \\
\text { personas }\end{array}$} & \multirow{12}{*}{$\begin{array}{l}\text { Derecho } \\
\text { a tener } \\
\text { una buena } \\
\text { muerte }\end{array}$} & Valores & Deberes \\
\hline & & \multirow[t]{7}{*}{$\begin{array}{l}\text { Calidad de la atención en- } \\
\text { caminada a facilitar una } \\
\text { gestión más autónoma del } \\
\text { proceso de final de la vida } \\
\text { (Autonomía) }\end{array}$} & $\begin{array}{l}\text { Proporcionar al paciente una información ve- } \\
\text { raz, completa, gradual y compasiva que le faci- } \\
\text { lite la toma de decisiones, la verdad soportable. } \\
\text { Evitar pacto del silencio. }\end{array}$ \\
\hline & & & $\begin{array}{l}\text { Obtener el consentimiento informado para } \\
\text { cualquier procedimiento diagnóstico y terapéu- } \\
\text { tico. }\end{array}$ \\
\hline & & & $\begin{array}{l}\text { Potenciar la planificación anticipada de la aten- } \\
\text { ción y la realización de documentos de instruc- } \\
\text { ciones previas. }\end{array}$ \\
\hline & & & $\begin{array}{l}\text { Fomentar el modelo de decisiones comparti- } \\
\text { das, las conversaciones sensibles, de punto } \\
\text { crítico o conversaciones difíciles. }\end{array}$ \\
\hline & & & $\begin{array}{l}\text { Evitar la agresividad y la obstinación terapéuti- } \\
\text { ca. No indicar acciones fútiles. }\end{array}$ \\
\hline & & & $\begin{array}{l}\text { Hacer adecuación tanto diagnóstica como te- } \\
\text { rapéutica conforme a deseos y preferencias del } \\
\text { paciente y conforme a la buena práctica clínica. }\end{array}$ \\
\hline & & & $\begin{array}{l}\text { Respetar el deseo del paciente al rechazo del } \\
\text { tratamiento. }\end{array}$ \\
\hline & & \multirow[t]{4}{*}{$\begin{array}{l}\text { Igualdad de acceso y de re- } \\
\text { sultados (Equidad) }\end{array}$} & $\begin{array}{l}\text { Garantizar que toda persona, tanto en su do- } \\
\text { micilio como en un centro hospitalario, recibirá } \\
\text { una atención sanitaria de calidad en relación a } \\
\text { los cuidados al final de la vida. }\end{array}$ \\
\hline & & & $\begin{array}{l}\text { Asegurar una estrategia de dispositivos de cui- } \\
\text { dados paliativos accesibles a toda la población. }\end{array}$ \\
\hline & & & $\begin{array}{l}\text { Promover el trabajo en equipo y coordinado en- } \\
\text { tre los distintos niveles asistenciales para evitar } \\
\text { la fragmentación de los cuidados y optimizar } \\
\text { las transiciones asistenciales. }\end{array}$ \\
\hline & & & $\begin{array}{l}\text { Conseguir una adecuada formación en cuida- } \\
\text { dos paliativos de todos los profesionales po- } \\
\text { tencialmente implicados en este campo asis- } \\
\text { tencial. }\end{array}$ \\
\hline
\end{tabular}

Fuente: elaboración propia. 
Tabla 24. Definición de algunos conceptos relacionados con diferentes escenarios al final de la vida

\begin{tabular}{|c|c|}
\hline Término & Definición \\
\hline Eutanasia* & $\begin{array}{l}\text { Es la actuación de un profesional sanitario que tiene por objeto terminar deliberada- } \\
\text { mente con la vida de un paciente con una enfermedad terminal o irreversible, que } \\
\text { padece un sufrimiento que él vive como intolerable, a petición expresa, voluntaria y } \\
\text { reiterada de éste. }\end{array}$ \\
\hline $\begin{array}{l}\text { Limitación } \\
\text { del esfuerzo } \\
\text { terapéutico }\end{array}$ & $\begin{array}{l}\text { Decisión médica que consiste en no instaurar o retirar medidas diagnósticas y tera- } \\
\text { péuticas que no aportarán a la persona en situación de final de vida beneficio claro } \\
\text { cuando se percibe una desproporción entre los fines buscados y los medios emplea- } \\
\text { dos. Retirar o no iniciar dichas medidas (entre ellas hay equivalencia moral), permite } \\
\text { a la enfermedad continuar su curso evolutivo, que inexorablemente conduce al falle- } \\
\text { cimiento de la persona. }\end{array}$ \\
\hline $\begin{array}{l}\text { Adecuación de } \\
\text { las intervenciones } \\
\text { clínicas o } \\
\text { proporcionalidad } \\
\text { diagnóstico- } \\
\text { terapéutica }\end{array}$ & $\begin{array}{l}\text { Actuación clínica que implica ofertar solo aquellos procedimientos diagnósticos o } \\
\text { terapéuticos proporcionados al pronóstico y momento evolutivo de la enfermedad, } \\
\text { levando a cabo, únicamente, los consentidos por el paciente o su representante. }\end{array}$ \\
\hline $\begin{array}{l}\text { Obstinación } \\
\text { terapéutica }\end{array}$ & $\begin{array}{l}\text { Utilización de medios que no tienen más sentido que la prolongación de la vida bioló- } \\
\text { gica de la persona, cuando existen escasas posibilidades de supervivencia indepen- } \\
\text { diente de dichos medios o, de lograr sobrevivir, será con una calidad de vida ínfima } \\
\text { objetivamente considerada. }\end{array}$ \\
\hline $\begin{array}{l}\text { Suicidio } \\
\text { medicamente } \\
\text { asistido }\end{array}$ & $\begin{array}{l}\text { Se produce cuando la actuación del profesional se limita a proporcionar a la persona } \\
\text { los medios necesarios para que sea ella misma quien se ocasione la muerte, en igual } \\
\text { contexto que el definido para el concepto de eutanasia. Es una práctica penada en } \\
\text { nuestro ordenamiento jurídico. }\end{array}$ \\
\hline $\begin{array}{l}\text { Decisiones } \\
\text { compartidas }\end{array}$ & $\begin{array}{l}\text { Estilo de relación mediante el cual el profesional aplica conocimientos científicos y ha- } \\
\text { bilidades de comunicación teniendo en cuenta los valores y preferencias del paciente } \\
\text { para ayudarle y apoyarle en su decisión. }\end{array}$ \\
\hline $\begin{array}{l}\text { Planificación } \\
\text { anticipada de } \\
\text { los cuidados }\end{array}$ & $\begin{array}{l}\text { Es un proceso de comunicación de valores, deseos y expectativas de la persona que } \\
\text { se desarrolla de modo progresivo en el seno de la relación clínica y la continuidad } \\
\text { asistencial y toma en consideración el contexto físico, psicológico, social y asistencial } \\
\text { del paciente y su entorno afectivo/cuidadores. }\end{array}$ \\
\hline $\begin{array}{l}\text { Actuaciones } \\
\text { clínicas limitadas } \\
\text { en el tiempo }\end{array}$ & $\begin{array}{l}\text { Acuerdo entre los profesionales sanitarios y el paciente (o representante en caso de } \\
\text { incapacidad), sobre la utilización de ciertos tratamientos médicos durante un período } \\
\text { definido de tiempo evaluando la respuesta. }\end{array}$ \\
\hline $\begin{array}{l}\text { Sedación paliativa } \\
\text { (o sedación en } \\
\text { la agonía) }\end{array}$ & $\begin{array}{l}\text { Administración deliberada de fármacos para lograr el alivio, inalcanzable con otras } \\
\text { medidas, de un sufrimiento físico y/ o psicológico, mediante la disminución suficiente- } \\
\text { mente profunda y previsiblemente irreversible de la consciencia de un paciente cuya } \\
\text { muerte se prevé muy próxima y con su consentimiento. }\end{array}$ \\
\hline
\end{tabular}

Fuente: modificado de Comisión Galega de Bioética, 2012 (249).

* La Proposición de Ley Orgánica de regulación de la eutanasia aprobada en el Congreso de los Diputados el 17 de diciembre de 2020, en su preámbulo, hace referencia al término «eutanasia» a aquella que se produce de manera activa y directa, de manera que las actuaciones por omisión que se designaban como eutanasia pasiva (no adopción de tratamientos tendentes a prolongar la vida y la interrupción de los y instaurados conforme a la lex artis), o las que pudieran considerarse como eutanasia activa indirecta (utilización de fármacos o medios terapéuticos que alivian el sufrimiento físico o psíquico aunque aceleren la muerte del paciente -cuidados paliativos -) se han excluido del concepto bioético y jurídico-penal de eutanasia. 


\section{Aspectos legales}

A continuación, se hace una relación, no exhaustiva, de la normativa que regula los derechos de las personas y las obligaciones de los profesionales sanitarios que las atienden para hacer efectiva la plena dignidad en el proceso del final de la vida.

En efecto, la dignidad del ser humano (etimológicamente "excelencia”, "grandeza") es el hilo conductor en la normativa jurídica relativa al final de la vida y hace referencia al valor inherente al ser humano por el mero hecho de serlo, en cuanto a ser racional, dotado de libertad. No se trata de una cualidad otorgada por nadie, sino que es consustancial a la persona.

Dicha normativa, para una mejor sistematización, se va a clasificar en internacional, nacional y autonómica.

\section{Internacional}

\section{Declaración universal de los derechos humanos}

Aprobada por la 183 Asamblea General de las Naciones Unidas el 10 de diciembre de 1948, reafirma su fe en los derechos fundamentales del hombre, en la dignidad, el valor de la persona y en la igualdad de derechos de hombres y mujeres.

\section{Declaración universal sobre bioética y derechos humanos}

Aprobada por la Conferencia General de la UNESCO el 19 de octubre de 2005, determina en su artículo 5 que se habrá de respetar la autonomía de la persona en lo que se refiere a la facultad de adoptar decisiones.

\section{Carta de los derechos fundamentales de la Unión Europea}

Promulgada en 2010. Establece en su artículo 1 que la dignidad humana es inviolable y que debe de ser respetada y protegida. También hace referencia (dentro del artículo 3) a que en el marco de la medicina se debe de respetar el consentimiento libre e informado.

4. Recomendación del Consejo de Europa relativa a la protección de los derechos del hombre y de la dignidad de los enfermos terminales y los moribundos

Promulgada el 25 de junio de 1999. Con el fin de preservar la dignidad de los enfermos terminales hace una llamada de atención de que con frecuencia se ignora su calidad de vida, así como su sufrimiento, el de sus familiares y el del personal sanitario que los trata.

5. Recomendación 24 del Comité de ministros de los Estados miembros sobre la organización de cuidados paliativos

Aprobada el 12 de noviembre de 2003. Contiene un amplio elenco de recomendaciones dirigidas a los gobiernos de los Estados miembros de cara a adoptar políticas, legislaciones y otras medidas necesarias para el desarrollo de un marco político nacional coherente e integral para los cuidados paliativos. 
6. Convenio de 4 de abril de 1997 para la protección de los derechos humanos y la dignidad del ser humano con respecto a las aplicaciones de la Biología y la Medicina

También denominado Convenio de Oviedo. En España entró en vigor el 1 de enero de 2000. Aborda explícitamente la necesidad de reconocer los derechos de los pacientes, entre los cuales resaltan el derecho a la información, el consentimiento informado y la intimidad de la información relativa a la salud.

\section{Nacional}

\section{Constitución Española}

Promulgada en 1978. En su artículo 10 establece que la dignidad de la persona, los derechos inviolables que le son inherentes, el libre desarrollo de la personalidad, el respeto a la ley y a los derechos de los demás son el fundamento del orden político y de la paz social.

\section{Ley 14/1986, de 25 de abril, general de sanidad}

En su artículo 10 hace referencia a la personalidad, a la dignidad humana, a la información, a la confidencialidad y a la autorización previa del paciente para la realización de procedimientos diagnósticos y terapéuticos.

\section{Ley orgánica 10/1995, de 23 de noviembre, del código penal}

En su artículo 143 castiga con penas de prisión la inducción y la cooperación al suicidio. Además, castiga también al que causare o cooperare activamente con actos necesarios y directos a la muerte de otro, por la petición expresa, seria e inequívoca de éste, en el caso de que la víctima sufriera una enfermedad grave que conduciría necesariamente a su muerte, o que produjera graves padecimientos permanentes y difíciles de soportar.

4. La Ley 41/2002 de 14 de noviembre, reguladora de la autonomía del paciente y de derechos y obligaciones en materia de información y de documentación

Refuerza la autonomía del paciente. Hace referencia, entre otras cosas, al consentimiento informado, a las instrucciones previas y al derecho a la negativa al tratamiento.

\section{Ley 16/2003, de 28 de mayo, de cohesión y calidad del Sistema Nacional de Salud}

Establece en sus artículos 12 y 13 que tanto la atención primaria como la atención sanitaria especializada incluirán la atención paliativa a enfermos terminales.

\section{Ley 44/2003, de 21 de noviembre, de ordenación de las profesiones sanitarias}

Incluye dentro de su articulado el deber de los profesionales de respetar la personalidad, dignidad e intimidad de las personas a su cuidado incluyendo su participación en la toma de decisiones. También establece que la actualización permanente de conocimientos, mediante la formación continuada, es tanto un derecho como un deber de los profesionales. 
7. Ley 55/2003, de 16 de diciembre, del Estatuto marco del personal estatutario de los servicios de salud

Al igual que la anterior, también hace referencia a la necesidad de que los profesionales mantengan sus conocimientos actualizados y a respetar la dignidad y la intimidad personal de los usuarios.

8. Real decreto $1030 / 2006$, de 15 de septiembre, por el que se establece la cartera de servicios comunes del Sistema Nacional de Salud y el procedimiento para su actualización

Esta norma incluye la atención paliativa a enfermos terminales tanto dentro de la cartera de servicios de atención primaria como de atención especializada.

\section{Real Decreto 124/2007 de regulación del Registro Nacional de Instrucciones Previas y Fichero Automatizado de Datos}

\section{Autonómica}

Varias autonomías han legislado sobre los derechos y garantías de la dignidad de las personas en el proceso de la muerte. Andalucía ha sido la pionera. Se puede decir que todas estas leyes tienen unas mismas ideas clave. Su espíritu remarca la dignidad del paciente y sus derechos en cuanto a cuidados en la forma de vivir sus últimos días, así como los derechos de sus familiares. También hacen referencia a los derechos y deberes de los profesionales que los cuidan, tanto en los hospitales como en sus domicilios o en los centros sociosanitarios.

En este contexto, se puede enumerar, por orden cronológico, la siguiente normativa:

1. Ley $2 / 2010$, de 8 de abril, de derechos y garantías de la dignidad de la persona en el proceso de la muerte (Andalucía).

2. Ley 10/2011, de 24 de marzo, de derechos y garantías de la dignidad de la persona en el proceso de morir y de la muerte (Aragón).

3. Ley foral $8 / 2011$, de 24 de marzo, de derechos y garantías de la dignidad de la persona en el proceso de la muerte (Navarra).

4. Ley $1 / 2015$, de 9 de febrero, de derechos y garantías de la dignidad de la persona ante el proceso final de su vida (Canarias).

5. Ley $4 / 2015$, de 23 de marzo, de derechos y garantías de la persona en el proceso de morir (Baleares).

6. Ley $5 / 2015$, de 26 de junio, de derechos y garantías de la dignidad de las personas enfermas terminales (Galicia).

7. Ley $11 / 2016$, de 8 de julio, de garantía de los derechos y de la dignidad de las personas en el proceso final de su vida (País Vasco).

8. Ley 4/2017, de 9 de marzo, de Derechos y Garantías de las Personas en el Proceso de Morir, (Madrid). 
9. Ley $5 / 2018$, de 22 de junio, sobre derechos y garantías de la dignidad de las personas en el proceso del final de la vida (Asturias).

10. Ley $16 / 2018$, de 28 de junio, de derechos y garantías de la dignidad de la persona en el proceso de atención al final de la vida (Comunidad Valenciana).

\section{Aspectos deontológicos}

Algunos de los códigos deontológicos de las profesiones sanitarias, como no podría ser de otra manera, incluyen en su articulado referencias a los cuidados paliativos y al final de la vida.

\section{Código de deontología médica}

Aprobado por el Consejo General de colegios oficiales de médicos en 2011. Incluye en su artículo 36 los siguientes puntos:

- El médico tiene el deber de intentar la curación o mejoría del paciente siempre que sea posible. Cuando ya no lo sea, permanece la obligación de aplicar las medidas adecuadas para conseguir su bienestar, aun cuando de ello pudiera derivarse un acortamiento de la vida.

- El médico no deberá emprender o continuar acciones diagnósticas o terapéuticas sin esperanza de beneficios para el enfermo, inútiles u obstinadas. Ha de tener en cuenta la voluntad explícita del paciente a rechazar dicho tratamiento para prolongar su vida. Cuando su estado no le permita tomar decisiones, tendrá en consideración y valorará las indicaciones anteriormente hechas y la opinión de las personas vinculadas responsables.

- El médico nunca provocará intencionadamente la muerte de ningún paciente, ni siquiera en caso de petición expresa por parte de éste.

- El médico está obligado a atender las peticiones del paciente reflejadas en el documento de voluntades anticipadas, a no ser que vayan contra la buena práctica médica.

- La sedación en la agonía es científica y éticamente correcta sólo cuando existen síntomas refractarios a los recursos terapéuticos disponibles y se dispone del consentimiento del paciente implícito, explícito o delegado.

\section{Código deontológico de la enfermería española}

Aprobado por el Consejo General de Enfermería en 1989. Establece en su artículo 18 que, ante un enfermo terminal, la enfermera/o, consciente de la alta calidad profesional de los cuidados paliativos, se esforzará por prestarle hasta el final de su vida, con competencia y compasión, los cuidados necesarios para aliviar sus sufrimientos. También proporcionará a la familia la ayuda necesaria para que puedan afrontar la muerte, cuando ésta ya no pueda evitarse.

\section{Código deontológico del Consejo general de colegios oficiales de psicólogos}

La última versión fue aprobada en 2010. No hace ninguna referencia específica a los cuidados al final de la vida, pero sí a la salud y a la calidad de vida de las personas. 
Establece que la profesión se rige por los principios del respeto a la persona, la protección de los derechos humanos, el sentido de la responsabilidad, la honestidad, la prudencia y la competencia profesional.

\section{Código deontológico de trabajo social}

Aprobado en 2012. En su artículo 7 establece que el trabajo social está fundado sobre los valores indivisibles y universales de la dignidad humana, la libertad y la igualdad. Asimismo, en el artículo 15 promueve el compromiso de la profesión en la implicación de las personas en responsabilizarse en la toma de decisiones y acciones que puedan afectar a su vida. 


\section{Anexo 13. Abreviaturas}

AEMPS: Agencia Española de Medicamentos y Productos Sanitarios

BDZ: Benzodiazepina

BPC: Buena Práctica Clínica

CIMA: Centro de información online de medicamentos de la AEMPS

CINa: Cloruro de Sodio

CP: Cuidados Paliativos

${ }^{\circ} \mathbf{C}$ : Grados Centígrados

DIP: Documento de Instrucciones Previas

DNI: Documento Nacional de Identidad

EAPC: Del inglés European Association for Palliative Care

ECA: Ensayo clínico aleatorizado

ECOG: Del inglés Eastern Cooperative Oncology Group

EE. UU.: Estados Unidos

EPOC: Enfermedad pulmonar obstructiva crónica

EtR: Del inglés Evidence to Recommendation

EVA: Escala Visual Analógica

GEG: Grupo elaborador de la guía

GPC: Guías de Práctica Clínica

HA: Hidratación artificial

mEq: Miliequivalente

NCCN: Del inglés National Comprehensive Cancer Network

NICE: Del inglés National Institute for Health and Care Excellence

OMC: Organización Médica Colegial

OMS: Organización Mundial de la Salud

PAINAID: Del inglés Pain Assessment in Advanced Dementia

PCA: Planificación compartida de la atención

PPS: Del inglés Palliative Performance Score

RASS: Del inglés Richmond Agitation Sedation Scale

RedETS: Red Española de Agencias de Evaluación de Tecnologías Sanitarias y Prestaciones del Sistema Nacional de Salud

SECPAL: Sociedad Española de Cuidados Paliativos

SNS: Sistema Nacional de Salud

SSF: Suero salino fisiológico

SUD: Situación de los últimos días

UNESCO: Del inglés United Nations Educational, Scientific and Cultural Organization 



\section{Anexo 14. Declaración de interés}

Rosendo Bugarín González declaró haber recibido financiación para reuniones y congresos (varios laboratorios y fechas); honorarios como docente en cursos del Colegio Médico (varias fechas).

Carlos Ferrer Albiach declaró haber recibido financiación para la Inscripción al Congreso SEOR, en Santiago de Compostela del 15-18 junio de 2019. (Janssen lab); honorarios como ponente en Astellas Pharma, Kiowa Kyrin en 2019, (Janssen lab).

Inés Esther González Bolaños declaró haber recibido honorarios como ponente en el Seminario APDAY. Atención a la fase de agonía y la familia del paciente terminal el 2 de febrero de 2020 (SEMFYC).

Leyre Díez Porres declaró haber recibido financiación para el XXXIX Congreso Nacional de la SEMI / VI Congreso Ibérico de Medicina Interna / XXXIII Congreso de la SOCALMI el 21 de noviembre de 2018. (Kyowa Kirin Farmacéutica, S.L.U.); y honorarios como ponente en la $3^{\text {a }}$ Jornada de Actualización en Cuidados Paliativos el 14 de noviembre de 2017 (Kyowa Kirin Farmacéutica, S.L.U.)

Víctor Mayoral Rojals declaró haber recibido financiación para inscripciones, desplazamiento y alojamiento en diferentes congresos nacionales e internacionales de dolor en los últimos 30 años (Grünenthal, Pfizer, Kyowa-Kirin, Takeda, Boston, Menarini); honorarios como ponente (Grünenthal, Menarini) en los últimos 30 años; financiación para el curso de ESADE de liderazgo en 2013 (Pfizer); Financiación por participar en una investigación Consultoría Almirall, Grünenthal, Gebro en los últimos 10 años; Intereses económicos en una empresa privada relacionada con la salud como socio del Instituto Aliaga en centro Médico Teknon de Barcelona desde el 2016; Ayuda económica para la financiación de una investigación de diversos estudios promocionados por la industria (Grünenthal, Kyowa Kirin) del 2010 al 2017; Financiación de cursos de neuromodulación para la unidad (Medtronic, Abbott, Boston, Prim) en los últimos 6 años han ido a formarse varios miembros de la unidad.

Ramón de las Peñas Bataller declaró haber recibido financiación como coordinador grupo de trabajo (MYLAN) en julio del 2020.

El resto de integrantes del grupo de revisión de la GPC declararon ausencia de conflictos de interés. 

Anexo 15. Información para familiares y allegados de personas en situación de últimos días

\section{Información para}

\section{familiares y allegados} de personas en situación de últimos días

Recomendaciones para acompañar a su ser querido

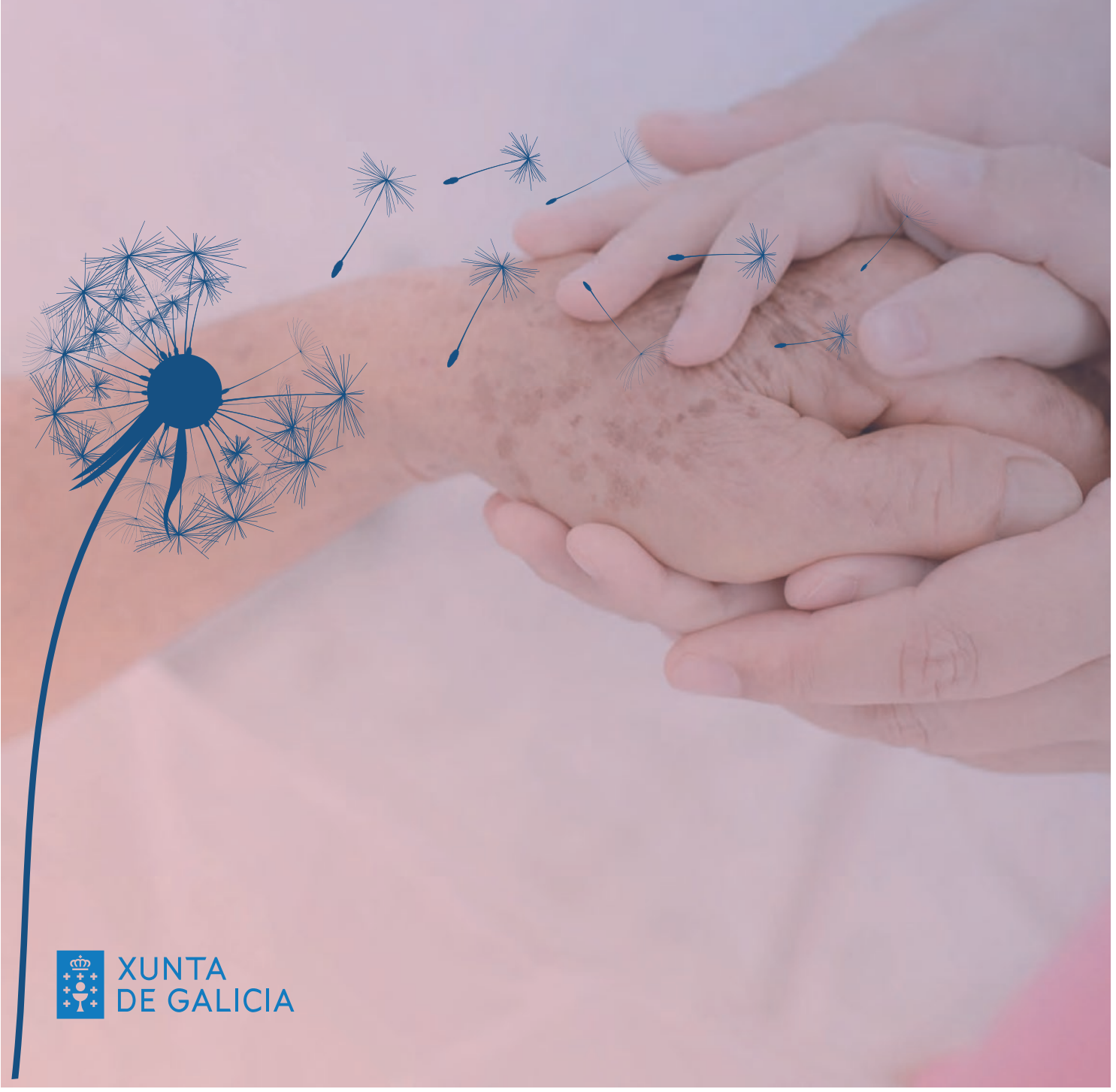


El grupo elaborador de la guía de práctica clínica desea dar las gracias a todos los pacientes, familiares y profesionales que han colaborado en la elaboración y revisión de este material. Esta información ha sido elaborada a partir del conocimiento basado en la literatura científica disponible en el momento de la publicación.

Este documento ha sido realizado por la Unidad de Asesoramiento Científico-técnico, Avalia-t, de la Agencia de Conocimiento en Salud (ACIS) en el marco de la financiación del Ministerio de Sanidad para el desarrollo de las actividades del Plan anual de trabajo de la Red Española de Agencias de Evaluación de Tecnologías Sanitarias y Prestaciones del SNS. Conocimiento en Salud (ACIS); 2021. Guías de Práctica Clínica en el SNS. 


\section{Información para familiares y allegados de personas en situación de últimos días}

Recomendaciones para acompañar a su ser querido 


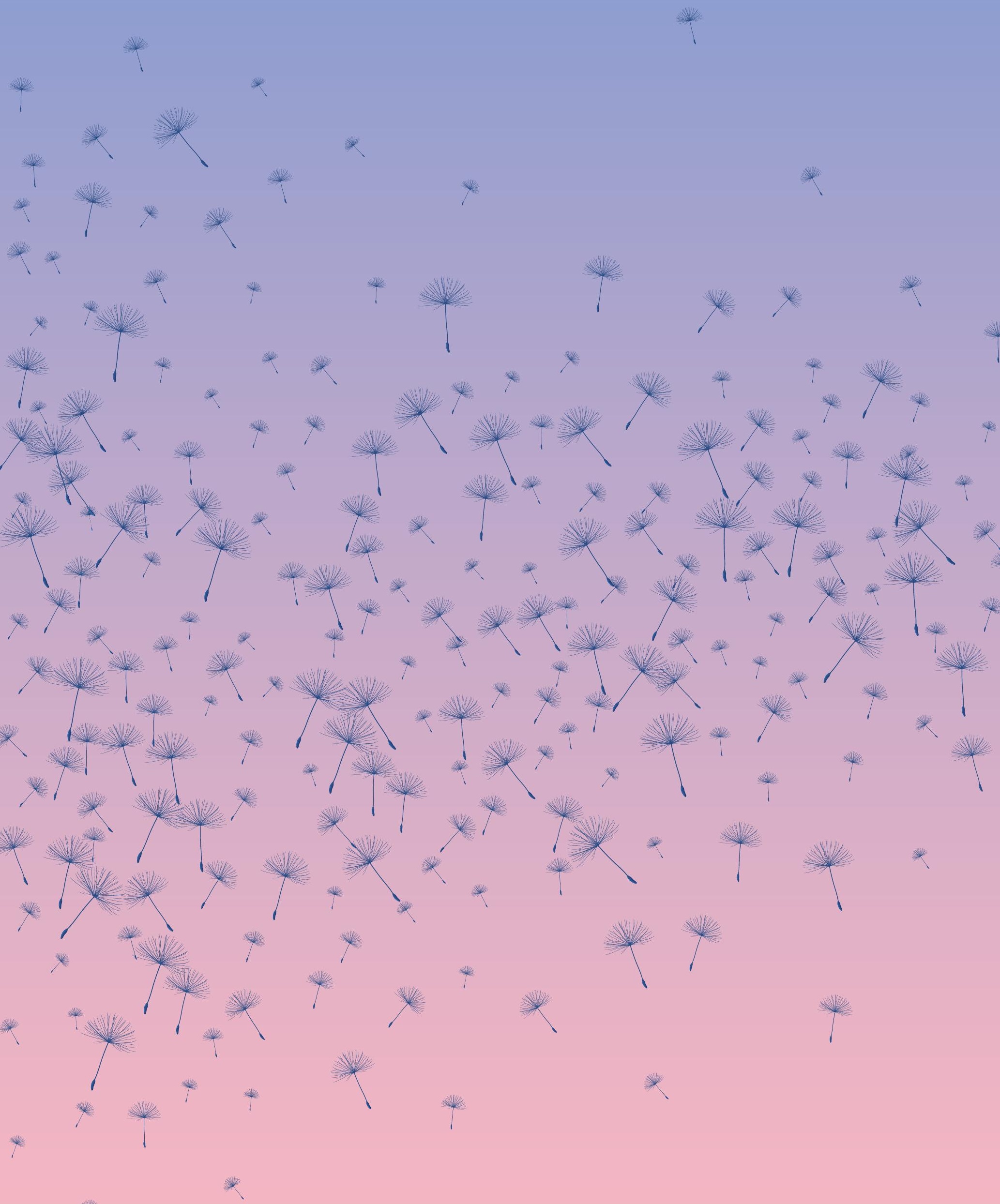




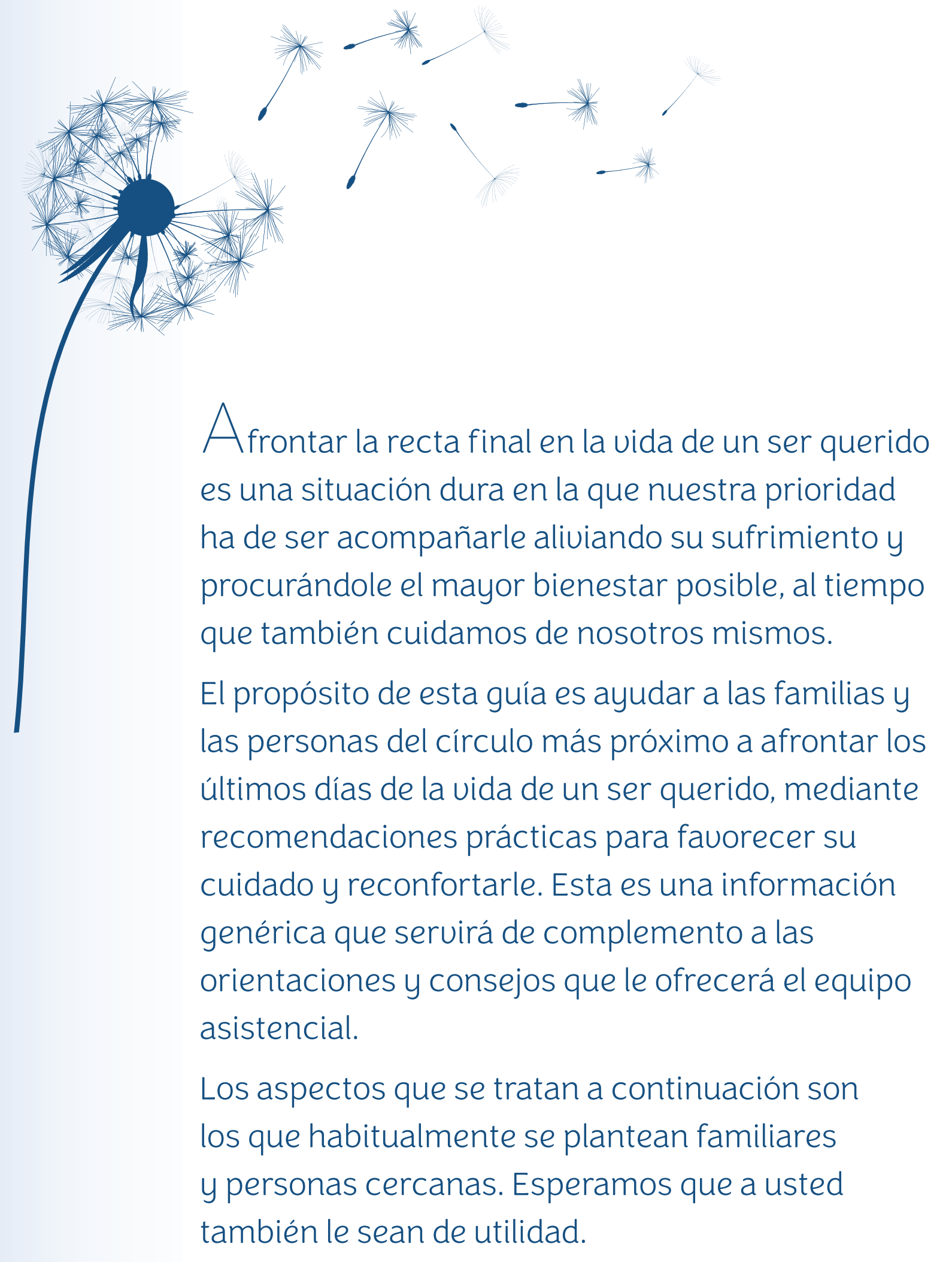




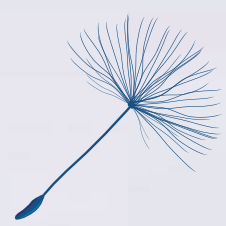

\section{Qué es la situación de últimos días y cómo se} reconoce

La agonía o situación de últimos días es el estado natural que precede a la muerte. Se debe al fracaso de los órganos principales del cuerpo a causa del avance de la enfermedad y es irreversible.

La duración de este proceso es variable: puede resolverse en horas o alargarse varios días. Se reconoce a través de un deterioro muy importante del estado general, que se manifiesta en una gran debilidad muscular, encamamiento, pérdida de la capacidad para comer y beber, cambios en las funciones corporales, somnolencia profunda y, en ocasiones, agitación.

En este momento, la atención tanto de los profesionales como de las personas cuidadoras debe centrarse en mantener el máximo confort físico, emocional y espiritual, así como en proporcionar cuidados básicos al ser querido, respondiendo a sus deseos, tranquilizando sus temores y administrando solo los fármacos imprescindibles.

Consulte a los profesionales todas las dudas que tenga. 


\section{Qué puede hacer para reconfortar a su ser querido en sus últimos días}

\section{Cuidar el ambiente}

- Procure una ubicación cómoda y tranquila, con luz tenue y sin ruidos.

- Limite las visitas, evitando aquellas que resulten innecesarias o que puedan alterar y molestar.

- Cree un clima de afecto, serenidad y gratitud que facilite la despedida.

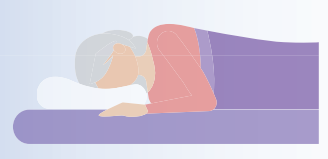

\section{Favorecer una buena postura}

- Si es posible, debe mantener a la persona en posición cómoda, preferentemente de lado.

- Procure moverla lo menos posible, buscando siempre su confort.

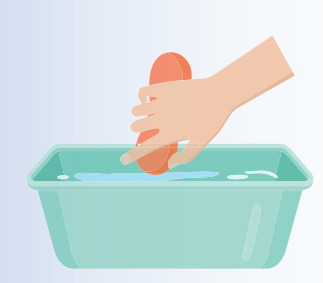

\section{Adaptar la higiene}

- Evite las molestias que pueda suponer un ajetreo excesivo, dando prioridad al aseo superficial en la cama.

- Mantenga la boca de la persona limpia e hidratada para evitar incomodidades.

\section{Mimar la comunicación}

- Háblele con serenidad, usando frases cortas y sencillas, tratando de que su familiar o amigo/a se sienta escuchado y querido. Saber escuchar es una parte fundamental de la comunicación en este momento.

- Si expresa angustia, temor o tristeza, es importante aceptar estas emociones sin negarlas ni minimizarlas, transmitiéndole que en todo momento va a estar cuidado/a y acompañado/a.

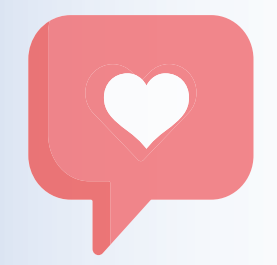

- Si le resulta difícil encontrar palabras para responderle, cójale de la mano y corresponda a sus emociones desde la comunicación no verbal. De esta manera se sentirá acompañado/a en su dolor.

- La persona enferma puede oír y sentir la mano de quienes le acompañan hasta el último momento, dado que los sentidos del tacto y el oído se conservan hasta el fin de la vida. Si bien puede llegar un momento en que parezca desconectada del entorno y probablemente no pueda percibir lo que ocurre a su alrededor como antes, escuchar la voz de sus personas más cercanas y sentir su contacto físico le trasmitirá tranquilidad y seguridad.

- Las expresiones de dolor y tristeza son normales, pero evite aquellas que puedan provocarle intranquilidad y priorice las que, según su criterio y el conocimiento que tiene de la persona, contribuyan a la serenidad y la aceptación. 


\section{Favorecer la espiritualidad}

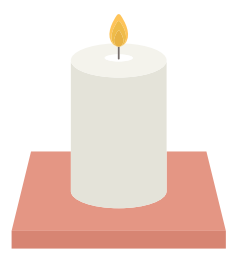

- Aunque no lo expresen, muchas personas son capaces de intuir que su final está cerca. En este momento pueden surgir pensamientos trascendentales o preguntas que no tienen respuesta. Facilite a su ser querido hablar, despedirse, expresar sentimientos (amor, perdón, tristeza, felicidad), hacer un repaso de lo que ha sido su vida, buscar sentido, etc.

- En caso de que le transmita el deseo de dejar un legado a sus seres queridos, ayúdele a hacerlo como él o ella elija: a través de gestos, conversaciones, regalos, instrucciones finales, etc. Comprenda que es su forma de trascender en los demás cuando ya no esté.

- Facilite las prácticas rituales según las creencias de su ser querido.

\section{Respetar sus decisiones}

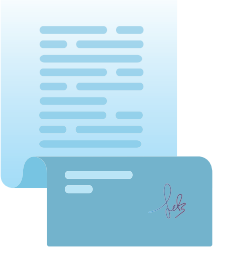

- Respete sus deseos y preferencias, entendiendo que las personas tienen derecho a tomar sus propias decisiones hasta el final (tratamientos que desea o que rechaza, lugar de atención y fallecimiento, etc.).

- En caso de que la persona ya no sea capaz de tomar decisiones, puede hacerlo quien haya sido designado por él o ella de forma expresa mediante un documento de voluntades anticipadas o instrucciones previas, durante el proceso de planificación compartida con el equipo sanitario, etc.

- Si su ser querido no ha expresado sus preferencias sobre el lugar de fallecimiento, considere la importancia de valorarlo cuanto antes. En caso de que las condiciones lo permitan, él o ella lo desee y la familia sea capaz de afrontar la situación con apoyo de profesionales sanitarios, fallecer en el domicilio ha de contemplarse como una posibilidad.

\section{Incluir a los más pequeños}

- Si hay niños y niñas en casa, facilíteles que expresen sus emociones, sentimientos, miedos y preocupaciones. Los menores ven lo que pasa y sufren a su manera este proceso.

- Permítales estar presentes en la medida en que ellos quieran.

- Hábleles con tranquilidad sobre la situación, adaptando el lenguaje a su comprensión y evitando inventar historias inverosímiles. 


\section{Cuidar de uno/a mismo/a}

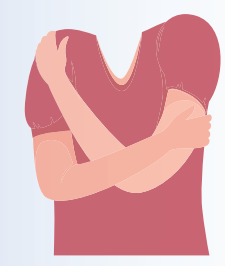

- Sea consciente de que esta situación puede ser muy estresante y agotadora, tanto física como emocionalmente, y de que si usted no se cuida difícilmente va a poder cuidar bien de otra persona. Busque ayuda en su entorno para compartir los cuidados y poder encontrar momentos de descanso.

- Apóyese en el equipo sanitario, que conoce bien la situación por la que está pasando. Consúltele cualquier duda o acuda a sus profesionales simplemente para desahogarse. Tenga en cuenta que puede ser de gran ayuda hablar con un psicólogo o psicóloga.

- Acepte la situación sin autoimponerse nada. Algunas personas aseguran que haber cuidado y acompañado a alguien a lo largo de una enfermedad avanzada o en su proceso de final de vida ha sido una experiencia que a la larga resultó positiva, reconfortante y satisfactoria. Sin embargo, no tiene por qué ocurrir de esta manera. 


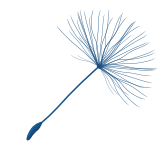

\section{Cómo actuar ante los síntomas y cambios físicos más frecuentes}

En la etapa final de la vida toda persona necesita tranquilidad, confort $y$ alivio ante los posibles sufrimientos derivados de la enfermedad. En esto consisten los cuidados paliativos.

En el aspecto físico, durante los últimos días de vida el cuerpo comienza un proceso en el que se van apagando todas sus funciones. Por lo general esto ocurre de forma paulatina, con cambios progresivos que no precisan de tratamientos ni intervenciones agresivas. Estos cambios son normales y naturales y lo mejor es proporcionar cuidados orientados al alivio, el confort y el bienestar.

En el terreno emocional, es importante asumir que nuestro ser querido comienza el proceso final de distanciamiento sobre su propio cuerpo y su entorno (trabajo, familia, amigos, etc.). Estar en paz con la propia historia de vida, haber resuelto asuntos pendientes y sentir que obtiene el "permiso" de las personas queridas para dejar este mundo son facilitadores de un buen final de vida.

Los síntomas y los cambios que a continuación se describen no ocurren todos al mismo tiempo ni tampoco necesariamente de forma consecutiva. En cada apartado se proponen una serie de cuidados que pueden ayudar. Consulte al personal sanitario para plantear cualquier duda o resolver cualquier situación no contemplada en los siguientes puntos. 


\section{DISMINUCIÓN O FALTA DE APETITO}

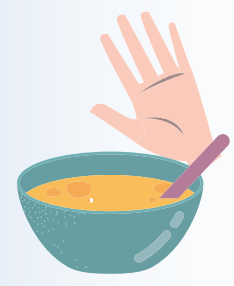

Un tema que suele preocupar mucho a las familias es que la persona enferma deje de comer y/o beber. Culturalmente consideramos la comida como algo fundamental para el bienestar de nuestros seres queridos, pero debemos ser conscientes de que en la etapa final de la vida las necesidades de energía son mínimas o nulas.

Piense que no es una cuestión de fuerza de voluntad. La debilidad de su ser querido es consecuencia de la enfermedad y no de dejar de comer o beber. En este momento su alimento principal ha de ser la tranquilidad y la compañía de sus seres queridos.

Forzarle a comer o beber solo conseguiría provocar incomodidad o incluso, cuando la persona se encuentra ya con bajo nivel de conciencia, llegar a ser peligroso, ya que podría atragantarse. La sensación de ahogo es muy desagradable y aumenta el sufrimiento.

Ofrézcale de vez en cuando algún alimento fresco (yogur, natillas o algo que le diga que le apetece) y, si lo rechaza, no insista.

En cuanto a la bebida, el mejor criterio para saber si hay que darle de beber o no es ofrecer líquidos con una gasa húmeda. Si es capaz de chupar y de tragar el escaso líquido, puede intentar darle más con una cucharilla pequeña.

Para mejorar y aliviar la sequedad de boca, una molestia que se da con frecuencia, suele funcionar ofrecerle pequeños trocitos de hielo para chupar, helado, agua fría o zumos ligeramente ácidos que estimulen la salivación. Otras formas de paliar la sequedad de boca son mojar frecuentemente los labios con una gasa húmeda, usar un espray de manzanilla o aplicar glicerina en los labios para mantenerlos hidratados. Una toalla húmeda fresca en la frente también suele dar alivio. Por último, es recomendable mantener la higiene bucal siempre que sea posible y sin incomodar.

\section{DOLOR}

Hay enfermedades que pueden provocar dolor y es probable que en los últimos días aumenten las necesidades de analgesia. Además, la debilidad extrema puede hacer que la persona enferma sufra con cualquier movimiento, incluso con el roce en la piel. 
Existen diferentes medicamentos para el alivio del dolor. Los analgésicos más potentes se llaman opioides. Entre ellos están la morfina, el fentanilo y la oxicodona, que se pueden administrar por vía oral o nasal, por vena, subcutáneos, en parches pegados a la piel, etc. Hay muchos prejuicios con respecto a los opioides, especialmente la morfina, pero son medicamentos muy útiles para el control del dolor y la sensación de falta de aire y no solo se utilizan al final de la vida, sino en otras muchas situaciones. Ante una enfermedad incurable lo más importante es evitar el sufrimiento y estos medicamentos pueden ayudar. En todo caso, tenga en cuenta que no aceleran ni frenan la evolución natural de la enfermedad, como tampoco adelantan ni retrasan el momento de la muerte.

Intente evitar movimientos o gestos que provoquen dolor.

Administre los medicamentos que le hayan recomendado los profesionales. Si la persona enferma no es capaz de tragar, comuníqueselo al personal sanitario porque puede ser necesario colocar una palomilla subcutánea para la administración de medicación que alivie este y otros síntomas.

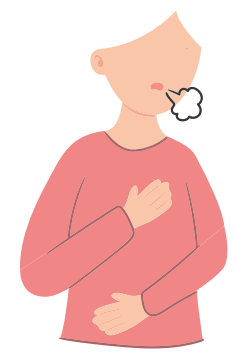

\section{SENSACIÓN DE FALTA DE AIRE (DISNEA)}

En esta fase es frecuente que la persona sienta que le falta el aire, dificultad para respirar o sensación de ahogo, habitualmente acompañado de ansiedad y angustia. Esta sensación no siempre se asocia a niveles bajos de oxígeno.

Mantenga la calma y tranquilice a su ser querido.

Incorpórelo, intente que respire más despacio y profundo y proporcione corriente de aire abriendo las ventanas o utilizando un ventilador o un abanico.

Administre la medicación que le hayan indicado los profesionales (habitualmente ansiolíticos u opioides de acción rápida y a veces oxígeno). 


\section{NÁUSEAS Y VÓMITOS}

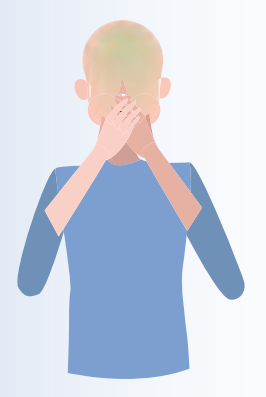

A veces la persona enferma puede sentir náuseas o vomitar. Esto es desagradable tanto para él o ella como para su entorno. Además, existe el peligro de que se atragante con su propio vómito.

Póngale de lado con una toalla o empapador para proteger la ropa de cama. Si hay sangre, utilice toallas preferiblemente oscuras para disminuir el impacto visual.

Administre la medicación que tenga pautada para estos casos y comente el problema con su equipo sanitario de referencia por si necesitara una valoración por su parte.

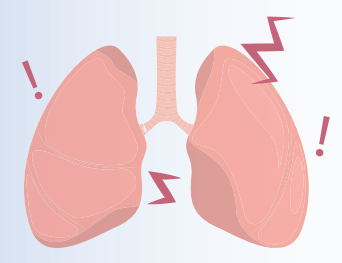

\section{CAMBIOS EN EL RITMO RESPIRATORIO}

En los últimos días, la forma de respirar puede volverse irregular, con periodos sin respiración durante bastantes segundos, seguidos de otros en los que se produce una respiración rápida. También es posible que aparezcan otros fenómenos como el hipo.

Incorpore un poco a su ser querido en la cama, colocándole una almohada debajo de la cabeza. En ocasiones, ladearle la cabeza puede mejorar su comodidad.

\section{DESORIENTACIÓN E INQUIETUD}

La persona puede parecer confundida sobre la hora, el lugar o incluso sobre quiénes son los miembros de su familia, sobre todo a partir del atardecer. En ocasiones aparecen alucinaciones, desorientación y agitación. Las causas pueden ser múltiples: desde estreñimiento, retención de la orina o infecciones hasta alteraciones de la sangre o como efecto de los fármacos. A esto contribuye también el mal funcionamiento de los órganos (riñones, hígado, cerebro).

Cuando se acerque a su ser querido, identifíquese recordándole su nombre en lugar de obligarle a adivinarlo. Si no le reconoce, sepa que en esta situación puede ser normal. 
Háblele suavemente, con claridad y franqueza.

Puede darle algún masaje en la frente, leerle algo relajante o ponerle música suave. Por la noche, mantenga una luz tenue encendida que no le moleste.

En caso de que esté tomando analgésicos, debe valorarse si el malestar que manifiesta está producido por dolor y necesita una dosis extra. Las muecas de dolor o los quejidos suelen indicar que esto es necesario.

En caso de confusión extrema, alucinaciones o agitación, y siempre ante cualquier duda, consulte al personal sanitario.

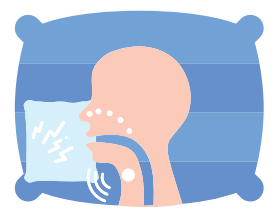

\section{RUIDOS Y SECRECIONES RESPIRATORIAS (ESTERTORES)}

En las fases más próximas a la muerte, la persona podría producir sonidos de gorgoteo o murmullo al respirar, como si tuviera burbujas de líquido en el pecho o la garganta. Estos ruidos no significan que tenga más dolor o sufra más y, aunque pueden ser molestos para las personas acompañantes, no lo son ya para su ser querido, que tiene su conciencia disminuida.

Tenga en cuenta que es poco recomendable aspirar las secreciones con aspirador, ya que puede producirse el efecto contrario al deseado, es decir, un aumento de estas.

Ladéele la cabeza y permita que las secreciones salgan hacia fuera, colocando una toalla para que no moje la almohada. También puede limpiar las que lleguen a su boca con una gasa húmeda.

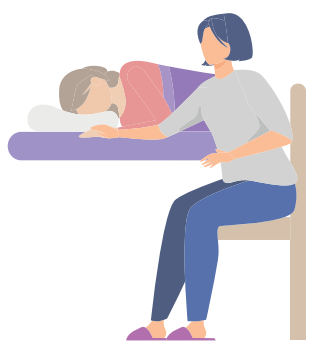

\section{SOMNOLENCIA}

Es normal que su ser querido se encuentre más callado que de costumbre y con poco interés por lo que le rodea. También que pase gran parte del tiempo durmiendo, mucho más de lo habitual, hasta el punto de que llegue a ser difícil despertarle. 
Organícese para pasar con él o ella el máximo tiempo que permanezca despierto/a.

Siéntese a su lado, tome su mano, háblele con voz suave y natural, como lo haría normalmente, incluso aunque parezca dormido/a. No le pregunte cosas porque probablemente no podrá responder.

Nunca suponga que no puede oírle. El oído y el tacto se pueden mantener hasta el final. Procure no hablar en susurros en la habitación para no molestar.

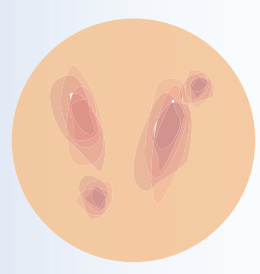

\section{CAMBIOS EN LA PIEL}

Las manos, los pies, los brazos y las piernas suelen estar frías al tacto. Al mismo tiempo, hay cambios en el color de la piel, que se vuelve pálida y con manchas, a causa de que la sangre se concentra en los órganos vitales y se reduce su circulación por las extremidades.

Trate de mantener el calor corporal para asegurar la comodidad de su ser querido.

Evite que las mantas supongan un peso excesivo que le incomode.

\section{FIEBRE}

En esta fase puede aparecer fiebre elevada $\left(39-40^{\circ} \mathrm{C}\right)$. Las causas más frecuentes son infecciones, alteraciones de las zonas del cerebro que regulan nuestra temperatura o bien sustancias que son liberadas por tumores en caso de pacientes oncológicos. A veces esta fiebre no responde a la medicación, que en todo caso ha de ser indicada por el equipo sanitario.

Colóquele en la frente paños humedecidos con agua fresca (no helada), evitando mojar la almohada.

Ventile la habitación y póngale ropa de algodón ligera y cómoda. 


\section{INCONTINENCIA}

Debido a la relajación de los músculos, en los momentos finales la persona puede perder el control de la expulsión de orina y heces.

Trate de asegurar su comodidad usando dispositivos que facilitan mantener la piel limpia y seca a pesar de la incontinencia (pañales, empapadores, cremas hidratantes e hidrófugas, colectores de orina, cuñas, etc.).

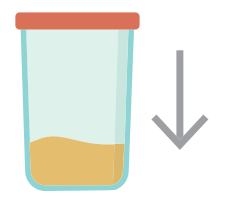

\section{REDUCCIÓN DE LA ORINA}

La cantidad de orina disminuirá en volumen y tomará un color cada vez más oscuro, debido a que cada vez estará más concentrada. Esto se debe a la reducción en el consumo de líquidos y a que los riñones funcionan cada vez menos.

Si su ser querido deja de orinar puede tener molestias en la región del bajo vientre o manifestar inquietud. Consulte al personal sanitario para que valore si hay una retención de orina y es necesario colocar una sonda que alivie el malestar.

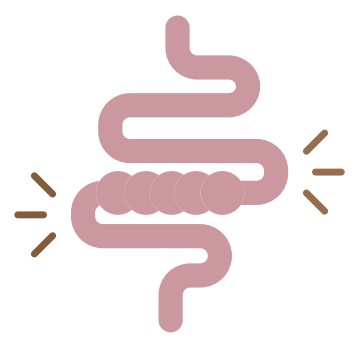

\section{ESTREÑIMIENTO}

Los analgésicos, la inmovilidad y la escasa ingesta de líquidos suelen provocar estreñimiento en el final de la vida.

Consulte con el personal sanitario para que puedan valorar la necesidad de prescribir un medicamento específico o tomar alguna otra medida. 


\section{Qué hacer en caso de emergencia}

Cuando el final de la vida está cerca se pueden dar situaciones que generen mucho sufrimiento en la persona enferma y mucho estrés en las personas cercanas. Los profesionales sanitarios que atienden a su ser querido en el domicilio le darán recomendaciones sobre cómo actuar en distintas situaciones, pero ante cualquier imprevisto o en una situación en la que no sepa cómo actuar puede hacer lo siguiente:

Si considera que su ser querido está sufriendo una crisis y le han dejado instrucciones para el alivio de determinados síntomas (dolor, falta de aire, náuseas, etc.), intente identificar cuáles son y administre la medicación que le hayan pautado. Busque la ayuda de otra persona si tiene dudas o le asaltan los nervios.

En caso de que la situación no mejore, llame por teléfono a los profesionales de referencia si están en su horario de trabajo. Si no (por ejemplo, por la noche), Ilame a los servicios de emergencia (061 o 112, dependiendo de su comunidad autónoma). Explique lo más claro posible que su familiar está en situación de últimos días y los síntomas que nota. Intentarán darle instrucciones telefónicas y enviarán a profesionales a su domicilio si fuera necesario.

Tras administrarle la medicación pautada y/o mientras llega el personal sanitario si fuera el caso, acompañe a su ser querido en ese trance. Puede darle la mano, acariciarle y hablarle usando expresiones que ayuden a tranquilizarle ("estoy aquí", "no estás solo/a", "respira despacio", etc.).

En todo caso, cuando tenga dudas sobre si una situación es o no una emergencia, trate de guardar la calma para poder identificar las señales. Cuando se acercan las últimas horas de vida de una persona, su aspecto y sus manifestaciones físicas pueden ser impactantes para los demás, especialmente si no tienen experiencias previas de ver morir a alguien.

La palidez, la delgadez, la apariencia de falta de vida y los ruidos respiratorios no son agradables, pero lo más importante es que no le generan sufrimiento. Aunque en principio puedan provocarnos angustia a quienes le rodeamos, no representan una emergencia.

Intente superar el impacto de lo que ve y procure ver a su ser querido como una persona que experimenta con tranquilidad un momento único y especial: la despedida de la vida. Concéntrese en acompañarle y transmitirle serenidad, paz y gratitud. 


\section{Qué ocurre con la medicación}

En esta fase final de la vida, el tratamiento farmacológico que recibe su ser querido se centra en su bienestar y en el control de sus síntomas. Esto significa que se suspenderán aquellos tratamientos que no aporten beneficio a la situación actual del paciente (por ejemplo, el protector gástrico o tratamientos para controlar la tensión arterial y reducir el colesterol o el riesgo de fracturas). En definitiva, se busca simplificar al máximo tanto los medicamentos como la forma de administrarlos, buscando siempre el mayor confort del paciente.

En los últimos días, el equipo asistencial está más presente y disponible. Realiza una valoración continua, ajustando el tratamiento según las necesidades para asegurar un buen control de síntomas. La persona enferma y la familia podrán participar activamente en la toma de decisiones con base en sus preferencias, incluyendo el derecho a rechazar la opción terapéutica que se plantee. De esta manera, antes de iniciar un nuevo tratamiento, el médico o médica les informará acerca de sus posibles beneficios y efectos secundarios para que puedan valorarlo y decidir. Para algunas personas no son aceptables, por ejemplo, la somnolencia o las náuseas provocadas por algunas medicaciones que se usan para controlar el dolor.

La forma elegida para administrar el tratamiento será la que resulte menos molesta para el paciente (generalmente oral o subcutánea, es decir, mediante una palomita insertada en la piel).

Resulta de gran utilidad tener instrucciones claras y por escrito sobre la medicación, que incluyan pautas fijas y otras específicas para momentos de crisis. Asegúrese de que su equipo sanitario se las proporciona. En caso de dudas, si los síntomas no mejoran o hay efectos secundarios indeseables, consulte a los profesionales (ver apartado Qué hacer en caso de emergencia).

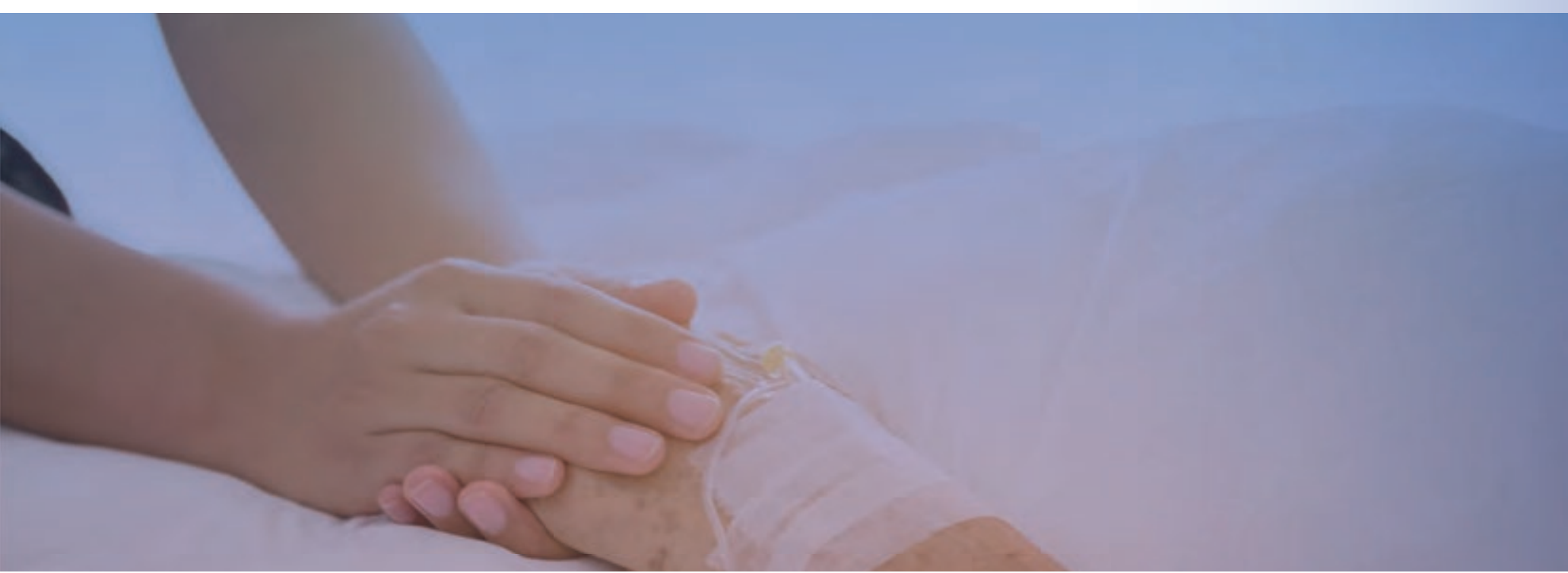




\section{Qué es la sedación paliativa}

La sedación paliativa consiste en administrar fármacos que disminuyen el nivel de conciencia de una persona en estado terminal para aliviar el sufrimiento físico o psíquico que no ha podido controlarse de ninguna otra manera. Puede ser puntual (para aliviar un momento concreto de sufrimiento) o continua. Además, puede tener carácter superficial o profundo.

Se trata de un procedimiento médico aceptado ética y jurídicamente. Requiere del consentimiento de la persona enferma o de su representante, si esta no se encuentra en condiciones de tomar una decisión.

En la sedación paliativa los fármacos se van ajustando a la respuesta del paciente y a sus necesidades, buscando el alivio de su sufrimiento y bajo el acuerdo entre el equipo asistencial y la persona afectada o su familia. A lo largo de este proceso el nivel de conciencia irá disminuyendo, pudiendo llegar a pasar todo el día dormido/a. Aunque la persona parezca completamente desconectada del entorno, escuchar la voz de sus familiares y amigos y sentir su contacto físico le trasmitirá tranquilidad y seguridad.

La sedación, la eutanasia y el suicidio asistido son cosas distintas. El objetivo de la sedación paliativa no es provocar la muerte, sino únicamente disminuir la conciencia con el objetivo de reducir el sufrimiento que no ha podido ser aliviado con otras medidas.

La eutanasia consiste en la administración de una medicación a dosis letales para provocar la muerte inmediata del paciente, a petición de este y en un contexto sanitario. No se trata de un proceso, como ocurre con la terapia de sedación, sino que las dosis administradas garantizan una muerte rápida.

Al igual que la eutanasia, el suicidio asistido busca provocar la muerte para liberar del sufrimiento a través de la administración de fármacos en dosis letales que garanticen un final rápido. En el suicidio asistido es el propio paciente el que se administra el fármaco. 


\title{
Qué puede hacer cuando llega la muerte
}

\author{
Aunque crea estar preparado para el momento de la muerte, si no ha tenido \\ experiencias previas puede que le resulte difícil saber cuándo se aproxima. \\ Conviene que pregunte al equipo sanitario si tiene alguna duda, pero lo primero \\ es asumir que la muerte es algo normal y natural. De hecho, si aceptamos el final \\ y tomamos conciencia de su trascendencia, puede ser un momento de paz y \\ serenidad.
}

Incluso en los últimos segundos de vida puede acompañar a su ser querido dándole la mano, acariciándolo y transmitiéndole tranquilidad ("vamos a estar bien", "ve tranquila", "gracias por ser tan buen padre", etc.).

Con frecuencia, las familias prefieren permanecer al lado de la persona enferma el mayor tiempo posible, esperando poder estar allí en el momento en que se produce la muerte. Sin embargo, a veces la persona fallece justo en el momento en que nos hemos ausentado, aunque sea por unos minutos. Esto pasa muy a menudo y es importante que no nos sintamos culpables por ello.

En algunos casos, también ocurre que queremos que todo se acabe cuanto antes. Esto no significa que se desee la muerte de nuestro familiar o amigo. Es un pensamiento normal, ya que forma parte de la esencia humana buscar el alivio del sufrimiento del otro y el de uno mismo.

Las señales de que la muerte se ha producido son falta de respiración y de pulso, ausencia de respuesta a los estímulos (al tacto o al sonido), ojos entreabiertos sin parpadear, pupilas dilatadas, boca entreabierta y cambio de coloración.

\section{LOS PRIMEROS MOMENTOS TRAS LA MUERTE}

Tómese su tiempo para despedirse de su ser querido antes de llamar a los servicios sanitarios y funerarios. Si lo desea, pase unos minutos a solas con la persona fallecida.

Este momento puede generar nerviosismo, pero intente mantener la calma y avisar a algún familiar o amigo. Mientras se despide, estas otras personas pueden ocuparse de llamar al médico, que tendrá que certificar el fallecimiento, y también a la funeraria. Tenga a mano el DNI del fallecido, ya que se lo van a pedir, y algún informe médico reciente. 


\section{INFORMACIÓN RELATIVA A TRÁMITES}

Los trámites se desarrollan de forma diferente dependiendo del lugar en el que se haya producido el fallecimiento:

En un centro hospitalario, residencia de mayores o similar: el centro se encarga de que una médica o un médico certifique la defunción. Para ello necesitará que usted le facilite el DNI de la persona fallecida. Posteriormente, el mismo centro comunicará la defunción y realizará los trámites oportunos ante el Registro Civil.

En el domicilio: los seres queridos de la persona fallecida avisan a su médico/a de referencia -si está en horario laboral- o al 061 o 112, que enviará a otro/a profesional para certificar la defunción. Para ello se necesita un impreso que suele facilitar la funeraria. Esta última acostumbra a ocuparse también de notificar la defunción en el Registro Civil en nombre de la familia.

Es de gran ayuda saber con antelación si la persona fallecida tenía contratada una funeraria o un seguro de decesos. En caso de no disponer de ninguna de estas opciones, sería conveniente consultar en las funerarias o tanatorios de la zona, incluso antes del fallecimiento, para hacer los preparativos oportunos.

Cuando se sienta preparado/a, deberá iniciar los trámites posteriores, como los relativos a los certificados de últimas voluntades, el certificado de seguros con cobertura de fallecimiento, prestaciones económicas y pensiones de viudedad y orfandad, cambios de titularidad de vivienda, contratos de luz y gas, etc. Tenga en cuenta que para cualquiera de estos trámites necesitará el DNI de la persona fallecida y el certificado de defunción. 


\section{El proceso de duelo}

El duelo es el proceso que experimentamos cuando perdemos a alguien importante para nosotros. Durante este proceso aprendemos a vivir sin la persona fallecida.

Se trata de una etapa normal y necesaria, de duración variable. En ella aparecen sentimientos, pensamientos y comportamientos naturales como tristeza, enfado, culpa, autorreproche, ansiedad, soledad, fatiga, incredulidad, confusión, sensación de presencia de la persona fallecida, trastornos del sueño y de la alimentación, problemas de concentración, aislamiento y llanto. También pueden aparecer síntomas físicos como opresión en el pecho y dolores musculares o de cabeza.

Hay personas a las que les cuesta más adaptarse a la pérdida. Si cree que este puede ser su caso no dude en consultar con su equipo de salud. En principio el duelo no precisa de medicamentos, pero si se complica puede ser necesaria atención especializada.

Si hay menores que hayan sufrido la pérdida de cerca es bueno que les deje expresar sus sentimientos, hablando de la persona fallecida con naturalidad y permitiéndoles participar en los ritos funerarios si lo desean. Si tiene cualquier duda sobre este tema consúltelo también con los profesionales. 
Clicando en siguientes links tendrá acceso a más información sobre el proceso de duelo:

Cómo comunicarse con otras personas a medida que se aproxima el final de la vida.

https://www.cancer.org/es/tratamiento/atencion-en-la-etapa-final-de-lavida/cuando-el-final-de-la-vida-esta-cerca/comunicacion.html

Explícame qué ha pasado. Guía para ayudar a los adultos a hablar de la muerte y el duelo con los niños.

http://www.codajic.org/sites/www.codajic.org/files/Explicame\%20que\%20 ha\%20pasado.\%20Gu\%C3\%ADa\%20para\%20adultos\%20para\%20 trabajar\%20duelo\%20en\%20ni\%C3\%B1os\%20-\%2OFMLC.pdf

\section{Pérdida de un ser querido.}

https://www.aecc.es/es/todo-sobre-cancer/viviendo-con-cancer/final-vida/ perdida-ser-querido

Hay niños delante. Cáncer en la familia: cómo informar a tus hijos. www.chospab.es/cursos_jornadas/2018/hay_ninos_delante/ninos_delante.pdf Modelo IDA para la intervención en duelo infantil.

https://dialnet.unirioja.es/descarga/articulo/6114011.pdf

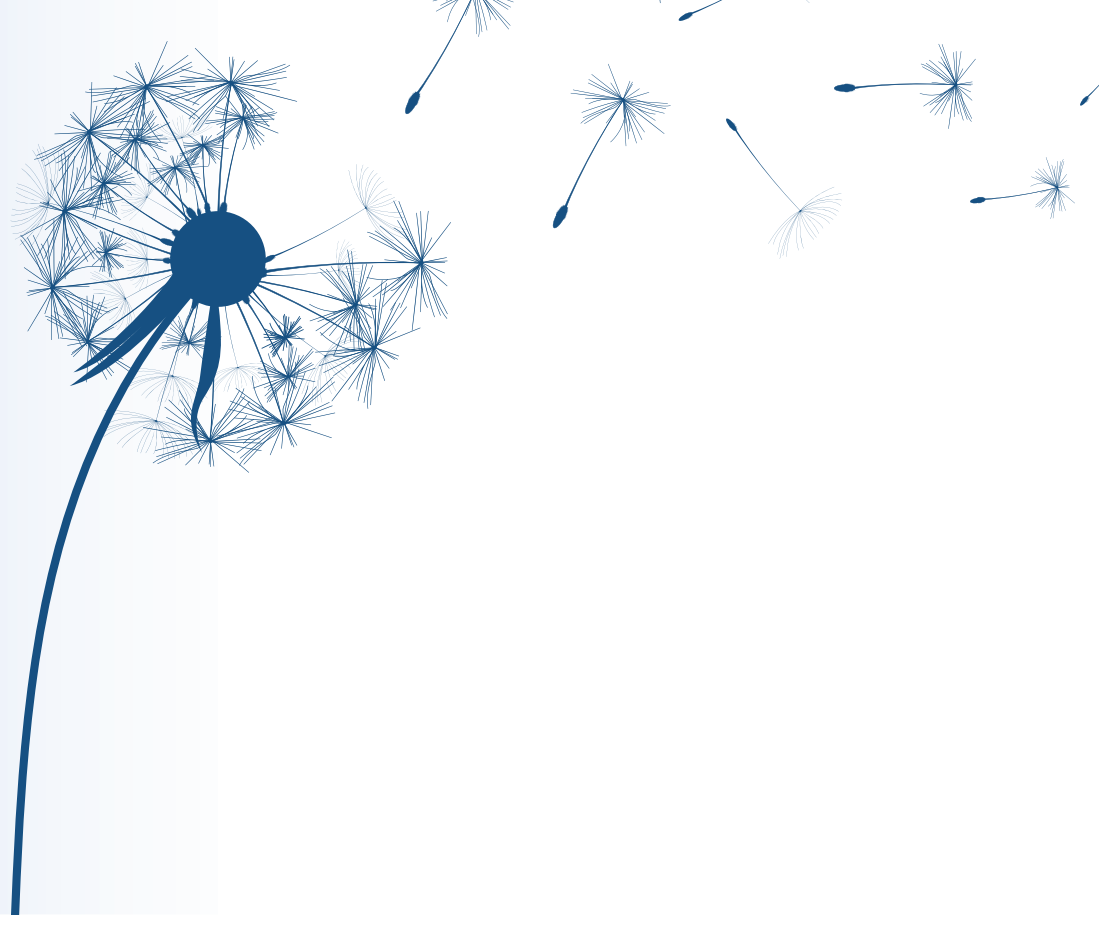




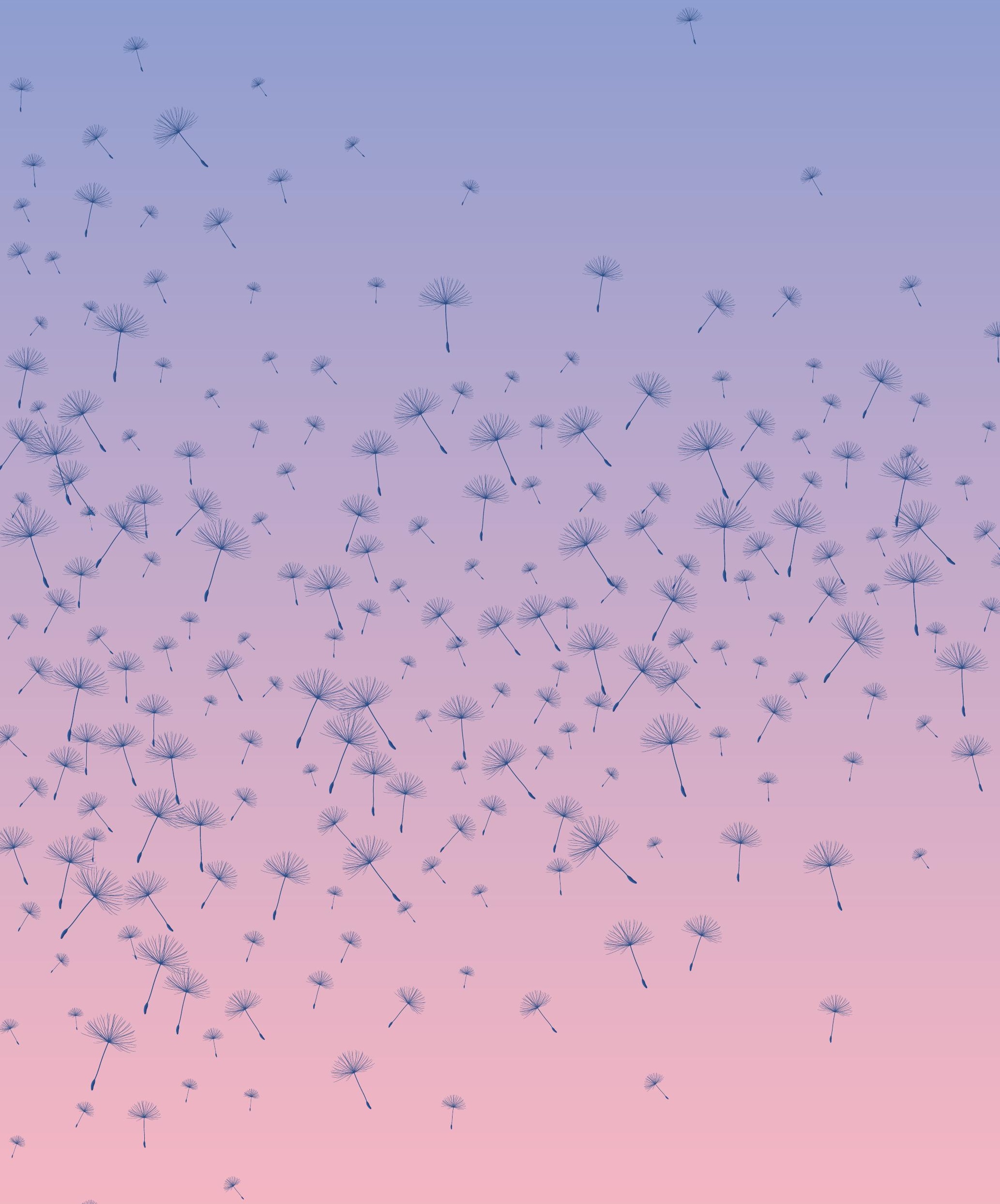




\section{Fuentes consultadas y de interés}

Care of dying adults in the last days of life. Information for the public. NICE; 2016.

https://www.nice.org.uk/guidance/ng31/ifp/chapter/About-this-information

Recomendaciones para el acompañamiento en los últimos días. Govern de les Illes Balears; 2015.

https://www.universidadpopular.es/images/PDFs/Acompanamiento-ultimos-dias-Versio-final.pdf

Guía de orientación a la familia y personas cuidadoras de últimos días. Dirección Territorial de Ceuta; 2017.

http://www.carehome.com.ar/uploads/Guia_Cuidadoras.pdf

Pacientes al final de su vida. Guía informativa y de divulgación para familias y personas cuidadoras. Gobierno de Cantabria; 2009.

https://saludcantabria.es/uploads/pdf/ciudadania/cp_cantabria-pacientes.pdf

Guía práctica para a familia en coidados paliativos. Sociedade Galega de Coidados Paliativos.

Guía sobre o dó. Sociedade Galega de Coidados Paliativos; 2005.

At the End. Australian Department of Health; 2020.

https://www.caresearch.com.au/caresearch/tabid/1073/Default.aspx

Guía Secpal para familiares en duelo.

http://ico.gencat.cat/web/.content/minisite/ico/professionals/documents/qualy/arxius/doc_guia_para_familiares_ en_duelo.pdf

Guía SECPAL de acompañamiento espiritual.

http://www.secpal.com/\%5CDocumentos\%5CBlog\%5Carchivo_7.pdf

Neimeyer RA. Aprender de la pérdida. Barcelona: Paidós; 2002.

Worden W. El tratamiento del duelo. Barcelona: Paidos Ibérica; 2013. 


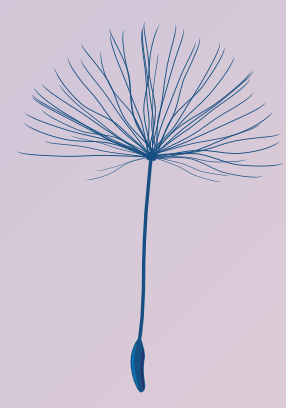

\section{XUNTA}

DE GALICIA 


\section{Bibliografía}

1 McNamara B, Rosenwax LK, Holman CD. A method for defining and estimating the palliative care population. J Pain Symptom Manage. 2006;32(1):5-12. DOI: 10.1016/j. jpainsymman.2005.12.018.

2 Ministerio de Sanidad Servicio Sociales e Igualdad.Estrategia para el abordaje de la cronicidad del Sistema Nacional de Salud [Internet]. Madrid: Ministerio de Sanidad, Servicios Sociales e Igualdad; 2012 [consultado 23 sep 2020]. Disponible en: https://www.mscbs.gob.es

3 Haun MW, Estel S, Rücker G, Friederich HC, Villalobos M, Thomas M, et al. Early palliative care for adults with advanced cancer. Cochrane Database Syst Rev. 2017;6(6):Cd011129. DOI: 10.1002/14651858.CD011129.pub2.

4 Meléndez A, Limón E, Coords. Del «paliativo no oncológico» al «paciente crónico avanzado». Más allá de las palabras. El reto de los cuidados paliativos del siglo xxi. 2018. En: Cronicidad avanzada [Monografía en internet]. 2018. [consultado 24 may 2021]. Disponible en: http:// www.secpal.com.

$5 \quad$ Kelley AS, Morrison RS. Palliative Care for the Seriously Ill. N Engl J Med. 2015;373(8):74755. DOI: $10.1056 /$ NEJMra1404684.

6 The goals of medicine. Setting new priorities. Hastings Cent Rep. 1996;26(6):S1-27.

7 Bayés R.Morir en paz:evaluación de los factoresimplicados.Med Clin(Barc).2004;122(14):53941. DOI: $10.1016 / \mathrm{s} 0025-7753(04) 74299-2$.

8 Bayés R, Limonero JT, Romero E, Arranz P. Qué puede ayudarnos a morir en paz? Med Clin (Barc). 2000;115(15):579-82. DOI: 10.1016/s0025-7753(00)71630-7.

9 Emanuel EJ, Emanuel LL. The promise of a good death. Lancet. 1998;351 Suppl 2:Sii21-9. DOI: 10.1016/s0140-6736(98)90329-4.

10 Meier EA, Gallegos JV, Thomas LP, Depp CA, Irwin SA, Jeste DV. Defining a Good Death (Successful Dying): Literature Review and a Call for Research and Public Dialogue. Am J Geriatr Psychiatry. 2016;24(4):261-71. DOI: 10.1016/j.jagp.2016.01.135.

11 Weisman AD, Hackett TP. Predilection to death. Death and dying as a psychiatric problem. Psychosom Med. 1961; 23:232-56.

12 The SUPPORT Principal Investigators. A controlled trial to improve care for seriously ill hospitalized patients. The study to understand prognoses and preferences for outcomes and risks of treatments (SUPPORT) JAMA. 1995;274(20):1591-8.

13 Ameneiros-Lago E, Carballada-Rico C, Garrido-Sanjuán JA. Mortalidad esperable en Medicina Interna: ¿cómo son los últimos días de vida en los pacientes en los que la muerte es previsible? Medicina Paliativa. 2017:63-71.

14 CIS. Atención a pacientes con enfermedades en fase terminal. Madrid: CIS; 2009. Informe $\mathrm{N}^{\circ}$.: 2803. Disponible en: http://www.cis.es.

15 Woitha K, Garralda E, Martin-Moreno JM, Clark D, Centeno C. Ranking of Palliative Care Development in the Countries of the European Union. J Pain Symptom Manage. 2016;52(3):370-7. DOI: 10.1016/j.jpainsymman.2016.03.008.

16 Barón-Duarte FJ. La agresividad terapéutica y los tratamientos limitados en el tiempo en pacientes oncológicos al final de la vida: fundamentos éticos y aplicación clínica [Tesis Doctoral]. Santiago de Compostela: Universidad de Santiago de Compostela; 2015. 
17 Asociación Española contra el Cáncer. Informe de la situación actual en cuidados paliativos. Fact sheet. 2014.

18 Plaza Canteli S, Marco Martínez J. Internists and death in the hospital. Rev Clin Esp. 2019;219(3):145-6. DOI: 10.1016/j.rce.2019.01.002.

19 Díez-Manglano J, Isasi de Isasmendi Pérez S, Rubio Gómez M, Formiga F, Sánchez Muñoz LÁ, Castiella Herrero J, et al. Cuidados en los últimos días de vida en los pacientes hospitalizados en medicina interna. Rev Clin Esp. 2019;219(3):107-15. DOI: 10.1016/j.rce.2018.06.010.

20 Grupo de Trabajo de la Guía de Práctica Clínica sobre Cuidados Paliativos. Guía de Práctica Clínica sobre Cuidados Paliativos. Vitoria: Agencia de Evaluación de Tecnologías Sanitarias del País Vasco; 2008. Guías de Práctica Clínica en el SNS: OSTEBA Nº 2006/08.

21 Bernal Sobrino JL, Elola Somoza J, Palanca Sánchez I, Paniagua Caparrós JL, Pascual López A. Unidad de cuidados paliativos. Estándares y recomendaciones. Madrid: Ministerio de Sanidad y Política Social; 2009.

22 National Institute for Health and Care Excellence. Care of dying adults in the last days of life. London: National Institute for Health and Care Excellence; 2015. [consultado 12 oct 2018]. Disponible en: https://www.nice.org.uk/guidance/ng31.

23 Baik D, Russell D, Jordan L, Dooley F, Bowles KH, Masterson Creber RM. Using the Palliative Performance Scale to Estimate Survival for Patients at the End of Life: A Systematic Review of the Literature. J Palliat Med. 2018;21(11):1651-61. DOI: 10.1089/jpm.2018.0141.

24 Ellershaw J, Ward C. Care of the dying patient: the last hours or days of life. Bmj. 2003;326(7379):30-4.

25 Kennedy C, Brooks-Young P, Brunton Gray C, Larkin P, Connolly M, Wilde-Larsson B, et al. Diagnosing dying: an integrative literature review. BMJ Support Palliat Care. 2014;4(3):26370. DOI: $10.1136 /$ bmjspcare-2013-000621.

26 Christakis NA, Lamont EB. Extent and determinants of error in doctors' prognoses in terminally ill patients: prospective cohort study. Bmj. 2000;320(7233):469-72. DOI: 10.1136/ bmj.320.7233.469.

27 Middlewood S, Gardner G, Gardner A. Dying in hospital: medical failure or natural outcome? J Pain Symptom Manage. 2001;22(6):1035-41. DOI: 10.1016/s0885-3924(01)00362-1.

28 Fins JJ, Miller FG, Acres CA, Bacchetta MD, Huzzard LL, Rapkin BD. End-of-life decisionmaking in the hospital: current practice and future prospects. J Pain Symptom Manage. 1999;17(1):6-15. DOI: 10.1016/s0885-3924(98)00109-2.

29 Toscani F, Di Giulio P, Brunelli C, Miccinesi G, Laquintana D. How people die in hospital general wards: a descriptive study. J Pain Symptom Manage. 2005;30(1):33-40. DOI: 10.1016/j. jpainsymman.2005.01.013.

30 Neuberger J, Guthrie C, Aaronovitch D, Hameed K, Bonser T, Harries R, et al. More care, less pathway: a review of the Liverpool Care Pathway. Liverpool: Independent Review of the Liverpool Care Pathway; 2013.

31 Chiang JK, Lai NS, Wang MH, Chen SC, Kao YH. A proposed prognostic 7-day survival formula for patients with terminal cancer. BMC Public Health. 2009;9:365. DOI:10.1186/14712458-9-365.

32 Kao YH, Chen CN, Chiang JK, Chen SS, Huang WW. Predicting factors in the last week of survival in elderly patients with terminal cancer: a prospective study in southern Taiwan. J Formos Med Assoc. 2009;108(3):231-9. DOI: 10.1016/s0929-6646(09)60057-7. 
33 Escalante CP, Martin CG, Elting LS, Price KJ, Manzullo EF, Weiser MA, et al. Identifying risk factors for imminent death in cancer patients with acute dyspnea. J Pain Symptom Manage. 2000;20(5):318-25.

34 Hui D, dos Santos R, Chisholm G, Bansal S, Silva TB, Kilgore K, et al. Clinical signs of impending death in cancer patients. Oncologist. 2014;19(6):681-7. DOI: 10.1634/theoncologist.2013-0457.

35 Loekito E, Bailey J, Bellomo R, Hart GK, Hegarty C, Davey P, et al. Common laboratory tests predict imminent death in ward patients. Resuscitation. 2013;84(3):280-5. DOI: 10.1016/j. resuscitation.2012.07.025.

36 Loekito E, Bailey J, Bellomo R, Hart GK, Hegarty C, Davey P, et al. Common laboratory tests predict imminent medical emergency team calls, intensive care unit admission or death in emergency department patients. Emerg Med Australas. 2013;25(2):132-9. DOI: 10.1111/17426723.12040 .

37 Matsunuma R, Tanbo Y, Asai N, Ohkuni Y, Watanabe S, Murakami S, et al. Prognostic factors in patients with terminal stage lung cancer. J Palliat Med. 2014;17(2):189-94. DOI: 10.1089/ jpm.2013.0448.

38 Hui D, Dos Santos R, Chisholm G, Bansal S, Souza Crovador C, Bruera E. Bedside clinical signs associated with impending death in patients with advanced cancer: preliminary findings of a prospective, longitudinal cohort study. Cancer. 2015;121(6):960-7. DOI: 10.1002/cncr.29048.

39 Johnson DC, Kutner JS, Armstrong JD, 2nd. Would you be surprised if this patient died?: Preliminary exploration of first and second year residents' approach to care decisions in critically ill patients. BMC Palliat Care. 2003;2(1):1.

40 Dendaas NR. Prognostication in advance cancer: nurses' perceptions of the dying process. Oncol Nurs Forum. 2002;29(3):493-9. DOI: 10.1188/02.onf.493-499.

41 van der Werff GF, Paans W, Nieweg RM. Hospital nurses' views of the signs and symptoms that herald the onset of the dying phase in oncology patients. Int J Palliat Nurs. 2012;18(3):143-9. DOI: 10.12968/ijpn.2012.18.3.143.

42 Abarshi E, Echteld M, Donker G, Van den Block L, Onwuteaka-Philipsen B, Deliens L. Discussing end-of-life issues in the last months of life: a nationwide study among general practitioners. J Palliat Med. 2011;14(3):323-30. DOI: 10.1089/jpm.2010.0312.

43 Domeisen BF, Ostgathe C, Clark J, Costantini M, Daud ML, Grossenbacher-Gschwend B, et al. International palliative care experts' view on phenomena indicating the last hours and days of life. Support Care Cancer. 2013;21(6):1509-17.

44 Brandt HE, Deliens L, Ooms ME, van der Steen JT, van der Wal G, Ribbe MW. Symptoms, signs, problems, and diseases of terminally ill nursing home patients: a nationwide observational study in the Netherlands. Arch Intern Med. 2005;165(3):314-20. DOI: 10.1001/ archinte.165.3.314.

45 Christakis NA, Lamont EB. Extent and determinants of error in physicians' prognoses in terminally ill patients: prospective cohort study. West J Med.2000;172(5):310-3. DOI: 10.1136/ ewjm.172.5.310.

46 Kumagai Y, Maekawa A, Abe M. Prognostic items for the last 10 and 3 days of life of cancer patients at home. Cancer Nurs. 2012;35(5):390-6. DOI: 10.1097/NCC.0b013e318235287d.

47 Fosse A, Zuidema S, Boersma F, Malterud K, Schaufel MA, Ruths S. Nursing Home Physicians' Assessments of Barriers and Strategies for End-of-Life Care in Norway and The Netherlands. J Am Med Dir Assoc. 2017;18(8):713-8. DOI: 10.1016/j.jamda.2017.03.005. 
48 Hui D, Bansal S, Park M, Reddy A, Cortes J, Fossella F, et al. Differences in attitudes and beliefs toward end-of-life care between hematologic and solid tumor oncology specialists. Ann Oncol. 2015;26(7):1440-6. DOI: 10.1093/annonc/mdv028.

49 Wright AA, Zhang B, Ray A, Mack JW, Trice E, Balboni T, et al. Associations between endof-life discussions, patient mental health, medical care near death, and caregiver bereavement adjustment. JAMA. 2008;300(14):1665-73. DOI: 10.1001/jama.300.14.1665.

50 Anselm AH, Palda V, Guest CB, McLean RF, Vachon ML, Kelner M, et al. Barriers to communication regarding end-of-life care: perspectives of care providers. J Crit Care. 2005;20(3):214-23. DOI: 10.1016/j.jcrc.2005.05.012.

51 Aslakson RA, Wyskiel R, Thornton I, Copley C, Shaffer D, Zyra M, et al. Nurse-perceived barriers to effective communication regarding prognosis and optimal end-of-life care for surgical ICU patients: a qualitative exploration. J Palliat Med.2012;15(8):910-5. DOI:10.1089/ jpm.2011.0481.

52 Gutiérrez KM. Experiences and needs of families regarding prognostic communication in an intensive care unit: supporting families at the end of life. Crit Care Nurs Q. 2012;35(3):299313. DOI: $10.1097 / C N Q .0 b 013 e 318255$ ee0d.

53 Jackson A, Purkis J, Burnham E, Hundt GL, Blaxter L. Views of relatives, carers and staff on end of life care pathways. Emerg Nurse. 2010;17(10):22-6. DOI: 10.7748/en2010.03.17.10.22. c7616.

54 Houttekier D, Witkamp FE, van Zuylen L, van der Rijt CC, van der Heide A. Is physician awareness of impending death in hospital related to better communication and medical care? J Palliat Med. 2014;17(11):1238-43. DOI: 10.1089/jpm.2014.0203.

55 Sullivan AM, Lakoma MD, Matsuyama RK, Rosenblatt L, Arnold RM, Block SD. Diagnosing and discussing imminent death in the hospital: a secondary analysis of physician interviews. J Palliat Med. 2007;10(4):882-93. DOI: 10.1089/jpm.2007.0189.

56 Generous MA, Keeley M. Wished for and avoided conversations with terminally ill individuals during final conversations. Death Stud.2017;41(3):162-72.DOI:10.1080/07481187.2016.1236850.

57 Odgers J. No one said he was dying: families' experiences of end-of-life care in an acute setting. Australian Journal of Advanced Nursing. 2018;35(3):21-31.

58 Park EM, Check DK, Yopp JM, Deal AM, Edwards TP, Rosenstein DL. An exploratory study of end-of-life prognostic communication needs as reported by widowed fathers due to cancer. Psychooncology. 2015;24(11):1471-6. DOI: 10.1002/pon.3757.

59 Nouvet E, Strachan PH, Kryworuchko J, Downar J, You JJ. Waiting for the body to fail: limits to end-of-life communication in Canadian hospitals. Mortality. 2016;21(4):340-56. DOI: 10.1080/13576275.2016.1140133.

60 Rodenbach RA, Rodenbach KE, Tejani MA, Epstein RM. Relationships between personal attitudes about death and communication with terminally ill patients: How oncology clinicians grapple with mortality. Patient Education and Counseling. 2016;99(3):356-63. DOI: http:// dx.doi.org/10.1016/j.pec.2015.10.010.

61 Brogan P, Hasson F, Mcllfatrick S. Shared decision-making at the end of life: A focus group study exploring the perceptions and experiences of multi-disciplinary healthcare professionals working in the home setting. Palliat Med. 2018;32(1):123-32. DOI: $10.1177 / 0269216317734434$.

62 Belanger E, Rodríguez C, Groleau D. Shared decision-making in palliative care: a systematic mixed studies review using narrative synthesis. Palliat Med. 2011;25(3):242-61. DOI: 10.1177/0269216310389348. 
63 Addicott R. Delivering better end-of-life care in England: barriers to access for patients with a non-cancer diagnosis. Health Econ Policy Law. 2012;7(4):441-54. DOI: 10.1017/ s1744133112000230.

64 Boot M, Wilson C. Clinical nurse specialists perspectives on advance care planning conversations: a qualitative study. Int J Palliat Nurs. 2014;20(1):9-14. DOI: 10.12968/ ijpn.2014.20.1.9.

65 Fields A, Finucane AM, Oxenham D. Discussing preferred place of death with patients: staff experiences in a UK specialist palliative care setting. Int J Palliat Nurs. 2013;19(11):558-65. DOI: 10.12968/ijpn.2013.19.11.558.

66 Minto F, Strickland K. Anticipating emotion: a qualitative study of advance care planning in the community setting. Int J Palliat Nurs. 2011;17(6):278-84. DOI: 10.12968/ijpn.2011.17.6.278.

67 Seymour J, Almack K, Kennedy S. Implementing advance care planning: a qualitative study of community nurses' views and experiences. BMC Palliat Care. 2010;9:4. DOI: 10.1186/1472$684 \mathrm{x}-9-4$.

68 Stevens I, Whyte F. Advance care planning: will it work in diseases other than cancer? European Journal of Palliative Care. 2011;18(6):280-4.

69 Tan HM, Lee SF, O'Connor MM, Peters L, Komesaroff PA. A case study approach to investigating end-of-life decision making in an acute health service. Aust Health Rev. 2013;37(1):93-7. DOI: 10.1071/ah11125.

70 Thompson TD, Barbour RS, Schwartz L. Health professionals' views on advance directives: a qualitative interdisciplinary study. Palliat Med. 2003;17(5):403-9. DOI: 10.1191/0269216303pm784oa.

71 Willard C, Luker K. Challenges to end of life care in the acute hospital setting. Palliat Med. 2006;20(6):611-5. DOI: 10.1177/0269216306071064.

72 Dillworth J, Dickson VV, Mueller A, Shuluk J, Yoon HW, Capezuti E. Nurses' perspectives: hospitalized older patients and end-of-life decision-making. Nurs Crit Care.2016;21(2):e1-e11. DOI: $10.1111 /$ nicc.12125.

73 Ho A, Jameson K, Pavlish C. An exploratory study of interprofessional collaboration in endof-life decision-making beyond palliative care settings. J Interprof Care. 2016;30(6):795-803. DOI: $10.1080 / 13561820.2016 .1203765$.

74 Laurent A, Bonnet M, Capellier G, Aslanian P, Hebert P. Emotional Impact of End-of-Life Decisions on Professional Relationships in the ICU: An Obstacle to Collegiality? Crit Care Med. 2017;45(12):2023-30. DOI: 10.1097/ccm.0000000000002710.

75 Romoren M, Pedersen R, Forde R. How do nursing home doctors involve patients and next of kin in end-of-life decisions? A qualitative study from Norway. BMC Med Ethics. 2016;17:5. DOI: 10.1186/s12910-016-0088-2.

76 Washington KT, Oliver DP, Gage LA, Albright DL, Demiris G. A multimethod analysis of shared decision-making in hospice interdisciplinary team meetings including family caregivers. Palliat Med. 2016;30(3):270-8. DOI: 10.1177/0269216315601545.

77 Brooks LA, Manias E, Nicholson P. Communication and Decision-Making About End-of-Life Care in the Intensive Care Unit. Am J Crit Care. 2017;26(4):336-41. DOI:10.4037/ajcc2017774.

78 Abbott KH, Sago JG, Breen CM, Abernethy AP, Tulsky JA. Families looking back: one year after discussion of withdrawal or withholding of life-sustaining support. Crit Care Med. 2001;29(1):197-201. 
79 Almack K, Cox K, Moghaddam N, Pollock K, Seymour J. After you: conversations between patients and healthcare professionals in planning for end of life care. BMC Palliat Care. 2012;11:15. DOI: 10.1186/1472-684x-11-15.

80 Caron CD, Griffith J, Arcand M. End-of-life decision making in dementia: the perspective of family caregivers. Dementia (14713012). 2005; 4(1):113-136.

81 Hsieh HF, Shannon SE, Curtis JR. Contradictions and communication strategies during end-of-life decision making in the intensive care unit. J Crit Care. 2006;21(4):294-304. DOI: 10.1016/j.jcrc.2006.06.003.

82 Lind R, Lorem GF, Nortvedt P, Hevroy O. Family members' experiences of "wait and see" as a communication strategy in end-of-life decisions. Intensive Care Med. 2011;37(7):1143-50. DOI: $10.1007 / \mathrm{s} 00134-011-2253-\mathrm{x}$.

83 Lind R, Nortvedt P, Lorem G, Hevroy O. Family involvement in the end-of-life decisions of competent intensive care patients. Nurs Ethics. 2013;20(1):61-71. DOI: 10.1177/0969733012448969.

84 Nolan MT, Kub J, Hughes MT, Terry PB, Astrow AB, Carbo CA, et al. Family health care decision making and self-efficacy with patients with ALS at the end of life. Palliat Support Care. 2008;6(3):273-80. DOI: 10.1017/s1478951508000412.

85 Royak-Schaler R, Gadalla S, Lemkau J, Ross D, Alexander C, Scott D. Family perspectives on communication with healthcare providers during end-of-life cancer care. Oncol Nurs Forum. 2006;33(4):753-60. DOI: 10.1188/06.onf.753-760.

86 Tilden VP, Tolle SW, Garland MJ, Nelson CA. Decisions about life-sustaining treatment. Impact of physicians' behaviors on the family. Arch Intern Med. 1995;155(6):633-8.

87 Vig EK, Starks H, Taylor JS, Hopley EK, Fryer-Edwards K. Surviving surrogate decisionmaking: what helps and hampers the experience of making medical decisions for others. $\mathrm{J}$ Gen Intern Med. 2007;22(9):1274-9. DOI: 10.1007/s11606-007-0252-y.

88 Lee MC, Sulmasy DP, Gallo J, Kub J, Hughes MT, Russell S, et al. Decision-Making of Patients With Implantable Cardioverter-Defibrillators at End of Life: Family Members' Experiences. Am J Hosp Palliat Care. 2017;34(6):518-23. DOI: 10.1177/1049909116641622.

89 Nelson JE, Hanson LC, Keller KL, Carson SS, Cox CE, Tulsky JA, et al. The Voice of Surrogate Decision-Makers. Family Responses to Prognostic Information in Chronic Critical Illness. Am J Respir Crit Care Med. 2017;196(7):864-72. DOI: 10.1164/rccm.201701-0201OC.

90 Rosemond C, Hanson LC, Zimmerman S. Goals of Care or Goals of Trust? How Family Members Perceive Goals for Dying Nursing Home Residents. J Palliat Med. 2017;20(4):360-5. DOI: 10.1089/jpm.2016.0271.

91 Yamamoto S, Arao H, Masutani E, Aoki M, Kishino M, Morita T, et al. Decision Making Regarding the Place of End-of-Life Cancer Care:The Burden on Bereaved Families and Related Factors. J Pain Symptom Manage. 2017;53(5):862-70.DOI:10.1016/j.jpainsymman.2016.12.348.

92 Cross LA. Compassion Fatigue in Palliative Care Nursing: A Concept Analysis. J Hosp Palliat Nurs. 2019;21(1):21-8. DOI: 10.1097/njh.0000000000000477.

93 Sudore RL, Lum HD, You JJ, Hanson LC, Meier DE, Pantilat SZ, et al. Defining Advance Care Planning for Adults: A Consensus Definition From a Multidisciplinary Delphi Panel. J Pain Symptom Manage. 2017;53(5):821-32.e1. DOI: 10.1016/j.jpainsymman.2016.12.331.

94 Rietjens JAC, Sudore RL, Connolly M, van Delden JJ, Drickamer MA, Droger M, et al. Definition and recommendations for advance care planning: an international consensus supported by the European Association for Palliative Care. Lancet Oncol.2017;18(9):e543-e51. DOI: $10.1016 / \mathrm{s} 1470-2045(17) 30582-\mathrm{x}$. 
95 Couceiro Vidal A, Pandiella A. La EPOC: un paradigma para el uso de directivas previas y la planificación anticipada de decisiones. Arch Bronconeumol. 2010;46(6):325-31.

96 Buckman R, Kanson Y. Breaking bad news: a six-step protocol. En: R B, editor. How to break bad news: a guide for heath care professionals. Baltimore: The Johns Hopkins University Press; 1992. p. 65-97.

97 Barrio IM, Simón P, Pascau MJ. El papel de la enfermera en la planificación anticipada de las decisiones: más allá de las instrucciones previas o voluntades anticipadas. Enfermería clínica. 2004;14(4):235-41.

98 Raijmakers NJ, van Zuylen L, Costantini M, Caraceni A, Clark J, Lundquist G, et al. Artificial nutrition and hydration in the last week of life in cancer patients. A systematic literature review of practices and effects. Ann Oncol. 2011;22(7):1478-86. DOI: 10.1093/annonc/mdq620.

99 Del Rio MI, Shand B, Bonati P, Palma A, Maldonado A, Taboada P, et al. Hydration and nutrition at the end of life: a systematic review of emotional impact, perceptions, and decisionmaking among patients, family, and health care staff. Psychooncology. 2012;21(9):913-21. DOI: 10.1002/pon.2099.

100 Good P, Richard R, Syrmis W, Jenkins-Marsh S, Stephens J. Medically assisted hydration for adult palliative care patients. Cochrane Database Syst Rev. 2014 (4):Cd006273. DOI: 10.1002/14651858.CD006273.pub3.

101 Druml C, Ballmer PE, Druml W, Oehmichen F, Shenkin A, Singer P, et al. ESPEN guideline on ethical aspects of artificial nutrition and hydration. Clin Nutr. 2016;35(3):545-56. DOI: 10.1016/j.clnu.2016.02.006.

102 Bruera E, Hui D, Dalal S, Torres-Vigil I, Trumble J, Roosth J, et al. Parenteral hydration in patients with advanced cancer: a multicenter, double-blind, placebo-controlled randomized trial. J Clin Oncol. 2013;31(1):111-8. DOI: 10.1200/jco.2012.44.6518.

103 Bruera E, Sala R, Rico MA, Moyano J, Centeno C, Willey J, et al. Effects of parenteral hydration in terminally ill cancer patients: a preliminary study. J Clin Oncol. 2005;23(10):2366-71. DOI: 10.1200/jco.2005.04.069.

104 Cerchietti L, Navigante A, Sauri A, Palazzo F. Hypodermoclysis for control of dehydration in terminal-stage cancer. Int J Palliat Nurs. 2000;6(8):370-4. DOI: 10.12968/ijpn.2000.6.8.9060.

105 Viola R. Studying Fluid Status and the Dying: The Challenge of Clinical Research in Palliative Care. 1997.

106 Morita T, Hyodo I, Yoshimi T, Ikenaga M, Tamura Y, Yoshizawa A, et al. Association between hydration volume and symptoms in terminally ill cancer patients with abdominal malignancies. Ann Oncol. 2005;16(4):640-7. DOI: 10.1093/annonc/mdi121.

107 Davies AN, Waghorn M, Webber K, Johnsen S, Mendis J, Boyle J. A cluster randomised feasibility trial of clinically assisted hydration in cancer patients in the last days of life. Palliat Med. 2018;32(4):733-43. DOI: 10.1177/0269216317741572.

108 Gent MJ, Fradsham S, Whyte GM, Mayland CR. What influences attitudes towards clinically assisted hydration in the care of dying patients? A review of the literature. BMJ Support Palliat Care. 2015;5(3):223-31. DOI: 10.1136/bmjspcare-2013-000562.

109 Ferris F, Balfour H, Bowen K, Farley J, Hardwick M, Lamontagne C, et al. A Model to Guide Hospice Palliative Care. Ottawa, ON: Canadian Hospice Palliative Care Association, 2002.

110 Carvajal Valcárcel A, Martínez García M, Centeno Cortés C. Versión española del Edmonton Symptom Assessment Sytem </span $>($ ESAS): un instrumento de referencia para la valoración sintomática del paciente con cáncer avanzado. Medicina Paliativa. 2013;20(4):143-9. DOI: 10.1016/j.medipa.2013.02.001. 
111 Delgado-Silveira E, Mateos-Nozal J, Muñoz - García M, Rexach-Canoc L, Vélez-DíazPallarés M, Albeniz-López J, et al. Uso potencialmente inapropiado de fármacos en cuidados paliativos: versión en castellano de los criterios STOPP-Frail (STOPP-Pal). Rev Esp Geriatr Gerontol. 2019;54(3):151-5.

112 Martin-Roselló ML, Fernández-López A, Sanz-Amores R, Gómez-García R, Vidal-España F, Cia-Ramos R. IDC-Pal (Instrumento Diagnóstico de la Complejidad en Cuidados Paliativos) [Internet]. Sevilla: Consejeria de Igualdad, Salud y Politicas sociales. Fundación Cudeca; [consultado 20 sep 2020]. Disponible en: http://www.juntadeandalucia.es/salud/IDCPal.

113 Supportive PDQ, Palliative Care Editorial B. Last Days of Life (PDQ $\left.{ }^{\circledR}\right)$ : Health Professional Version. PDQ Cancer Information Summaries. Bethesda (MD): National Cancer Institute (US); 2019.

114 Coyne P, Mulvenon C, Paice JA. American Society for Pain Management Nursing and Hospice and Palliative Nurses Association Position Statement: Pain Management at the End of Life. Pain management nursing : official journal of the American Society of Pain Management Nurses. 2018;19(1):3-7. DOI: 10.1016/j.pmn.2017.10.019.

115 Prácticas seguras para el uso de opioides en pacientes con dolor crónico. Madrid: Ministerio de Sanidad, Servicios Sociales e Igualdad; 2015.

116 Twycross RG. Choice of strong analgesic in terminal cancer: diamorphine or morphine? Pain. 1977;3(2):93-104. DOI: 10.1016/0304-3959(77)90072-0.

117 Sathornviriyapong A, Nagaviroj K, Anothaisintawee T. The association between different opioid doses and the survival of advanced cancer patients receiving palliative care. BMC Palliat Care. 2016;15(1):95-. DOI: 10.1186/s12904-016-0169-5.

118 Bercovitch M, Adunsky A. Patterns of high-dose morphine use in a home-care hospice service: should we be afraid of it? Cancer. 2004;101(6):1473-7. DOI: 10.1002/cncr.20485.

119 Seow H, Barbera L, Sutradhar R, Howell D, Dudgeon D, Atzema C, et al. Trajectory of performance status and symptom scores for patients with cancer during the last six months of life. J Clin Oncol. 2011;29(9):1151-8. DOI: 10.1200/JCO.2010.30.7173.

120 Tishelman C, Petersson L-M, Degner LF, Sprangers MAG. Symptom prevalence, intensity, and distress in patients with inoperable lung cancer in relation to time of death. J Clin Oncol. 2007;25(34):5381-9. DOI: 10.1200/JCO.2006.08.7874.

121 The Criteria Committee of the New York Heart Association. Nomenclature and Criteria for Diagnosis of Diseases of the Heart and Great Vessels. $9^{\text {a }}$ ed. Boston: Little, Brown \& Co; 1994. p. 253-6.

122 Borg G. Simple rating methods for estimation of perceived exertion. Wenner-Gren Center International Symposium. 1976; Series 28:39-47.

123 Campbell ML, Templin T, Walch J.A Respiratory Distress Observation Scale for patients unable to self-report dyspnea. J Palliat Med. 2010 Mar;13(3):285-90. DOI: 10.1089/jpm.2009.0229.

124 Barnes H, McDonald J, Smallwood N, Manser R. Opioids for the palliation of refractory breathlessness in adults with advanced disease and terminal illness. Cochrane Database Syst Rev. 2016;3(3):Cd011008. DOI: 10.1002/14651858.CD011008.pub2.

125 Simon ST, Higginson IJ, Booth S, Harding R, Weingärtner V, Bausewein C. Benzodiazepines for the relief of breathlessness in advanced malignant and non-malignant diseases in adults. Cochrane Database Syst Rev. 2016;10(10):Cd007354. DOI: 10.1002/14651858.CD007354. pub3. 
126 Navigante AH, Cerchietti LC, Castro MA, Lutteral MA, Cabalar ME. Midazolam as adjunct therapy to morphine in the alleviation of severe dyspnea perception in patients with advanced cancer. J Pain Symptom Manage. 2006;31(1):38-47. DOI: 10.1016/j.jpainsymman.2005.06.009.

127 Booth S, Kelly MJ, Cox NP, Adams L, Guz A. Does oxygen help dyspnea in patients with cancer? Am J Respir Crit Care Med. 1996;153(5):1515-8. DOI: 10.1164/ajrccm.153.5.8630595.

128 Clemens KE, Quednau I, Klaschik E. Use of oxygen and opioids in the palliation of dyspnoea in hypoxic and non-hypoxic palliative care patients: a prospective study. Support Care Cancer. 2009;17(4):367-77. DOI: 10.1007/s00520-008-0479-0.

129 Twycross R, Back I. Nausea and vomiting in advanced cancer. Eur J Palliat Care. 1998;5:39-45.

130 Edmonds P, Karlsen S, Khan S, Addington-Hall J. A comparison of the palliative care needs of patients dying from chronic respiratory diseases and lung cancer. Palliat Med. 2001;15(4):28795. DOI: 10.1191/026921601678320278.

131 Klinkenberg M, Willems DL, van der Wal G, Deeg DJ. Symptom burden in the last week of life. J Pain Symptom Manage. 2004;27(1):5-13. DOI: 10.1016/j.jpainsymman.2003.05.008.

132 Mystakidou K, Tsilika E, Kalaidopoulou O, Chondros K, Georgaki S, Papadimitriou L. Comparison of octreotide administration vs conservative treatment in the management of inoperable bowel obstruction in patients with far advanced cancer: a randomized, doubleblind, controlled clinical trial. Anticancer Res. 2002;22(2b):1187-92.

133 Ripamonti C, Mercadante S, Groff L, Zecca E, De Conno F, Casuccio A. Role of octreotide, scopolamine butylbromide, and hydration in symptom control of patients with inoperable bowel obstruction and nasogastric tubes: a prospective randomized trial. J Pain Symptom Manage. 2000;19(1):23-34. DOI: 10.1016/s0885-3924(99)00147-5.

134 Mercadante S, Casuccio A, Fulfaro F. The course of symptom frequency and intensity in advanced cancer patients followed at home. J Pain Symptom Manage. 2000;20(2):104-12. DOI: $10.1016 / \mathrm{s} 0885-3924(00) 00160-3$.

135 Mercadante S, Casuccio A, Agnello A, Serretta R, Calderone L, Barresi L. Morphine versus methadone in the pain treatment of advanced-cancer patients followed up at home. J Clin Oncol. 1998;16(11):3656-61. DOI: 10.1200/jco.1998.16.11.3656.

136 Cox L, Darvill E, Dorman S. Levomepromazine for nausea and vomiting in palliative care. Cochrane Database Syst Rev. 2015;2015(11):Cd009420. DOI: 10.1002/14651858.CD009420. pub3.

137 Storrar J, Hitchens M, Platt T, Dorman S. Droperidol for treatment of nausea and vomiting in palliative care patients. Cochrane Database Syst Rev. 2014;2014(11):Cd006938. DOI: 10.1002/14651858.CD006938.pub3.

138 Vayne-Bossert P, Haywood A, Good P, Khan S, Rickett K, Hardy JR. Corticosteroids for adult patients with advanced cancer who have nausea and vomiting (not related to chemotherapy, radiotherapy, or surgery). Cochrane Database Syst Rev. 2017;7(7):Cd012002. DOI: 10.1002/14651858.CD012002.pub2.

139 Sutherland A, Naessens K, Plugge E, Ware L, Head K, Burton MJ, et al. Olanzapine for the prevention and treatment of cancer-related nausea and vomiting in adults. Cochrane Database Syst Rev. 2018;9(9):Cd012555. DOI: 10.1002/14651858.CD012555.pub2.

140 Murray-Brown F, Dorman S. Haloperidol for the treatment of nausea and vomiting in palliative care patients. Cochrane Database Syst Rev. 2015;2015(11):Cd006271. DOI: 10.1002/14651858. CD006271.pub3.

141 Levy M, Smith T, Alvarez-Perez A, Back A, Baker JN, Beck AC, et al. Palliative Care Version 1.2016. J Natl Compr Canc Netw. 2016;14(1):82-113. DOI: 10.6004/jnccn.2016.0009. 
142 Guidelines and Protocols Advisory Committee (BC). Part 2: Pain and symptom management. 2017. En: Palliative care for the patient with incurable cancer or advanced disease [Monografía en internet]. Victoria: BC; 2017. [consultado 20 sept 2020]. Disponible n: https://www2.gov. bc.ca.

143 Kehl KA, Kowalkowski JA. A systematic review of the prevalence of signs of impending death and symptoms in the last 2 weeks of life. Am J Hosp Palliat Care. 2013;30(6):601-16. DOI: $10.1177 / 1049909112468222$.

144 Hosie A, Davidson PM, Agar M, Sanderson CR, Phillips J. Delirium prevalence, incidence, and implications for screening in specialist palliative care inpatient settings: a systematic review. Palliat Med. 2013;27(6):486-98. DOI: 10.1177/0269216312457214.

145 Zigmond AS, Snaith RP. The hospital anxiety and depression scale. Acta Psychiatr Scand. 1983;67(6):361-70. DOI: 10.1111/j.1600-0447.1983.tb09716.x.

146 McCleary E, Cumming P. Improving early recognition of delirium using SQiD (Single Question to identify Delirium): a hospital based quality improvement project. BMJ Qual Improv Rep. 2015;4(1). DOI: 10.1136/bmjquality.u206598.w2653.

147 Tobar E, Romero C, Galleguillos T, Fuentes P, Cornejo R, Lira MT, et al. Método para la evaluación de la confusión en la unidad de cuidados intensivos para el diagnóstico de delírium: adaptación cultural y validación de la versión en idioma español. Med Intensiva. 2010;34(1):413. DOI: 10.1016/j.medin.2009.04.003.

148 Bellelli G, Morandi A, Davis DH, Mazzola P, Turco R, Gentile S, et al. Validation of the 4AT, a new instrument for rapid delirium screening: a study in 234 hospitalised older people. Age Ageing. 2014 Jul;43(4):496-502. DOI: 10.1093/ageing/afu021.

149 Noguera A, Carvajal A, Alonso-Babarro A, Chisholm G, Bruera E, Centeno C. First Spanish version of the Memorial Delirium Assessment Scale: psychometric properties, responsiveness, and factor loadings. J Pain Symptom Manage. 2014;47(1):189-97. DOI: 10.1016/j.jpainsymman.2013.02.020.

150 Trzepacz PT, Mittal D, Torres R, Kanary K, Norton J, Jimerson N. Validation of the Delirium Rating Scale-revised-98: comparison with the delirium rating scale and the cognitive test for delirium. J Neuropsychiatry Clin Neurosci. 2001 Spring;13(2):229-42. DOI: 10.1176/ jnp.13.2.229.

151 Finucane AM, Jones L, Leurent B, Sampson EL, Stone P, Tookman A, et al. Drug therapy for delirium in terminally ill adults. Cochrane Database Syst Rev. 2020;1(1):Cd004770. DOI: 10.1002/14651858.CD004770.pub3.

152 Jansen K, Haugen DF, Pont L, Ruths S. Safety and Effectiveness of Palliative Drug Treatment in the Last Days of Life-A Systematic Literature Review. J Pain Symptom Manage. 2018;55(2):508-21.e3. DOI: 10.1016/j.jpainsymman.2017.06.010.

153 Salt S, Mulvaney CA, Preston NJ. Drug therapy for symptoms associated with anxiety in adult palliative care patients. Cochrane Database Syst Rev. 2017;5(5):Cd004596. DOI: 10.1002/14651858.CD004596.pub3.

154 Lokker ME, van Zuylen L, van der Rijt CCD, van der Heide A. Prevalence, impact, and treatment of death rattle: a systematic review. J Pain Symptom Manage. 2014;47(1):105-22. DOI: 10.1016/j.jpainsymman.2013.03.011.

155 Clark K, Currow DC, Agar M, Fazekas BS, Abernethy AP. A pilot phase II randomized, crossover, double-blinded, controlled efficacy study of octreotide versus hyoscine hydrobromide for control of noisy breathing at the end-of-life. J Pain Palliat Care Pharmacother. 2008;22(2):1318. DOI: 10.1080/15360280801992058. 
156 Likar R, Molnar M, Rupacher E, Pipam W, Deutsch J, Mörtl M, et al. Klinische Untersuchung über die Wirkung von Scopolamin-Hydrobromicum beim terminalen Rasseln (randomisierte, doppelblind, plazebokontrollierte Studie). Palliativmedizin. 2002;3(01):15-9.

157 Likar R, Rupacher E, Kager H, Molnar M, Pipam W, Sittl R. [Efficacy of glycopyrronium bromide and scopolamine hydrobromide in patients with death rattle: a randomized controlled study]. Wien Klin Wochenschr. 2008;120(21-22):679-83. DOI: 10.1007/s00508-008-1094-2.

158 Wildiers H, Dhaenekint C, Demeulenaere P, Clement PM, Desmet M, Van Nuffelen R, et al. Atropine, hyoscine butylbromide, or scopolamine are equally effective for the treatment of death rattle in terminal care. J Pain Symptom Manage. 2009;38(1):124-33. DOI: 10.1016/j. jpainsymman.2008.07.007.

159 Heisler M, Hamilton G, Abbott A, Chengalaram A, Koceja T, Gerkin R. Randomized doubleblind trial of sublingual atropine vs. placebo for the management of death rattle. J Pain Symptom Manage. 2013;45(1):14-22. DOI: 10.1016/j.jpainsymman.2012.01.006.

160 Back IN, Jenkins K, Blower A, Beckhelling J. A study comparing hyoscine hydrobromide and glycopyrrolate in the treatment of death rattle. Palliat Med. 2001;15(4):329-36. DOI: 10.1191/026921601678320313.

161 HugelH,Ellershaw J, Gambles M. Respiratory tract secretions in the dying patient:a comparison between glycopyrronium and hyoscine hydrobromide. J Palliat Med. 2006;9(2):279-84. DOI: 10.1089/jpm.2006.9.279.

162 Kåss RM, Ellershaw J. Respiratory tract secretions in the dying patient: a retrospective study. J Pain Symptom Manage. 2003;26(4):897-902. DOI: 10.1016/s0885-3924(03)00292-6.

163 Hughes A, Wilcock A, Corcoran R, Lucas V, King A. Audit of three antimuscarinic drugs for managing retained secretions. Palliat Med.2000;14(3):221-2.DOI:10.1191/026921600670188257.

164 Star A, Boland JW. Updates in palliative care - recent advancements in the pharmacological management of symptoms. Clinical medicine (London, England). 2018;18(1):11-6. DOI: 10.7861/clinmedicine.18-1-11.

165 Mercadante S, Marinangeli F, Masedu F, Valenti M, Russo D, Ursini L, et al. Hyoscine Butylbromide for the Management of Death Rattle: Sooner Rather Than Later. J Pain Symptom Manage. 2018 Dec;56(6):902-7. DOI: 10.1016/j.jpainsymman.2018.08.018.

166 van Esch HJ, van Zuylen L, Oomen-de Hoop E, van der Heide A, van der Rijt CCD. Scopolaminebutyl given prophylactically for death rattle: study protocol of a randomized double-blind placebo-controlled trial in a frail patient population (the SILENCE study). BMC Palliat Care. 2018;17(1):105. DOI: 10.1186/s12904-018-0359-4.

167 A controlled trial to improve care for seriously ill hospitalized patients. The study to understand prognoses and preferences for outcomes and risks of treatments (SUPPORT). The SUPPORT Principal Investigators. JAMA. 1995;274(20):1591-8.

168 Doyle D, Woodruff R. The IAHCP Manual of PalliativeCare. $2^{\mathrm{a}}$ ed. International Association for Hospice and Palliative Care Press; 2008.

169 Morita T, Chinone Y, Ikenaga M, Miyoshi M, Nakaho T, Nishitateno K, et al. Efficacy and safety of palliative sedation therapy: a multicenter, prospective, observational study conducted on specialized palliative care units in Japan. J Pain Symptom Manage. 2005;30(4):320-8. DOI: 10.1016/j.jpainsymman.2005.03.017.

170 Cowan JD, Clemens L, Palmer T. Palliative sedation in a southern Appalachian community. Am J Hosp Palliat Care. 2006;23(5):360-8. DOI: 10.1177/1049909106292173.

171 de Graeff A, Dean M.Palliative sedation therapy in the last weeks of life: a literature review and recommendations for standards. J Palliat Med. 2007;10(1):67-85. DOI: 10.1089/jpm.2006.0139. 
172 Cherny NI, Radbruch L, Board of the European Association for Palliative C. European Association for Palliative Care (EAPC) recommended framework for the use of sedation in palliative care. Palliat Med. 2009;23(7):581-93. DOI: 10.1177/0269216309107024.

173 Cherny NI, Portenoy RK. Sedation in the management of refractory symptoms: guidelines for evaluation and treatment. J Palliat Care. 1994;10(2):31-8.

174 Beller EM, van Driel ML, McGregor L, Truong S, Mitchell G. Palliative pharmacological sedation for terminally ill adults. Cochrane Database Syst Rev. 2015;1(1):CD010206-CD. DOI: 10.1002/14651858.CD010206.pub2.

175 Alonso-Babarro A, Varela-Cerdeira M, Torres-Vigil I, Rodríguez-Barrientos R, Bruera E. Athome palliative sedation for end-of-life cancer patients. Palliat Med. 2010;24(5):486-92. DOI: $10.1177 / 0269216309359996$.

176 Bulli F, Miccinesi G, Biancalani E, Fallai M, Mannocci M, Paci E, et al. Continuous deep sedation in home palliative care units: case studies in the Florence area in 2000 and in 20032004. Minerva Anestesiol. 2007;73(5):291-8.

177 Caraceni A, Zecca E, Martini C, Gorni G, Campa T, Brunelli C, et al. Palliative sedation at the end of life at a tertiary cancer center. Support Care Cancer. 2012;20(6):1299-307. DOI: $10.1007 / \mathrm{s} 00520-011-1217-6$.

178 Chiu TY, Hu WY, Lue BH, Cheng SY, Chen CY. Sedation for refractory symptoms of terminal cancer patients in Taiwan. J Pain Symptom Manage. 2001;21(6):467-72. DOI: 10.1016/s08853924(01)00286-x.

179 Fainsinger RL, Landman W, Hoskings M, Bruera E. Sedation for uncontrolled symptoms in a South African hospice. J Pain Symptom Manage. 1998;16(3):145-52. DOI: 10.1016/s08853924(98)00066-9.

180 Kohara H, Ueoka H, Takeyama H, Murakami T, Morita T. Sedation for terminally ill patients with cancer with uncontrollable physical distress. J Palliat Med. 2005;8(1):20-5. DOI: 10.1089/ jpm.2005.8.20.

181 Maltoni M, Pittureri C, Scarpi E, Piccinini L, Martini F, Turci P, et al. Palliative sedation therapy does not hasten death: results from a prospective multicenter study. Ann Oncol. 2009;20(7):1163-9. DOI: 10.1093/annonc/mdp048.

182 Maltoni M, Miccinesi G, Morino P, Scarpi E, Bulli F, Martini F, et al. Prospective observational Italian study on palliative sedation in two hospice settings: differences in casemixes and clinical care. Support Care Cancer. 2012;20(11):2829-36. DOI: 10.1007/s00520-012-1407-x.

183 Muller-Busch HC, Andres I, Jehser T. Sedation in palliative care - a critical analysis of 7 years experience. BMC Palliat Care. 2003;2(1):2-. DOI: 10.1186/1472-684X-2-2.

184 Radha Krishna LK, Poulose VJ, Goh C. The use of midazolam and haloperidol in cancer patients at the end of life. Singapore medical journal. 2012;53(1):62-6.

185 Rietjens JAC, van Zuylen L, van Veluw H, van der Wijk L, van der Heide A, van der Rijt CCD. Palliative sedation in a specialized unit for acute palliative care in a cancer hospital: comparing patients dying with and without palliative sedation. J Pain Symptom Manage. 2008;36(3):22834. DOI: 10.1016/j.jpainsymman.2007.10.014.

186 Stone P,Phillips C, Spruyt O, Waight C.A comparison of the use of sedatives in a hospital support team and in a hospice. Palliat Med. 1997;11(2):140-4. DOI: 10.1177/026921639701100208.

187 Sykes N, Thorns A. Sedative use in the last week of life and the implications for end-of-life decision making. Arch Intern Med. 2003;163(3):341-4. DOI: 10.1001/archinte.163.3.341.

188 Vitetta L, Kenner D, Sali A.Sedation and analgesia-prescribing patterns in terminally ill patients at the end of life.Am J Hosp Palliat Care.2005;22(6):465-73.DOI:10.1177/104990910502200601. 
189 Prado BL, Gomes DBD, Usón Júnior PLS, Taranto P, França MS, Eiger D, et al. Continuous palliative sedation for patients with advanced cancer at a tertiary care cancer center. BMC Palliat Care. 2018;17(1):13-. DOI: 10.1186/s12904-017-0264-2.

190 Boulanger A, Chabal T, Fichaux M, Destandau M, La Piana JM, Auquier P, et al. Opinions about the new law on end-of-life issues in a sample of french patients receiving palliative care. BMC Palliat Care. 2017;16(1):7-. DOI: 10.1186/s12904-016-0174-8.

191 Bruinsma SM, Brown J, van der Heide A, Deliens L, Anquinet L, Payne SA, et al. Making sense of continuous sedation in end-of-life care for cancer patients: an interview study with bereaved relatives in three European countries. Support Care Cancer. 2014;22(12):3243-52. DOI: $10.1007 / \mathrm{s} 00520-014-2344-7$.

192 Bruinsma SM, van der Heide A, van der Lee ML, Vergouwe Y, Rietjens JAC. No Negative Impact of Palliative Sedation on Relatives' Experience of the Dying Phase and Their Wellbeing after the Patient's Death: An Observational Study. PloS one. 2016;11(2):e0149250-e. DOI: 10.1371/journal.pone.0149250.

193 Eun Y, Hong I-W, Bruera E, Kang JH. Qualitative Study on the Perceptions of Terminally Ill Cancer Patients and Their Family Members Regarding End-of-Life Experiences Focusing on Palliative Sedation. J Pain Symptom Manage. 2017;53(6):1010-6. DOI: 10.1016/j. jpainsymman.2016.12.353.

194 Fainsinger RL, Núñez-Olarte JM, Demoissac DM. The cultural differences in perceived value of disclosure and cognition: Spain and Canada. J Palliat Care. 2003;19(1):43-8.

195 Morita T, Ikenaga M, Adachi I, Narabayashi I, Kizawa Y, Honke Y, et al. Family experience with palliative sedation therapy for terminally ill cancer patients. J Pain Symptom Manage. 2004;28(6):557-65. DOI: 10.1016/j.jpainsymman.2004.03.004.

196 Shen H-S, Chen S-Y, Cheung DST, Wang S-Y, Lee JJ, Lin C-C. Differential Family Experience of Palliative Sedation Therapy in Specialized Palliative or Critical Care Units. J Pain Symptom Manage. 2018;55(6):1531-9. DOI: 10.1016/j.jpainsymman.2018.02.007.

197 Tursunov O, Cherny NI, Ganz FD. Experiences of Family Members of Dying Patients Receiving Palliative Sedation. Oncol Nurs Forum. 2016;43(6):E226-E32. DOI: 10.1188/16. ONF.E226-E232.

198 van Dooren S, van Veluw HTM, van Zuylen L, Rietjens JAC, Passchier J, van der Rijt CCD. Exploration of concerns of relatives during continuous palliative sedation of their family members with cancer. J Pain Symptom Manage. 2009;38(3):452-9. DOI: 10.1016/j. jpainsymman.2008.11.011.

199 Vayne-Bossert P, Zulian GB. Palliative sedation: from the family perspective. Am J Hosp Palliat Care. 2013;30(8):786-90. DOI: 10.1177/1049909112472930.

200 Rietjens JAC, Deschepper R, Pasman R, Deliens L. Medical end-of-life decisions: does its use differ in vulnerable patient groups? A systematic review and meta-analysis. Social science \& medicine (1982). 2012;74(8):1282-7. DOI: 10.1016/j.socscimed.2011.12.046.

201 Benítez-Rosario MA, Morita T. Palliative sedation in clinical scenarios: results of a modified Delphi study. Support Care Cancer. 2019;27(5):1647-54. DOI: 10.1007/s00520-018-4409-5.

202 Raus K, Brown J, Seale C, Rietjens JAC, Janssens R, Bruinsma S, et al. Continuous sedation until death: the everyday moral reasoning of physicians, nurses and family caregivers in the UK, The Netherlands and Belgium. BMC Med Ethics. 2014;15:14-. DOI: 10.1186/1472-693915-14.

203 Papavasiliou EE, Payne S, Brearley S, Euroimpact. Current debates on end-of-life sedation: an international expert elicitation study. Support Care Cancer. 2014;22(8):2141-9. DOI: 10.1007/ s00520-014-2200-9. 
204 Abarshi E, Rietjens J, Robijn L, Caraceni A, Payne S, Deliens L, et al. International variations in clinical practice guidelines for palliative sedation: a systematic review. BMJ Support Palliat Care. 2017;7(3):223-9. DOI: 10.1136/bmjspcare-2016-001159.

205 Schildmann EK, Schildmann J, Kiesewetter I. Medication and monitoring in palliative sedation therapy: a systematic review and quality assessment of published guidelines. J Pain Symptom Manage. 2015;49(4):734-46. DOI: 10.1016/j.jpainsymman.2014.08.013.

206 Sedación paliativa del prcpex, uso y recomendaciones. Guía clínica [Internet]. Mérida: Servicio Extremeño de Salud. FundeSalud; 2014. [consultado 04 feb 2020]. Disponible en: https://saludextremadura.ses.es.

207 Sedación paliativa. Guía [Internet] Madrid: Consejo General de Colegios Oficiales de Médicos; 2012. [consultado 04 feb 2020]. Disponible en: https://www.cgcom.es.

208 Voeuk A, Nekolaichuk C, Fainsinger R, Huot A. Continuous Palliative Sedation for Existential Distress? A Survey of Canadian Palliative Care Physicians' Views. J Palliat Care. 2017;32(1):26-33. DOI: 10.1177/0825859717711301.

209 Rodrigues P, Crokaert J, Gastmans C. Palliative Sedation for Existential Suffering:A Systematic Review of Argument-Based Ethics Literature. J Pain Symptom Manage. 2018;55(6):1577-90. DOI: 10.1016/j.jpainsymman.2018.01.013.

210 Henry B. A systematic literature review on the ethics of palliative sedation: an update (2016). Current opinion in supportive and palliative care. 2016;10(3):201-7. DOI: 10.1097/ SPC.0000000000000224.

211 Twycross R. Reflections on palliative sedation. Palliative care. 2019;12:1178224218823511-. DOI: $10.1177 / 1178224218823511$.

212 Ely EW, Truman B, Shintani A, Thomason JWW, Wheeler AP, Gordon S, et al. Monitoring sedation status over time in ICU patients: reliability and validity of the Richmond AgitationSedation Scale (RASS). JAMA. 2003;289(22):2983-91. DOI: 10.1001/jama.289.22.2983.

213 Benítez-Rosario MA, Castillo-Padrós M, Garrido-Bernet B, González-Guillermo T, MartínezCastillo LP, González A, et al.Appropriateness and reliability testing of the modified Richmond Agitation-Sedation Scale in Spanish patients with advanced cancer. J Pain Symptom Manage. 2013;45(6):1112-9. DOI: 10.1016/j.jpainsymman.2012.05.015.

214 Sacristán Rodea A, Peláez Moya S, Bullich Marín I, García Aparicio M, Coords. Manejo en domicilio de pacientes al final de la vida que requieran sedación paliativa en el contexto de la pandemia por COVID-19. Madrid: Ministerio de Sanidad; 2020. Disponible en: https://www. mscbs.gob.es.

215 Grupo de trabajo para la actualización del Manual de Elaboración de GPC. Elaboración de Guías de Práctica Clínica en el Sistema Nacional de Salud. Actualización del Manual Metodológico [Internet]. Madrid: Ministerio de Sanidad, Servicios Sociales e Igualdad; Zaragoza: Instituto Aragonés de Ciencias de la Salud (IACS); 2016.

216 AGREE Next Steps Consortium. Appraisal of guidelines for research and evaluation II: AGREE II instrument [Internet]. Disponible en: http://www.agreetrust.org.

217 Schünemann HJ, Wiercioch W, Brozek J, Etxeandia-Ikobaltzeta I, Mustafa RA, Manja V, et al. GRADE Evidence to Decision (EtD) frameworks for adoption, adaptation, and de novo development of trustworthy recommendations: GRADE-ADOLOPMENT. J Clin Epidemiol. 2017;81:101-10. DOI: 10.1016/j.jclinepi.2016.09.009.

218 Shea BJ, Reeves BC, Wells G, Thuku M, Hamel C, Moran J, et al. AMSTAR 2: a critical appraisal tool for systematic reviews that include randomised or non-randomised studies of healthcare interventions, or both. Bmj. 2017;358:j4008. DOI: 10.1136/bmj.j4008. 
219 GRADE working group. Grading of Recommendations of Assessment Development and Evaluations[Internet].[consultado25 sep2020].Disponible en:http://www.gradeworkinggroup. org/.

220 Lewin S, Glenton C, Munthe-Kaas H, Carlsen B, Colvin CJ, Gülmezoglu M, et al. Using qualitative evidence in decision making for health and social interventions: an approach to assess confidence in findings from qualitative evidence syntheses (GRADE-CERQual). PLoS Med. 2015;12(10):e1001895. DOI: 10.1371/journal.pmed.1001895.

221 Melzack R. The McGill Pain Questionnaire: major properties and scoring methods. Pain. 1975;1(3):277-99. DOI: 10.1016/0304-3959(75)90044-5.

222 Cleeland CS, Ryan KM. Pain assessment: global use of the Brief Pain Inventory. Ann Acad Med Singap. 1994;23(2):129-38.

223 Monsalve V, Soriano J, De Andrés J. Utilidad del Índice de Lattinen (IL) en la evaluación del dolor crónico: relaciones con afrontamiento y calidad de vida. Rev Soc Esp Dolor. 2006;4:21629.

224 González-Escalada JR, Camba A, Muriel C, Rodríguez M, Contreras D, Barutell Cd. Validación del índice de Lattinen para la evaluación del paciente con dolor crónico. Rev Soc Esp Dolor. 2012;19(4):181-8.

225 Bouhassira D, Attal N, Alchaar H, Boureau F, Brochet B, Bruxelle J, et al. Comparison of pain syndromes associated with nervous or somatic lesions and development of a new neuropathic pain diagnostic questionnaire (DN4). Pain. 2005;114(1-2):29-36. DOI: 10.1016/j. pain.2004.12.010.

226 Perez C, Galvez R, Huelbes S, Insausti J, Bouhassira D, Diaz S, et al. Validity and reliability of the Spanish version of the DN4 (Douleur Neuropathique 4 questions) questionnaire for differential diagnosis of pain syndromes associated to a neuropathic or somatic component. Health Qual Life Outcomes. 2007;5:66. DOI: 10.1186/1477-7525-5-66.

227 Bennet M. The LANSS Pain Scale: the Leeds assessment of neuropathic symptoms and signs. Rev Soc Esp Dolor. 2002;9:74-87.

228 Kunz M, Scharmann S, Hemmeter U, Schepelmann K, Lautenbacher S. The facial expression of pain in patients with dementia. Pain. 2007;133(1):221-8.

229 Campbell JP, Dunnette MD, Arvey RD, Hellervik LV. The development and evaluation of behaviorally based rating scales. Journal of Applied Psychology. 1973;57(1):15-22.

230 Warden V, Hurley AC, Volicer L. Development and psychometric evaluation of the Pain Assessment in Advanced Dementia (PAINAD) scale. J Am Med Dir Assoc. 2003;4(1):9-15. DOI: 10.1097/01.jam.0000043422.31640.f7.

231 Sociedad española de cuidados paliativos. Guía de cuidados paliativos. Madrid: SECPAL. Disponible en: http://www.secpal.com//Documentos/Paginas/guiacp.pdf.

232 Mc Closkey Dochterman J, Bulechek GM. Ed. lit. Nursing Interventions Classification (NIC). Iowa: The University of Iowa; 2017

233 Materiales informativos y de apoyo para cuidadores y profesionales. Paliex (Programa Regional de Cuidados Paliativos de Extremadura) [Internet]. Cáceres: Servicio Extremeño de Salud; 2017 [consultado 20 sep 2020]. Disponible en: https://saludextremadura.ses.es/paliex/ materiales-informativos-y-de-apoyo-para-cuidadores-y-profesionales.

234 Pérez-Hernández C, Alonso-Babarro A, Ramo-Aguerri A, Villegas-Estévez F, VirizuelaEchaburu JA. Guía para el Abordaje Interdisciplinar del Dolor Oncológico. Disponible en: http://www.aeasarcomas.org/media/files/Documentos\%20pdf/Guia-GADO-Interactiva.pdf. 
235 Alvaro Pardo M, Bavestrello Aljaro P, Bleda Pérez M, Calsina-Berna A, Casas Homs E, Corcoy de Febrer B, et al. Control de síntomas en pacientes con cáncer. 4 ed. Madrid: Arán Ediciones; 2019.

236 González-Barboteo J, Trelis-Navarro J, Tuca-Rodríguez A, Gómez-Batiste X. Rotación de opioides: una alternativaen el tratamiento del dolor refractario en pacientes con cáncer. Med Clin (Barc). 2010;135 (13):617-22.

237 Mercadamte S. Death rattle: critical review and research agenda. Support Care Cancer. 2014;22(2):571-5. DOI: 10.1007/s00520-013-2047-5.

238 Ruíz Márquez MP, Alonso Prado ME. Guía Clínica. Uso y recomendaciones de la Vía Subcutánea en Cuidados Paliativos [Monografía en internet]: Observatorio Regional de Cuidados Paliativos de Extremadura; 2010 [consultado 13 ene 2021]. Disponible en: http:// www.secpal.com///Documentos/Blog/via\%20subcutanea.pdf.

239 Gallardo Avilés R, Gamboa Antiñolo F. Uso de la vía subcutánea en Cuidados Paliativos [Monografía en internet]; 2013. Disponible en: http://www.secpal.com/\%5CDocumentos\%5C Blog\%5Cmonografia_secpal_04.pdf.

240 National Ethics Committee VHA. The ethics of palliative sedation as a therapy of last resort. Am J Hosp Palliat Care. 2006;23(6):483-91. DOI: 10.1177/1049909106294883.

241 Hastings Center. Los fines de la medicina. $2^{\mathrm{a}}$ ed. Barcelona: Fundació Víctor Grifols i Lucas; 2007.

242 Marí-Klose M, Miguel JM. El canon de la muerte. Política y Sociedad. 2000;35:15-43.

243 Comité de Bioética de España. Atención al final de la vida: necesaria acreditación de los profesionales [Internet]. [consultado 29 sep 2018]. Disponible en: http://assets. comitedebioetica.es/files/documentacion/Declaracion \%20Cuidados \%20Paliativos \% 20-\%20 CBE.pdf.

244 Barbero J. El derecho del paciente a la información: el arte de comunicar. Anales del Sistema Sanitario de Navarra. 2006 (Supl 3):19-27.

245 Alonso BA. Atención a la familia. Aten Primaria. 2006;38(Supl 2):14-20.

246 Barrio I, Simón P, Júdez J. De las voluntades anticipadas o Instrucciones Previas a la planificación de las decisiones. Nure Investigacion. 2004 (5).

247 Emanuel EJ, Emanuel LL. Four models of the physician-patient relationship. JAMA. 1992;267(16):2221-6.

248 Earle CC, Park ER, Lai B, Weeks JC, Ayanian JZ, Block S. Identifying potential indicators of the quality of end-of-life cancer care from administrative data. J Clin Oncol. 2003;21(6):11338. DOI: $10.1200 /$ jco.2003.03.059.

249 Comisión Gallega de Bioética. Los cuidados al final de la vida. Santiago de Compostela: Xunta de Galicia, Consellería de Sanidad, Servicio Gallego de Salud; 2012

250 Ameneiros-Lago E, Carballada-Rico C, Garrido-Sanjuán JA, García Martínez A. Adecuación de las intervenciones clínicas en pacientes con enfermedad avanzada y compleja. Propuesta de algoritmo para la toma de decisiones. Rev Calid Asist. 2015;30(1):38-43. DOI: 10.1016/j. cali.2014.12.010.

251 Quill TE, Holloway R. Time-limited trials near the end of life. JAMA. 2011;306(13):1483-4. DOI: $10.1001 /$ jama.2011.1413.

252 Lipton HL. Do-not-resuscitate decisions in a community hospital. Incidence, implications, and outcomes. JAMA. 1986;256(9):1164-9. 
253 Ouslander J, Osterweil D, Morley J. Medical Care in the nursing home. Ethical and legal issues: McGraw-Hill; 1997.

254 Couceiro A. Ética en Cuidados Paliativos. Triacastela: Madrid; 2004.

255 Grupo de Trabajo Atención Médica al Final de la Vida, Organización Médica Colegial, Sociedad Española de Cuidados Paliativos. Ética de la alimentación e hidratación al final de la vida. Madrid; 2016. Disponible en: http://infocuidadospaliativos.com/wp-content/ uploads/2016/10/etica_alimentacioo\%CC\%81n_fin_de_la_vida_octubre16.pdf

256 Hart JT. The inverse care law. Lancet. 1971;1(7696):405-12. DOI: 10.1016/s01406736(71)92410-x.

257 Watt G. The inverse care law today. Lancet. 2002;360(9328):252-4. DOI: 10.1016/S01406736(02)09466-7.

258 Amor-Pan JR, Barón-Duarte FJ, Regueiro-García A, Vázquez-Rivera F. Bioética y Oncología. Una puerta abierta a la oportunidad. Vigo: Sociedad Oncológica de Galicia; 2017. 


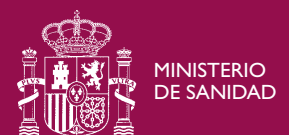

